Florida International University FIU Digital Commons

$10-29-2010$

\title{
Synthesis and Characterization of Photochromic Indolyl Substituted Fulgides and Fulgimides
}

Xi Chen

Florida International University, xchen001@fiu.edu

DOI: $10.25148 /$ etd.FI10112004

Follow this and additional works at: https://digitalcommons.fiu.edu/etd

\section{Recommended Citation}

Chen, Xi, "Synthesis and Characterization of Photochromic Indolyl Substituted Fulgides and Fulgimides" (2010). FIU Electronic Theses and Dissertations. 311.

https://digitalcommons.fiu.edu/etd/311 


\title{
FLORIDA INTERNATIONAL UNIVERSITY
}

\author{
Miami, Florida
}

\section{SYNTHESIS AND CHARACTERIZATION OF PHOTOCHROMIC INDOLYL SUBSTITUTED FULGIDES AND FULGIMIDES}

\author{
A dissertation submitted in partial fulfillment of the \\ requirements for the degree of \\ DOCTOR OF PHILOSOPHY \\ in \\ CHEMISTRY \\ by \\ Xi Chen
}

2010 
To: Dean Kenneth Furton

College of Arts and Sciences

This dissertation, written by $\mathrm{Xi}$ Chen, and entitled Synthesis and Characterization of Photochromic Indolyl Substituted Fulgides and Fulgimides, having been approved in respect to style and intellectual content, is referred to you for judgment.

We have read this dissertation and recommend that it be approved.

Kenneth Furton

Anthony McGoron

Kevin O'Shea

Kathleen Rein

Watson J. Lees, Major Professor

Date of Defense: October 29, 2010

The dissertation of Xi Chen is approved.

\begin{tabular}{r}
$\begin{array}{r}\text { Dean Kenneth Furton } \\
\text { College of Arts and Sciences }\end{array}$ \\
\hline Interim Dean Kevin O'Shea \\
University Graduate School
\end{tabular}

Florida International University, 2010 
(C) Copyright 2010 by Xi Chen

All rights reserved. 


\section{DEDICATION}

I dedicate this dissertation to my wife Chengtao, my mother Jiaxing and my father

Jianxiong. Without their understanding, encouragement, support, and most of all love, the completion of this work would not have been possible. 


\section{ACKNOWLEDGMENTS}

In the past five years, my graduate study at FIU has been a remarkable and rewarding journey of my life. I am so grateful that many people help me to achieve my goals in academics and personal life. First of all, I wish to thank my major professor, Dr. Watson J. Less, for giving me incredible guidance, support and encouragement over these years. I would never achieve so much without his patience and faith in me. Beyond academics, Dr. Lees is a wonderful person who is thoughtful, kind and always willing to help others. I would like to extend my thanks to my committee members, Dr. Kenneth Furton, Dr. Anthony McGoron, Dr. Kevin O’Shea and Dr. Kathleen Rein, for their insightful advices and guidance of my research, and helpful comments and suggestion to my dissertation. Also, I would like to thank Dr. Stanislaw Wnuk and Dr. Martin Quirke for their help in my cumulative exam and organic synthesis study.

I would like to thank Yali Hsu, Dr. Yaru Song for their help in operation of NMR and MS instruments. I also like to thank all members in Dr. Lees' research group: Sandra Garcia, Nadezhda Islamova, Amar Patel, Rachel Robles, Yingsong Wang. Special thanks to Kai Chen, Zheng Wang, Hui Tian, and all my friends and colleagues at FIU.

I would like to acknowledge National Institutes of Health, Department of Chemistry \& Biochemistry, and Dissertation Year Fellowship from University Graduate School at Florida International University for the financial support. Finally, I wish to express my appreciation to those who has helped me in any respect during my five years study at FIU. 


\title{
ABSTRACT OF THE DISSERTATION \\ SYNTHESIS AND CHARACTERIZATION OF PHOTOCHROMIC INDOLYL SUBSTITUTED FULGIDES AND FULGIMIDES
}

\author{
by
}

Xi Chen

Florida International University, 2010

Miami, Florida

\section{Professor Watson J. Lees, Major Professor}

The fulgide and fulgimide family constitutes an important class of organic photochromic compounds. The ability of fulgides and fulgimides to interconvert between two key forms by irradiation of different wavelength of light has made them promising material in optical memory devices, optical switches and sensors, and specialty dyes and inks. Thermal stability and hydrolytic stability of fulgides and fulgimides are essential for their practical applications. A deuterated trifluoromethyl indolylfulgide was synthesized based on the synthetic pathway of the proteo trifluoromethyl indolylfulgide using commercially available deuterated starting materials. Deuteration of the isopropylidene group improved the thermal stability of the indolylfulgide by a factor of 7 .

Fulgimides are the most important fulgide derivatives. Fulgimides improve the hydrolytic stability of fulgides by replacing the succinic anhydride ring with a succinimide ring. A novel trifluoromethyl $N$-ethoxycarbonylmethyl indolylfulgimide was synthesized from trifluoromethyl indolylfulgide. The trifluoromethyl indolylfulgide was synthesized on a large scale in five steps with an overall yield of $18 \%$. The indolylfulgide was then converted to indolylfulgimide by aminolysis follow by dehydration. The $N$ - 
ethoxycarbonylmethyl indolylfulgimide showed enhanced hydrolytic stability and photochemical stability in 70/30 ethanol/water.

Three novel aqueous soluble fulgimides, trifluoromethyl carboxylic acid indolylfulgimide, dicarboxylic acid indolylfulgimide, and H-carboxylic acid indolylfulgimide, were synthesized. In sodium phosphate buffer $(\mathrm{pH} 7.4)$ at $37{ }^{\circ} \mathrm{C}$, an unusual hydrolysis of the trifluoromethyl group of the closed form of the carboxylic acid indolylfulgimide resulted in the dicarboxylic acid indolylfulgimide which has an additional carboxylic acid group. The closed form of dicarboxylic acid indolylfulgimide was further decarboxylated to generate H-carboxylic acid indolylfulgimide which was not photochromic. The trifluoromethyl dicarboxylic acid indolylfulgimide is the most robust fulgimide yet reported in aqueous solution.

A novel aqueous soluble methyl carboxylic acid indolylfulgimide was synthesized from methyl indolylfulgide. The methyl indolylfulgide was synthesized in five steps with an overall yield of $21 \%$. The methyl carboxylic acid indolylfulgimide was synthesized by aminolysis follow by dehydration. The methyl carboxylic acid indolylfulgimide is expected to have improved thermal and photochemical stability in aqueous solutions relative to the trifluoromethyl analog. 


\section{TABLE OF CONTENTS}

CHAPTER $\quad$ PAGE

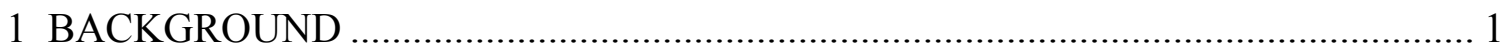

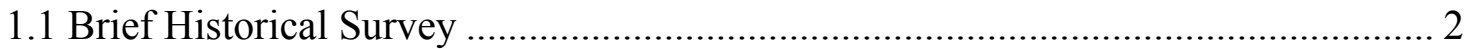

1.2 Definition and General Concepts of Photochromism .............................................. 3

1.3 Important Families of Organic Photochromic Compounds ......................................... 6

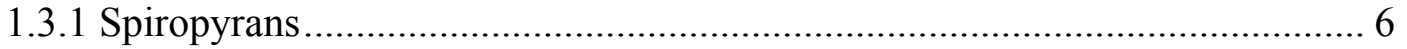

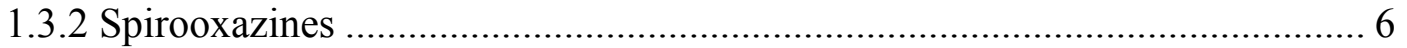

1.3.3 Diarylethenes with heteroaryl groups............................................................ 7

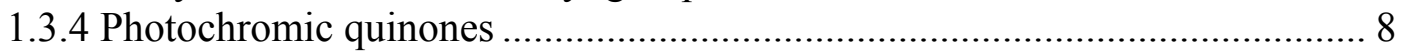

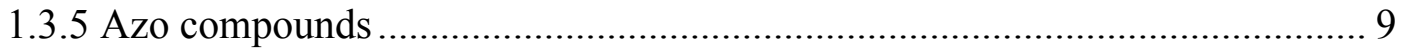

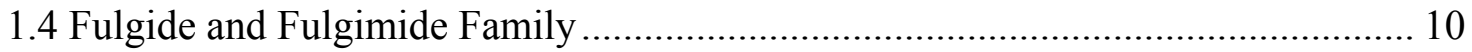

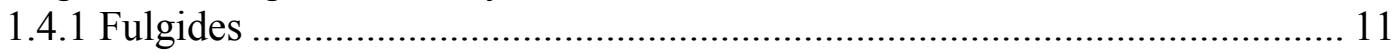

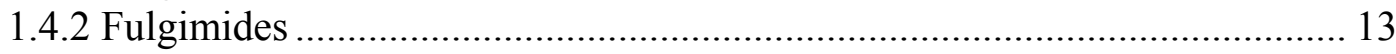

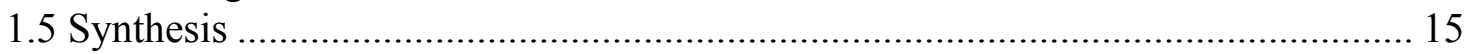

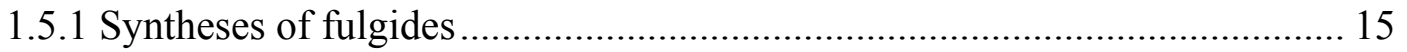

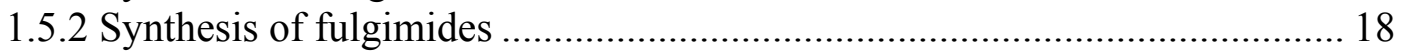

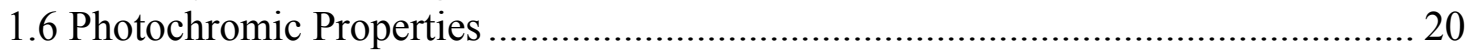

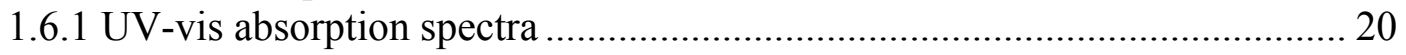

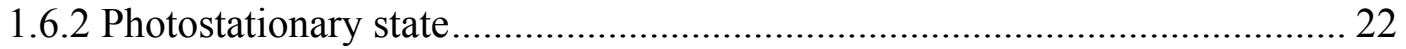

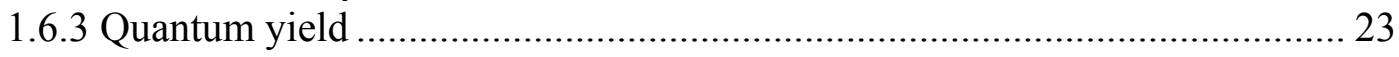

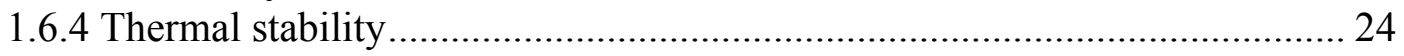

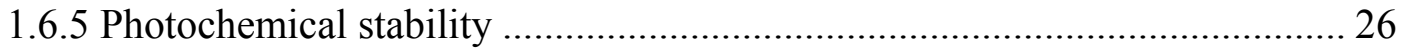

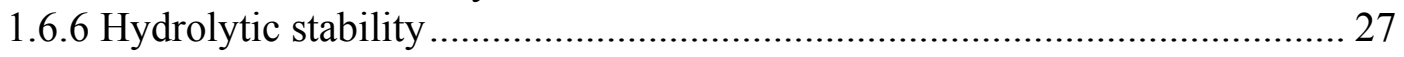

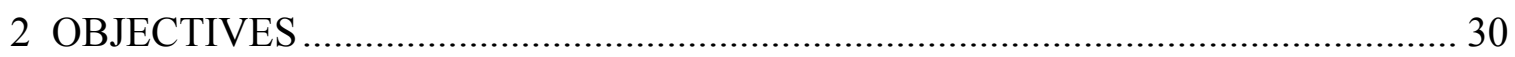

3 IMPROVING THE STABILITY OF PHOTOCHROMIC FLUORINATED

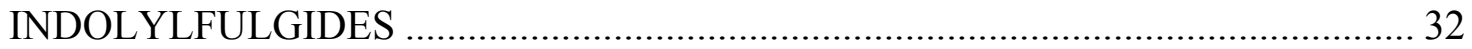

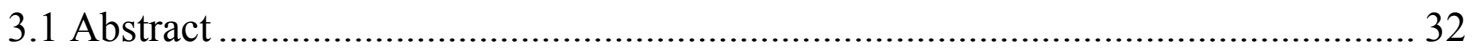

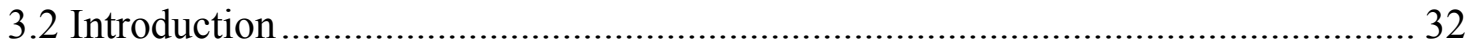

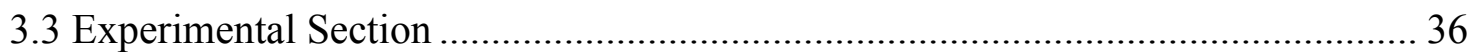

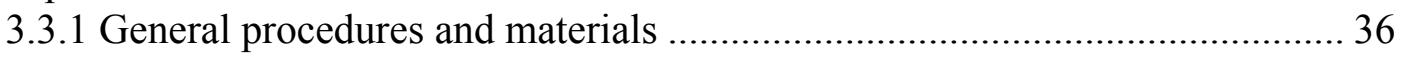

3.3.2 Synthesis of dimethyl octadeuteroisopropylidene succinate 12 .................... 36

3.3.3 Synthesis of hexadeuterated indolylfulgide 8 ………................................ 37

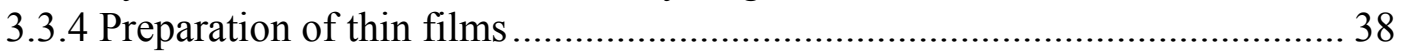

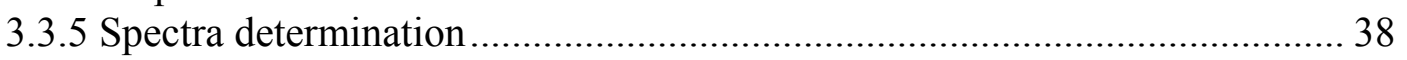

3.3.6 Photostationary state (PSS) measurements ................................................ 39

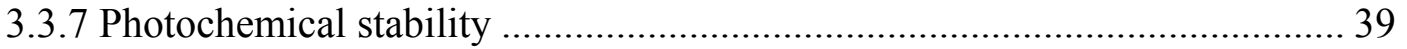

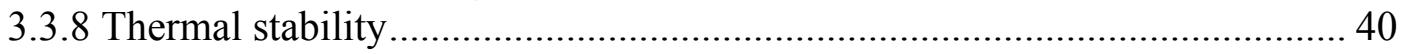

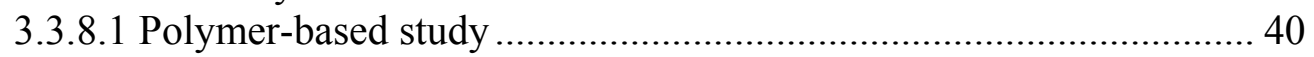




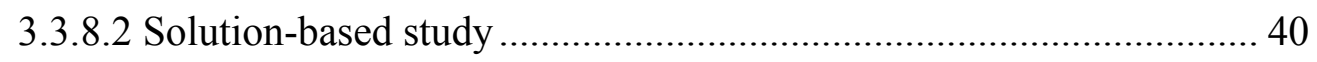

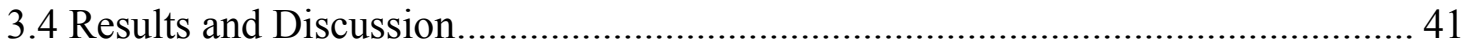

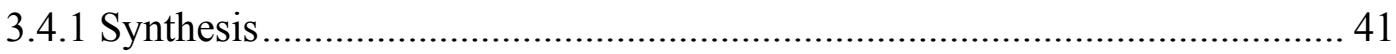

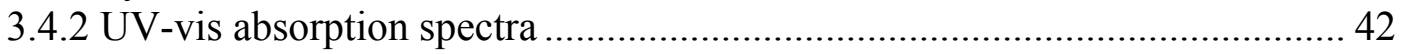

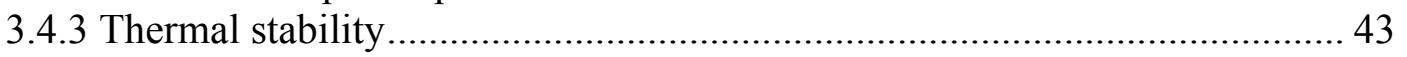

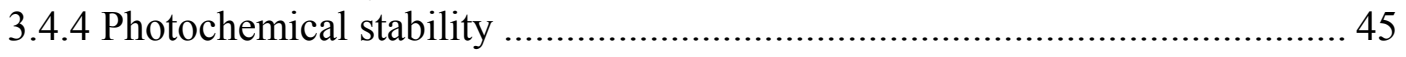

4 SYNTHESIS AND OPTICAL PROPERTIES OF A NOVEL TRIFLUOROMETHYL $N$-ETHOXYCARBONYLMETHYL INDOLYLFULGIMIDE ..................................... 47

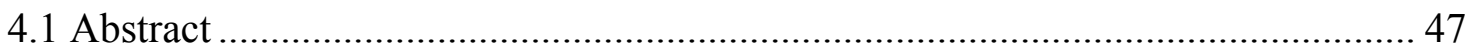

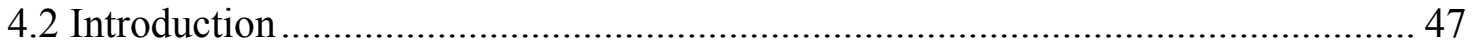

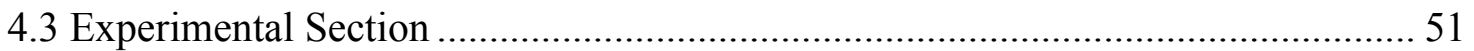

4.3.1 General procedures and materials ............................................................ 51

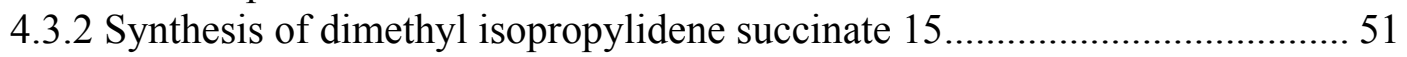

4.3.3 Synthesis of 1,2-dimethyl-3-trifluoroacetylindole 16 …………………....... 52

4.3.4 Synthesis of trifluoromethyl isopropylidene indolelactone 17..................... 52

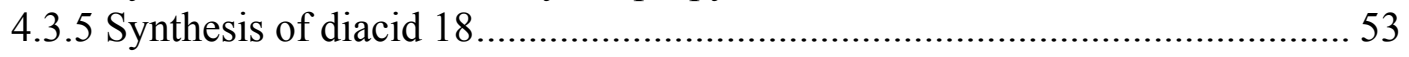

4.3.6 Synthesis of trifluoromethyl indolylfulgide 1 ............................................... 54

4.3.7 Synthesis of trifluoromethyl $N$-ethoxycarbonylmethyl indolylfulgimide 9 .. 54

4.3.8 Preparation of thin films ........................................................................ 55

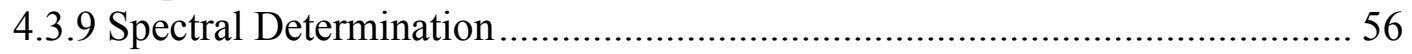

4.3.10 Photostationary state (PSS) measurements ............................................. 57

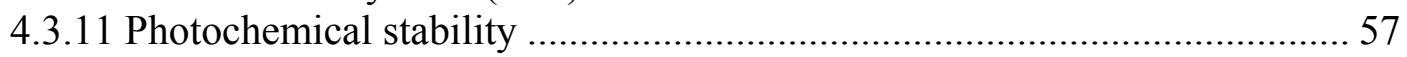

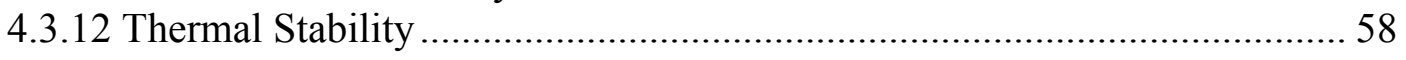

4.3.12.1 Polymer-Based Study................................................................ 58

4.3.12.2 Solution-Based Study................................................................ 58

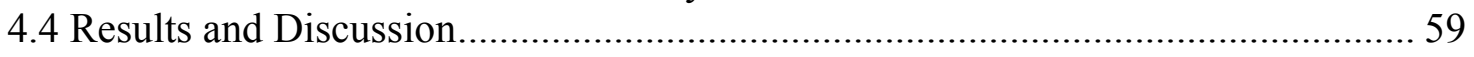

4.4.1 Synthesis of trifluoromethyl indolylfulgide 1 and indolylfulgimide 9 .......... 59

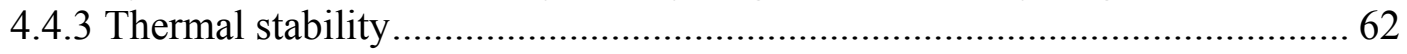

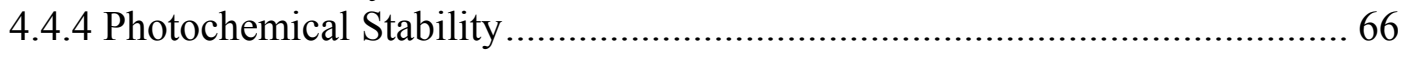

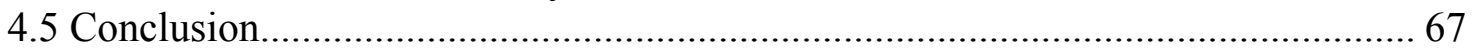

5 SYNTHESIS AND OPTICAL PROPERTIES OF AQUEOUS SOLUBLE

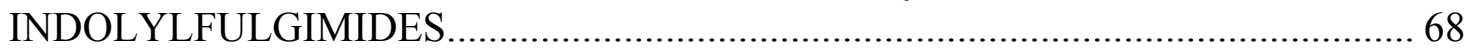

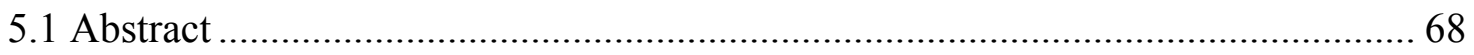

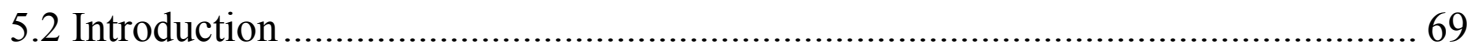

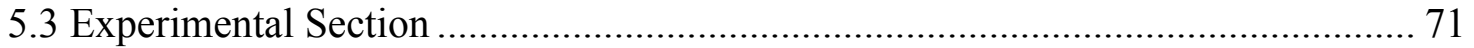

5.3.1 General procedures and materials .............................................................. 71

5.3.2 Synthesis of trifluoromethyl carboxylic acid indolylfulgimide 10................ 72

5.3.3 Synthesis of dicarboxylic acid indolylfulgimide 19..................................... 74

5.3.4 Synthesis of H-carboxylic acid indolylfulgimide 20 ……............................. 75

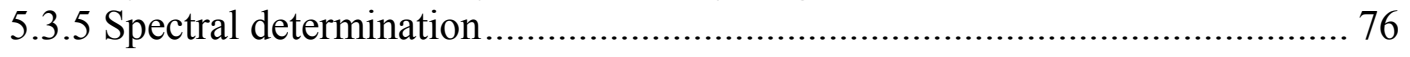

5.3.6 Photostationary state (PSS) measurements .................................................. 77 


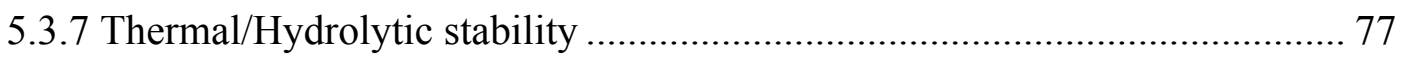

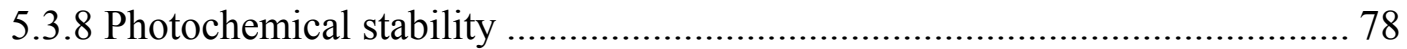

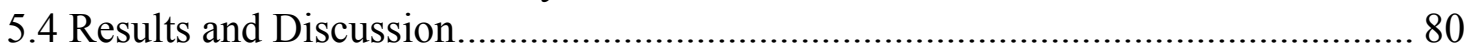

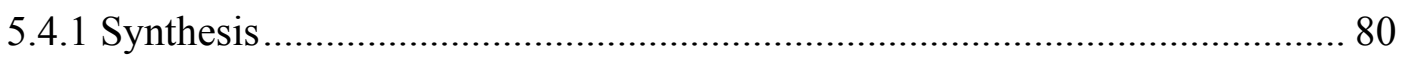

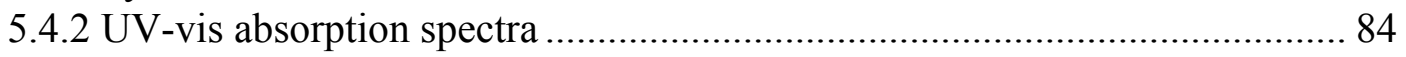

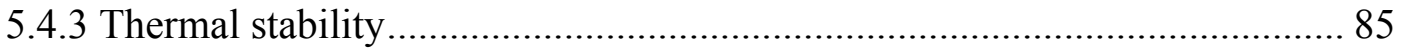

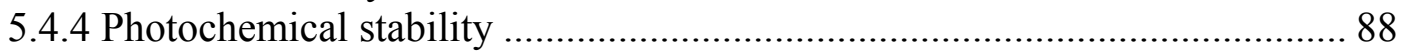

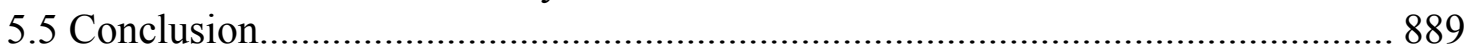

6 SYNTHESIS OF METHYL CARBOXYLIC ACID INDOLYLFULGIMIDE........... 91

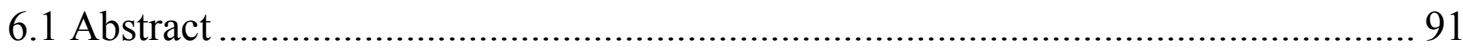

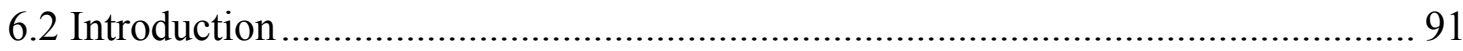

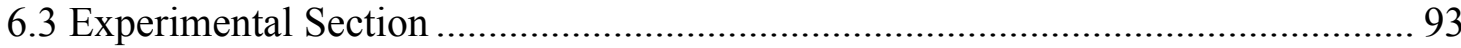

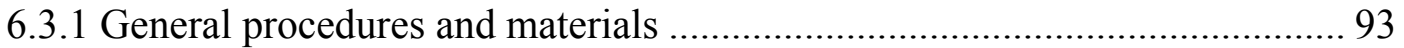

6.3.2 Synthesis of 3-acetyl-1,2-dimethylindole 21 ............................................... 93

6.3.3 Synthesis of cis/trans indole lactones 22 .................................................... 94

6.3.4 Synthesis of methyl indolylfulgide 2....................................................... 95

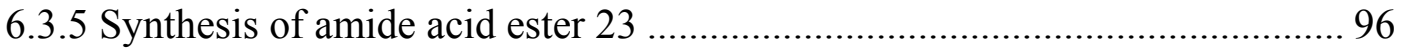

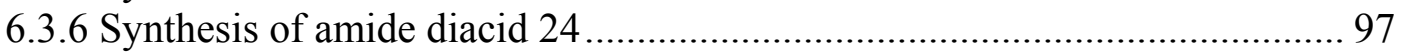

6.3.7 Synthesis of methyl carboxylic acid indolylfulgimide 11 ............................. 98

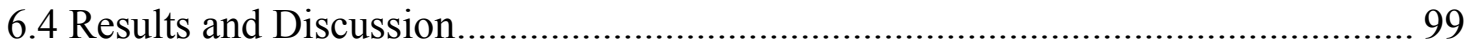

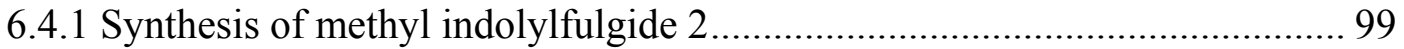

6.4.2 Synthesis of methyl carboxylic acid indolylfulgimide 11 ............................ 100

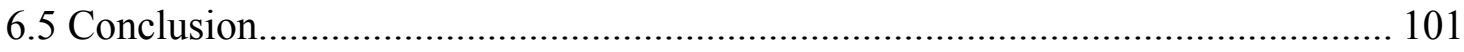

7 CONCLUSIONS AND FUTURE RESEARCH ……………………................... 102

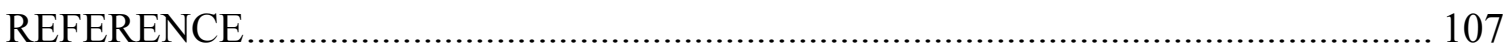

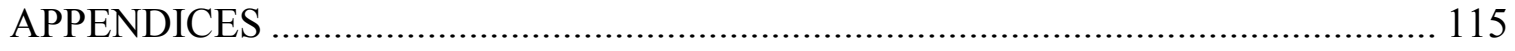

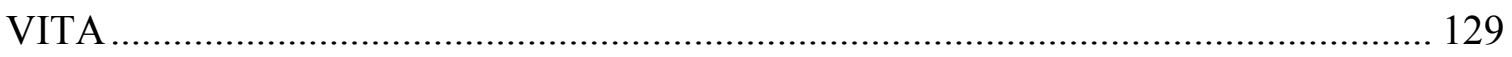




\section{LIST OF FIGURES}

FIGURE

PAGE

1. Photochromic reactions and absorption spectra of photochromic compounds.............. 4

2. UV-vis absorption spectra of trifluoromethyl indolylfulgide 1 .............................. 21

3. Absorption maxima of the closed forms of furanyl, thienyl and pyrryl fulgides......... 21

4. Absorption maxima of methyl, trifluoromethyl, heptafluoropropyl fulgides .............. 22

5. Quantum yields of indolylfulgides with different substituent group ......................... 24

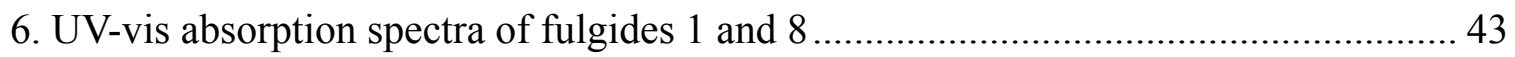

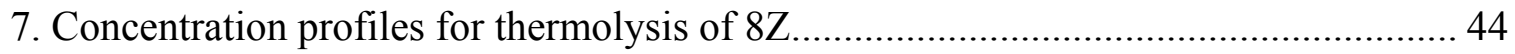

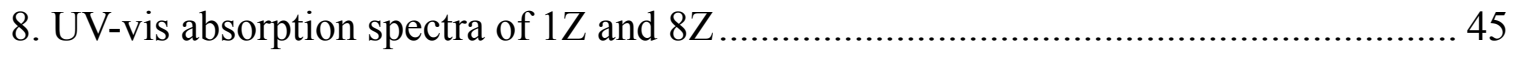

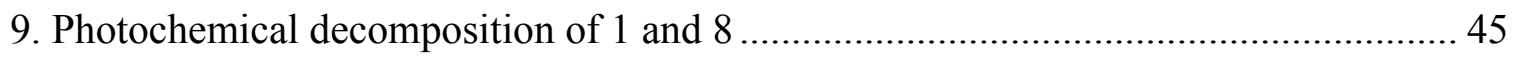

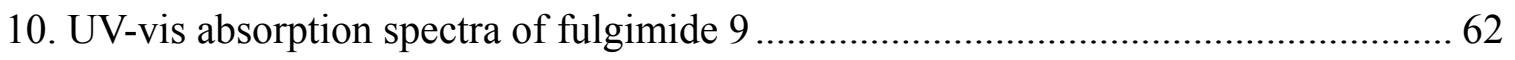

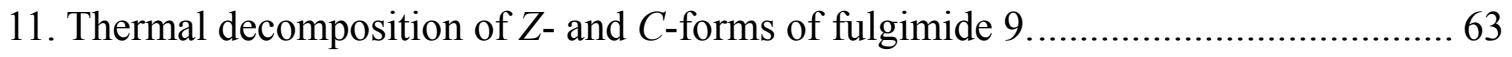

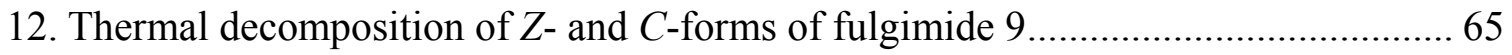

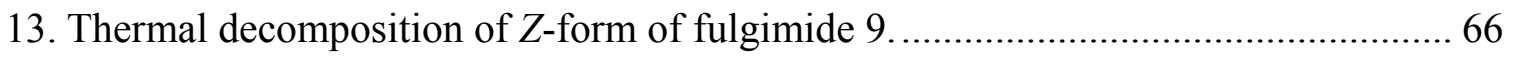

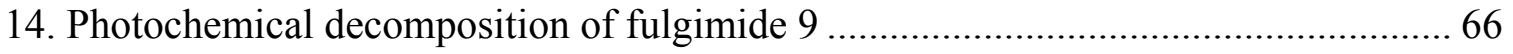

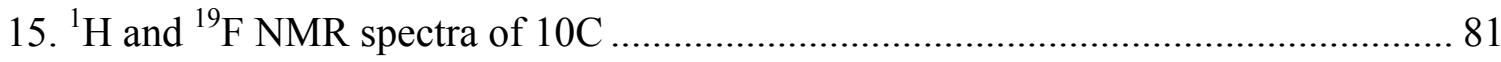

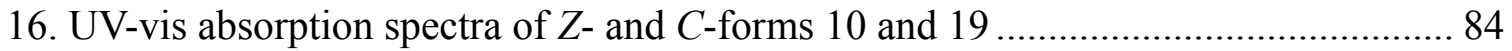

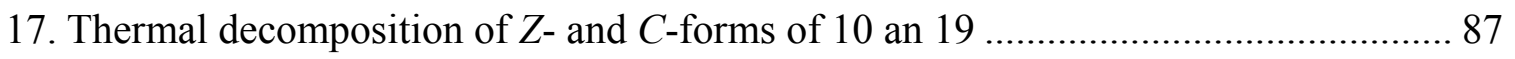

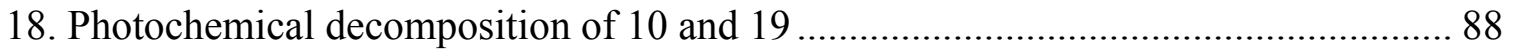




\section{LIST OF SCHEMES}

SCHEME

PAGE

1. Photochromic reaction of trifluoromethyl indolylfulgide 1 .................................. 5

2. Photochromism of trifluoromethyl indolylfulgides and fulgimides ......................... 10

3. General synthetic pathway of fulgides.............................................................. 16

4. Synthetic pathway of indolylfulgide by Yokoyama et al...................................... 16

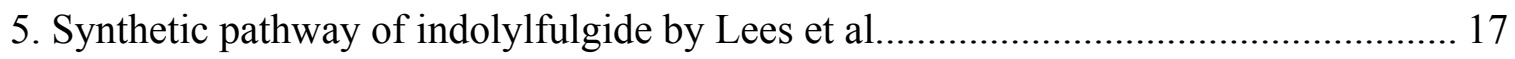

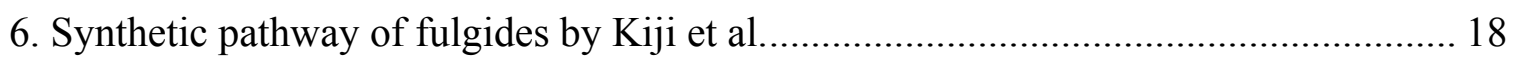

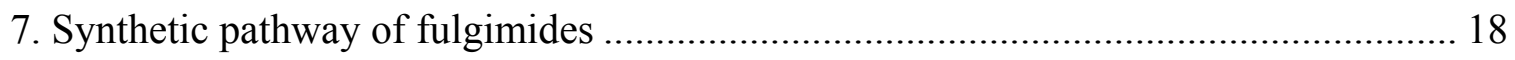

8. Synthetic pathway of fulgimides by Rentzepis et al.......................................... 18

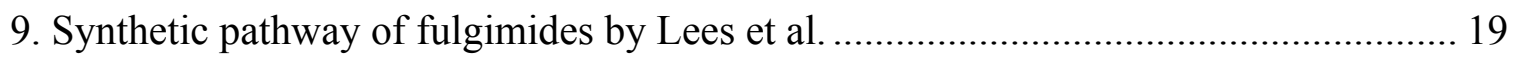

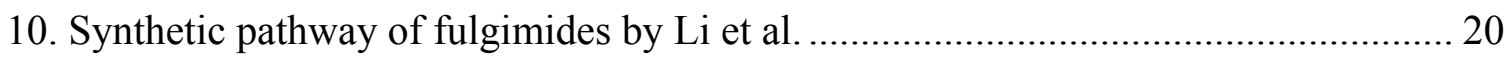

11. Proposed thermolysis mechanism of the $Z$-form trifluoromethyl indolylfulgide $1 \ldots .24$

12. Thermolysis of trifluoromethyl cyclopentylidene indolylfulgide.......................... 26

13. Proposed photochemical degradation pathway for methyl indolylfulgides............... 27

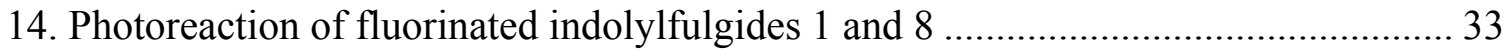

15. Proposed thermolysis mechanism of fluorinated indolylfulgides 1 and 8 ................. 34

16. Potential photochemical degradation pathway for indolylfulgides ......................... 35

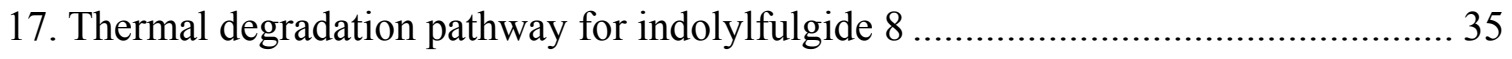

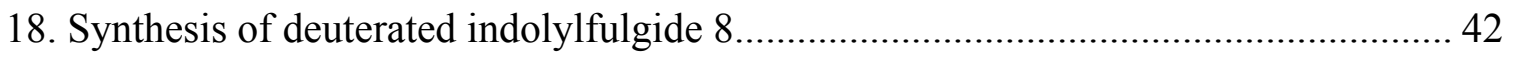

19. Photochemical reactions of trifluoromethyl indolylfulgides and indolylfulgimides .. 48

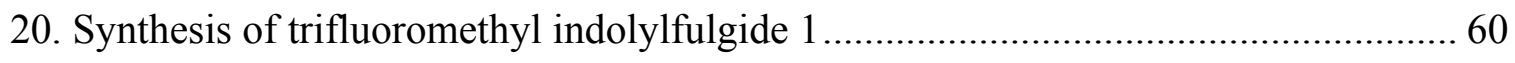

21. Synthesis of trifluoromethyl $N$-ethoxycarbonylmethyl indolylfulgimide $9 \ldots \ldots \ldots \ldots \ldots . . . . .61$ 


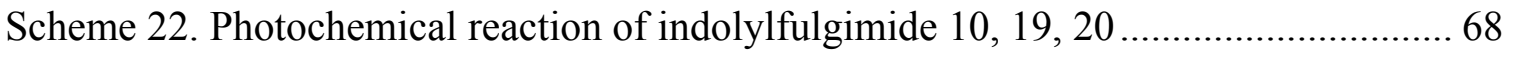

Scheme 23. Photoreactions of fulgides and fulgimides .................................................... 69

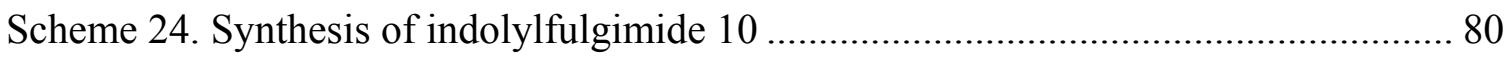

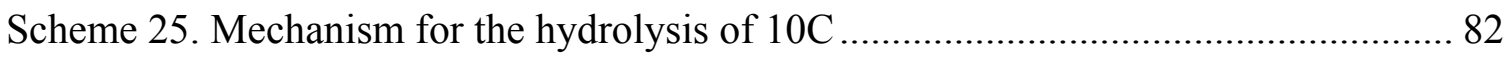

Scheme 26. Decarboxylation of $19 \mathrm{C}$ and photochemical reaction of 20......................... 83

Scheme 27. Hydrolysis and subsequent decarboxylation of fulgimide 10 ...................... 92

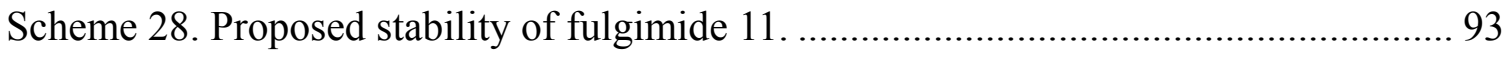

Scheme 29. Synthesis of methyl indolylfulgide 2 ....................................................... 100

Scheme 30. Synthesis of methyl carboxylic indolylfulgimide 11 ................................ 100 


\section{LIST OF TABLES}

TABLE

PAGE

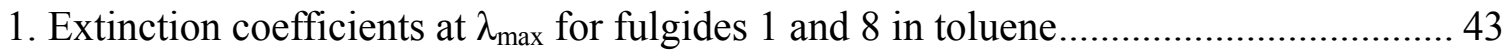

2. Rate constants by fitting the NMR data using Euler's method................................. 44

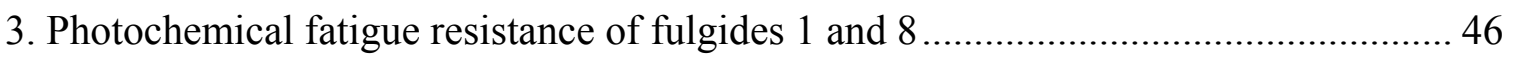

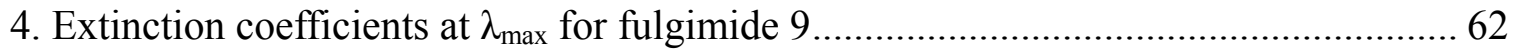

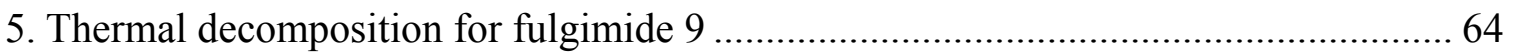

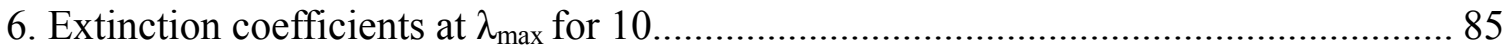

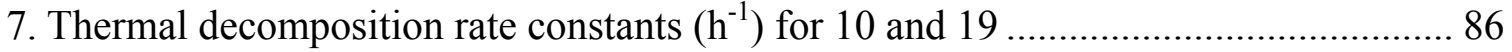




\section{LIST OF ABBREVIATIONS}

\begin{tabular}{|c|c|}
\hline ABBREVIATION & FULLNAME \\
\hline Anal. & Combustion elemental analysis \\
\hline Calcd & Calculated \\
\hline $\mathrm{cm}$ & Centimeter(s) \\
\hline concd & Concentrated \\
\hline $\mathrm{d}$ & $\operatorname{day}(\mathrm{s})$ \\
\hline EtOAc & Ethyl acetate \\
\hline h & hour(s) \\
\hline LDA & Lithium diisopropylamide \\
\hline M & Molar \\
\hline $\mathrm{M}^{+}$ & Parent molecular ion \\
\hline $\mathrm{MHz}$ & Megahertz \\
\hline $\min$ & minute(s) \\
\hline$m / z$ & mass to charge ratio \\
\hline $\mathrm{nm}$ & nanometer(s) \\
\hline NMR & Nuclear magnetic resonance \\
\hline PMMA & Poly (methyl methacrylate) \\
\hline PSS & Photostationary state \\
\hline $\mathrm{THF}$ & Tetrahydrofuran \\
\hline TMS & Trimethylsilane \\
\hline Tol & Toluene \\
\hline UV-vis & Ultraviolet-visible \\
\hline
\end{tabular}




\section{CHAPTER 1}

\section{BACKGROUND}

Photochromic compounds have become well known because of their successful commercial application in photochromic lenses which darken in sunlight (absorption of UV photons) and decolorized in diffuse light. The first commercial photochromic lenses contain inorganic photochromic salts (silver/copper halide) in glass lenses. ${ }^{1}$ Recently, organic photochromic compounds in plastic ophthalmic lenses have become more popular in the world market as they are lighter and more comfortable to wear., ${ }^{2,3}$

The ability of photochromic compounds to change their absorption spectra with exposure to UV-vis light in a reversible manner is called photochromism. ${ }^{2}$ Photochromic compounds have many potential applications, such as media for high capacity optical information storage, ${ }^{4,5}$ optical molecular switches, ${ }^{6}$ biological sensors, and specialty inks and dyes. ${ }^{2,7}$ All these applications depend on the binary nature of photochromic compounds.

The history of photochromic compounds involved the discovery of the phenomenon of photochromism, studies of the mechanism of the photoprocesses, determination of the structure, development of synthetic pathways, and investigation of the properties and potential applications. In the past several decades, many organic photochromic compounds were synthesized, and their photochromic properties were explored in great details. ${ }^{2,8}$ Some compounds had real applications and became commercially successful, while others are considered as promising material for various applications. ${ }^{2,7,8}$

Herein, a brief history of photochromism and photochromic compounds will be introduced followed by the general definition and concepts of photochromism. The 
properties and applications of some important families of organic photochromic compounds will be discussed briefly, including spiropyrans, spirooxazines, diarylethenes, quinones, and azobenzenes. Finally, a comprehensive introduction of fulgides and fulgimides will be presented. The photochromic properties, synthesis, and potential applications of fulgides and fulgimides will be described in detail.

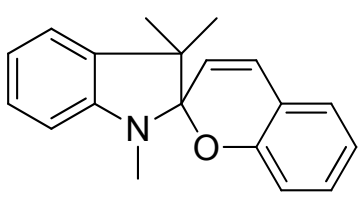

Spiropyran

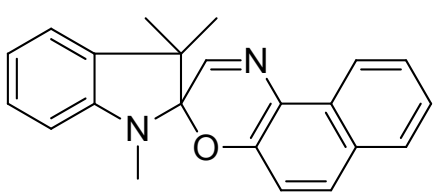

Spirooxazine

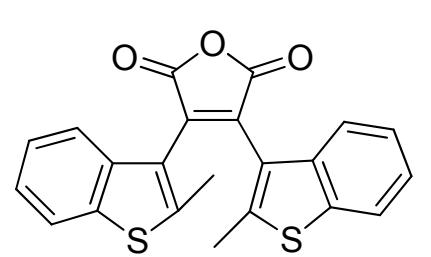

Diarylethene<smiles>CC1=C(C)C(=O)c2c(cc(C)c(C)c2Oc2ccccc2)C1=O</smiles>

Quinone

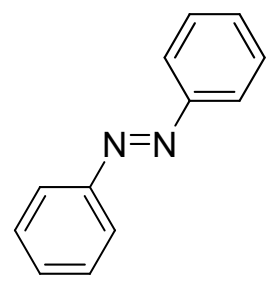

Azobenzene

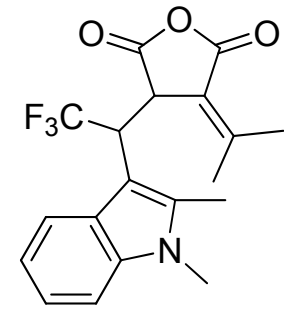

Fulgide

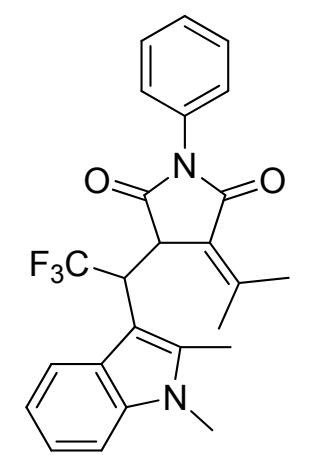

Fulgimide

\subsection{Brief Historical Survey}

The phenomenon of photochromism was first observed by Fritzsche in $1867 .{ }^{9} \mathrm{He}$ reported that the orange color of tetracene in solution was bleached in daylight and regenerated in the dark. Later in 1876, ter Meer discovered that the solid potassium salt of dinitroethane was red in daylight and yellow in the dark. ${ }^{10}$ In 1899, Marckwald used the term "phototropy" to describe this phenomenon and he believed it was a pure physical 
phenomenon. ${ }^{11}$ However, the word "phototropy" is no longer used to describe this phenomenon and is now used to denote biological phenomena.

Since 1940, the mechanistic, structural, and synthetic studies of photochromic compounds have substantially increased, particularly by Hirshberg and Fisher in Israel. ${ }^{12,13}$ In 1950, Hirshberg suggested the term "photochromism" which was derived from Greek words: phos (light) and chroma (color) and is still applied today. ${ }^{13}$ In the 1960s, the development of the modern techniques such as IR, UV, X-ray, NMR, timeresolved, and flash spectroscopy has significantly expanded research on photochromism. ${ }^{7}$ The first photochromic glasses were commercialized during this period. ${ }^{1}$ However, the development of organic photochromic compounds was challenging because fast photodegradation (also known as fatigue) limited their potential applications. ${ }^{14}$

In the 1980 s, the synthesis of fatigue resistant organic photochromic compounds, such as spirooxazine and chromene derivatives, started a new era in the study of organic photochromism. The plastic photochromic ophthalmic lenses became commercially successful in world market, and many new organic photochromic compounds were synthesized and investigated for various applications. ${ }^{2,8}$ Numerous scientific articles and several books were published on photochromism. ${ }^{2,7,15}$ In addition, a large number of patents were issued. The International Symposium on Organic Photochromism has been organized since 1990 in France, and the most recent one is in Japan 2010.

\subsection{Definition and General Concepts of Photochromism}

"Photochromism is a reversible transformation of chemical species, induced in one or both directions by electromagnetic radiation, between two states having observable light absorptions in different regions." 

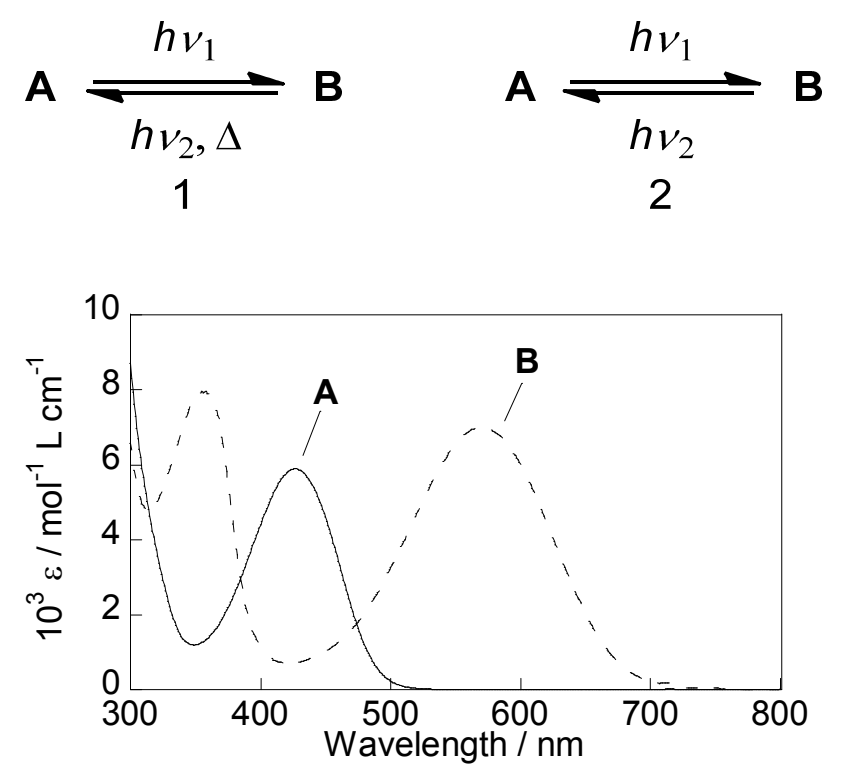

Figure 1. Photochromic reactions and absorption spectra of photochromic compounds

Figure 1 shows that A form is the most thermally stable of the two forms. In general, the longest wavelength absorption maxima of A form occurs at a shorter wavelength than that of $\mathrm{B}$ form. The forward reaction (A to $\mathrm{B}$ ) occurs photochemically. The reverse reaction (B to A) occurs both thermally and photochemically (system 1) or only photochemically (system 2). In the case of system 1, the reverse reaction is thermally driven and can be photoinduced but the thermal reaction normally predominates, e.g. in spiropyrans and spirooxazines. For system 2, the B form is thermally stable and the reverse reaction is dominated by a photochemical reaction, e.g. see trifluoromethyl indolylfulgide 1 (Scheme 1). The most common organic photochromic systems involve unimolecular reactions (A to $\mathrm{B})$. 


\section{Scheme 1. Photochromic reaction of trifluoromethyl indolylfulgide 1}

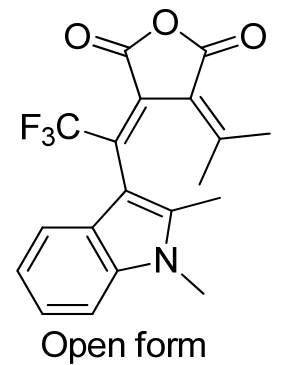

12

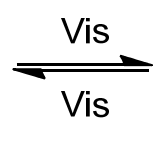

Most organic photochromic compounds have a colorless A and a colored B form.

(B to A) is a decoloration or bleaching reaction. Many applications such as photochromic lenses, fluid flow visualization, and security inks and dyes utilize the color changes of the two species (A and B). ${ }^{1-3}$ For some compounds, physical and chemical properties such as conductivity, refractive index, and electrical moment also change during the photochromic reaction. Optical switches, optical information storage and optoelectronic systems are potential applications that utilize the physical and chemical property changes. $^{4,5}$

Several chemical processes are involved in photochromism, including pericyclic reactions, cis-trans isomerizations, intramolecular hydrogen transfer, intramolecular group transfers, dissociation processes and electron transfers. ${ }^{2}$ In the following sections, organic photochromic systems, such as spiropyrans, spirooxazines, diarylethenes, and fulgides, which undergo pericyclic reactions, will be introduced. Quinones, which undergo proton and group transfers and azobenzenes, which undergo the cis-trans isomerizations, will be discussed. 


\subsection{Important Families of Organic Photochromic Compounds}

\subsubsection{Spiropyrans}

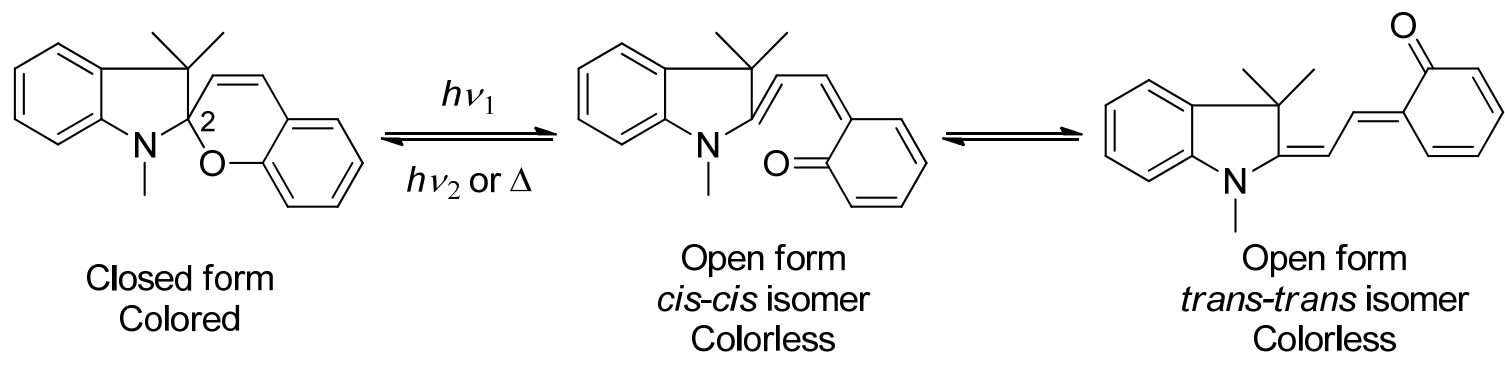

Spiropyrans are the most extensively studied photochromic compounds because of their potential applications in optical memory devices, optical switches and senors. ${ }^{16,17}$ The general structure of spiropyrans contains a second ring system attached to pyran in a spiro manner at the 2 position. The photochromism of spiropyrans occurs photochemically or thermally (system 1). The open merocyanine form exists as ciscis/trans-trans mixture which is at equilibrium. Most studies have focused on indolinospirodipyrans which are readily available and have many potential applications. ${ }^{2}$

Initially, the practical applications of spiropyrans were concentrated on photochromic dyes and plastic ophthalmic sunglasses. ${ }^{2}$ However, the rapid photodegradation of indolinospirodipyrans significantly limited their applications. Recently, spiropyrans incorporated into polymers have become widespread and are considered as promising photochromic materials for optical information storage. ${ }^{16,17}$

\subsubsection{Spirooxazines}<smiles>CN1c2ccccc2C(C)(C)C12C=Nc1c(ccc3ccccc13)O2</smiles>

Closed form Colorless
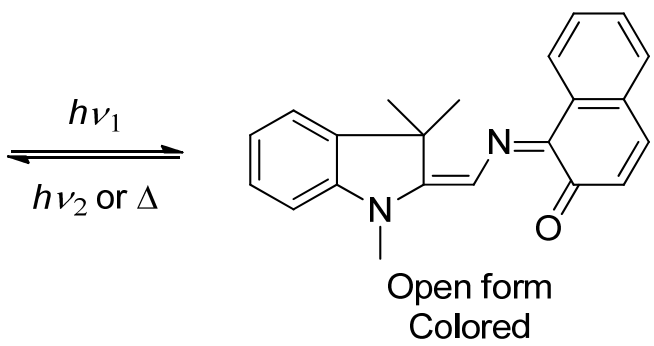
Photochromic spirooxazines have a similar structure to spiropyrans except that the pyran is replaced by an oxazine. The first photochromic indolinospironaphthoxazine ring system was reported by Ono and Osada ${ }^{18}$ and Arnold and Vollmer ${ }^{19}$ in 1970. However, the importance of the spirooxazine systems was unnoticed until the 1980s because of the focus on spiropyrans during that time..$^{20,21}$ Hobley et al. reported that the indolinospironaphthoxazine exhibited excellent resistance towards photodegradation in 1982. ${ }^{20}$ As a result of the $\mathrm{g}$ photochemical resistance, a significant increase in the number of publications and patents on spirooxazines was observed. ${ }^{2,22,23}$

The most successful application of spirooxazines was in commercial plastic photochromic lenses. In 1982, American Optical introduced spirooxazines photochromic lenses called Photolite. Since then, many companies have commercialized plastic photochromic lenses containing various types of spirooxazines, and these lenses have become a part of everyday life. ${ }^{1,3}$ Other applications such as photochromic inks and dyes and cosmetic products also utilized spirooxazines. ${ }^{2}$ The synthesis of a large number of new spirooxazines has extended the possibility of using spirooxazines as a media for information storage, and as optical switches and sensors. ${ }^{22}$

\subsubsection{Diarylethenes with heteroaryl groups}

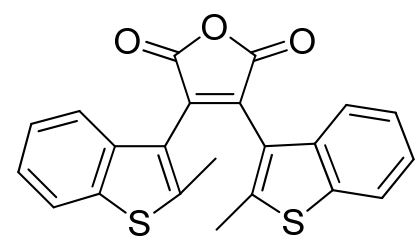

Open form

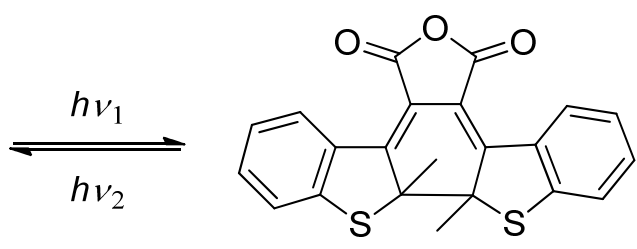

Closed form

Diarylethenes with heteroaryl groups are photochromic compounds that have thermally stable closed forms, and both the coloration and the decoloration processes are 
driven photochemically. ${ }^{2}$ Thermal irreversibility is an essential property for applications in optical memory devices. Hence, most studies have focused on increasing the thermal stability of the closed form of diarylethenes. ${ }^{24}$ Theoretical studies have indicated that the type of aryl group determines the thermally stability of diarylethene. ${ }^{25}$ A number of diarylethenes with varies types of aryl groups were synthesized and the theoretical prediction was confirmed. ${ }^{26,27}$ When the aryl group was furan or thiophene, the closed forms were thermally stable, and the decoloration reaction was thermally forbidden. On the other hand, diarylethenes exhibited thermally reversible reactions when the aryl group was phenyl or indole. ${ }^{2}$ The thermally irreversible diarylethenes also demonstrated great fatigue resistance. Most of the benzothiopene diarylethenes underwent more than 10,000 photochromic cycles. ${ }^{2}$ The thermal irreversibility and fatigue resistant make diarylethenes promising material for applications in optical information storage.

\subsubsection{Photochromic quinones}

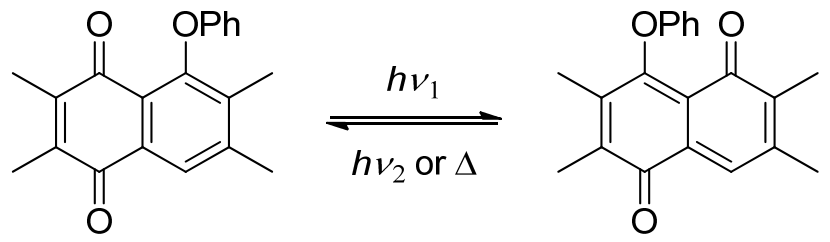

Photochromic quinones are a class of organic photochromic compounds which were discovered in $1971 .^{2}$ During the past 40 years, various photochromic quinones have been synthesized, and their photochromic properties have been examined. ${ }^{28-31}$ Quinones differ from the photochromic compounds described above, as the reversible transformation between the two forms of quinones is caused by the photochemical migration of a functional group, usually hydrogen, aryl, or acyl. ${ }^{29}$ 
Many photochromic quinones demonstrate enhanced thermal stability and fatigue resistance, and have potential applications in optical information storage.$^{30}$ Procedures of fabrication of polymeric and polymolecular films containing photochromic quinones have been developed. ${ }^{2}$ The polymer films exhibit the appropriate stability and fatigue resistance required for application as light-sensitive recording media. ${ }^{2}$ Future modifications of the structures of quinones will lead to enhanced properties make quinones suitable for practical applications.

\subsubsection{Azo compounds}

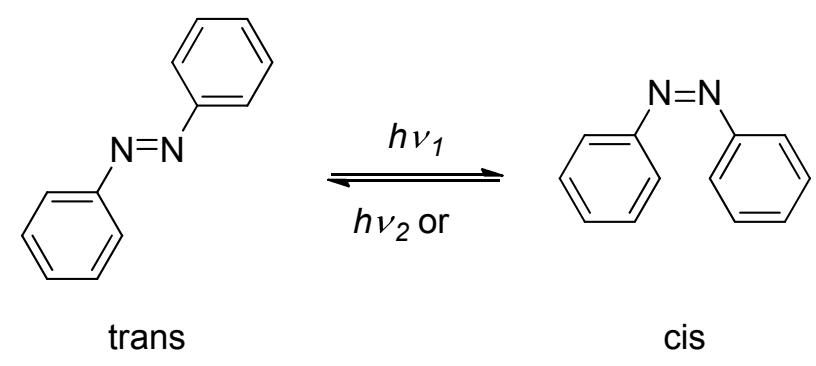

Azo compounds that undergo photochemical cis-trans isomerizations have been recognized and studied for many years. ${ }^{8,32}$ Among many azo compounds, azobenzenes have attracted the most interest. The reversible photoisomerization of azobenzenes involves a transformation between the more stable trans isomer and the less stable cis isomer. ${ }^{33-35}$ The reverse process occurs thermally as well as photochemically. ${ }^{36}$ The research on azobenzenes has provided many fundamental insights into photochemistry. The facile synthesis of relatively robust and chemically stable azo compounds has prompt many studies of azobenzenes for various applications. ${ }^{32,33,35}$

Development of azobenzene-containing polymers (azopolymers) and liquid crystals (LC) has trigged extensive studies of photoresponsive polymers and crystals. ${ }^{33,37,38}$ Many azopolymers and liquid crystals were synthesized and investigated as potential materials 
for optical information storage and as optical switches. Recently, the discovery of new properties of azopolymers and liquid crystals, such as optical bending of cross-linked LC azopolymers, have extended the research to optical surface patterns and diverse functional materials. ${ }^{32,33}$

\subsection{Fulgide and Fulgimide Family}

The fulgide and fulgimide family constitutes an important class of organic photochromic compounds. Stobbe first synthesized fulgides and discovered their photochromism in the early 20th century. ${ }^{39}$ Various fulgides and their derivatives have been synthesized, and fulgimides are the most important and practical derivatives. Fulgimides improve the hydrolytic stability of fulgides by replacing the succinic anhydride ring with a succinimide ring (Scheme 2). ${ }^{40,41}$ Additionally, the succinimide ring allows another substituent to be attached onto the fulgimide without a significant change of photochromic properties.

\section{Scheme 2. Photochromism of trifluoromethyl indolylfulgides and fulgimides}
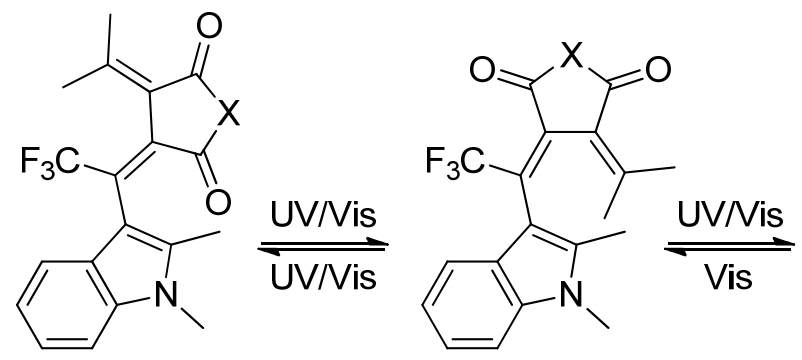

E
Open forms

$$
\begin{array}{ll}
\text { Fulgides } & X=O \\
\text { Fulgimides } & X=N-R
\end{array}
$$<smiles></smiles>

Closed form

C

The photochromism of fulgides and fulgimides involves three isomers (Scheme 2). In the case of trifluoromethyl indolylfulgide or indolylfulgimide, the open forms contain 
both $E$ and $Z$ isomers, which can be interconverted by irradiation with UV-vis light. However, only one open form ( $Z$-form in this case) is photochromic and can be converted to the closed form ( $C$-form) upon illumination with $\mathrm{UV}$-vis light. The reverse reaction occurs by irradiation of the $C$-form under visible light. However, not all fulgides and fulgimides undergo ring-closing reaction (open to closed form). Previous reports indicated that indolylfulgides and indolylfulgimides having a hydrogen at the bridging position instead of trifluoromethyl group undergo $E / Z$ isomerization but do not produce the $C$-form under photochemical conditions. ${ }^{42-44}$

Fulgides and fulgimides exhibit great photochromic properties, such as readily distinguishable absorption spectrum for each form, efficient photoreactions, and thermal and photochemical stabilities. The promising properties of fulgides and fulgimides make them suitable for applications in optical memory devices, optical switches and sensors, and specialty inks and dyes. ${ }^{15,45}$ Studies have been conducted to optimize the photochromic properties of fulgides and fulgimides for specific applications. ${ }^{46-48}$ Optimization has resulted in more thermally and photochemically stable compounds such as fluorinated indolylfulgide 1, which was originally synthesized by Yokoyama and Takahashi. ${ }^{49-52}$ The most photochemically stable fulgide, a fluorinated indolylfulgide synthesized by Lees et al. undergoes 10,000 photochemical cycles (back and forth conversion between the two key forms) before degrading by $13 \%$ in toluene. ${ }^{52}$

\subsubsection{Fulgides}

Fulgides, derivatives of 1,3-butadiene-2,3-dicarboxylic acid anhydride, were first synthesized by Stobbe in $1905 .{ }^{39}$ For fulgides to undergo photochromic reactions, at least one of the $\mathrm{R}$ groups should be aromatic or contain one double bond. Although the 
photochromism of fulgides was discovered in the early twentieth century, the chemical process and mechanism remained unclear until the 1960s. ${ }^{15}$ Becker et al. reported the photochromic mechanism of a phenyl-substituted fulgide in $1968 .{ }^{53}$ The reaction mechanism is a photochemical $6 \pi$ electrocyclization of the hexatriene moiety.<smiles>[R]C([R])=C1C(=O)OC(=O)C1=C([R])[R]</smiles>

Fulgide<smiles>[R]C([R])=C1C(=O)OC(=O)C1=C([R])c1ccccc1</smiles><smiles></smiles>

Open form

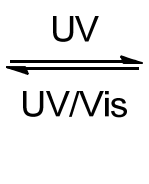

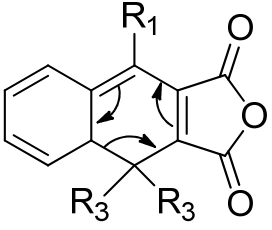

Closed form

Until 1981, the closed form of fulgides was thermally unstable and the reverse reaction (ring-opening reaction) occurred thermally. Thermal reversibility complicated the fulgide system and limited its usefulness. In 1981, Heller et al. reported a thermally irreversible fulgide which had a 2,5-dimethyl-3-furyl moiety instead of a phenyl group. ${ }^{54,55}$ From 1981 onwards, research has focused on improving the properties of furylfulgides and developing new thermally stable fulgides. ${ }^{56-58}$ Fulgides with different aromatic substituents, such as thienylfulgide, pyrrylfulgide were synthesized and displayed improved photochromic properties. ${ }^{2}$<smiles>CC(C)=C1C(=O)OC(=O)C1=C(C)c1cc(C)[X]c1C</smiles>

Z

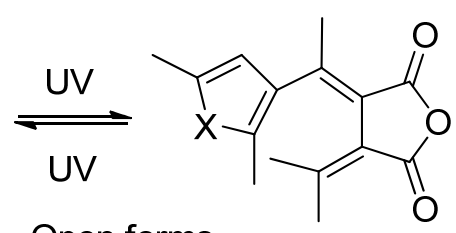

E Open forms

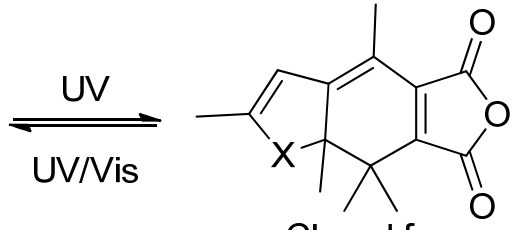

Closed form

Furylfulgide $X=O$, Thienylfulgide $X=S$, Pyrrylfulgide $X=N$

Indolylfulgides were synthesized and attracted particular research interest because of their promising photochromic properties, such as increased thermal stability, enhanced 
fatigue resistance, and visible wavelength absorption. ${ }^{59,60}$ Subsequent studies reported several indolylfulgides with various substituents on the indole ring and bridging carbon. $^{58,61-63}$ Recently, Yokoyama et al. reported a trifluoromethyl substituted indolylfulgide which demonstrated the most promising photochromic properties. ${ }^{49}$ The synthesis and photochromic properties of the trifluoromethyl indolylfulgide were thoroughly studied by Lees et al. ${ }^{60,64,65}$ Compared to the methyl indolylfulgide 2, the trifluoromethyl indolylfulgide has greater thermal stability, increased fatigue resistance, an enhanced quantum yield for the ring closing reaction, and an open form that absorbs in the visible region.

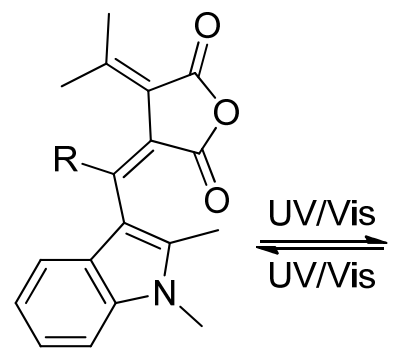

Open forms

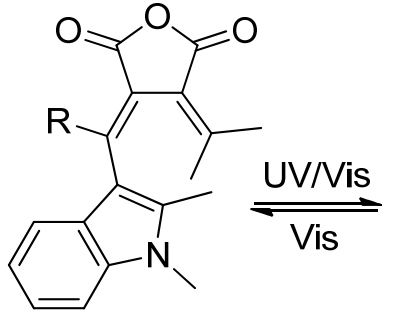

Vis

Trifluoromethyl indolylfulgide $1 \mathrm{R}=\mathrm{CF}_{3}$ Methyl indolylfulgide $2 \quad \mathrm{R}=\mathrm{CH}_{3}$<smiles>[R]C1=C2c3ccccc3N(C)C2(C)C(C)(C)C2=C1C(=O)OC2=O</smiles>

Closed form

\subsubsection{Fulgimides}

Fulgimide, a succinimide derivative of fulgide, was first synthesized by Goldschmidt in $1957 .{ }^{66,67}$ However, the name "fulgimide" was introduced by Heller et al. in $1968 .{ }^{67}$ Fulgimides replace the succinic anhydride ring of a fulgide with a succinimide ring. ${ }^{40,41}$ The imide group allows another substituent to be attached onto the fulgimide without a significant change of photochromic properties. Furthermore, fulgimides have a higher hydrolytic stability compared to fulgides because of the imide group (Scheme 1). 
Applications of fulgimides have been reported in several studies. Porphyrinfulgimide dyads were synthesized to control the generation of a porphyrin excited state by Straight et al ${ }^{68}$ A fulgimide was also used as an "on-off" fluorescence switch in live cells. ${ }^{6}$ In the case of attaching fulgimides to polymers, Rentzepis et al. synthesized a photochromic cross-linked copolymer which contains a 2-indolylfulgimide as a crosslinker. ${ }^{69}$ However, there were no applications reported for this kind of polymer.

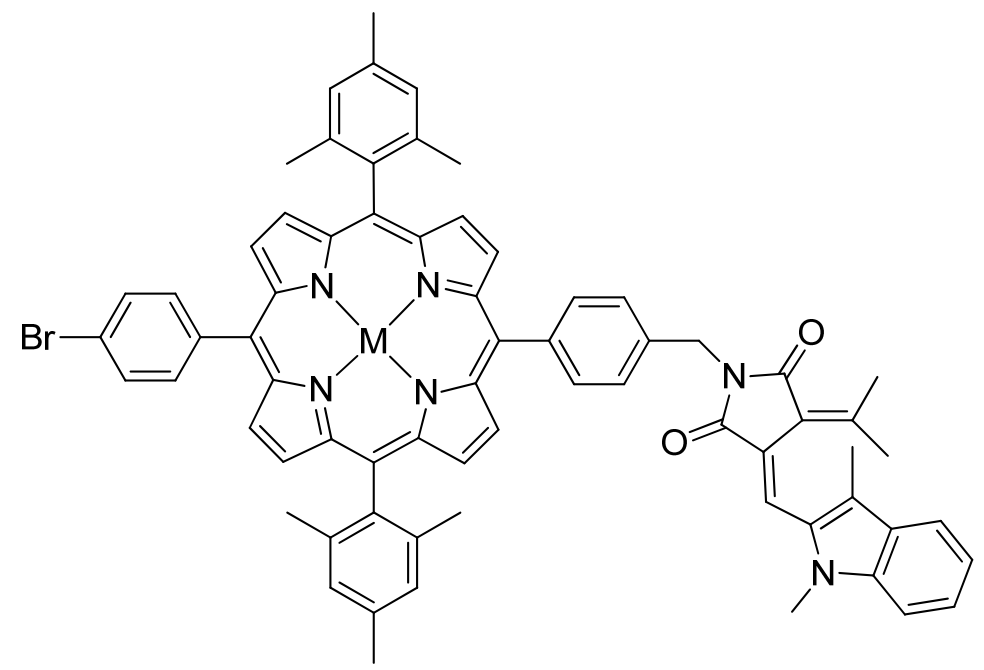

Porphyrin-fulgimide dyad ${ }^{68}$

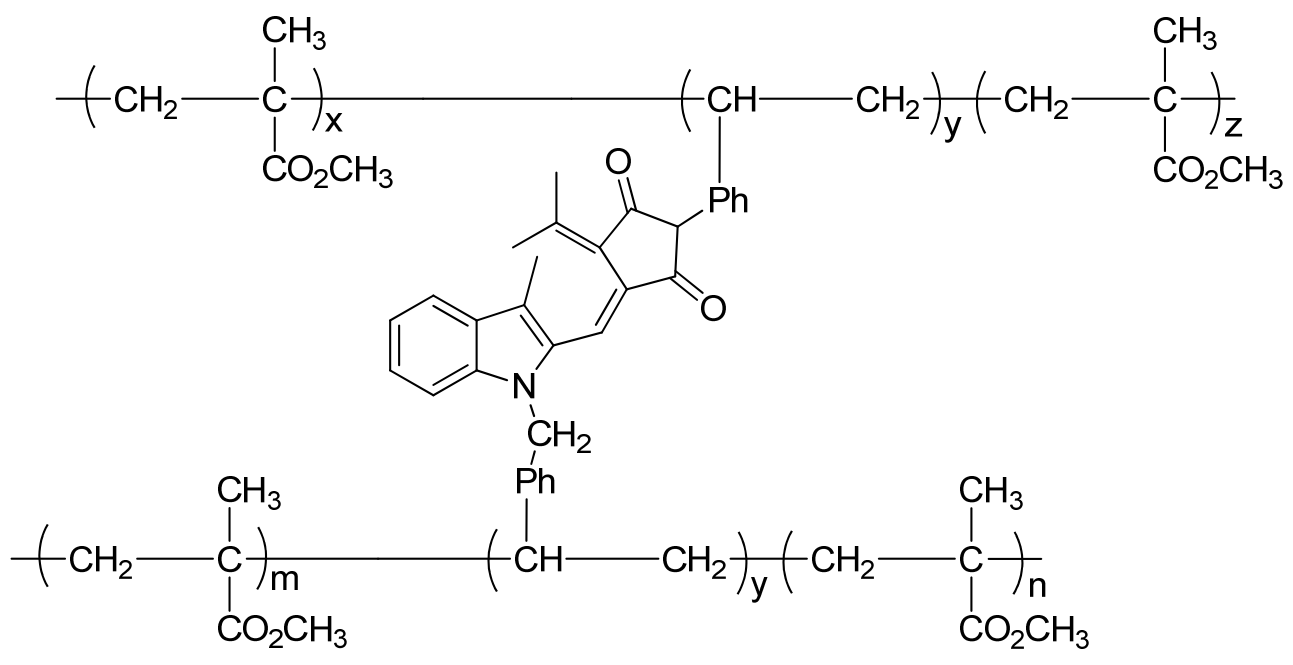

Fulgimide cross-linked copolymer ${ }^{69}$ 
Hydrolytic stability of fulgides and fulgimides is an important property for their applications in optical memory devices and biological optical switches. ${ }^{6,15}$ In memory devices, materials are required to maintain stability and function in humid environments. Optical switches need to function in aqueous solvent systems in many biological applications. ${ }^{6,70}$ Previous studies demonstrated that fulgides were unstable in protic solvents because of the highly reactive succinic anhydride ring. ${ }^{41,71}$ On the other hand, fulgimides have an improved hydrolytic stability because of the succinimide ring. Several studies have reported the photochromic properties of fulgimides in protic solvents, ${ }^{6,40,41,70,71}$ The closed form of $N$-phenyl trifluoromethyl indolylfulgimide displayed three orders of magnitude greater stability in 70/30 ethanol/water relative to the parent fulgide 1 at $25{ }^{\circ} \mathrm{C} .{ }^{41}$ The stability of fulgimides in aqueous solution was also examined. ${ }^{6,70,72}$ In one particular study fulgimide derivatives were covalently attached to the lysine residues on concanavalin $\mathrm{A}$, and the open form of the fulgimide was shown to be stable in aqueous solution for $48 \mathrm{~h}$ at $25{ }^{\circ} \mathrm{C} \cdot{ }^{70}$ The study by Willner et al. also indicated that the fulgimide can cycle back and forth between the open and the closed forms at least twice. ${ }^{70}$ A recent study in live cells demonstrated that fulgimides can switch back and forth seven times in cellular membranes but not very well in water. ${ }^{6}$

\subsection{Synthesis}

\subsubsection{Syntheses of fulgides}

In general, fulgides are synthesized by a Stobbe condensation of an aryl aldehyde or ketone with an substituted methylene succinate, followed by hydrolysis and dehydration of the dicarboxylic acid (Scheme 3). ${ }^{2}$ Synthesis of fulgides is usually low yielding. ${ }^{49,51}$ 
Difficulties in the synthesis have impeded the utilization of fulgides in all manner of applications.

\section{Scheme 3. General synthetic pathway of fulgides ${ }^{2}$}

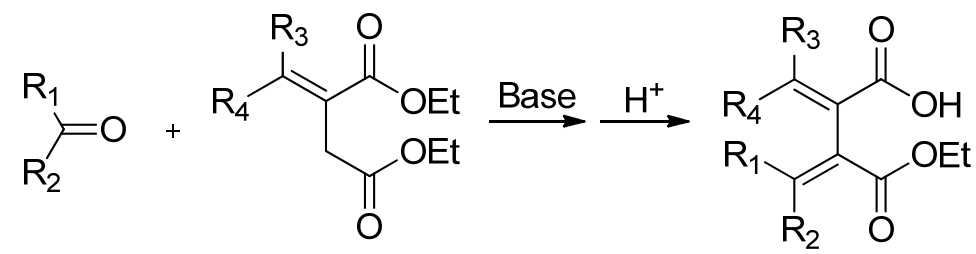<smiles>[R]C([R])=C1C(=O)OC(=O)C1=C([R])[R]</smiles>

A fluorinated indolylfulgide was first synthesized by Yokoyama in $1996 .{ }^{49}$ As shown in Scheme 4, 1,2-dimethyl-3-trifluoroacetylindole was prepared from trifluoroacetyl trifluoromethanesulfonate and 1,2-dimethylindole with a $42 \%$ yield. Stobbe condensation of the trifluoroacetylindole with dimethyl isopropylidene succinate followed by hydrolysis, dehydration, and purification yielded the trifluoromethyl indolylfulgide in $1 \%$ from 1,2-dimethylindole (Scheme 4). Although the fluorinated indolylfulgide displayed excellent photochromic properties, the low yielding synthesis significantly limited further research and applications.

Scheme 4. Synthetic pathway of indolylfulgide by Yokoyama et al. ${ }^{49}$

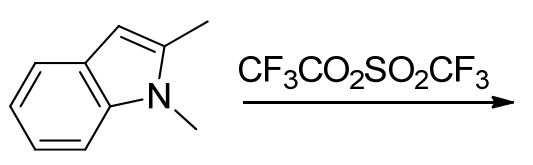<smiles>Cc1c(C(=O)C(F)(F)F)c2ccccc2n1C</smiles>

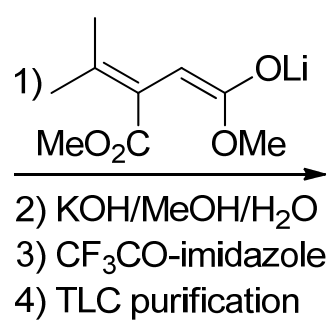<smiles>CC(C)=C(C)C(=C1C(=O)OC(=O)C1=C(C)C)c1c(C)n(C)c2ccccc12</smiles> 
An improved synthesis of indolylfulgides was developed by Lees et al. in $2001 .^{60}$ The new methodology increased the overall yield of trifluoromethyl indolylfulgide from $1 \%$ to $29 \%$ (Scheme 5 ). ${ }^{60}$ Lee et al. obtained 1,2-dimethyl-3-trifluoroacetylindole in $96 \%$ yield by treating 1,2-dimethylindole with trifluoroacetic anhydride in 1,2dichloroethane. ${ }^{60}$ In the hydrolysis step, using $\mathrm{NaH}$ followed by addition of water in DMF, both cis and trans indolelactones form the dicarboxylic acid in $83 \%$ yield. Whereas in Yokoyama's procedure, the cis indolelactone formed unwanted decomposition products. ${ }^{49,60}$ Lees et al. also demonstrated that the new method improved the yield of both fluorinated and nonfluorinated indolylfulgide derivatives. The improved procedure has broad applicability and afforded enough materials to thoroughly study the photochromic properties of several indolylfulgides. ${ }^{50,64,73}$

\section{Scheme 5. Synthetic pathway of indolylfulgide by Lees et al. ${ }^{60}$}
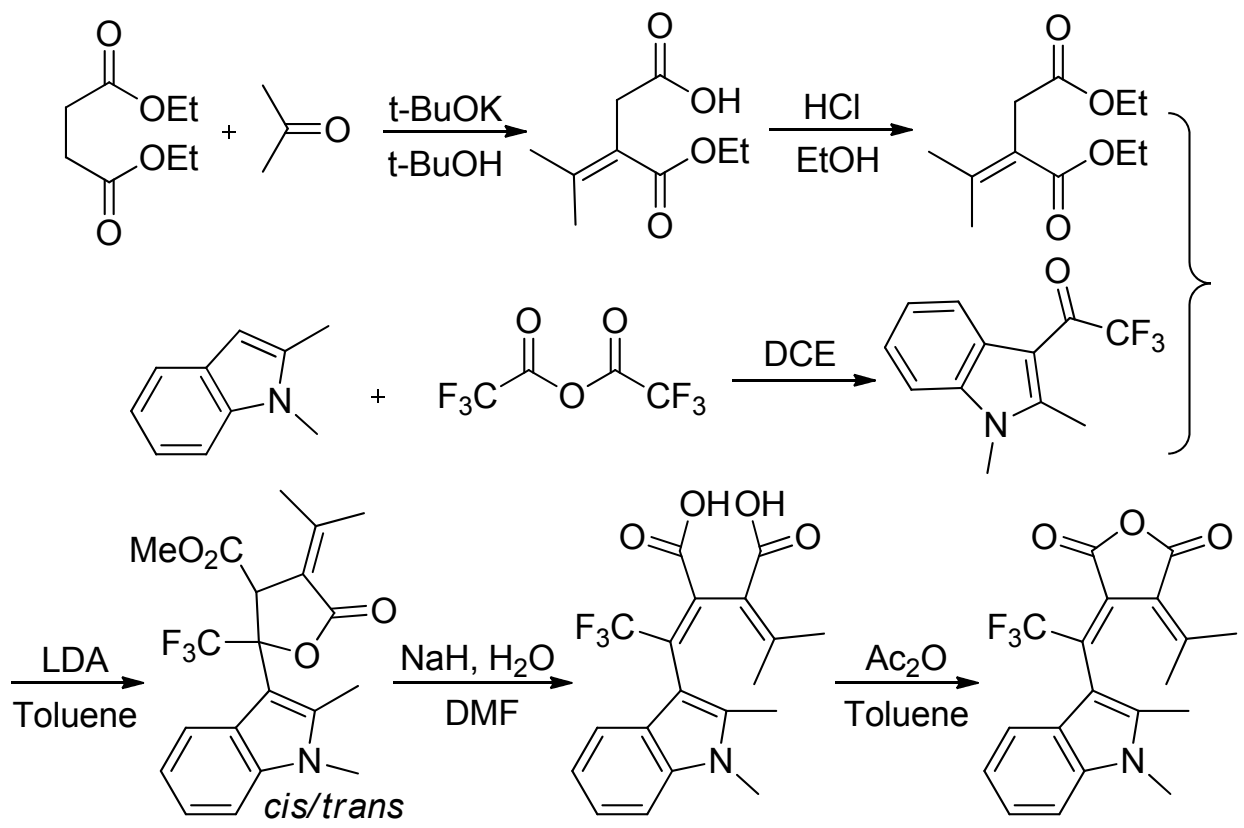

Kiji et al. developed another pathway to synthesize fulgides in a high yield using palladium catalyst (Scheme 6). ${ }^{74-77}$ A one step synthesis of fulgide was achieved by 
reacting a substituted 1,4-butynediol with carbon monoxide in the presence of palladium catalyst. Furyl- and thienylfulgides were synthesized in approximately $50 \%$ yields by Kiji's method. ${ }^{75}$ However, indolylfulgides were not synthesized efficiently by Kiji's method because of the more electron rich indole ring.

Scheme 6. Synthetic pathway of fulgides by Kiji et al. ${ }^{77}$

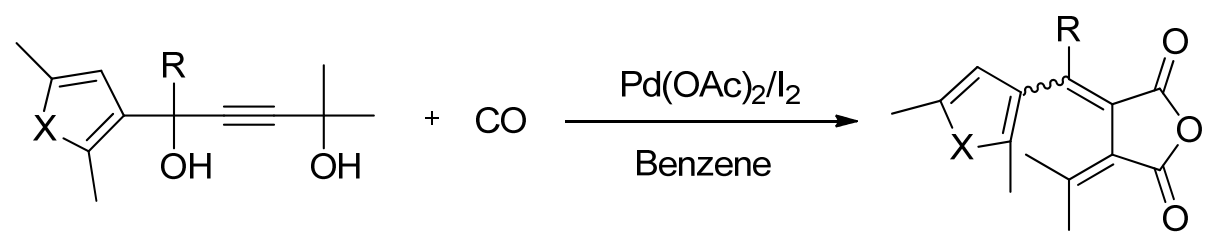

\subsubsection{Synthesis of fulgimides}

Generally, fulgimides are synthesized from the corresponding fulgides. As shown in Scheme 7, a succinamic acid intermediate is obtained by treating a fulgide with a primary amine, subsequent dehydration yields the corresponding fulgimide. ${ }^{2}$ In most cases, synthesis of fulgimides is low yielding. ${ }^{2}$ Studies have been conducted to improve the yield of fulgimides so that they can be thoroughly characterized.

Scheme 7. Synthetic pathway of fulgimides ${ }^{2}$

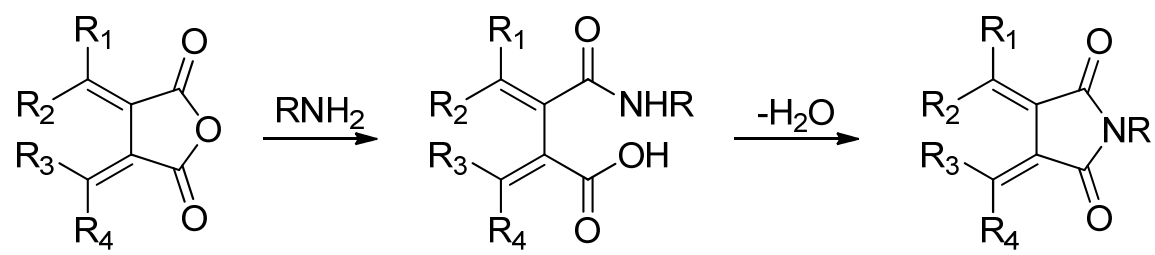

Scheme 8. Synthetic pathway of fulgimides by Rentzepis et al. ${ }^{78}$

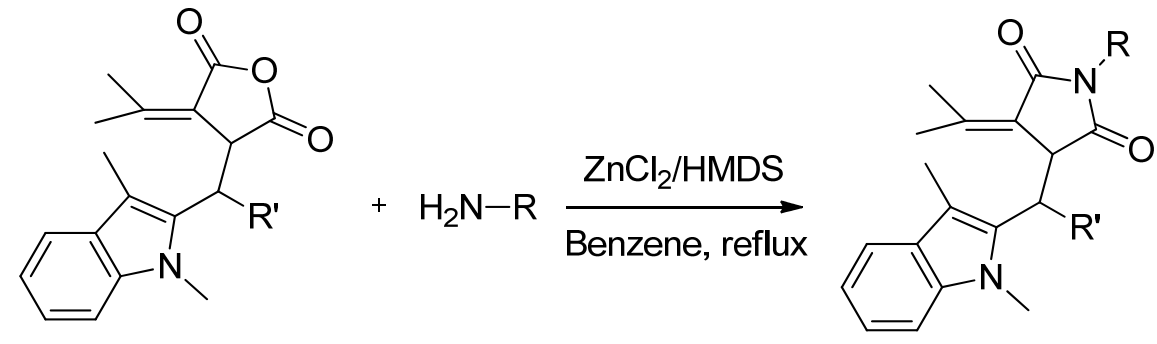


Several studies have reported the synthesis of fulgimides in high yields. ${ }^{41,78}$ Rentzepis et al. demonstrated that by reacting indolylfulgides with an amine in the presence of a Lewis acid, $\mathrm{ZnCl}_{2}$, and hexamethyldisilazane (HMDS), indolylfulgimides could be obtained in over $80 \%$ yield (Scheme 8 ). ${ }^{78}$ The Lewis acid and HMDS promoted synthesis of imides was first reported by Toru and utilized by Rentzepis et al. in fulgimide synthesis. ${ }^{78,79}$ Toru et al. indicated that the anhydride first reacts with amine to produce the amic acid intermediate, and the dehydration is promoted by the Lewis acid and HMDS to form the imide. The type of Lewis acid has a strong effect on the reaction. $\mathrm{ZnCl}_{2}, \mathrm{ZnBr}_{2}$, and $\mathrm{ZnI}_{2}$ gave high yields while $\mathrm{AlCl}_{3}$ resulted in very low yields and $\mathrm{MgCl}_{2}$ showed no reaction. ${ }^{79}$

\section{Scheme 9. Synthetic pathway of fulgimides by Lees et al. ${ }^{78}$}

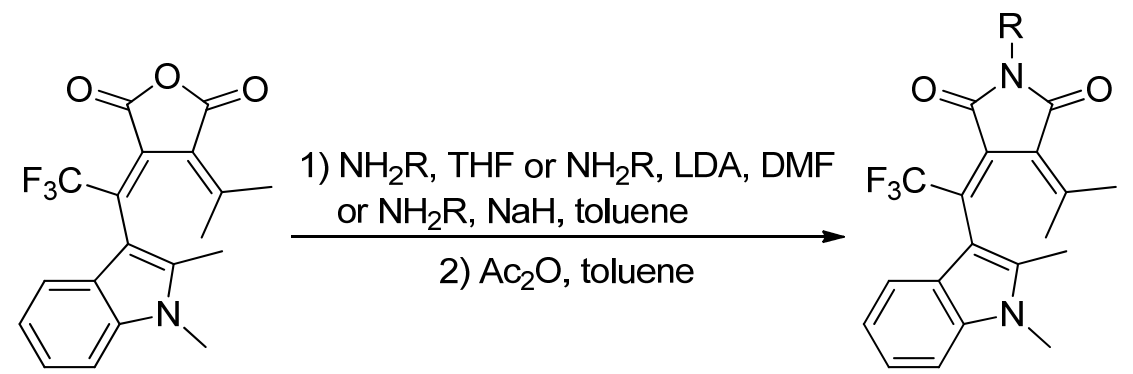

Lees et al. synthesized a series of trifluoromethyl indolylfulgimides by treating the precursor fulgide with substituted anilines. ${ }^{41}$ Dehydration of the amide acid intermediates was performed with acetic anhydride in toluene to yield the corresponding fulgimides (Scheme 9). ${ }^{41}$

Recently, microwave assisted synthesis of fulgimides was reported. ${ }^{80,81}$ Compared to traditional methods, using the microwave increased the yield of fulgimides up to $85 \%$ and the reaction time was reduced from $24 \mathrm{~h}$ to less than $40 \mathrm{~min} .{ }^{81}$ Furthermore, less solvent was used which simplified the purification procedure. The methyl indolylfulgimides 
synthesized by the microwave assisted method showed an improved average yield of $70 \%$ (Scheme 10). Therefore, microwave assisted synthesis should be an alternative for the synthesis of trifluoromethyl indolylfulgimides.

\section{Scheme 10. Synthetic pathway of fulgimides by Li et al. ${ }^{80}$}

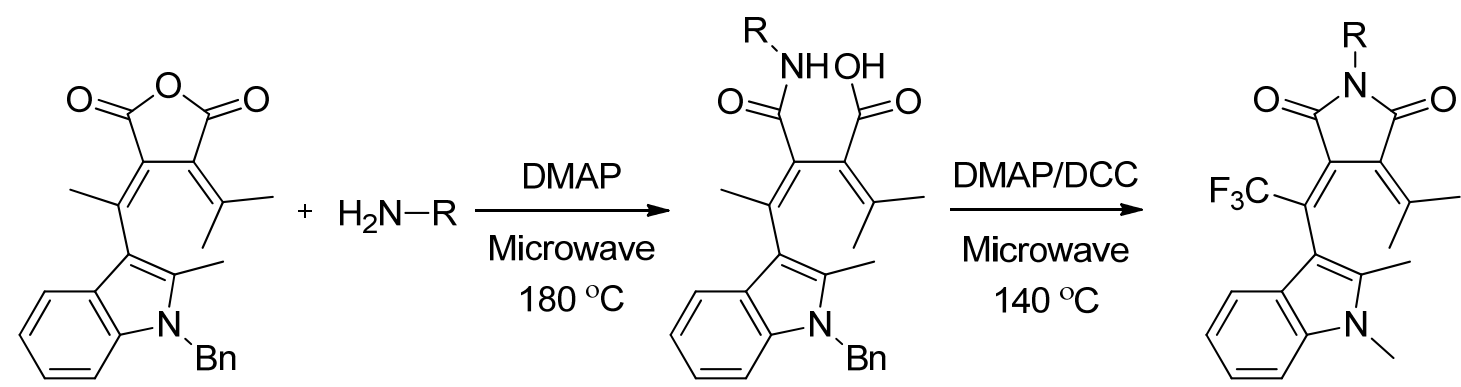

\subsection{Photochromic Properties}

Measurement of the photochromic properties is essential to determine the ideal photochromic compounds for various applications. Photochromic properties include UVvis absorption spectra, photostationary state, quantum yield, photochemical stability (fatigue resistance), and thermal stability. Generally, fulgides and fulgimides exhibit similar photochromic properties in solvents and polymer films. However, fulgimides demonstrate enhanced hydrolytic stability which is an important characteristic for applications in aqueous environments.

\subsubsection{UV-vis absorption spectra}

The definition of photochromism requires that all photochromic compounds have at least two different forms with different absorption spectra. In the case of fulgides and fulgimides, the closed (C) form has at least one absorption maximum in the visible region. The $E$ - and $Z$-forms display similar absorption maxima which are at a shorter wavelength than that of the $C$-form (Figure 2). For example, the open form of trifluoromethyl 
indolylfulgide 1 is irradiated with $427 \mathrm{~nm}$ light, a ring closing reaction occurs and the closed form is produced. The reverse ring opening reaction occurs by irradiating the closed form with $571 \mathrm{~nm}$ light. $^{64}$

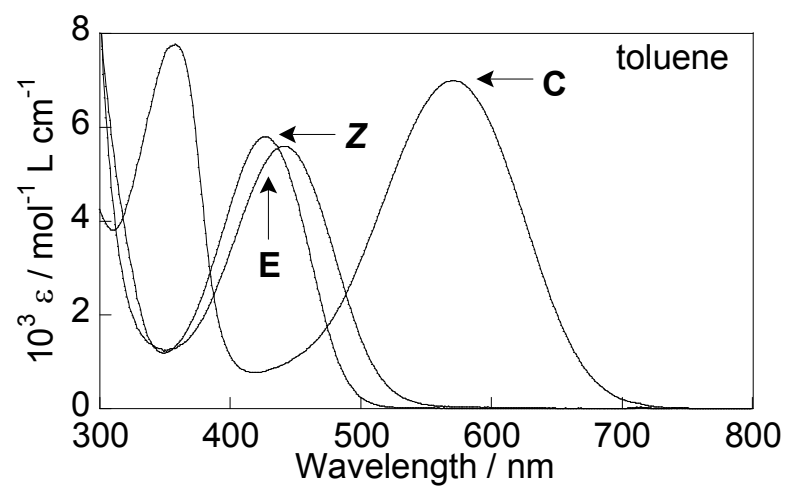

Figure 2. UV-vis absorption spectra of trifluoromethyl indolylfulgide $\mathbf{1}$ in toluene

In practical applications, absorption in the visible region is preferred because UV light can be damaging to living organism and material. The heteroaromatic substituent of fulgides and fulgimides has a strong effect on the absorption spectra. As shown in Figure 3 , increasing the electron donating ability of the aromatic group shifts the absorption maximum of the closed form towards longer wavelength. ${ }^{61,82}$ However, the absorption maxima of the open forms are usually in the UV region.

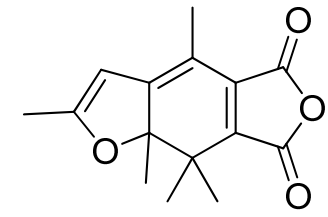

$494 \mathrm{~nm}$

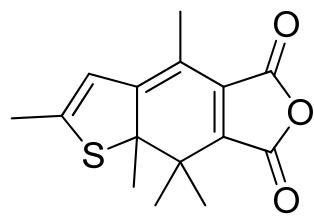

$540 \mathrm{~nm}$

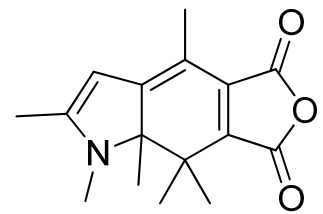

$632 \mathrm{~nm}$

Figure 3. Absorption maxima of the closed forms of furanyl, thienyl and pyrryl fulgides in toluene ${ }^{82}$

The substituent at the bridging position also affects the absorption spectra of fulgides. 
Yokoyama et al. reported that replacing the methyl group with a trifluoromethyl group on the bridging position of indolylfulgides shifts the absorption maximum of the $Z$-form 42 $\mathrm{nm}$ towards longer wavelength (Figure 4). ${ }^{15,49}$ A more recent study demonstrated that an indolylfulgide with a $\mathrm{C}_{3} \mathrm{~F}_{7}$ group at the bridging position also exhibits a bathochromic shift of the $Z$-form at the absorption maximum. All previous results suggested that a more electron withdrawing group on the bridging position of indolylfulgides shifts the absorption spectra of the open form towards longer wavelength. ${ }^{64}$ The ability of both the open and closed forms of trifluoromethyl indolylfulgide to absorb in the visible region allows the use of inexpensive light source for photochromic reactions.

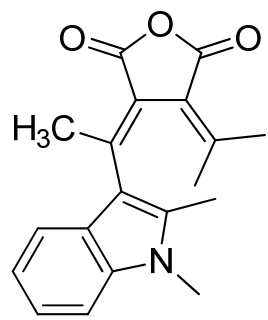

$385 \mathrm{~nm}$

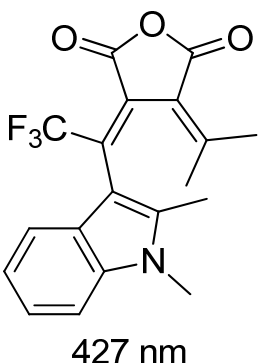

$427 \mathrm{~nm}$

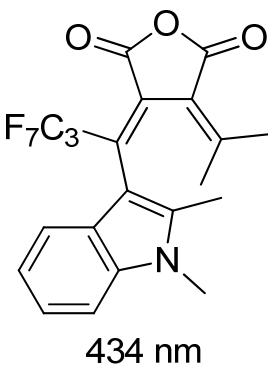

$434 \mathrm{~nm}$

Figure 4. Methyl, trifluoromethyl, heptafluoropropyl fulgides and their absorption maxima of the open forms ${ }^{49,64}$

\subsubsection{Photostationary state}

Photostationary state (PSS) is the steady state composition of a photochromic reaction upon irradiation at specific wavelength. Typically, a ratio or percentage of the chemical species is used to describe the photostationary state. The photostationary state of trifluoromethyl indolylfulgide $\mathbf{1}$ is determined at absorbance maximum of the open forms which produce highest percentage of $C$-form. At $435 \mathrm{~nm}$, the photostationary state contains over $90 \% C$-form. On the other hand, the ring opening reaction ( $C$ to $Z$ ) at 571 
$\mathrm{nm}$ is quantitative because $Z$-form has no absorbance above $530 \mathrm{~nm} .^{64}$

\subsubsection{Quantum yield}

For photochromic compounds, the quantum yield is the number of molecules that undergo the photochromic reaction per photon absorbed. The quantum yield is an important property that demonstrates the photochromic efficiency of the reactions. Higher quantum yields ensure fast and effective photochromic reactions with low energy light sources. For applications as optical switches and sensors, high quantum yields are required to guarantee fast responds and high sensitivity. Previous studies indicated that quantum yield can depend upon the polarity of the solvent. ${ }^{83}$ Rentzepis et al. demonstrated that 2-indolylfulgide displayed higher quantum yield in non-polar solvent than polar solvent for both ring-opening and ring-closing reactions. ${ }^{83}$

Several studies report the quantum yields of indolylfulgides having different substituents on the bridging position, indole ring, and anhydride ring. ${ }^{61,64,65,83}$ The trifluoromethyl indolylfulgide exhibits an enhanced quantum yield of the ring closing reaction by a factor of five relative to the methyl indolylfulgide (Figure 1-4). ${ }^{64}$ However, the ring opening reaction shows a modest decrease in the quantum yield for trifluoromethyl indolylfulgide relative to methyl indolylfulgide. ${ }^{64}$ The electron donating methoxy group on the indole ring further decreased the quantum yield of the ring opening reaction by stabilizing the closed form. ${ }^{65}$ Recently, an indolylfulgide with an adamantylidene group instead of an isopropylidene group was synthesized. ${ }^{65}$ The quantum yield of the ring opening reaction was significantly increased by adamantylidene substitution but the quantum yield of the ring closing reaction was dramatically decreased (Figure 5). ${ }^{65}$ Further investigation of the substituent effects on 
quantum yield are required to design more efficient fulgides.
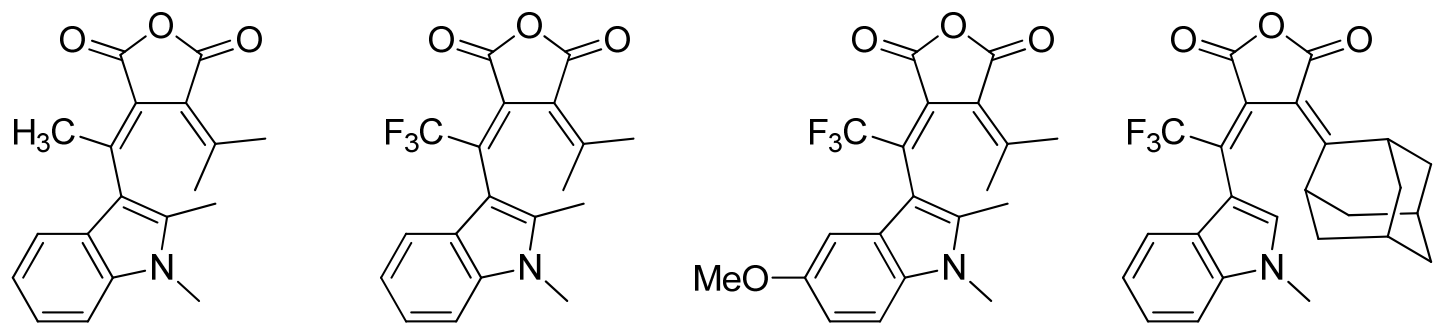

$\Phi_{\mathrm{EC}}(403 \mathrm{~nm})=0.040$

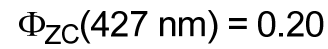

$\Phi_{\mathrm{ZC}}(427 \mathrm{~nm})=0.169$

$\Phi_{\mathrm{ZC}}(427 \mathrm{~nm})=0.051$

$\Phi_{\mathrm{CE}}(608 \mathrm{~nm})=0.051$

$\Phi_{\mathrm{CZ}}(559 \mathrm{~nm})=0.043$

$\Phi_{\mathrm{CZ}}(559 \mathrm{~nm})=0.012$

$\Phi_{\mathrm{CZ}}(559 \mathrm{~nm})=0.325$

Figure 5. Quantum yields of indolylfulgides with different substituent group ${ }^{61,64,65,83}$

\subsubsection{Thermal stability}

\section{Scheme 11. Proposed thermolysis mechanism of the $Z$-form trifluoromethyl} indolylfulgide $1^{50}$

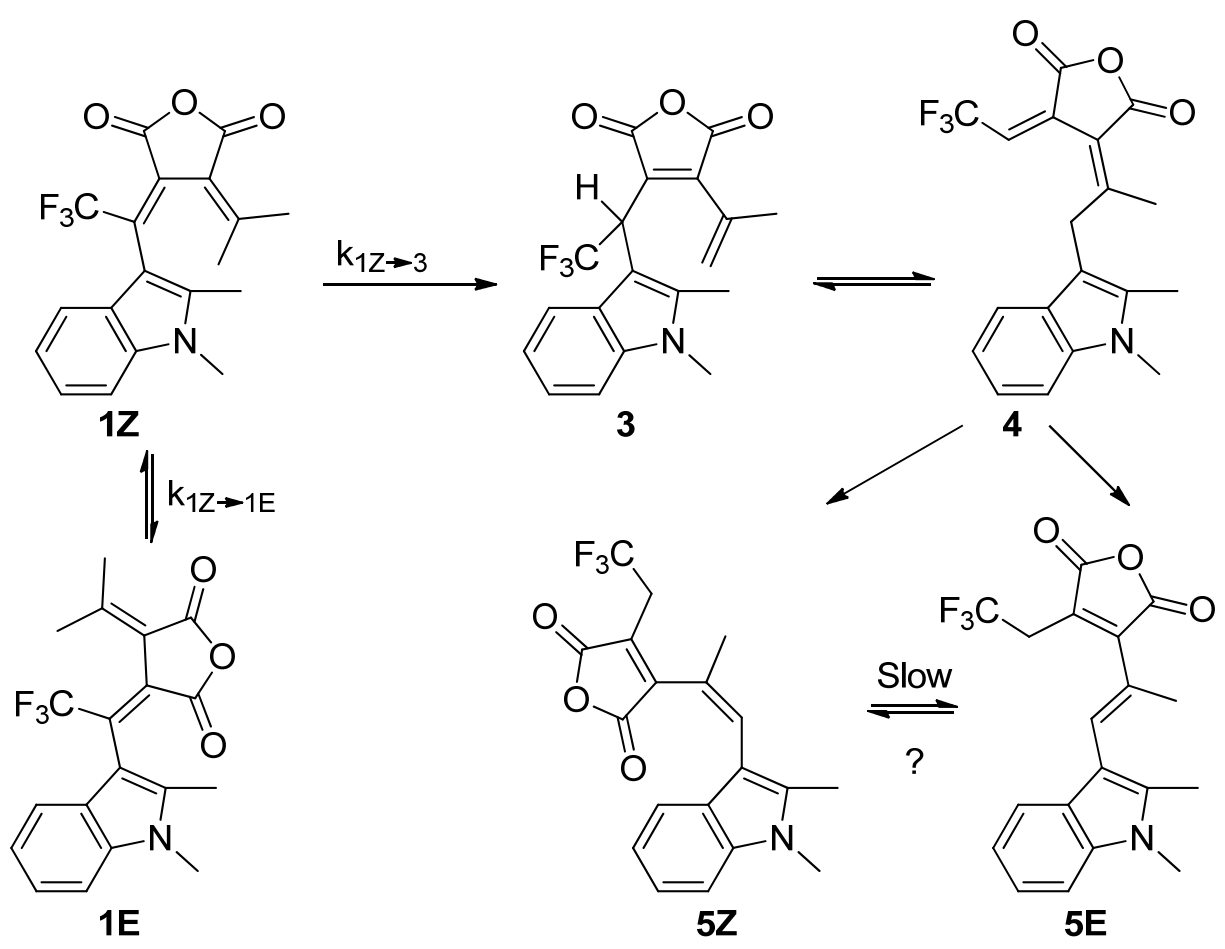

Since the discovery of a thermally irreversible fulgide, the potential application of fulgides as media for rewritable optical memory devices has been investigated extensively. ${ }^{15,57}$ Current commercial data storage devices, such as computer hard drives, 
DVDs, and magnetic tapes are expected to maintain viability to at least $50{ }^{\circ} \mathrm{C}$ for prolonged periods. ${ }^{50}$ Many fulgides and fulgimides have been synthesized with enhanced thermal stability, and the thermolysis mechanism has been studied. ${ }^{49,50}$ Trifluoromethyl indolylfulgide 1 demonstrates increased thermal stability in solvents and polymer films. ${ }^{49,64}$ The open (Z) and closed (C) forms of indolylfulgide $\mathbf{1}$ show no thermal decomposition at room temperature after one month in hexane, chloroform, acetonitrile, or poly(methyl methacrylate) (PMMA) films. ${ }^{84}$

Further investigation in PMMA films at $80{ }^{\circ} \mathrm{C}$ indicates that the $Z$-form indolylfulgide 1 shows a relatively rapid degradation, loss of $25 \%$ of absorbance at absorbance maxima in $17.5 \mathrm{~h}$. The $C$-form maintains thermal stability, only $6 \%$ decrease of the absorbance at absorbance maxima in $85 \mathrm{~h} .{ }^{64}$ Therefore, the mechanism of $Z$-form trifluoromethyl indolylfulgide 1 degradation was elucidated, and the decomposition products were isolated (Scheme 11). ${ }^{50}$ The proposed thermolysis mechanism starts with the irreversible conversion of $\mathbf{1}$ to intermediate $\mathbf{3}$ via a 1,5-hydrogen shift from the isopropylidene group, followed by a formal 1,5-migration of the indolyl moiety ( 3 to 4 ) and a final 1,5-hydrogen shift (4 to $\mathbf{5}){ }^{50}$ The mechanistic results indicated that the initial hydrogen migration from the isopropylindene group is the rate determining step of the thermal decomposition process.

Thus, modification of the isopropylindene group to diminish the rate of the 1,5 hydrogen shift should enhance the thermal stability. Fluorinated adamantylidene indolylfulgides were synthesized and they displayed enhanced thermal stability relative to the isopropylidene analogs. ${ }^{65}$ An NMR study of the thermal degradation of the $Z$-form of trifluoromethyl adamantylidene indolylfulgide displayed minor $E / Z$ isomerization in 
toluene at $80{ }^{\circ} \mathrm{C}$ after $168 \mathrm{~h}$, and no new peaks indicative any thermal degradation products. ${ }^{65}$ A recent study replacing the isopropylidene group of a trifluoromethyl indolylfulgides with a cycloalkylidene group was reported. ${ }^{85}$ The thermal degradation product of trifluoromethyl cyclopentylidene indolylfulgide, an indolylethenylanhydride, maintained photochromic properties and displayed outstanding thermal and photochemical stability (Scheme 12). ${ }^{85}$

\section{Scheme 12. Thermolysis of trifluoromethyl cyclopentylidene indolylfulgide ${ }^{85}$}

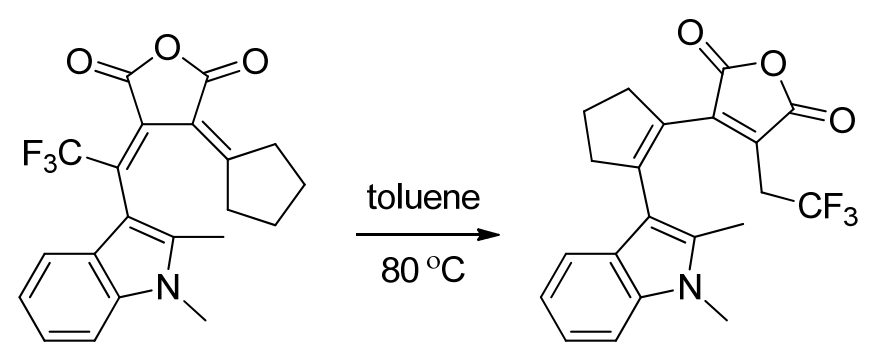

The thermal stability of trifluoromethyl indolylfulgimides is similar to the corresponding fulgide. The $Z$-form of the fulgimides displayed greater thermal stability in PMMA films at $80{ }^{\circ} \mathrm{C}$ than the corresponding fulgide and are proposed to undergo a similar degradation pathway. ${ }^{41}$ The $C$-form of indolylfulgimides was found to be more stable than $Z$-form, which is the same as seen in the indolylfulgide analog. ${ }^{41}$

\subsubsection{Photochemical stability}

Photochemical stability, also known as fatigue resistance, is the percentage of the molecules remaining photochromic after a certain number of photochromic cycles. ${ }^{86}$ Extensive studies have been conducted to enhanced the photochemical stability of photochromic compounds. ${ }^{2}$ The synthesis of photochemically stable spirooxazines led to their application in commercial plastic photochromic lenses. ${ }^{2}$ Developing more photochemically stable fulgides and fulgimides are essential for their practical 
applications.

Scheme 13. Proposed photochemical degradation pathway for methyl indolylfulgides ${ }^{49}$

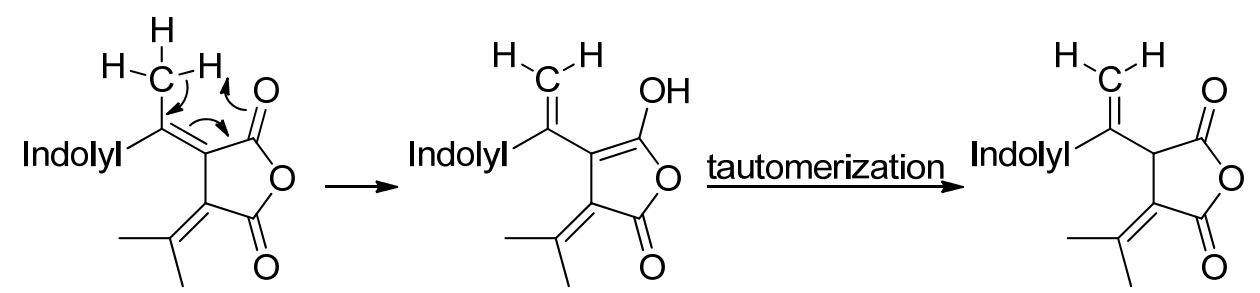

Indolylfulgides and indolylfulgimides undergo from less than a hundred to several thousand photochromic ring-opening/ring-closing cycles before significant degradation. ${ }^{51,61,64}$ Yokoyama proposed that the photochemical decomposition of methyl indolylfulgide was attributable to a 1,5-hydrogen migration (Scheme 13). ${ }^{49}$ The replacement of the methyl group with a trifluoromethyl group significantly enhanced the photochemical stability of indolylfulgides. ${ }^{49}$ The trifluoromethyl group cannot undergo 1,5-hydrogen migration via the proposed pathway. Fluorinated indolylfulgimides displayed similar photochemical stability in aprotic solvent as their fulgide anolog. ${ }^{41,86}$ However, no photochemical decomposition product of indolylfulgides or indolylfulgimides has been isolated and the photochemical decomposition pathway remains unclear.

\subsubsection{Hydrolytic stability}

Hydrolytic stability corresponds to the ability of photochromic compounds to resist solvolysis in protic environments or aqueous solutions. Hydrolytic stability is crucial for applications in biological systems and humid environments. Although, fulgides display promising photochromic properties, the succinic anhydride ring causes rapid solvolytic 
degradation in protic solvents or aqueous media. ${ }^{59,71}$ On the other hand, fulgimides, the imide derivatives of fulgides, exhibit much higher resistance to hydrolysis and retain the promising photochromic properties. Matsushima et al. reported that a carboxylated arylfulgimide 6 shows good solubility and thermal stability in 50/50 water/ethanol at room temperature. ${ }^{71}$ The carboxylated arylfulgimide maintained photochromic activity in 50/50 water/ethanol, while fulgides (if soluble) would have rapidly degraded. ${ }^{71}$ The hydrolytic stability of trifluoromethyl indolylfulgimides was examined by Lees et al. Both $Z$ - and $C$-forms of trifluoromethyl $N$-phenyl indolylfulgimide 7 displayed greater stability in 70/30 ethanol/water than the parent indolylfulgide at room temperature. ${ }^{41}$
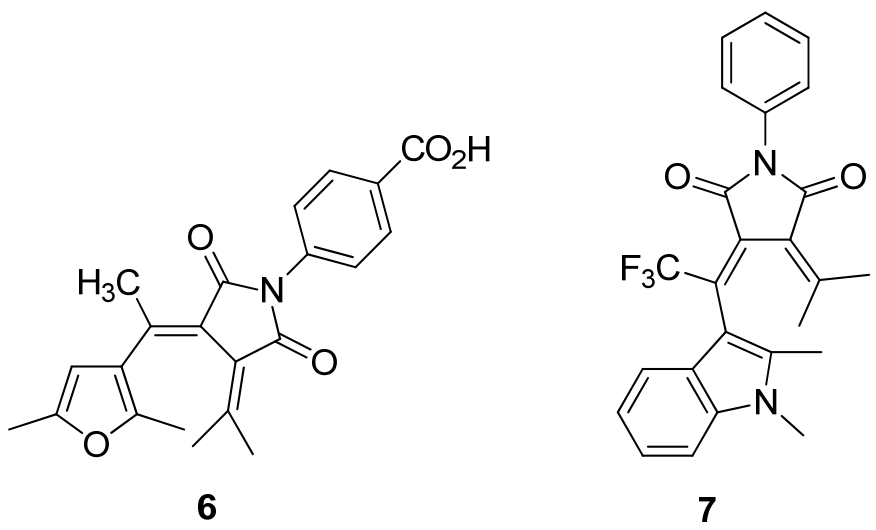

Stability of fulgimides in aqueous solutions was also reported. ${ }^{6,70}$ A study of fulgimide derivatives attached to concanavalin A demonstrated that the open form of a fulgimide was stable in aqueous solution for $48 \mathrm{~h}$ at room temperature and could undergo at least two photochromic cycles. ${ }^{70}$ A recent study reported that fulgimides can switch back and forth seven times in cellular membranes inside living Potorous tridactylis cells. ${ }^{6}$ However, limited number of photochromic cycles and low thermal stability of fulgimides in aqueous solutions limited further application in biological systems, such as biological optical switches and sensors. Therefore, it is necessary to synthesize fulgimides with 
enhanced hydrolytic stability in protic solvents and aqueous solutions. 


\section{CHAPTER 2}

\section{OBJECTIVES}

The overall aim of my research is to develop indolylfulgides and indolylfulgimides with improve properties.

1) To improve the thermal stability of indolylfulgides

Deuterated isopropylidene substituted trifluoromethyl indolylfulgide $\mathbf{8}$ is synthesized to improve thermal stability of the $Z$-form relative to the proteo isopropylidene substituted trifluoromethyl indolylfulgide $\mathbf{1}$.

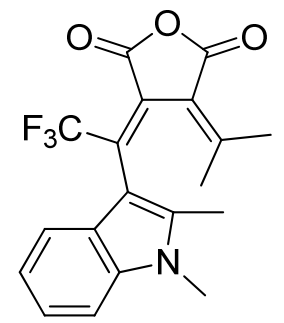

1

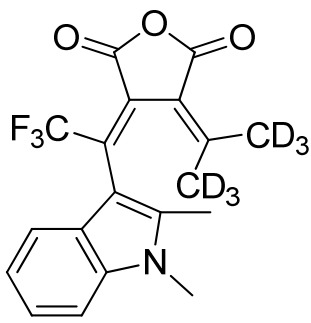

8

2) To improve the hydrolytic stability of indolylfulgimides

Trifluoromethyl $N$-ethoxycarbonylmethyl indolylfulgimide 9 is synthesized to improve the thermal and photochemical stabilities in protic solvent.

Trifluoromethyl carboxylic acid indolylfulgimide $\mathbf{1 0}$ is synthesized to improve thermal and photochemical properties in aqueous solution.

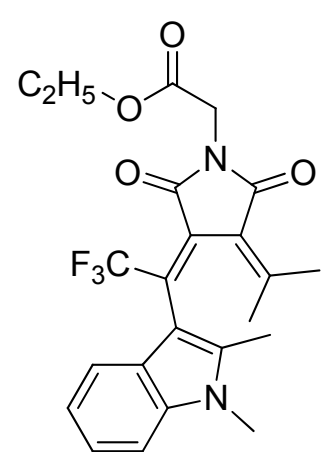

9

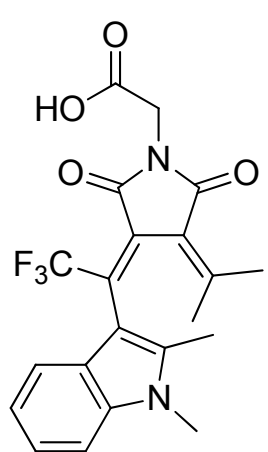

10 
3) To improve the thermal stability by replacing that trifluoromethyl group a with methyl group

Methyl carboxylic acid indolylfulgimide $\mathbf{1 1}$ is synthesized from methyl indolylfulgide 2 to improve thermal and photochemical properties in aqueous solution.

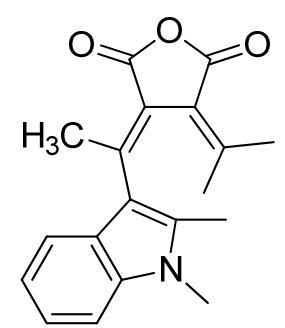

2

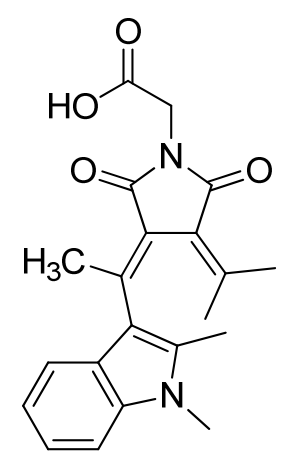

11 


\section{CHAPTER 3}

\section{IMPROVING THE STABILITY OF PHOTOCHROMIC FLUORINATED}

\section{INDOLYLFULGIDES}

\subsection{Abstract}

Fluorinated indolylfulgides, promising photochromic compounds, have been considered as potential material for applications in optical switches and memory. Previous mechanistic studies indicated that the thermal stability of trifluoromethyl indolylfulgides such as $\mathbf{1}$ was controlled by a 1,5-hydrogen shift from the isopropylidene group. Therefore, to take advantage of kinetic isotope effects, a deuterated trifluoromethyl indolylfulgide $\mathbf{8}$ was designed to enhance thermal stability. The synthetic pathway was developed on the basis of that of 1 using commercially available deuterated starting materials. The absorption spectra, thermal stabilities in toluene and poly (methyl methacrylate) (PMMA) films, and photochemical fatigue resistances in toluene of both indolylfulgides were measured. Deuteration of the isopropylidene group improved the thermal stability of the indolylfulgide by a factor of 7 , which corresponded to the expected kinetic isotope effect for a 1,5-hydrogen shift.

\subsection{Introduction}

Fulgides, an important class of photochromic compounds, can interconvert between the open cyclizable form ( $Z$-form) and the closed form ( $C$-form) upon exposure to certain wavelengths of light (Scheme 14). ${ }^{2,7}$ Indolyl substituted fulgides have attracted attention because of their potential applications in optical devices, such as optical memory, sensors, and switches. ${ }^{2,15,51,61,62,83,87,88}$ 


\section{Scheme 14. Photoreaction of fluorinated indolylfulgides 1 and 8}

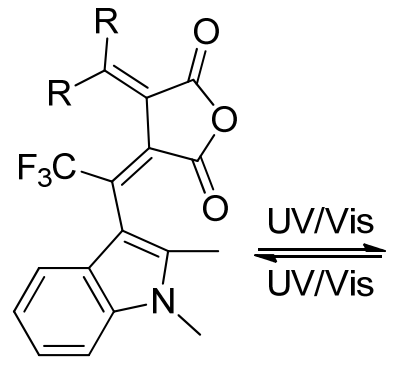

Open forms

$E$

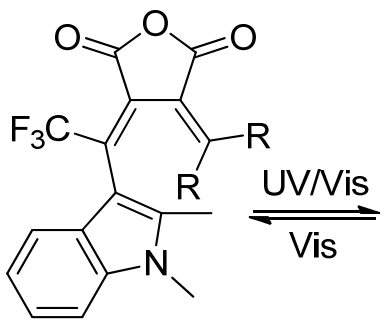

Z<smiles>[R]C1([R])C2=C(C(=O)OC2=O)C(C(F)(F)F)=C2c3ccccc3N(C)C21C</smiles>

Closed form

C

1. $\mathrm{R}=\mathrm{CH}_{3} ; \mathbf{8} \cdot \mathrm{R}=\mathrm{CD}_{3}$

Several properties are required for fulgides to be useful in optical devices, such as readily distinguishable absorption spectra for each form, thermal and photochemical stability, large quantum yields, and large molar absorption coefficients. ${ }^{15,57}$ Yokoyama and Takahashi synthesized a fluorinated indolylfulgide which possessed great thermal and photochemical properties, suitable for applications in optical devices. ${ }^{49}$ Fluorination at the bridging position exhibited several advantages, such as longer wavelength absorption maximum for the $Z$-form, improved photochemical stability in both toluene and PMMA films, enhanced coloration quantum yields in toluene, and higher thermal resistance of the $C$-form upon treatment at $80^{\circ} \mathrm{C}$ in PMMA films. ${ }^{49}$ However, the $Z$-form of the fluorinated substituted indolylfulgides rapidly decomposed in both toluene and PMMA upon prolonged exposure to elevated temperatures. ${ }^{50,64}$ The proposed thermolysis mechanism involved the irreversible conversion of $\mathbf{1 Z}$ to intermediate $\mathbf{3}$ via a $1,5-$ hydrogen shift from the isopropylidene group, the rate determining step of the thermal decomposition process (Scheme 15). ${ }^{50}$ 


\section{Scheme 15. Proposed thermolysis mechanism of fluorinated indolylfulgides 1 and 8}

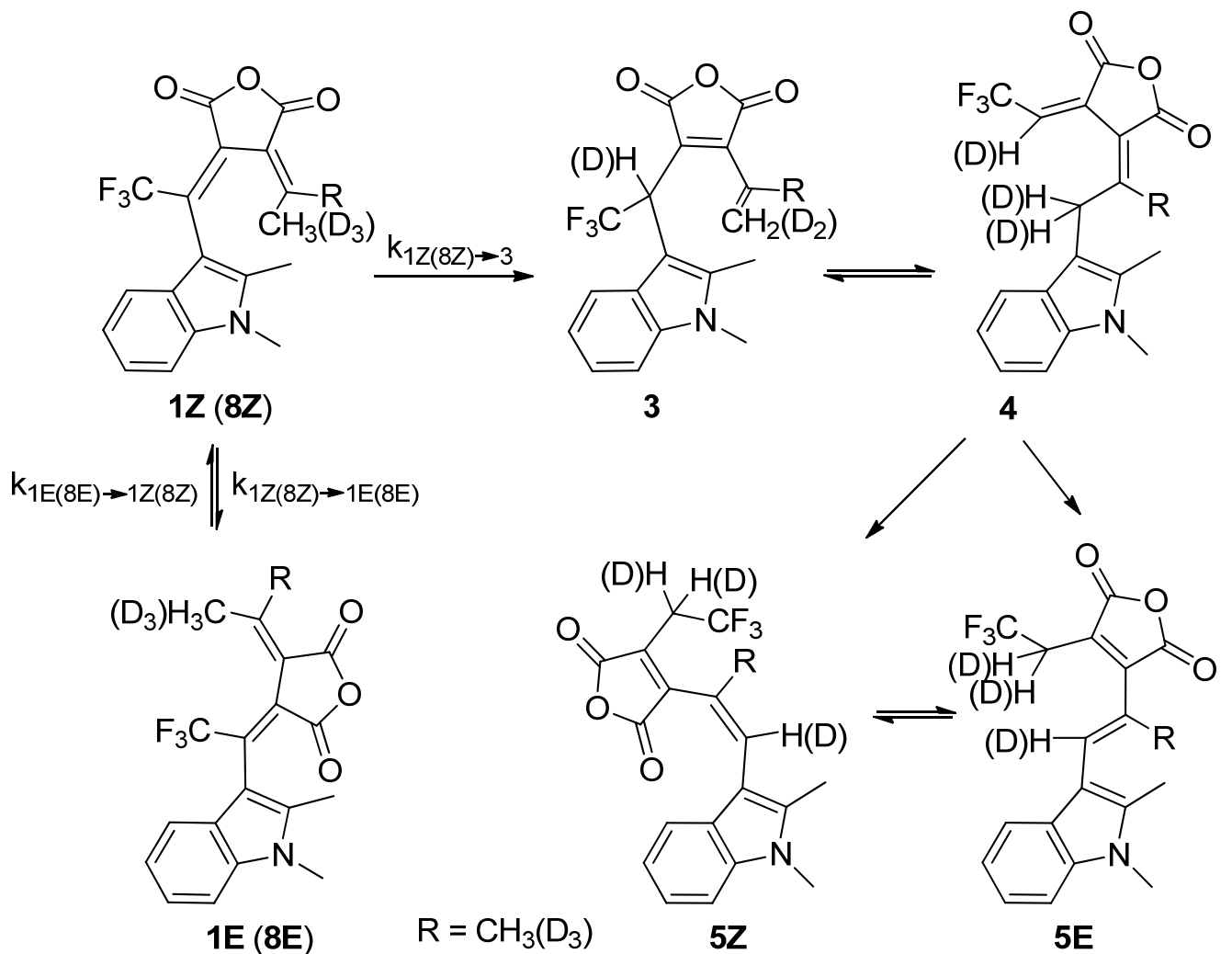

Interestingly, a 1,5-hydrogen shift from the isopropylidene group may also be responsible for the photochemical degradation of fulgides. A mechanism for the photochemical degradation of non-fluorinated fulgides was proposed by Yokoyama et al., (Scheme 16) ${ }^{49}$ The first step involves a 1,5-hydrogen migration from the methyl group to the carbonyl group and yielded an enol product. The enol further tautomerizes to a nonconjugated compound with concurrent loss of photochromic properties.

Fluorinated fulgides cannot undergo such photochemical degradation as the methyl group is replaced by a trifluoromethyl group which has no hydrogens. However, a parallel mechanism may occur between the isopropylidene group and the second carbonyl group (Scheme 16). Therefore, diminishing the rate of the 1,5-hydrogen shifts 
by modification of the isopropylidene group may enhance thermal stability and photochemical stability. Previous studies substituted the isopropylidene group with an adamantylidene group, however, the cycling time between the open and closed forms was too long to measure the photochemical stability and the thermal stability of closed form was poor. ${ }^{65}$

\section{Scheme 16. Potential photochemical degradation pathway for indolylfulgides}

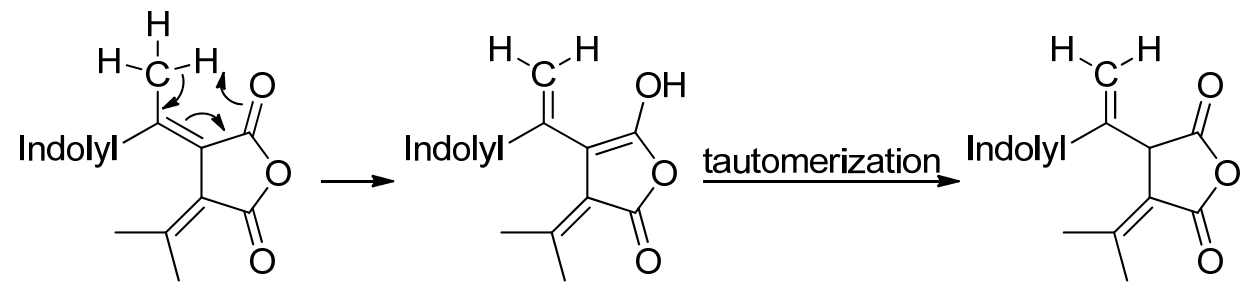

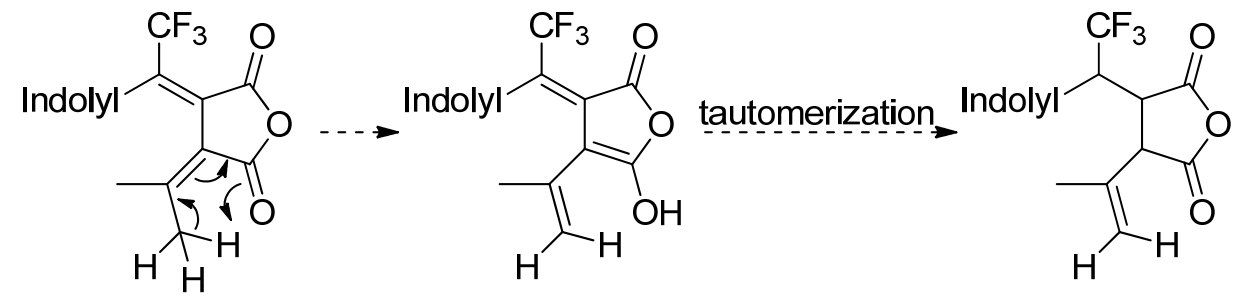

Herein, I have synthesized and characterized a deuterated trifluoromethyl indolylfulgide 8 (Scheme 14), which was expected to have higher thermal stability in toluene and PMMA film. The rate determining step for thermal decomposition, a 1,5hydrogen shift, will be significantly decreased by the kinetic isotope effect (Scheme 17).

\section{Scheme 17. Thermal degradation pathway for indolylfulgide 8}

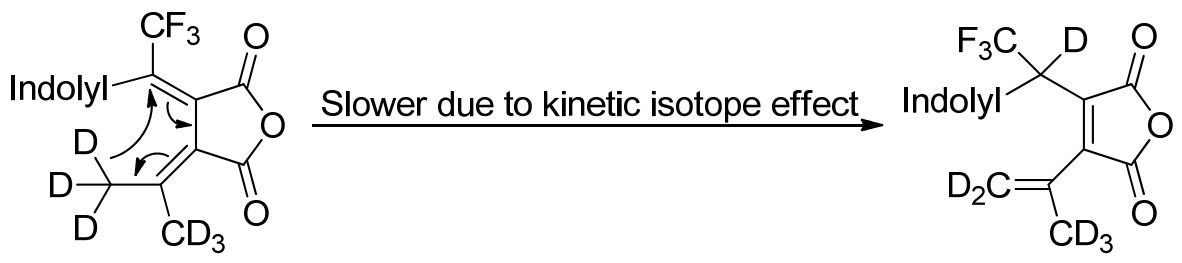

8 


\subsection{Experimental Section}

\subsubsection{General procedures and materials}

All commercially available materials were used without further purification. The NMR spectra were recorded on a Brüker $400 \mathrm{MHz}$ NMR spectrometer. The ${ }^{1} \mathrm{H}$ and ${ }^{13} \mathrm{C}$ NMR samples were internally referenced to TMS $(0.00 \mathrm{ppm})$ or solvent $(7.26$ and 77.00 ppm, respectively for $\left.\mathrm{CDCl}_{3}\right)$. The UV-vis spectra were recorded with a Cary 300 Spectrophotometer. Flash chromatography was performed with 230-400 mesh silica gel. Indolylfulgide 1 was synthesized as described previously. ${ }^{60}$

\subsubsection{Synthesis of dimethyl octadeuteroisopropylidene succinate 12}<smiles>[2H]C([2H])([2H])C([2H])([2H])C(=O)OC</smiles>

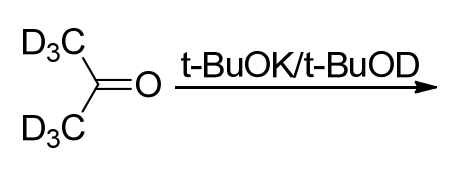<smiles>[2H]C([2H])([2H])C(C)=C(C(=O)OC)C([2H])([2H])C(=O)O</smiles><smiles>[2H]C([2H])([2H])[13CH3]</smiles>

12

The tert-Butanol-OD (5 mL), dimethyl 2,2,3,3-tetradeuterosuccinate (5.0 g, 33.3 mmol) and perdeuterated acetone $(1.7 \mathrm{~g}, 26.6 \mathrm{mmol})$ were added to a mixture of potassium tert-butoxide (3.4 g, $30.1 \mathrm{mmol}$ ) in $50 \mathrm{~mL}$ of tert-butanol-OD under argon gas. The mixture was refluxed for $4 \mathrm{~h}$, and the tert-butanol-OD was evaporated. Diethyl ether $(25 \mathrm{~mL})$ was added, and the reaction was quenched with $50 \mathrm{~mL}$ of $\mathrm{NaOD}$ in $\mathrm{D}_{2} \mathrm{O}(2 \mathrm{M})$. The aqueous solution was extracted with diethyl ether $(3 \times 50 \mathrm{~mL})$ and then acidified with deuterated sulfuric acid $\left(8.5 \mathrm{~mL} \mathrm{D}_{2} \mathrm{SO}_{4}\right.$ in $\left.40 \mathrm{~mL} \mathrm{D} \mathrm{D}_{2} \mathrm{O}\right)$. The aqueous layer was further extracted with $\mathrm{CH}_{2} \mathrm{Cl}_{2}(4 \times 75 \mathrm{~mL})$. The combined organic layers were dried over $\mathrm{MgSO}_{4}$, filtered, and concentrated in vacuo. The resulting octadeuterated half-acid, halfester was esterified via $50 \mathrm{~mL}$ of acidified monodeuterated methanol. The reaction 
mixture was stirred for $6 \mathrm{~d}$ under argon gas. The reaction mixture was then concentrated in vacuo and $50 \mathrm{~mL}$ of deuterated ice water was added. The ice water slurry was extracted with diethyl ether $(4 \times 20 \mathrm{~mL})$. The organic layers were combined and extracted with deuterated sodium carbonate solution $(3 \times 20 \mathrm{~mL})$. The organic layer was dried over $\mathrm{MgSO}_{4}$, filtered, and concentrated in vacuo to provide $1.95 \mathrm{~g}$ of product 12 (38\% yield). This synthesis was performed by Ghislaine Guez in Dr. Lees' group.

\subsubsection{Synthesis of hexadeuterated indolylfulgide 8}

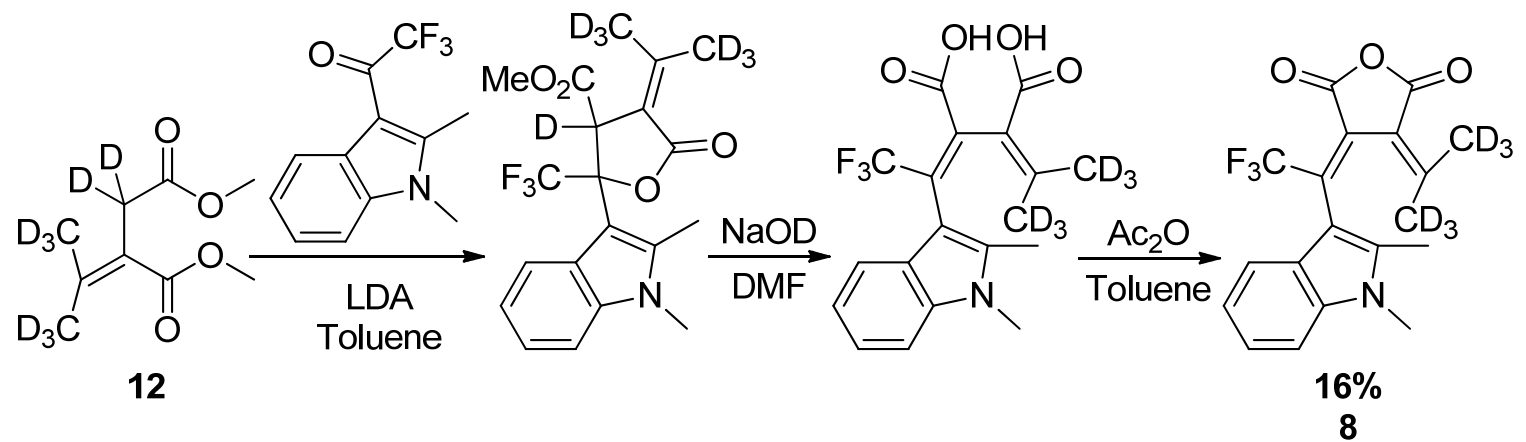

Dimethyl octadeuteroisopropylidene succinate $12(0.95 \mathrm{~g}, 4.90 \mathrm{mmol})$ was added to a mixture of 1,2-dimethyl-3-trifluoroacetylindole (previously synthesized, $0.66 \mathrm{~g}, 2.74$ $\mathrm{mmol}$ ) in $100 \mathrm{~mL}$ of toluene. The mixture was evaporated in vacuo to approximately 50 $\mathrm{mL}$. Lithium diisopropylamide ( $2.45 \mathrm{~mL}$ of a $2 \mathrm{M}$ solution, $4.90 \mathrm{mmol}$ ) was added slowly at room temperature under argon gas. After $16 \mathrm{~h}$, the mixture was acidified with aqueous acid $\left(1.5 \mathrm{~mL} \mathrm{D}_{2} \mathrm{SO}_{4}\right.$ in $\left.29 \mathrm{~mL} \mathrm{D}_{2} \mathrm{O}\right)$ and then extracted with diethyl ether $(3 \times 30 \mathrm{~mL})$. The combined organic layers were dried over $\mathrm{MgSO}_{4}$, filtered, and concentrated in vacuo. The resulting liquid was purified by silica gel chromatography $\left(1: 1 \mathrm{CH}_{2} \mathrm{Cl}_{2} /\right.$ hexanes $)$ and then recrystallized from ethanol to provide $0.39 \mathrm{~g}$ of the hexadeuterated indolelactone as a cis/trans mixture. To the hexadeuterated indolelactone $(0.39 \mathrm{~g}, 0.97 \mathrm{mmol})$ dissolved in $40 \mathrm{~mL}$ of DMF at $0{ }^{\circ} \mathrm{C}$ was added $1.5 \mathrm{~mL}$ of sodium deuteroxide $\left(30 \%\right.$ in $\left.\mathrm{D}_{2} \mathrm{O}\right)$. The 
solution was stirred and allowed to warm to room temperature overnight. Solvent was removed in vacuo and the residue partitioned between $20 \mathrm{~mL} \mathrm{H}_{2} \mathrm{O}$ and $50 \mathrm{~mL}$ EtOAc. The aqueous layer was acidified with $5 \% \mathrm{H}_{2} \mathrm{SO}_{4}$ solution to $\mathrm{pH} 1$ and extracted with EtOAc $(4 \times 25 \mathrm{~mL})$. The combined organic layers were dried over $\mathrm{MgSO}_{4}$, filtered, and concentrated in vacuo to provide a light yellow solid. The solid was then triturated with $\mathrm{CHCl}_{3}$ to provide $0.33 \mathrm{~g}$ of crude diacid (white solid). The diacid was suspended in a mixture of $7 \mathrm{~mL}$ toluene and $4 \mathrm{~mL}$ of acetic anhydride. The solid immediately dissolved and the solution turned dark orange. After stirring overnight, the solvent was removed in vacuo. Crystallization was accomplished using isopropanol $/ \mathrm{CH}_{2} \mathrm{Cl}_{2}$ to provide $0.16 \mathrm{~g}$ of deuterated fulgide $\mathbf{8 Z}$ (16\% yield from 1,2-dimethyl-3-trifluoroacetylindole). The ${ }^{1} \mathrm{H}$ NMR spectrum matched that of the proteo compound with the exception that the resonances at 2.16 and $0.97 \mathrm{ppm}$ were greatly diminished. The two methyl groups were approximately $85 \%$ perdeuterated.

\subsubsection{Preparation of thin films}

An initial solution was prepared by adding $2-4 \mathrm{mg}$ of fulgide to a solution of $10 \%$ poly(methyl methacrylate) (PMMA-low molecular weight, average $\left.M_{\mathrm{w}} c a .120,000\right)$ in 5 $\mathrm{mL}$ of $\mathrm{CH}_{2} \mathrm{Cl}_{2}$. The polymer solution $(1.5 \mathrm{~mL})$ was then deposited via pipet onto a circular 1 inch $\times 1 / 16$ inch BK-7 glass slides (escoproducts) and allowed to spread over the surface of the slide. The sample was allowed to dry overnight inside a glass Petri dish at room temperature. The resulting films were utilized in the thermal stability studies.

\subsubsection{Spectra determination}

Concentrated, air-saturated stock solutions of the $Z$-form or $E$-form of the fulgides in toluene were prepared in duplicate or triplicate. From each stock solution, 5 samples 
ranging in concentration from 0.20 to $0.05 \mathrm{mM}$ were then prepared by dilution with toluene. A UV-vis spectrum was acquired for each sample. Extinction coefficients and $\lambda_{\max }$ were determined. The $C$-forms were obtained by irradiating $Z$-form solutions with $419 \mathrm{~nm}$ light in a Rayonet reactor followed by purification via silica gel chromatography (toluene). Stock solutions containing freshly purified $C$-form in toluene were diluted to 4 or 5 different concentrations, and their UV-vis spectra were obtained. Each $C$-form solution was then quantitatively converted to $Z$-form with $570 \mathrm{~nm}$ light and the concentration of fulgide present was ascertained using the predetermined $Z$-form extinction coefficients. Extinction coefficients and $\lambda_{\max }$ for the $C$-forms were then determined from the initial spectra.

\subsubsection{Photostationary state (PSS) measurements}

The photostationary state (PSS) was measured using NMR spectroscopy. An NMR tube containing $Z$-form fulgide in toluene- $\mathrm{d}_{8}$ was illuminated with $436 \mathrm{~nm}$ light until the photostationary state was reached. An NMR spectrum was then acquired and integrated, and the ratio of $E: Z: C$ was determined.

\subsubsection{Photochemical stability}

Air-saturated solutions of the $Z$-form were prepared in toluene with an initial absorbance of 0.6 at the absorption maxima. Samples were irradiated to the photostationary state with light supplied from an Oriel 1000W Hg (Xe) lamp utilizing a water filter followed by a hot mirror (blocking UV and IR light) followed by a $435 \mathrm{~nm}$ narrow bandpass filter. After measuring the UV-vis spectrum of the photostationary state, $\mathrm{PSS}_{435 \mathrm{~nm}}$, a pure $Z$-form solution was irradiated to $90 \%$ of the PSS, and the reaction was timed. The 90\% PSS mixture was then bleached with $>560 \mathrm{~nm}$ light using a separate 
filter, and the time taking for bleaching was determined. Absorbance at the $C$-form $\lambda_{\max }$ was $<0.01$ upon bleaching.

Once the duration of irradiation was established for both $90 \%$ PSS coloration and $<1 \%$ $C$-form bleaching reactions, the system was automated through the use of a filter switch. All solutions were capped and stirred. Control experiments were performed to correct for evaporation. After a designated number of irradiation cycles (coloration followed by decoloration), the samples were fully converted to $\mathrm{PSS}_{435 \mathrm{~nm}}$ and their UV-vis spectra scanned. The photochemical fatigue was then determined by comparison with the initial $\mathrm{PSS}_{435 \mathrm{~nm}}$ absorption spectrum. The cycling times were approximately $35 \mathrm{~s}(\mathrm{Z}-\mathrm{C})$ and $25 \mathrm{~s}$ (C-Z) for fulgides 1 and $\mathbf{8 .}$

\subsubsection{Thermal stability}

\subsubsection{Polymer-based study}

Thin films containing the $Z$-form of the fulgides were wrapped in aluminum foil and placed in an oven maintained at $80^{\circ} \mathrm{C}$. The films were removed, at prescribed intervals and their UV-vis spectra measured.

To determine the stability of the $C$-form, the thin films containing the $Z$-form, were illuminated with blue light (435 nm bandpass filter) until the photostationary state had been obtained. The thin films were then wrapped in aluminum foil and placed in an oven maintained at $80^{\circ} \mathrm{C}$. The films were removed, at prescribed intervals and their UV-vis spectra measured.

\subsubsection{Solution-based study}

A solution of the $Z$-forms of deuterated trifluoromethyl indolylfulgide 8 and 5 methoxy-2-methylindole (internal standard) was prepared in toluene- $\mathrm{d}_{8}$. The solution was 
transferred to an NMR tube. The tube was then sealed and submersed in a water bath maintained at $80^{\circ} \mathrm{C}$. At prescribed times, the tube was removed and its contents analyzed by ${ }^{1} \mathrm{H}$ NMR-spectroscopy. A control experiment in which approximately a 1:1 mixture of 1 and $\mathbf{8}$ was degraded was also performed. All the photochemical and thermal measurements were performed by Dr. Islamova in Dr. Lees' group.

\subsection{Results and Discussion}

\subsubsection{Synthesis}

The preparation of deuterated trifluoromethyl indolylfulgide $\mathbf{8 Z}$ was achieved for the first time following a similar pathway to $\mathbf{1 Z}$ with deuterated chemicals and modified methods (Scheme 18). ${ }^{60}$ The synthesis consisted of a five-step sequence. The first step, a Stobbe condensation, involved the reaction of dimethyl 2,2,3,3-tetradeuterosuccinate with perdeuterated acetone to produce an octadeuterated half-acid, half-ester. A Fisher esterification of the half-acid, half ester in acidified monodeuterated methanol produced dimethyl octadeuteroisopropylidenesuccinate. Another Stobbe condensation was performed with dimethyl octadeuteroisopropylidenesuccinate and 1,2 dimethyl-3trifluoroacetylindole to generate hexadeuterated indolelactone as a cis/trans mixture. Previous synthetic studies with methyl indolylfulgides indicated that only transindolelactone derivatives could be carried onto the final product. ${ }^{89}$ An improved synthesis of methyl and trifluoromethyl indolylfulgides by Lees et al. demonstrated that sodium hydride and potassium hydroxide in DMF allowed cis indolelactone derivatives to produce diacid. ${ }^{60}$ Furthermore, the method also increased the yield for both cis and trans isomers. ${ }^{60}$ Therefore, I treated the cis/trans hexadeuterated indolelactone with NaOD ( $\mathrm{NaD}$ was not commercially available) in DMF. The resulting diacid was further 
dehydrated with acetic anhydride to produce hexadeuterated indolylfulgide $\mathbf{8 Z}$. The ${ }^{1} \mathrm{H}$ NMR spectrum indicated that the resonances at 2.16 and $0.97 \mathrm{ppm}$ were greatly diminished while all others resonances matched the spectrum of proteo $\mathbf{1 Z}$. The perdeuteration ratio of the two methyl groups was approximately $85 \%$.

Scheme 18. Synthesis of deuterated indolylfulgide 8<smiles>[2H]C(C)(C)C(=O)OCC(C(=O)OC)C(=O)OC</smiles>

12

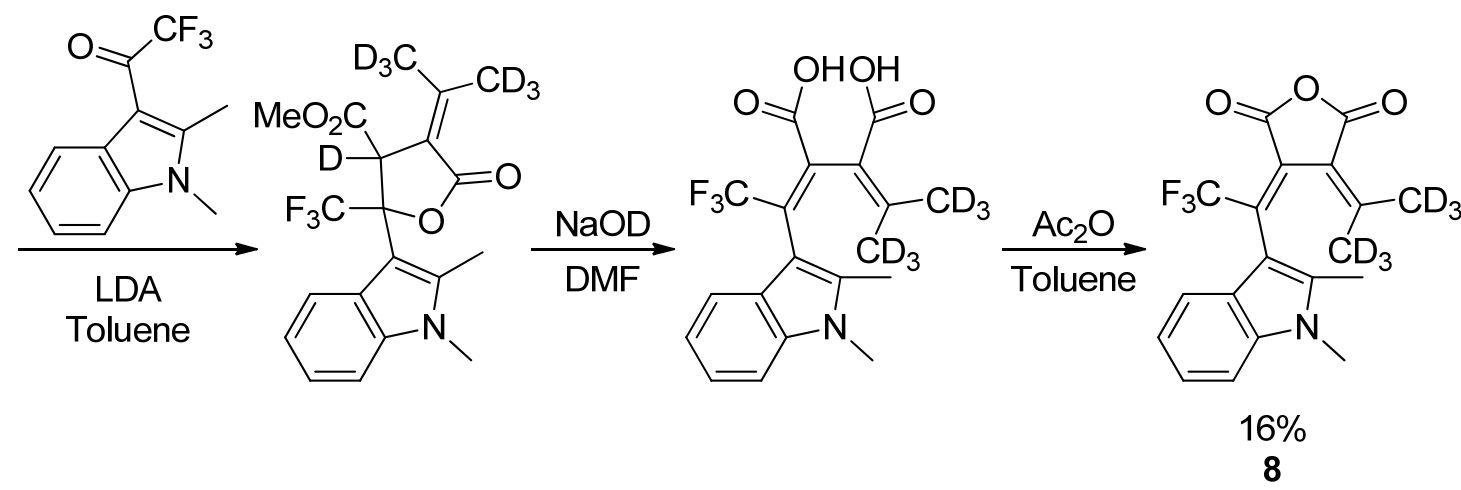

\subsubsection{UV-vis absorption spectra}

The UV-vis absorption spectra of $Z$-form and $C$-form deuterated trifluoromethyl indolylfulgide 8 in toluene are shown in Figure 6. The wavelength of maximum absorbance and the corresponding extinction coefficients of fulgides $\mathbf{1}$ and $\mathbf{8}$ in toluene are presented in Table 1. The absorption maxima of fulgides $\mathbf{1}$ and $\mathbf{8}$ are in the visible region, which allows the use of inexpensive light sources for their interconversion. Deuteration of the isopropylidene group does not change the absorption maxima and extinction coefficients, as expected. 

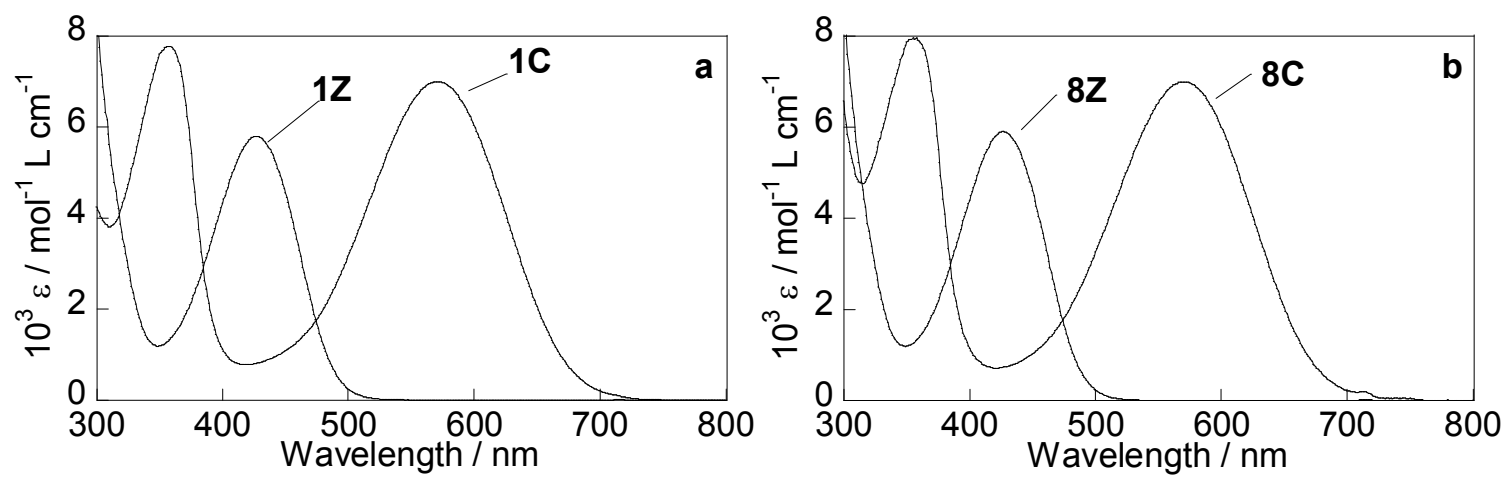

Figure 6. UV-vis absorption spectra of fulgides $\mathbf{1}$ and $\mathbf{8}$ in toluene

Table 1. Extinction coefficients at $\lambda_{\max }$ for fulgides 1 and 8 in toluene

\begin{tabular}{|c|c|c|c|}
\hline \multirow{2}{*}{ Fulgide } & \multicolumn{2}{|c|}{$\lambda_{\max } / \mathrm{nm}\left(\varepsilon_{\max } / \mathrm{mol}^{-1} \mathrm{~L} \mathrm{~cm}^{-1}\right)$} & \multirow{2}{*}{$\begin{array}{c}\mathrm{PSS}_{436 \mathrm{~nm}} \\
C: Z: E\end{array}$} \\
\hline & $Z$-form & $C$-form & \\
\hline 1 & $427(5800)$ & $571(7000)$ & $95: 3: 2$ \\
\hline 8 & $427(5900)$ & $571(7000)$ & $94: 3: 2$ \\
\hline
\end{tabular}

\subsubsection{Thermal stability}

Previous studies demonstrated that the thermal resistance of fulgides was an essential characteristic for their applications in optical devices. ${ }^{51,64,65,71,83}$ In my research, the thermal stability of fulgide $\mathbf{8}$ was measured in both toluene and PMMA film. In toluene, NMR spectroscopy was used to determine the thermal stability. As shown in Scheme 15, the first step of the thermolysis is a 1,5-hydrogen shift from the isopropylidene group of $\mathbf{1 Z}$ to form intermediate 3 , follows by a 1,5-indolyl migration and another 1,5-hydrogen shift to form the final thermal decomposition product $5 .^{50}$ Figure 7 indicates that the concentration of deuterated fulgide $\mathbf{8 Z}$ decreased and the concentrations of thermolysis products increased with time at $80{ }^{\circ} \mathrm{C}$ in toluene. The rate constants were obtained by fitting the NMR data using least-squares (Table 2). 


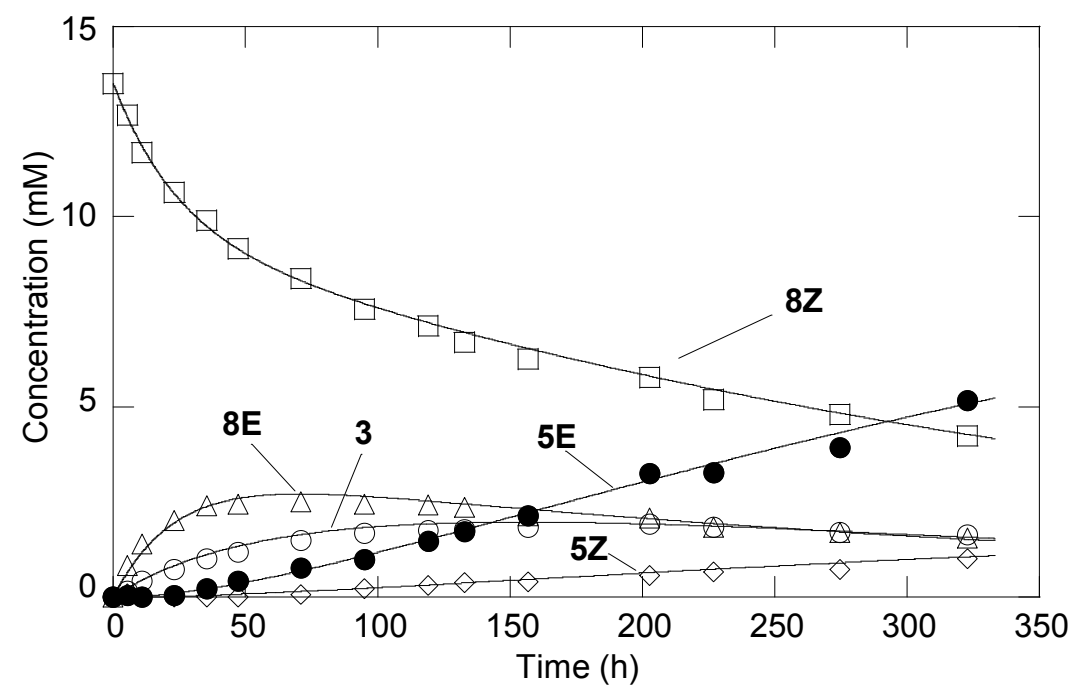

Figure 7. Concentration profiles for thermolysis of $8 \mathrm{Z}$ at $80{ }^{\circ} \mathrm{C}$ in toluene

The rate constants indicated that deuteration improved the thermal stability of $\mathbf{8 Z}$ by

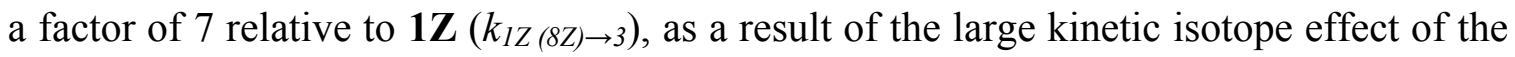
1,5-hydrogen shift, the rate determining step for the thermal decomposition. The $Z$-form of fulgide 8 degraded at about $4 \% /$ day at $80{ }^{\circ} \mathrm{C}$ in toluene.

Table 2. Rate constants by fitting the NMR data using Euler's method ( ${ }^{\mathrm{a}}$ ref 50)

\begin{tabular}{cccc}
\hline Rate constants $\left(\mathrm{min}^{-1}\right)$ & Fulgide $\mathbf{1}^{\mathrm{a}}$ & Fulgide 8 & Ratio of rate constants \\
\hline$k_{I Z(8 Z) \rightarrow 3}$ & $3.9 \times 10^{-4}$ & $5.8 \times 10^{-5}$ & 6.7 \\
$k_{I Z(8 Z) \rightarrow I E(8 E)}$ & $1.5 \times 10^{-4}$ & $1.7 \times 10^{-4}$ & 0.9 \\
$k_{I E(8 E) \rightarrow I Z(8 Z)}$ & $6 \times 10^{-4}$ & $5.2 \times 10^{-4}$ & 1.2 \\
$k_{3 \rightarrow 5 E}$ & $8.7 \times 10^{-4}$ & $1.9 \times 10^{-4}$ & 4.6 \\
$k_{3 \rightarrow 5 Z}$ & $1.7 \times 10^{-4}$ & $3.9 \times 10^{-5}$ & 4.3 \\
\hline
\end{tabular}



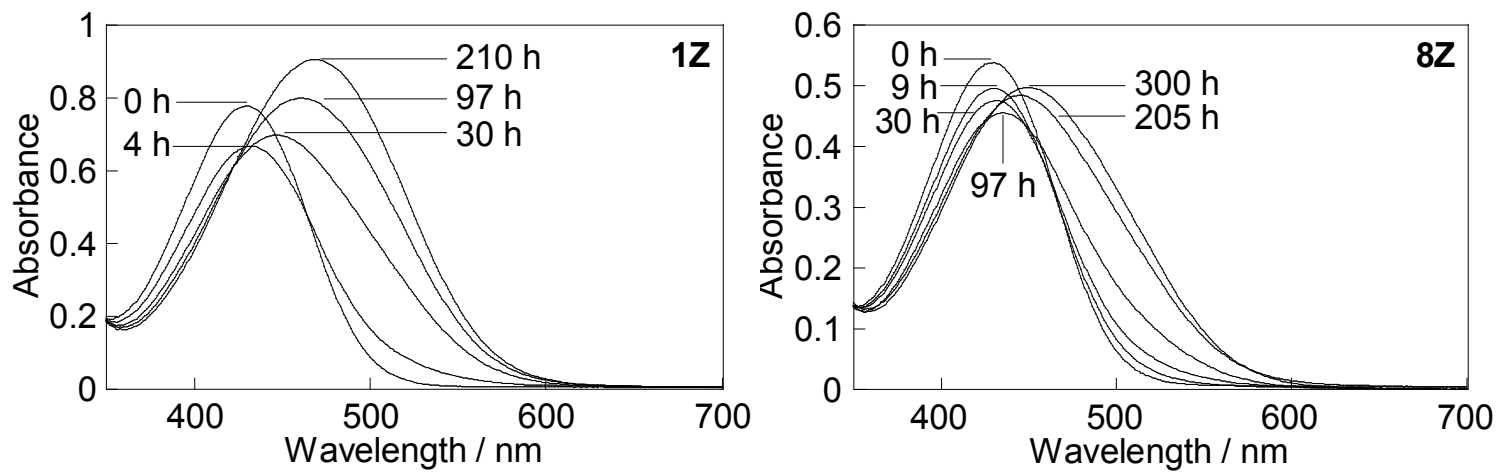

Figure 8. UV-vis absorption spectra of $\mathbf{1 Z}$ and $\mathbf{8 Z}$ in PMMA at $80{ }^{\circ} \mathrm{C}$

In PMMA, the increased thermal stability of the $Z$-form of $\mathbf{8}$ was also observed. Figure 8 showed UV-vis absorption spectra of fulgides $\mathbf{1 Z}$ and $\mathbf{8 Z}$ in PMMA with continuing treatment at $80{ }^{\circ} \mathrm{C}$. The absorbance spectrum of the $Z$-form of 1 reached a low point after only 4 h, but the $Z$-form of the deuterated analog 8 took $97 \mathrm{~h}$ before reaching a similar low point. The $C$-forms of $\mathbf{1}$ and $\mathbf{8}$ reverted back to the corresponding $Z$-forms at a rate of $0.3 \%$ /day over 23 days and $0.7 \%$ /day over 11 days, respectively at $80{ }^{\circ} \mathrm{C}$. Therefore, the $Z$-forms of $\mathbf{1}$ and $\mathbf{8}$ limited the thermal stability, and the overall thermal stability of $\mathbf{8}$ was enhanced by increasing the thermal stability of $\mathbf{8 Z}$.

\subsubsection{Photochemical stability}

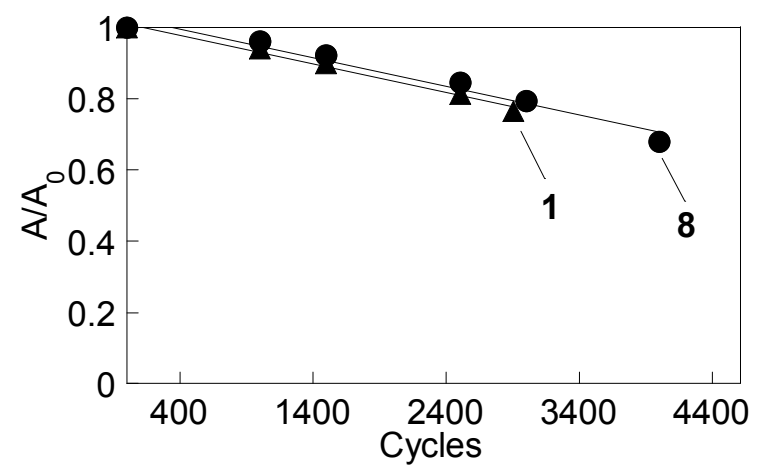

Figure 9. Photochemical decomposition of $\mathbf{1}$ and $\mathbf{8}$ in toluene: decreasing absorbance with repeated coloration and bleaching cycles: (1) triangles; $(\mathbf{8})$ circles 
Photochemical stability was measured in toluene. Fulgide $\mathbf{1}$ and $\mathbf{8}$ demonstrated similar behavior. They degrade at a rate of $0.008 \%$ per photochemical cycle indicating that deuteration of the isopropylidene group does not affect photochemical stability significantly (Figure 9, Table 3).

Table 3. Photochemical fatigue resistance of fulgides 1 and 8

\begin{tabular}{cccc}
\hline \multirow{2}{*}{ Fulgide } & \multicolumn{3}{c}{ Photochemical decomposition } \\
\cline { 2 - 4 } & Number of cycles & $\mathrm{A} / \mathrm{A}_{0}$ & \%/cycle \\
\hline $\mathbf{1}$ & 4000 & 0.679 & 0.008 \\
$\mathbf{8}$ & 3000 & 0.766 & 0.008 \\
\hline
\end{tabular}

\subsection{Conclusion}

In summary, I have synthesized a novel photochromic fluorinated indolylfulgide $\mathbf{8}$ with enhanced thermal stability. The new fulgide differs from the standard fluorinated indolylfulgide $\mathbf{1}$ in that the isopropylidene group was deuterated. The synthesis was successfully carried out in a similar manner as fulgide $\mathbf{1}$, but deuterated reagents and solvents were used. The thermal stability of the $Z$-form of deuterated indolylfulgide $\mathbf{8}$ in toluene was increased by a factor of 7 , as predicted on the basis of kinetic isotope effects. Deuteration should be considered as a general strategy to enhance the thermal stability of all fulgides that degrade via a similar mechanism. 


\section{CHAPTER 4}

\section{SYNTHESIS AND OPTICAL PROPERTIES OF A NOVEL TRIFLUOROMETHYL $N$-ETHOXYCARBONYLMETHYL INDOLYLFULGIMIDE}

\subsection{Abstract}

A novel trifluoromethyl $N$-ethoxycarbonylmethyl indolylfulgimide 9 was synthesized using trifluoromethyl indolylfulgide $\mathbf{1}$ as a precursor. Indolylfulgide $\mathbf{1}$ was synthesized in a large scale in five steps with an overall yield of $18 \%$. Fulgide 1 was then converted to fulgimide 9 by aminolysis follow by dehydration. The thermal and photochromic properties of trifluoromethyl $N$-ethoxycarbonylmethyl indolylfulgimide 9 were examined in a protic and aprotic environment. Both forms of fulgimide 9 showed high hydrolytic stability in $70 / 30$ ethanol/water at $50{ }^{\circ} \mathrm{C}$, degrading $1.3 \%$ per day for $Z$-form and $1.2 \%$ per day for $C$-form. In toluene at $80^{\circ} \mathrm{C}$, the $C$-form was very stable, degrading $0.5 \%$ per day, while the $Z$-form was less stable, degrading $20 \%$ per day. In addition, fulgimide 9 exhibited enhanced photochemical stability.

\subsection{Introduction}

Photochromic compounds, such as fulgides and fulgimides, have been recognized as possible candidates for optical switches and optical memory media. ${ }^{15}$ Fulgides and fulgimides can undergo a photochromic reaction, a reversible transformation between two key forms with different absorption spectra induced by light in at least one direction (Scheme 19). ${ }^{2,7}$ The mechanism involves an electrocyclic ring closing and an electrocyclic ring opening, respectively. 
Fluorinated indolylfulgides, first synthesized by Yokoyama et al, exhibit many advantageous properties, including well separated absorption spectra for each form, large molar absorption coefficients, thermal and photochemical stability, and large quantum yields. ${ }^{49}$ Therefore, studies were conducted to optimize the molecular structure of fluorinated indolylfulgides to achieve improved photochromic properties. ${ }^{50-52,62,64,65,83,85,87}$ The most photochemically stable fulgide, a dicyclopropyl fluorinated indolylfulgide, was recently synthesized and characterized. The compound underwent 10,000 photochemical cycles before degrading by $13 \% .{ }^{52}$

Scheme 19. Photochemical reactions of trifluoromethyl indolylfulgides and indolylfulgimides

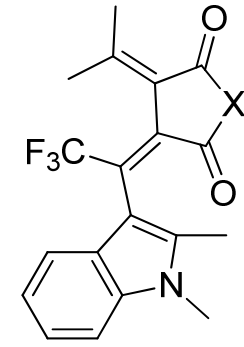

$\mathrm{E}$

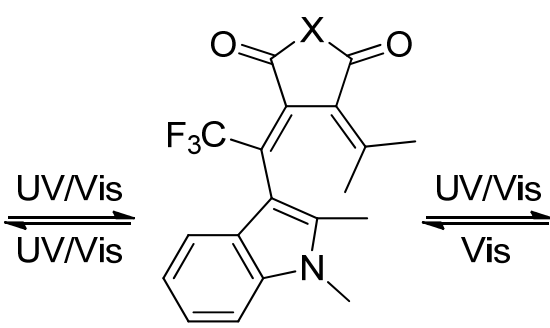

Open forms

$$
\text { Fulgides } \quad X=0
$$<smiles>[X]C1=C2C(=O)C(C(F)(F)F)=C3C(=C(C(F)(F)F)C2(C)N(C)c2ccccc23)C1(C)C</smiles>

Closed form

C

For applications in optical memory devices, stability in protic environments is an important characteristic. Photochromic compounds used in optical devices are expected to maintain viability in humid environments. Previous research has demonstrated that fulgides are very reactive towards protic solvents such as, ethanol, methanol and water because of the succinic anhydride ring in their structure. ${ }^{71}$ Therefore, fulgides were converted to fulgimides which replace the succinic anhydride ring with a more stable succinimide ring (Scheme 19) ${ }^{56,90,91}$ Earlier studies showed that the solvolytic stability of 
both the open and closed forms of fulgimides were improved by 200 to 1000 fold in $70 / 30$ ethanol/water relative to fulgides at $25^{\circ} \mathrm{C} .{ }^{41}$ The exothermicity of methanolysis of a typical fulgide was calculated to be less for the open form than for the closed form and fulgimides have a similar behavior. ${ }^{71}$

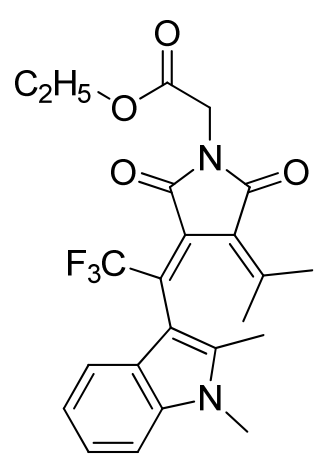

9

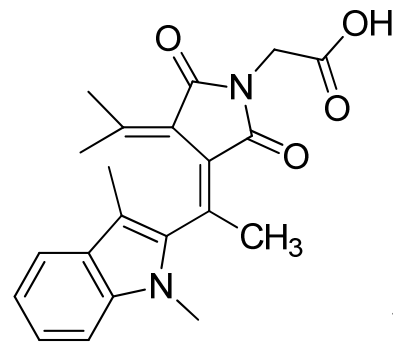

13

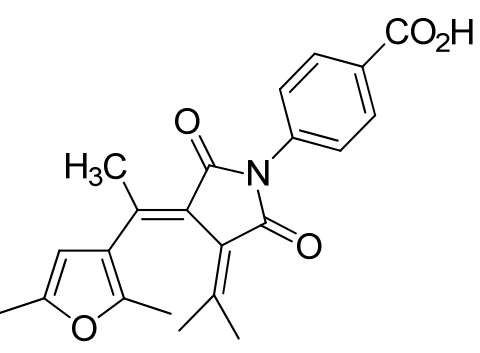

6

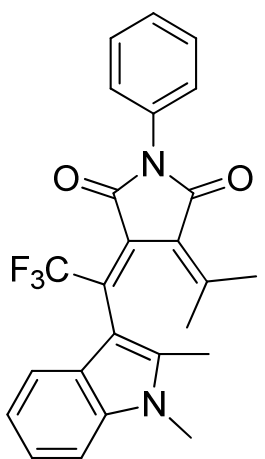

7

Although the properties of several fulgimides have been examined in protic solvents, a comprehensive study of their properties in protic solvents has not been conducted. ${ }^{6,41,70,71,92}$ For example, in aqueous solution, concanavalin A was modified with a fulgimide derivative which was randomly attached to lysine residues on the protein. ${ }^{70}$ The open form of the fulgimide was relatively stable in aqueous solution for 2 days at $25{ }^{\circ} \mathrm{C}$, and the fulgimide cycled back and forth between the open and closed forms at least twice. ${ }^{6}$ A more recent report in live cell indicated that fulgimide $\mathbf{1 3}$, substituted at the 2-position of the heteroaromatic ring, can cycle back and forth between the open and closed forms seven times in cellular membranes but not very well in aqueous solution.

A more detailed characterization of the properties of $N$-phenyl furanylfulgimide 6 substituted at the 3-position of the heteroaromatic ring in 50/50 ethanol/water was reported by Matsushima el al. ${ }^{71}$ Fulgimide 6 showed enhanced thermal stability, the 
closed form lost about $12 \%$ of its absorbance at $\lambda_{\max }$ after 10 days in $50 / 50$ ethanol/water at room temperature and $17 \%$ in pure toluene at $50{ }^{\circ} \mathrm{C}$. However, fulgimide 6 only underwent 10 photochemical cycles before degrading $15 \%$ and $19 \%$ in $50 / 50$ ethanol/water and toluene, respectively. ${ }^{71}$ Previously, eight $N$-phenyl fluorinated indolylfulgimides have different substituent on the $\mathrm{N}$-phenyl ring were synthesized and characterized. ${ }^{41}$ These fulgimides lost between 0 and $45 \%$ of their absorbance at $\lambda_{\max }$ after 14 days in 70/30 ethanol/water at room temperature, and the closed form was the least stable form of the two forms in all cases. ${ }^{41}$ The $N$-phenyl fluorinated indolylfulgimide 7 was the most thermally stable, the closed form lost $5 \%$ of its absorbance at $\lambda_{\max }$ after 14 days. Furthermore, electron withdrawing ability of the substituents on the phenyl ring was positively correlated with the loss in absorbance at $\lambda_{\max }$ for the closed form. Therefore, greater stability was expected by replacing the $\mathrm{N}$ phenyl group with a more electron donating group such as an $N$-alkyl group.

Herein, a new trifluoromethyl $N$-ethoxycarbonylmethyl indolylfulgimide 9 was synthesized. The precursor, trifluoromethyl indolylfulgide $\mathbf{1}$, was prepared on a 10 gram scale with an optimized synthetic pathway. Fulgimide 9 was expected to have higher aqueous solubility than $N$-phenyl fulgimide 7 because of the hydrophilic ethoxycarbonylmethyl group. Furthermore, the ethoxycarbonylmethyl group should improve the thermal stability towards hydrolysis of the succinimide ring. The photochromic properties of $\mathbf{9}$, including UV-vis absorbance spectra, extinction coefficient, and fatigue resistance were measured in both $70 / 30$ ethanol/water and toluene. The thermal stability of 9 in 70/30 ethanol/water, toluene, and poly (methyl methacrylate) (PMMA) was also examined. 


\subsection{Experimental Section}

\subsubsection{General procedures and materials}

All commercially available materials were used without further purification. The NMR spectra were recorded on a Brüker $400 \mathrm{MHz}$ NMR spectrometer. The ${ }^{1} \mathrm{H}$ and ${ }^{13} \mathrm{C}$ NMR samples were internally referenced to TMS $(0.00 \mathrm{ppm})$ or solvent $(7.26$ and 77.00 ppm, respectively for $\left.\mathrm{CDCl}_{3}\right)$. The UV-vis spectra were recorded with a Cary 300 Spectrophotometer. Flash chromatography was performed with 230-400 mesh silica gel. Galbraith performed all elemental analysis. Fulgimide 7 was synthesized as described previously. $^{41}$

\subsubsection{Synthesis of dimethyl isopropylidene succinate 15}

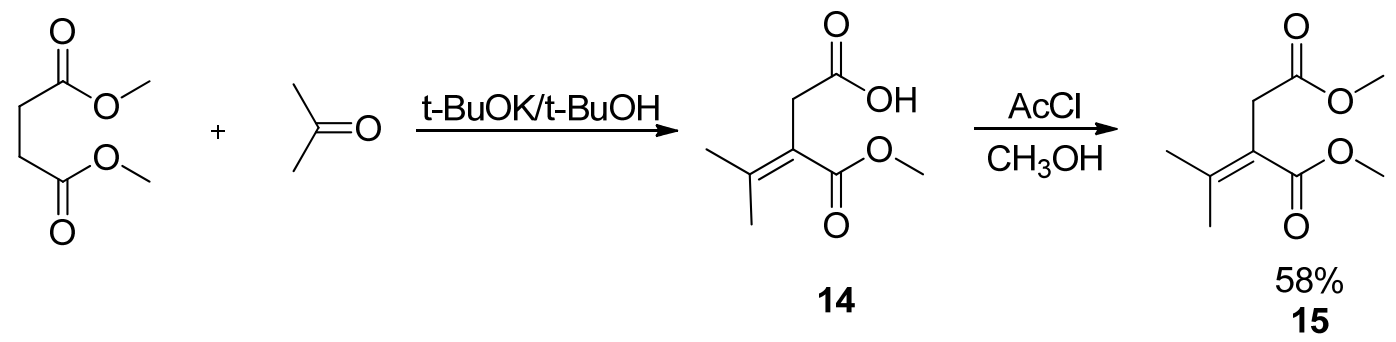

Dimethyl succinate $(233 \mathrm{~mL}, 1.77 \mathrm{~mol})$ and acetone $(131 \mathrm{~mL}, 1.77 \mathrm{~mol})$ were dissolved in $200 \mathrm{~mL}$ of tert-butyl alcohol and slowly added to a solution of potassium tert-butoxide (201 g, $1.79 \mathrm{~mol})$ in $2 \mathrm{~L}$ of tert-butyl alcohol. The solution was refluxed under argon gas for $2.5 \mathrm{~h}$. The solution was then cooled down in an ice bath and concentrated in vacuo. The residue was quenched with $1.6 \mathrm{~L}$ of aqueous $\mathrm{NaOH}(2 \mathrm{M})$ and extracted with diethyl ether $(3 \times 1.5 \mathrm{~L})$. The aqueous layer was acidified with $800 \mathrm{~mL}$ of aqueous $\mathrm{HCl}(6 \mathrm{M})$ and extracted with $\mathrm{CH}_{2} \mathrm{Cl}_{2}(4 \times 1 \mathrm{~L})$. The combined organic layers were dried over $\mathrm{MgSO}_{4}$, filtered, and concentrated in vacuo. The resulting orange liquid was dissolved in $2.6 \mathrm{~L}$ of methanol, and acetyl chloride $(183 \mathrm{~mL}, 2.57 \mathrm{~mol})$ was added 
dropwise under argon gas. After stirring for $24 \mathrm{~h}$, the solution was concentrated in vacuo. The residue was quenched with $1 \mathrm{~L}$ of saturated aqueous $\mathrm{NaHCO}_{3}$ and extracted with diethyl ether $(3 \times 1 \mathrm{~L})$. The combined organic layers were dried over $\mathrm{MgSO}_{4}$, filtered, and concentrated in vacuo. The resulting orange liquid was distilled in vacuo to provide $191.2 \mathrm{~g}(58 \%)$ dimethyl isopropylidene succinate $\mathbf{1 5}$ as a clear colorless oil.

\subsubsection{Synthesis of 1,2-dimethyl-3-trifluoroacetylindole 16}

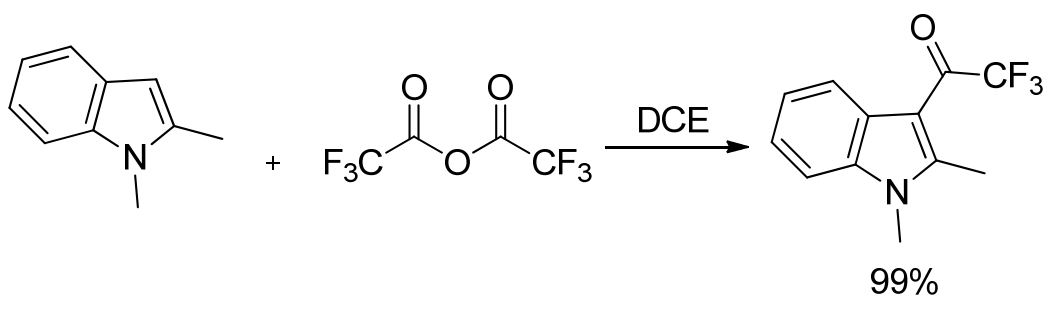

16

To a stirred solution of trifluoroacetic anhydride $(108 \mathrm{~g}, 0.95 \mathrm{~mol})$ in $550 \mathrm{~mL}$ of $1,2-$ dichloroethane at $0{ }^{\circ} \mathrm{C}$, a solution of 1,2-dimethylindole ( $49 \mathrm{~g}, 0.34 \mathrm{~mol}$ ) dissolved in 370 $\mathrm{mL}$ of 1,2-dichloroethane was added dropwise. After $2 \mathrm{~h}$ at room temperature, the reaction mixture was concentrated in vacuo. The purple residue was quenched with 500 $\mathrm{mL}$ of saturated aqueous $\mathrm{NaHCO}_{3}$ and extracted with $\mathrm{CH}_{2} \mathrm{Cl}_{2}(3 \times 600 \mathrm{~mL})$. The combined organic layers were dried over $\mathrm{MgSO}_{4}$, filtered, concentrated in vacuo, and to provide $81.3 \mathrm{~g}$ of 1,2-dimethyl-3-trifluoroacetylindole $\mathbf{1 6}(99 \%)$.

\subsubsection{Synthesis of trifluoromethyl isopropylidene indolelactone 17}<smiles>COC(=O)CC(C(=O)OC)=C(C)C</smiles>

15

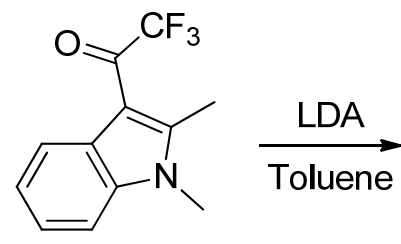

16

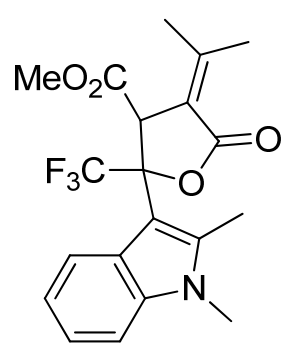

cis/trans mixture $41 \% \quad 17$ 
Lithium diisopropylamide ( $300 \mathrm{~mL}$ of a $2 \mathrm{M}$ solution, $0.6 \mathrm{~mol}$ ) was added to a stirred solution of dimethyl isopropylidene succinate $\mathbf{1 5}(152.1 \mathrm{~g}, 0.82 \mathrm{~mol})$ and 1,2-dimethyl-3trifluoroacetylindole $\mathbf{1 6}(81.3 \mathrm{~g}, 0.34 \mathrm{~mol})$ in $2 \mathrm{~L}$ of toluene under argon gas. After $2 \mathrm{~h}$, the reaction was quenched with $800 \mathrm{~mL}$ of $5 \% \mathrm{H}_{2} \mathrm{SO}_{4}$ solution and extracted with EtOAc $(4 \times 1 \mathrm{~L})$. The combined organic layers were dried over $\mathrm{MgSO}_{4}$, filtered and concentrated in vacuo. The residue was purified by silica gel chromatography (4:1 hexanes/EtOAc followed by $3: 1$ hexanes/EtOAc) and recrystallized from ethanol to provide $54.1 \mathrm{~g}(41 \%)$ of cis/trans isopropylidene indolelactone 17. The cis/trans mixture was used for the next step without further separation.

\subsubsection{Synthesis of diacid 18}

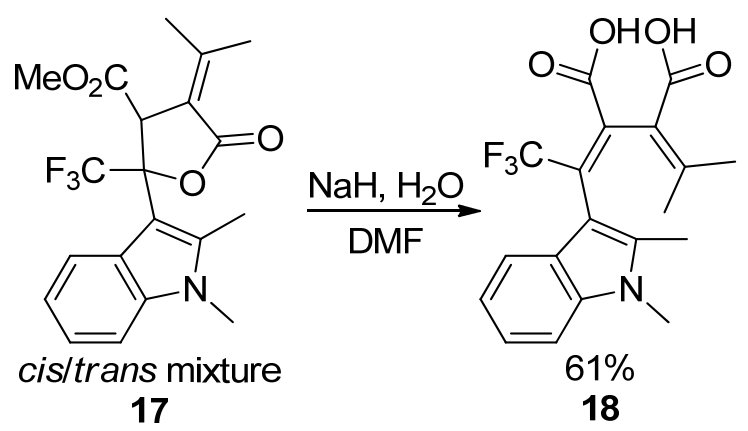

$\mathrm{NaH}(60 \%$ dispersion in oil, $12.0 \mathrm{~g}, 0.30 \mathrm{~mol})$ was added cis/trans indolelactone 17 (27.6 g, $0.07 \mathrm{~mol}$ ) in $800 \mathrm{~mL}$ of DMF at $0{ }^{\circ} \mathrm{C}$. Once the evolution of gas had ceased, 28.0 $\mathrm{mL}$ of water was added. The mixture was warmed to room temperature and stirred overnight. The mixture was concentrated in vacuo and the residue was then dissolved in $700 \mathrm{~mL}$ of water and extracted with $700 \mathrm{~mL}$ of EtOAc. The aqueous layer was acidified with $5 \% \mathrm{H}_{2} \mathrm{SO}_{4}$ to $\mathrm{pH} 1$ and extracted with EtOAc $(4 \times 700 \mathrm{~mL})$. The combined organic layers were dried over $\mathrm{MgSO}_{4}$, filtered, and concentrated in vacuo. The light orange solid was triturated with $\mathrm{CHCl}_{3}$ to provide $18.0 \mathrm{~g} \mathrm{(61 \% )} \mathrm{of} \mathrm{the} \mathrm{diacid} \mathbf{1 8}$ as a white solid. 


\subsubsection{Synthesis of trifluoromethyl indolylfulgide 1}

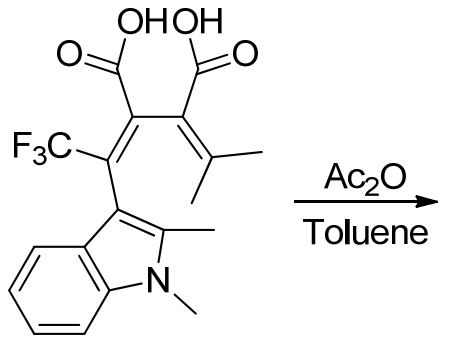

18

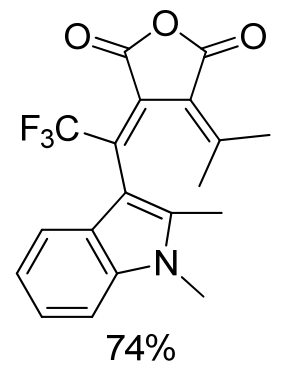

1

The resulting diacid 18 (18.0 g, $0.47 \mathrm{~mol})$ was suspended in $200 \mathrm{~mL}$ of toluene. Acetic anhydride $(187 \mathrm{~mL}, 1.98 \mathrm{~mol})$ was added, and the reaction mixture was stirred for $2 \mathrm{~d}$ under argon gas. The solution was then concentrated in vacuo. The residue was quenched with $800 \mathrm{~mL}$ of water and extracted with $\mathrm{CH}_{2} \mathrm{Cl}_{2}(3 \times 500 \mathrm{~mL})$. The combined organic layers were dried over $\mathrm{MgSO}_{4}$, filtered, and concentrated in vacuo. Recrystallization from $\mathrm{CH}_{2} \mathrm{Cl}_{2}$ /isopropanol provided $12.7 \mathrm{~g}$ (74\%) of trifluoromethyl indolylfulgide 1.

\subsubsection{Synthesis of trifluoromethyl $N$-ethoxycarbonylmethyl indolylfulgimide 9}<smiles>CCCOC(=O)C(C(=O)NCC(=O)OCC)=C(C(=O)O)C(=C(C)C)c1c(C)n(C)c2ccccc12</smiles>

1

$N, N$-Diisopropylethylamine $(1.30 \mathrm{~g}, 10.1 \mathrm{mmol})$ was added slowly with stirring to a mixture of the $\mathrm{HCl}$ salt of glycine ethyl ester $(0.37 \mathrm{~g}, 2.6 \mathrm{mmol})$, trifluoromethyl indolylfulgide $1(0.46 \mathrm{~g}, 1.3 \mathrm{mmol})$, and $30 \mathrm{~mL}$ of acetonitrile at $0{ }^{\circ} \mathrm{C}$. After stirring 
overnight the solvent was removed in vacuo. The residue was added to $30 \mathrm{~mL}$ of $\mathrm{HCl}$ $(0.5 \mathrm{M})$ and extracted with EtOAc $(3 \times 25 \mathrm{~mL})$. The combined organic layers were dried over $\mathrm{MgSO}_{4}$, filtered, and concentrated in vacuo. Purification of the residue by silica gel chromatography (60:40:2 hexanes/EtOAc/AcOH) provided $0.46 \mathrm{~g}$ of the crude amide acid ester. The amide acid ester was added to $8 \mathrm{~mL}$ of acetyl chloride $(8.8 \mathrm{~g}, 112 \mathrm{mmol})$, and the reaction mixture was refluxed under argon gas for $24 \mathrm{~h}$. Then the solvent was removed in vacuo. The residue was added to $30 \mathrm{~mL}$ of $\mathrm{H}_{2} \mathrm{O}$ and extracted with EtOAc (3 $\times 25 \mathrm{~mL}$ ). The combined organic layers were dried over $\mathrm{MgSO}_{4}$, filtered, and concentrated in vacuo. Purification was performed via silica gel chromatography (10:1 toluene/EtOAc) followed by recrystallization from methanol to provide $22 \mathrm{mg}(4 \%)$ of the indolylfulgimide 9. Z-form: ${ }^{1} \mathrm{H}$ NMR $\left(\mathrm{CDCl}_{3}\right), 7.32-7.26(\mathrm{~m}, 2 \mathrm{H}), 7.21$ (td, $J=7.0$, $1.2 \mathrm{~Hz}, 1 \mathrm{H}), 7.13(\mathrm{td}, J=7.5,1.3 \mathrm{~Hz}, 1 \mathrm{H}), 4.42$ (s, 2H), 4.24 (q, $J=7.1 \mathrm{~Hz}, 2 \mathrm{H}), 3.69$ (s, $3 \mathrm{H}), 2.23(\mathrm{~s}, 3 \mathrm{H}), 2.13(\mathrm{~s}, 3 \mathrm{H}), 1.60(\mathrm{~s}, 1 \mathrm{H}), 1.29(\mathrm{t}, J=7.1 \mathrm{~Hz}, 1 \mathrm{H}), 0.96(\mathrm{~s}, 3 \mathrm{H}) .{ }^{13} \mathrm{C}$ $\operatorname{NMR}\left(\mathrm{CDCl}_{3}\right), 166.3,165.9,163.6,153.9,136.5,136.1,131.8(\mathrm{q}, J=35 \mathrm{~Hz}), 128.7$, 124.8, 121.8, $121.7(\mathrm{q}, J=277 \mathrm{~Hz}), 121.3,120.3,119.0,108.5,106.9,61.2,38.4,29.3$, 26.0, 21.7, 13.4, 11.2. Anal. Calcd for $\mathrm{C}_{23} \mathrm{H}_{23} \mathrm{~F}_{3} \mathrm{~N}_{2} \mathrm{O}_{4}$ : C, 61.60, H, 5.17; N, 6.25. Found: C, 61.33; H, 5.34; N, 6.19. $C$-form: ${ }^{1} \mathrm{H}$ NMR $\left(\mathrm{CDCl}_{3}\right), 7.73(\mathrm{~d}, J=8.1 \mathrm{~Hz}, 1 \mathrm{H}), 7.35$ (td, $J=7.8,1.1 \mathrm{~Hz}, 1 \mathrm{H}), 6.78(\mathrm{td}, J=7.7,0.7 \mathrm{~Hz}, 1 \mathrm{H}), 6.63(\mathrm{~d}, J=8.3 \mathrm{~Hz}, 1 \mathrm{H}), 4.27-4.17(\mathrm{~m}$, 2H), $4.26(\mathrm{~s}, 2 \mathrm{H}), 2.92(\mathrm{~s}, 3 \mathrm{H}), 1.79(\mathrm{~s}, 3 \mathrm{H}), 1.35(\mathrm{~s}, 3 \mathrm{H}), 1.28(\mathrm{~s}, 3 \mathrm{H}), 1.25(\mathrm{t}, 3 \mathrm{H})$.

\subsubsection{Preparation of thin films}

An initial solution was prepared by adding 2-4 mg of indolylfulgimide 9 to a solution of $10 \%$ poly(methyl methacrylate) (PMMA-low molecular weight, average $M_{\mathrm{w}} c a$. $120,000)$ in $5 \mathrm{~mL}$ of $\mathrm{CH}_{2} \mathrm{Cl}_{2}$. The polymer solution $(1.5 \mathrm{~mL})$ was then deposited via pipet 
onto a circular 1 in $\times 1 / 16$ in BK-7 glass slides (escoproducts) and allowed to spread over the surface of the slide. The sample was allowed to dry overnight inside a glass Petri dish at room temperature. The resulting films were utilized in the thermal stability studies.

\subsubsection{Spectral Determination}

Concentrated, air-saturated stock solutions of the $Z$-form of indolylfulgimide 9 in toluene were prepared. From each stock solution, 5 samples ranging in concentration from 0.20 to $0.05 \mathrm{mM}$ were then prepared by dilution with toluene. Absorption coefficients and $\lambda_{\max }$ were determined.

The $C$-form was obtained by irradiating $Z$-form solutions with $405 \mathrm{~nm}$ light followed by purification via flash column chromatography (silica gel, toluene). Stock solutions containing freshly purified $C$-form in toluene were diluted to 4 or 5 different concentrations, and their UV-vis spectra obtained. Each $C$-form solution was then quantitatively converted to $Z$-form with yellow light $(>510 \mathrm{~nm}$ ) and the concentration of fulgimide present was ascertained using the predetermined $Z$-form extinction coefficients. Absorption coefficients and $\lambda_{\max }$ for the $C$-forms were then determined from the initial spectra.

A similar methodology was used to determine these values in 70/30 ethanol/water. The $C$-form fulgimide used in 70/30 ethanol/water, however, was still prepared in toluene and purified chromatographically on silica gel using toluene. The scan rate was 600 $\mathrm{nm} / \mathrm{min}$, the integration time was $0.1 \mathrm{~s}$, and slit bandwidth was $2 \mathrm{~nm}$. Each extinction coefficient was determined three times and the error from the Z-form was propagated to the error for the $C$-form. 


\subsubsection{Photostationary state (PSS) measurements}

PSS was measured using ${ }^{1} \mathrm{H}$ NMR spectroscopy. An NMR tube containing the $Z$ form of indolylfulgimide 9 in $70 / 30$ ethanol- $\mathrm{d}_{6} / \mathrm{D}_{2} \mathrm{O}$ or in toluene- $\mathrm{d}_{8}$ was illuminated with light that had passed through a hot mirror (blocking UV and IR light) and a $405 \mathrm{~nm}$ bandpass filter until PSS was reached. An ${ }^{1} \mathrm{H}$ NMR spectrum was then acquired and integrated, and the ratio of $E: Z: C$ was determined.

\subsubsection{Photochemical stability}

Air-saturated solutions of the Z-form of indolylfulgimide 9 were prepared in toluene with an initial absorbance of approximately 0.6 at the absorption maxima. Samples were irradiated to the PSS with light supplied from an Oriel $1000 \mathrm{~W} \mathrm{Hg}(\mathrm{Xe})$ lamp utilizing a water filter followed by a hot mirror followed by a $405 \mathrm{~nm}$ narrow bandpass filter. After

measuring the UV-vis spectrum of the photostationary state, $\mathrm{PSS}_{405 \mathrm{~nm}}$, a pure $Z$-form solution was irradiated to $90 \%$ of the PSS, and the reaction was timed. The $90 \%$ PSS mixture was then decolorized with $>515 \mathrm{~nm}$ light using a separate filter, and again the reacting times was recorded. Absorbance at the $C$-form $\lambda_{\max }$ was $<0.01$ upon decoloration. Once the duration of irradiation was established for both the $90 \%$ PSS coloration and $<1 \% C$-form decoloration reactions, the system was automated through the use of a filter switch. All solutions were capped and stirred. Control experiments were performed to correct for evaporation. After a designated number of irradiation cycles, the samples were fully converted to $\mathrm{PSS}_{405} \mathrm{~nm}$, and their UV-vis spectra scanned. The photochemical fatigue was then determined by comparison with the initial $\operatorname{PSS}_{405 \mathrm{~nm}}$ absorption spectrum. The procedure was then repeated in 70/30 ethanol/water for 9 and 7 and in PMMA for 9. The cycling times for 9 were approximately $50 \mathrm{~s}(Z-C)$ and $20 \mathrm{~s}(C$ 
- $Z$ ) in toluene, $90 \mathrm{~s}(Z-C)$ and $35 \mathrm{~s}(C-Z)$ in $70 / 30$ ethanol/water, and $35 \mathrm{~s}(Z-C)$ and $20 \mathrm{~s}(C-Z)$ in PMMA. The photochemical stability was measured three times in each solvent: toluene, ethanol/water, and PMMA.

\subsubsection{Thermal Stability}

\subsubsection{Polymer-Based Study}

Thin films containing the $Z$-form of the indolylfulgimide 9 were wrapped in aluminum foil and placed in an oven maintained at $80{ }^{\circ} \mathrm{C}$. The films were removed at predetermined intervals, and their UV-vis spectra measured. To determine the stability of the $C$-form, the thin films containing the $Z$-form were illuminated with blue light (405 nm bandpass filter) until the PSS had been obtained. The thin films were then wrapped in aluminum foil and placed in an oven maintained at $80{ }^{\circ} \mathrm{C}$. The films were removed at predetermined intervals, and their UV-vis spectra measured. The experiment was repeated three times.

\subsubsection{Solution-Based Study}

The thermal stability of the $Z$ - and $C$-forms of indolylfulgimide 9 in $70 / 30$ ethanol/water and in toluene was measured using UV-vis and ${ }^{1} \mathrm{H}$ NMR spectroscopy. The $Z$-form solutions of fulgimide 9 were prepared in 70/30 ethanol/water and toluene, or their deuterated analogs and then transferred into several ampoules or NMR tubes, respectively. Ampoules and NMR tubes were sealed and submersed in water baths maintained at $50{ }^{\circ} \mathrm{C}$ (ethanol/water) or at $80{ }^{\circ} \mathrm{C}$ (toluene). At predetermined times, ampoules and NMR tubes were removed, and their contents analyzed by UV-vis and ${ }^{1} \mathrm{H}$ NMR spectroscopy, respectively. To determine the stability of the $C$-form in these solvents, fresh $Z$-form solutions were illuminated with blue light ( $405 \mathrm{~nm}$ bandpass filter) 
until the PSS was achieved. The thermal stability was then measured as described for the $Z$-form. A similar experiment was also performed with the $Z$-form of 7 in 70/30 ethanol/water. For ${ }^{1} \mathrm{H}$ NMR spectroscopy, the residual solvent peak was used as an internal standard, and signals corresponding to the individual species were integrated relative to the internal standard. All the photochemical and thermal measurements were performed by Dr. Islamova in Dr. Lees' group.

\subsection{Results and Discussion}

\subsubsection{Synthesis of trifluoromethyl indolylfulgide 1 and indolylfulgimide 9}

Trifluoromethyl $N$-ethoxycarbonylmethyl indolylfulgimide 9 was synthesized from the precursor indolylfulgide 1. Additionally, I synthesized a series of fulgimides using indolylfulgide $\mathbf{1}$ as the precursor. Therefore, developing a reliable and productive pathway for synthesis of fulgide 1 on a large scale $(10 \mathrm{~g})$ was required. A previous study demonstrated an improved synthetic route to trifluoromethyl indolylfulgide 1 on a 1 gram scale. $^{60}$ The synthetic route involves five steps including two Stobbe condensations. Herein, the large scale synthesis of $\mathbf{1}$ was performed on the basis of the five step sequence with several modifications (Scheme 20). The first Stobbe condensation was performed between dimethyl succinate and acetone in potassium tert-butoxide/tertbutanol. The resulting half acid-half ester $\mathbf{1 4}$ was then treated with acidified methanol to yield the dimethyl isopropylidene succinate 15. The 1,2-dimethyl-3-trifluoroacetylindole 16 was prepared by reacting trifluoroacetic anhydride with 1,2-dimethylindole. Subsequently, the second Stobbe condensation combined the dimethyl isopropylidene succinate 15 and 1,2-dimethyl-3-trifluoroacetylindole 16. The resulting cis/trans indolelactones $\mathbf{1 7}$ was treated with sodium hydride in DMF at $0{ }^{\circ} \mathrm{C}$ for $1 \mathrm{~h}$ followed by 
the addition of 2 equivalent of water. However, the reaction gave a very low yield $(10 \%)$ and several impurities.

\section{Scheme 20. Synthesis of trifluoromethyl indolylfulgide 1}<smiles>COC(=O)CCC(=O)OC</smiles><smiles>Cc1c(C(=O)C(F)(F)F)c2ccccc2n1C</smiles>

LDA Toluene

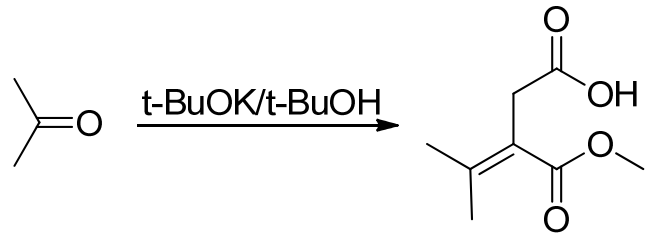

14

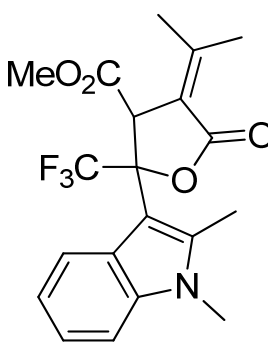

cis/trans mixture

17

18
$\underset{\mathrm{CH}_{3} \mathrm{OH}}{\stackrel{\mathrm{AcCl}}{\longrightarrow}}$<smiles>COC(=O)CC(C(=O)OC)=C(C)C</smiles>

15

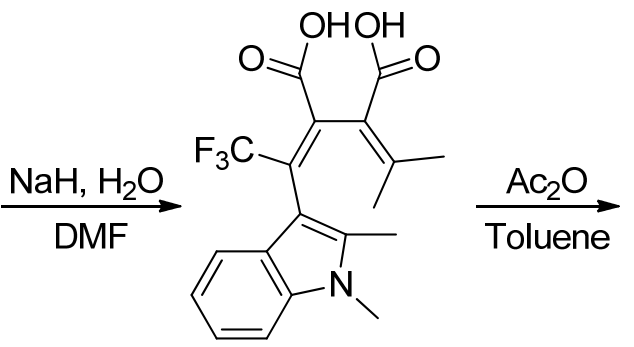<smiles>CC(C)=C1C(=O)OC(=O)C1=C(c1c(C)n(C)c2ccccc12)C(F)(F)F</smiles>

1

Historically, the cis-indolelactone with a methyl group on the bridging position was not reactive. ${ }^{89}$ The method developed by Lees et al. using sodium hydride and DMF enhanced the reactivity for both methyl and fluorinated cis-indolelactones. ${ }^{60}$ The method also increased the yield for cis/trans indolelactones on a small scale. However, on a large scale (20 grams or more), the sodium hydride and DMF reaction gave a surprisingly low yield. Further investigation of the reaction mechanism indicated that the presence of water was very important to the reaction. Previously, on a small scale synthesis, the small amount of water in DMF would prompt the reaction and prevent the generation of impurities. Additionally, during storage, part of the sodium hydride reacted with water in air and became sodium hydroxide. However, when the reaction was run on a large scale, new sodium hydride and DMF were used, which contained much less water. Moreover, 
according to the previous procedure, 2 equivalent of water was added after the reaction mixture was stirred for $1 \mathrm{~h}$, but by this time a significant amount of impurities had already been generated. Hence, I modified the procedure by adding the 2 equivalent of water immediately after all the sodium hydride was suspended in DMF. Using the new procedure, the large scale reaction of cis/trans indolelactones worked well and yielded the diacid 18 in $61 \%$. The trifluoromethyl indolylfulgide $1(12.7 \mathrm{~g}, 74 \%)$ was afforded by treating the diacid with acetic anhydride in toluene.

The synthesis of $\mathrm{N}$-ethoxycarbonylmethyl indolylfulgimide 9 was carried out with the trifluoromethyl indolylfulgide $\mathbf{1}$ as the precursor (Scheme 21). The anhydride ring of 1 was opened via addition of glycine ethyl ester. The resulting ethyl ester succinamic acid, one of the two possible regioisomers, was further treated with acetyl chloride to generate ethyl ester indolylfulgimide 9 in its open form.

\section{Scheme 21. Synthesis of trifluoromethyl $N$-ethoxycarbonylmethyl indolylfulgimide 9}

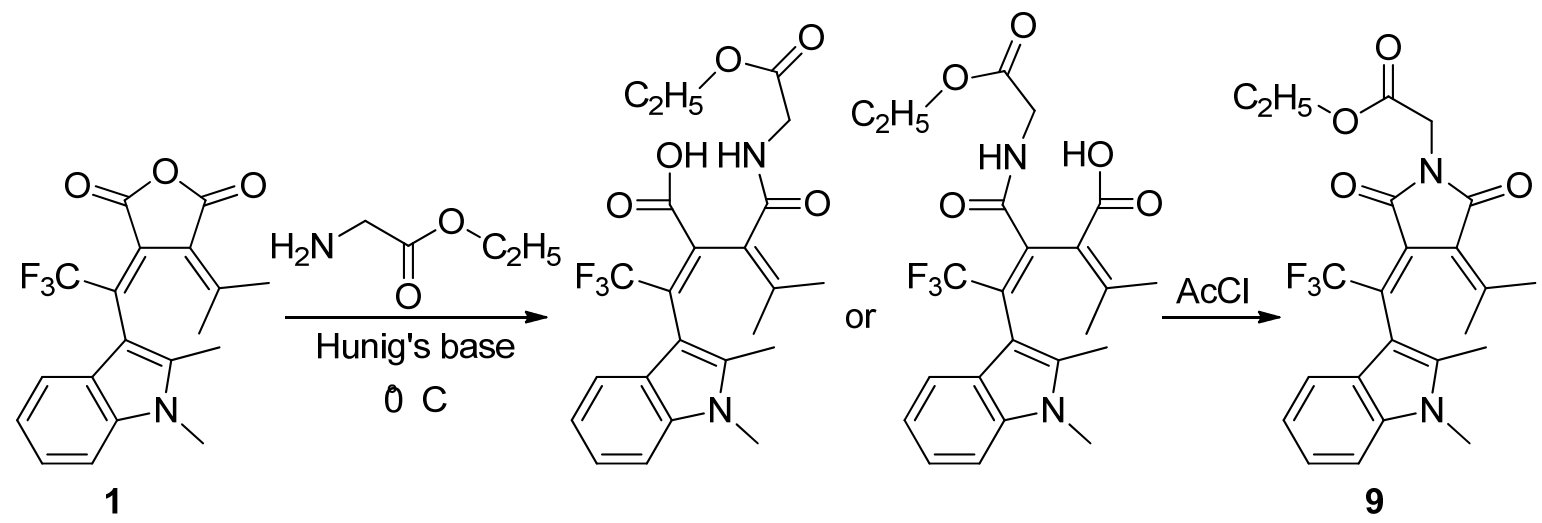

\subsubsection{UV-vis absorption spectra}

The UV-vis absorbance spectra of both $Z$ - and $C$-forms (also called the open and closed forms, respectively) of 9 were measured in 70/30 ethanol/water and in toluene (Figure 10). The 70/30 ratio of ethanol/water was selected to ensure enough solubility of 
both forms and compare with previous results. ${ }^{41}$ Bathochromic shifts were observed for both forms as the solvent polarity increased. The absorbance maxima of the open and closed forms increased by 12 and $17 \mathrm{~nm}$ as the solvent changed from toluene to 70/30 ethanol/water, respectively. Also, the extinction coefficients of both forms were slightly decreased in 70/30 ethanol/water (Table 4).
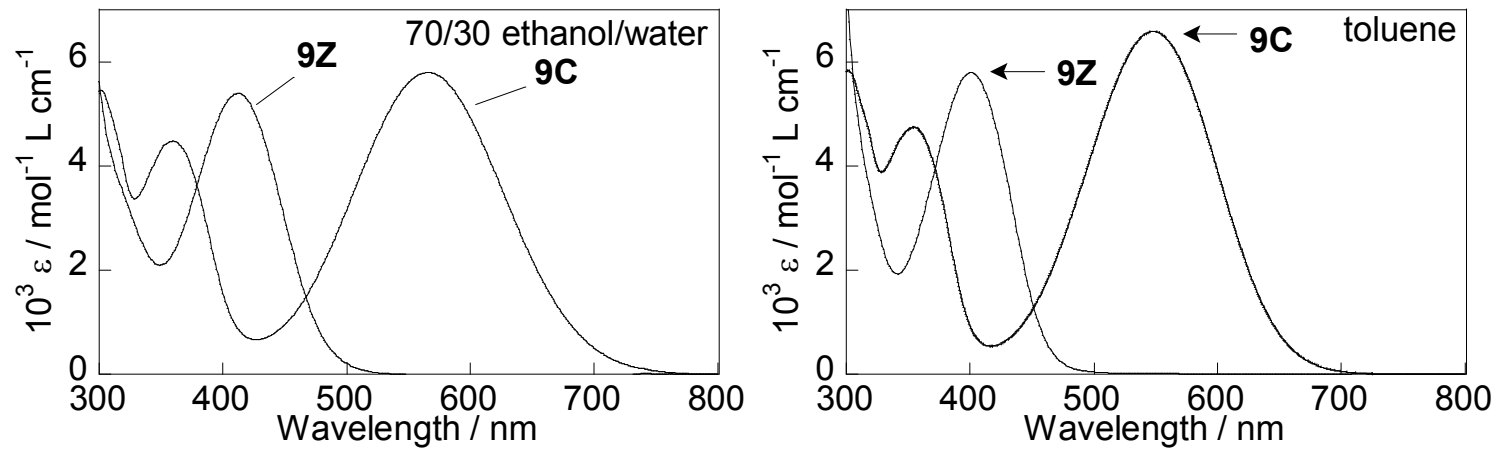

Figure 10. UV-vis absorption spectra of fulgimide 9 in 70/30 ethanol/water and toluene

Table 4. Extinction coefficients at $\lambda_{\max }$ for fulgimide 9 in $70 / 30$ ethanol/water and toluene

\begin{tabular}{|c|c|c|c|}
\hline \multirow{2}{*}{ Medium } & \multicolumn{2}{|c|}{$\lambda_{\max } / \mathrm{nm}\left(\varepsilon_{\max } / \mathrm{mol}^{-1} \mathrm{~L} \mathrm{~cm}^{-1}\right)^{\mathrm{a}}$} & \multirow{2}{*}{$\begin{array}{c}\mathrm{PSS}_{405 \mathrm{~nm}} \\
C: Z: E\end{array}$} \\
\hline & $Z$-form & $C$-form & \\
\hline 70/30 Ethanol/water & $412\left(5.4 \pm 0.2 \times 10^{3}\right)$ & $566\left(5.8 \pm 0.2 \times 10^{3}\right)$ & $76: 19: 5$ \\
\hline Toluene & $400\left(5.8 \pm 0.2 \times 10^{3}\right)$ & $549\left(6.6 \pm 0.2 \times 10^{3}\right)$ & $91: 7: 2$ \\
\hline
\end{tabular}

\subsubsection{Thermal stability}

To be used in optical switches and sensors, thermal stability of fulgimides is very important. In these applications, fulgimides are anticipated to stay in the open or closed forms in a variety of environments without interconversion or decomposition. Therefore, 
the thermal stability of the open and closed forms of 9 was measured in 70/30 ethanol/water, toluene, and thin films of poly (methyl methacrylate) (PMMA). In toluene and PMMA, $80{ }^{\circ} \mathrm{C}$ was used as the standard temperature for the thermal stability measurement. However, because of the lower boiling point of ethanol, thermal stability measurements were performed at $50{ }^{\circ} \mathrm{C}$ in ethanol/water solution. ${ }^{71}$ The thermal stability was followed by both ${ }^{1} \mathrm{H}$ NMR spectroscopy and by UV-vis spectroscopy in ethanol/water and toluene, and followed by UV-vis spectroscopy in PMMA.
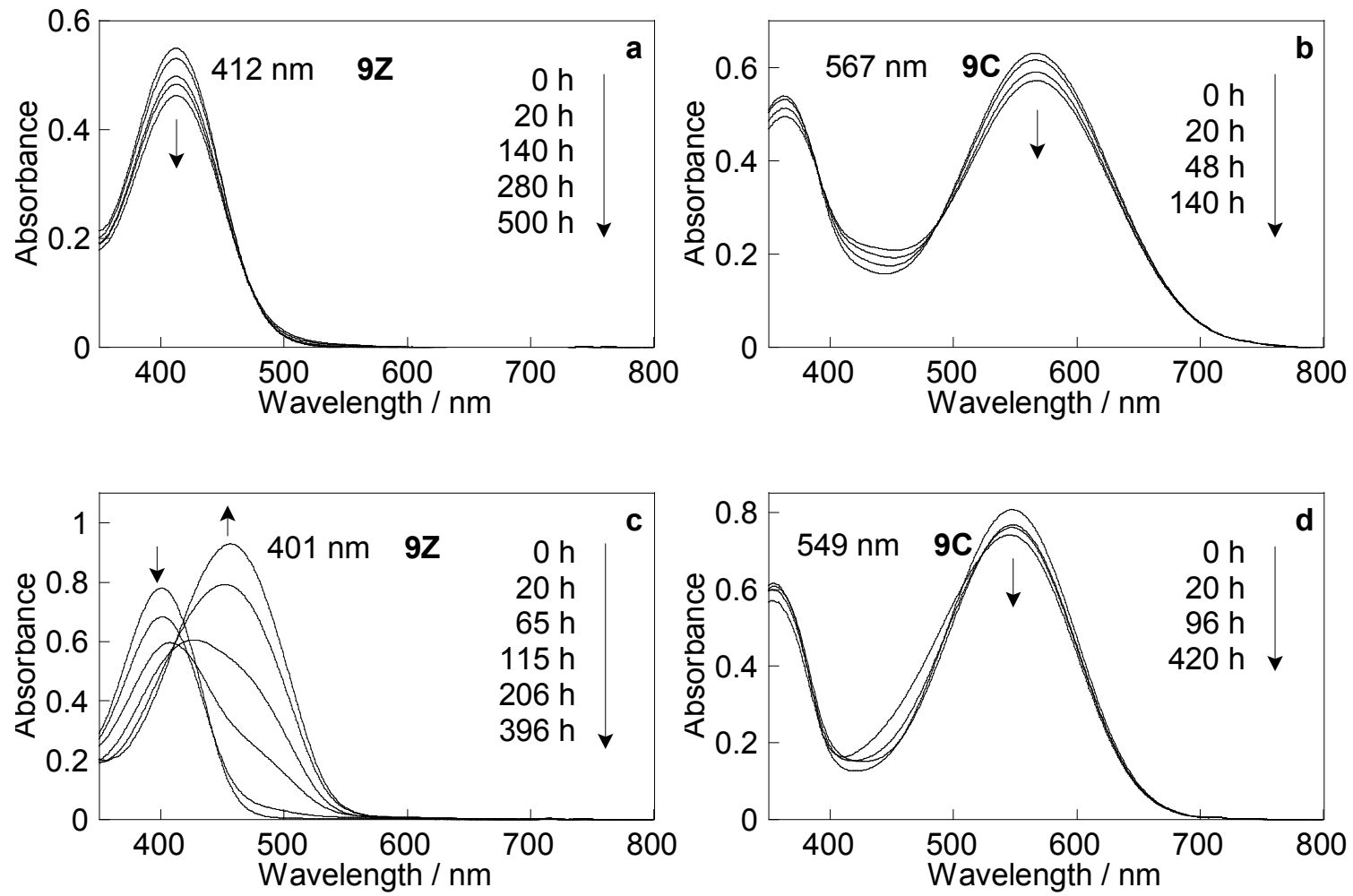

Figure 11. Thermal decomposition of $Z$ - and $C$-forms of fulgimide 9 in 70/30 ethanol/water at $50{ }^{\circ} \mathrm{C}(\mathrm{a}, \mathrm{b})$ and in toluene at $80{ }^{\circ} \mathrm{C}(\mathrm{c}, \mathrm{d})$. Arrows indicate the change in absorbance with time. (b) After $140 \mathrm{~h}$ spectra did not change.

In $70 / 30$ ethanol/water at $50{ }^{\circ} \mathrm{C}, Z$-form and $C$-form degraded $22 \pm 5 \%$ and $10 \pm 1 \%$ respectively after 21 days (Figure $11 \mathrm{a}, 10 \mathrm{~b}$, Table 5). The $Z$-form of fulgimide 9 was 
much more stable compared to the $Z$-form of $N$-phenyl fulgimide 7 which lost $52 \%$ of its absorbance after 21 days at $50{ }^{\circ} \mathrm{C}$. Previous studies indicated that the $C$-forms of fulgimides and fulgides were hydrolytically less stable than the $Z$-forms at room temperature. $^{41}$

Table 5. Thermal decomposition for fulgimide 9 in 70/30 ethanol/water, toluene, and PMMA

\begin{tabular}{|c|c|c|c|c|c|c|c|c|}
\hline \multirow{3}{*}{ Medium } & \multicolumn{4}{|c|}{ UV-vis } & \multicolumn{4}{|c|}{${ }^{1} \mathrm{H}$ NMR } \\
\hline & \multicolumn{2}{|c|}{$Z$-form } & \multicolumn{2}{|c|}{$C$-form } & \multicolumn{2}{|c|}{$Z$-form } & \multicolumn{2}{|c|}{$C$-form } \\
\hline & $\mathrm{A} / \mathrm{A}_{0}$ & $\% /$ day & $\mathrm{A} / \mathrm{A}_{0}$ & $\% /$ day & {$[9] /[9]_{0}$} & $\% /$ day & {$[9] /[9]_{0}$} & $\% /$ day \\
\hline $\begin{array}{l}\text { Ethanol/water } \\
70 / 30\left(50{ }^{\circ} \mathrm{C}\right)^{\mathrm{a}}\end{array}$ & 0.78 & 1.1 & 0.90 & 0.5 & 0.74 & 1.3 & 0.74 & 1.2 \\
\hline Toluene $\left(80^{\circ} \mathrm{C}\right)^{\mathrm{b}}$ & 0.57 & 2.6 & 0.96 & 0.2 & 0.03 & $\mathrm{c}$ & 0.93 & 0.5 \\
\hline PMMA $\left(80^{\circ} \mathrm{C}\right)^{\mathrm{d}}$ & 0.62 & 3.8 & $\mathrm{e}$ & $\mathrm{e}$ & - & - & - & - \\
\hline
\end{tabular}

${ }^{\mathrm{a}}$ Absorbance at $\lambda_{\max }$ relative to initial absorbance after $500 \mathrm{~h}$;

${ }^{\mathrm{b}}$ Absorbance at $\lambda_{\max }$ relative to initial absorbance after $400 \mathrm{~h}$;

${ }^{\mathrm{c}} Z$-form almost completely decomposed after $400 \mathrm{~h}$, it decomposed $20 \%$ during the first day;

${ }^{\mathrm{d}}$ Absorbance at $\lambda_{\max }$ relative to initial absorbance after $240 \mathrm{~h}$;

${ }^{\mathrm{e}}$ No decomposition observed after $240 \mathrm{~h}$.

The stability of both forms of fulgimide 9 was also followed by ${ }^{1} \mathrm{H}$ NMR spectroscopy in sealed NMR tubes at $50{ }^{\circ} \mathrm{C}$ containing $70 / 30$ ethanol- $\mathrm{d}_{6} / \mathrm{D}_{2} \mathrm{O}$ (Figure 12 , Table 5). Both forms degraded $26 \pm 3 \%$ after 21 days. The $C$-form of fulgimide 9 has a higher degradation rate by NMR measurement compared with UV-vis measurement. The presumable explanation is that some of the decomposition products from $9 \mathrm{C}$ also absorb at the absorbance maxima. Therefore, on the basis of NMR measurements, both the open 
and closed forms of fulgimide $\mathbf{9}$ have similar stabilities and are surprisingly stable in 70/30 ethanol/water.

In toluene at $80{ }^{\circ} \mathrm{C}, \mathrm{UV}$-vis measurement showed that $\mathbf{9 Z}$ decomposed $43 \pm 2 \%$ and 9C decomposed $4 \pm 1 \%$ after 17 days (Figure 11c, 10d, Table 4). According to ${ }^{1} \mathrm{H}$ NMR measurement $9 \mathrm{Z}$ decomposed $97 \pm 1 \%$ and $9 \mathrm{C}$ decomposed $7 \pm 2 \%$ in deuterated toluene at $80{ }^{\circ} \mathrm{C}$ after 17 days (Figure 12, Table 4). To sum up, the $Z$-form of fulgimide 9 was less stable than the $C$-form in toluene at $80^{\circ} \mathrm{C}$ and fulgimide 9 has a similar thermal stability as the corresponding fulgide $1 .{ }^{52}$
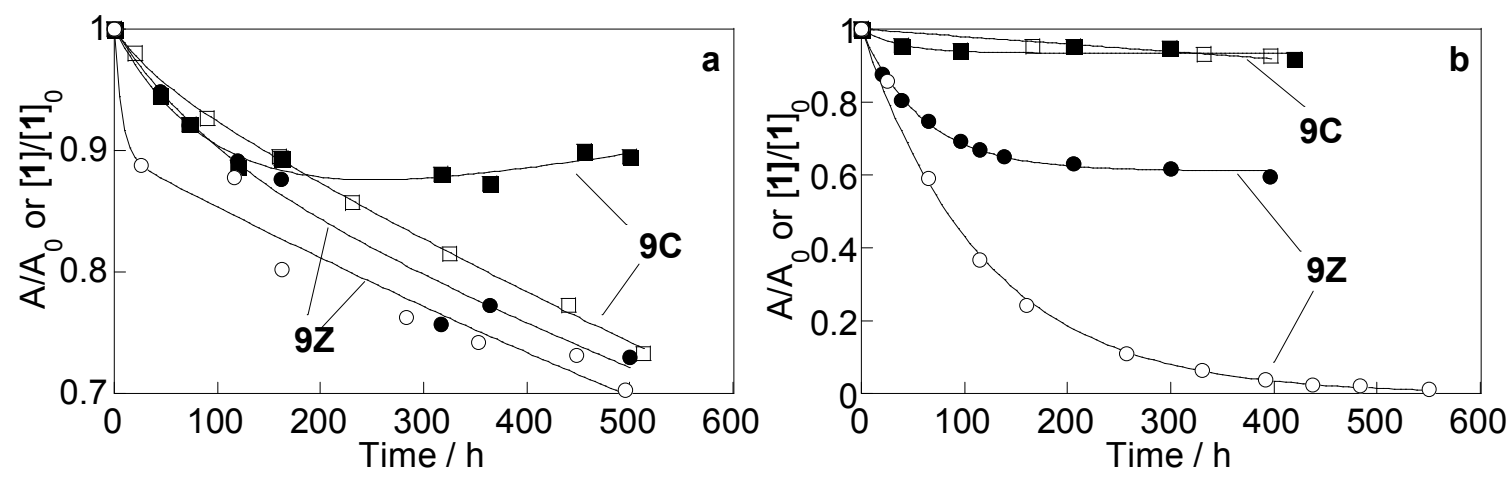

Figure 12. Thermal decomposition of $Z$ - (circles) and $C$-forms (squares) of fulgimide 9 as a function of time as measured by UV-vis spectroscopy (closed symbols) and NMR spectroscopy (open symbols) in $70 / 30$ ethanol/water at $50{ }^{\circ} \mathrm{C}$ (a) and in toluene at $80{ }^{\circ} \mathrm{C}$ (b)

In PMMA at $80{ }^{\circ} \mathrm{C}$, UV-vis measurement showed that $\mathbf{9 Z}$ decomposed $38 \pm 2 \%$ while 9C showed no decomposition after 10 days (Figure 13, Table 4). The absorbance spectra for $\mathbf{9 Z}$ at $80{ }^{\circ} \mathrm{C}$ indicated similar changes in PMMA and toluene. Nevertheless, the decomposition rate in PMMA appeared to be slower than that in toluene to some extent. 


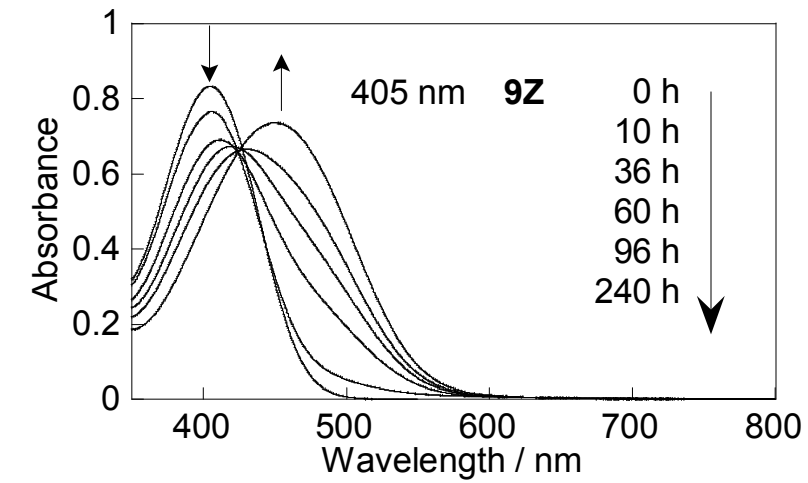

Figure 13. Thermal decomposition of $Z$-form of fulgimide 9 in PMMA at $80{ }^{\circ} \mathrm{C}$. Arrows indicate the change in absorbance with time.

\subsubsection{Photochemical Stability}

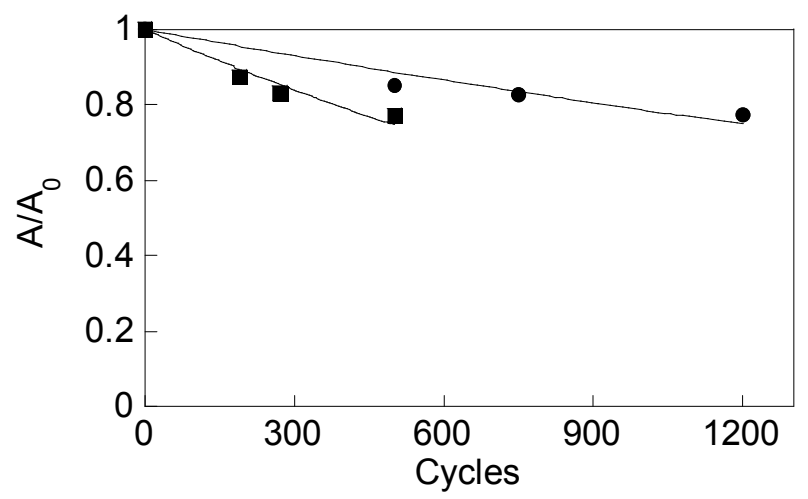

Figure 14. Photochemical decomposition of fulgimide 9 in 70/30 ethanol/water (squares) and in toluene (circles). Decrease in absorbance with repeated coloration and decoloration cycles

The ability of fulgides to repeatedly interconvert between the open and closed forms is vital for their applications as optical switches. Switches required fulgides to photochemically switch back and forth between two forms hundreds of times without significant degradation. In 70/30 ethanol/water, fulgimide 9 underwent $360 \pm 20$ 
photochemical cycles before degrading $20 \%$ while the fulgimide 7 only underwent 170 photochemical cycles. In toluene, fulgimide 9 underwent $1000 \pm 100$ (Figure 14).

\subsection{Conclusion}

In summary, trifluoromethyl indolylfulgide $\mathbf{1}$ was successfully synthesized on a large scale for the first time. The synthetic route was optimized and provided indolylfulgide $\mathbf{1}$ with an overall yield of $18 \%$. A new trifluoromethyl $N$-ethoxycarbonylmethyl indolylfulgimide 9 was synthesized from 1 as a precursor. The UV-vis absorbance spectra, extinction coefficient, and photochemical stability of $\mathbf{9}$ were characterized in 70/30 ethanol/water and toluene. Moreover, the thermal stability of the open and closed forms of 9 was measured in 70/30 ethanol/water, toluene, and PMMA. Fulgimide 9 was found to be stable in $70 / 30$ ethanol/water at $50{ }^{\circ} \mathrm{C}$ after 21 days. On the basis of the UVvis and ${ }^{1} \mathrm{H}$ NMR data, $9 \mathrm{Z}$ degraded $22 \%$ and $26 \%$ and $9 \mathrm{C}$ degraded $10 \%$ and $26 \%$ respectively, much more stable than the Z-form of 7 which degraded 52\% (UV-vis measurement). In toluene and PMMA, fulgimide 9 displayed a reasonable stability and the $C$-form was the most stable form. The photochemical stability of 9 appeared to be solvent dependent to some extent. In 70/30 ethanol/water, fulgimide 9 underwent 360 photochemical cycles while the $N$-phenyl indolylfulgimide 7 underwent 170 cycles before degrading by $20 \%$. In toluene, fulgimide 9 was more stable and underwent 1000 photochemical cycles before degrading by $20 \%$. In conclusion, the results demonstrated that fulgimide 9 was thermally and photochemically stable in both protic and aprotic solvents and could be consider as a potential material for optical switches. 


\section{CHAPTER 5}

\section{SYNTHESIS AND OPTICAL PROPERTIES OF AQUEOUS SOLUBLE INDOLYLFULGIMIDES}

\subsection{Abstract}

Three novel aqueous soluble fulgimides, trifluoromethyl carboxylic acid indolylfulgimide 10, dicarboxylic acid indolylfulgimide 19, and H-carboxylic acid indolylfulgimide 20, were synthesized (Scheme 22). Both 10 and 19 can switch back and forth between open and closed forms upon illumination with specific wavelengths of light, while 20 can only switch from the closed form to the open form. In sodium phosphate buffer ( $\mathrm{pH} 7.4$ ) at $37^{\circ} \mathrm{C}$, an unusual hydrolysis of the trifluoromethyl group of the closed form of $\mathbf{1 0}$ resulted in $\mathbf{1 9}$ which has an additional carboxylic acid group. The closed form of $\mathbf{1 9}$ was further decarboxylated to generate $\mathbf{2 0}$ which was not photochromic.

\section{Scheme 22. Photochemical reaction of indolylfulgimide 10, 19, 20}

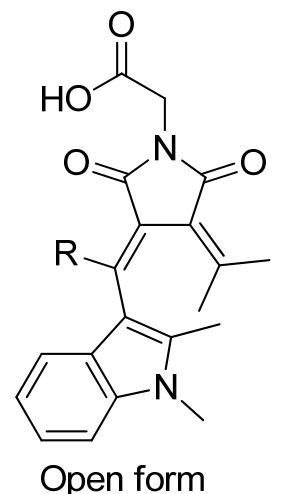

10. $\mathrm{R}$

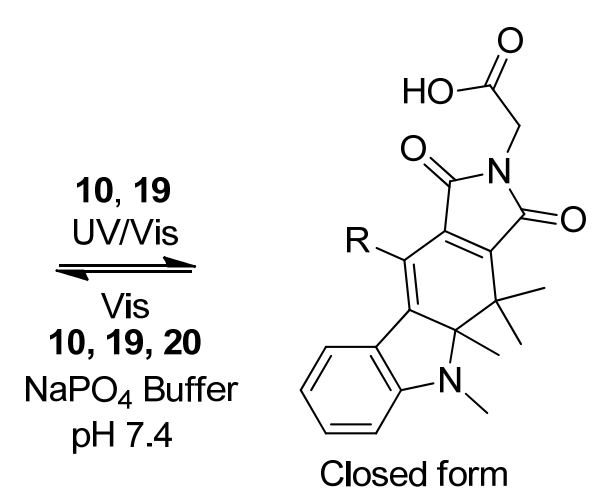

Closed form

In buffer, the open form of $\mathbf{1 0}$ degraded $20 \%$ after 10 days while the closed form of 10 was converted to 19 rapidliuy. In buffer, both forms of 19 degraded less than $20 \%$ after 21 days at $37^{\circ} \mathrm{C}$, and 19 underwent 670 photochemical cycles before degrading by 
$20 \%$. The dicarboxylic acid indolylfulgimide 19 is the most robust fulgimide yet reported in aqueous solution.

\subsection{Introduction}

Photochromic compounds have potential applications in high capacity optical information storage devices, optical molecular switches, and biological sensors. ${ }^{6,15,64}$ All these applications depend on the binary nature of photochromic compounds. The interconversion between two key forms upon exposure to specific wavelengths of light is known as photochromism (Scheme 23).

\section{Scheme 23. Photoreactions of fulgides and fulgimides}

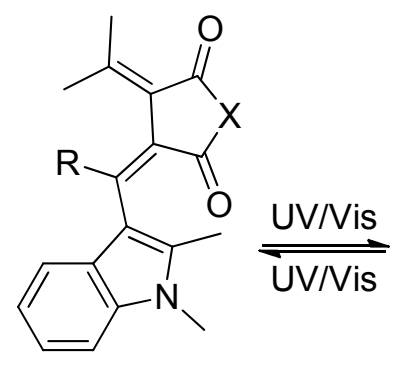

Open forms

E

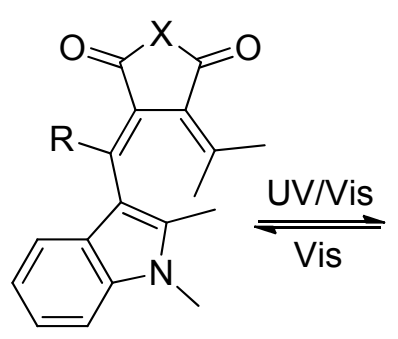

$Z$<smiles>[X]C1=C2C(=O)C3=C(C([R])=C4c5ccccc5N(C)C34C)C(C)(C)C2=C1</smiles>

Closed form

C

Fulgide 1. $\mathrm{R}=\mathrm{CF}_{3}, \mathrm{X}=\mathrm{O}$

Fulgimides 7. $\mathrm{R}=\mathrm{CF}_{3}, \mathrm{X}=\mathrm{N}-\mathrm{C}_{6} \mathrm{H}_{6}$

9. $\mathrm{R}=\mathrm{CF}_{3}, \mathrm{X}=\mathrm{N}-\mathrm{CH}_{2}-\mathrm{COOEt}$

10. $\mathrm{R}=\mathrm{CF}_{3}, \mathrm{X}=\mathrm{N}-\mathrm{CH}_{2}-\mathrm{COOH}$

19. $\mathrm{R}=\mathrm{COOH}, \mathrm{X}=\mathrm{N}-\mathrm{CH}_{2}-\mathrm{COOH}$

Fulgides and fulgimides, promising photochromic compounds, have been considered as potential optical memory materials because of the readily distinguishable absorption spectrum for each key form, efficient photoreactions, and thermal and photochemical stabilities. ${ }^{15,45}$ Studies have been conducted to optimize the photochromic properties of fulgides for specific applications. ${ }^{46-48}$ Optimization has resulted in more thermally and photochemically stable compounds such as fluorinated indolylfulgide $\mathbf{1}$, which was 
originally synthesized by Yokoyama and Takahashi. ${ }^{50-52}$ The most photochemically stable fulgide, a fluorinated indolylfulgide synthesized by Lees et al., undergoes 10,000 photochemical cycles (back and forth conversion between the two key forms) before degrading by $13 \%$ in toluene. ${ }^{52}$ Optimization in almost all cases has been performed in aprotic solvents. However, the properties of fulgides or fulgimides in aqueous solutions have not been thoroughly examined.

Stability in protic environments is an important property of photochromic compounds for their application in optical memory devices and biological optical switches. ${ }^{6,15}$ Materials used for memory devices are required to maintain stability and function in humid environments. In many biological applications, optical switches need to function in aqueous solvent systems. ${ }^{6,70}$ Previous studies demonstrated that fulgides were unstable in protic solvents because of the highly reactive succinic anhydride ring in their structure. ${ }^{41,71}$ Fulgimides, the most important fulgide derivatives, were synthesized to improve stability by replacing the succinic anhydride ring with a succinimide ring. ${ }^{40,41}$ The closed form of $\mathrm{N}$-phenyl fulgimide 7 displayed three orders of magnitude greater stability in $70 / 30$ ethanol/water relative to the parent fulgide $\mathbf{1}$ at $25{ }^{\circ} \mathrm{C}$ (Scheme 23). ${ }^{41}$ One of the recent studies indicated that the open form of ethyl ester fulgimide 9 lost $22 \%$ of its absorbance at the absorbance maxima while 7 lost $52 \%$ after 21 days in $70 / 30$ ethanol/water at $50{ }^{\circ} \mathrm{C} .{ }^{40}$ Furthermore, ethyl ester fulgimide 9 underwent 360 photochemical cycles in 70/30 ethanol/water before degrading by $20 \%$ while 7 underwent 170 cycles. ${ }^{40}$ The photochemical stability of fulgides in ethanol/water was not reported because of their rapid decomposition. Although several studies have determined the photochemical properties of fulgimides in protic solvents, ${ }^{6,40,41,70,71}$ only a few of these 
studies have reported the properties of fulgimides in aqueous solution. ${ }^{6,70,72}$ In one particular study fulgimide derivatives were covalently attached to the lysine residues on concanavalin A, where the open form of the fulgimide was shown to be stable in aqueous solution for $48 \mathrm{~h}$ at $25{ }^{\circ} \mathrm{C} .{ }^{70}$ This report also indicated that the fulgimide can cycle back and forth between the open and the closed forms at least twice. A recent study in living cells demonstrated that fulgimides can switch back and forth seven times in cellular membranes but not very well in water. ${ }^{6}$ Therefore, a more systematic study of the photochemical and thermal properties of fulgimides in aqueous solution would accelerate their applications as biological optical switches and sensors.

Herein, I have synthesized and characterized two new photochromic indolylfulgimides, 10 and 19 (Scheme 23). Fulgimide 10 was prepared from fluorinated indolylfulgide 1. An unusual hydrolysis of $\mathbf{1 0}$ in sodium phosphate buffer resulted in fulgimide 19, while further decarboxylation of 19 yielded a non-photochromic fulgimide 20. Fulgimides $\mathbf{1 0}$ and $\mathbf{1 9}$ were water soluble at physiological $\mathrm{pH}$ because of the hydrophilicity of the carboxylate anion. The absorption spectra, and thermal and photochemical stabilities for $\mathbf{1 0}$ and $\mathbf{1 9}$ have also been analyzed.

\subsection{Experimental Section}

\subsubsection{General procedures and materials}

All commercially available materials were used without further purification. The NMR spectra were recorded on a Brüker $400 \mathrm{MHz}$ NMR spectrometer. The ${ }^{1} \mathrm{H}$ and ${ }^{13} \mathrm{C}$ NMR spectra were internally referenced to TMS $(0.00 \mathrm{ppm})$ or solvent (7.26 and 77.00 ppm for $\mathrm{CDCl}_{3} ; 3.31$ and $49.00 \mathrm{ppm}$ for $\mathrm{CD}_{3} \mathrm{OD} ; 4.79 \mathrm{ppm}$ for $\mathrm{D}_{2} \mathrm{O}$ ). The $\mathrm{UV}$-vis spectra were recorded with a Cary 300 Spectrophotometer. Flash chromatography was performed 
with 230-400 mesh silica gel. Galbraith performed all elemental analysis. Fulgide 1Z was synthesized as described in chapter 4 .

\subsubsection{Synthesis of trifluoromethyl carboxylic acid indolylfulgimide 10}
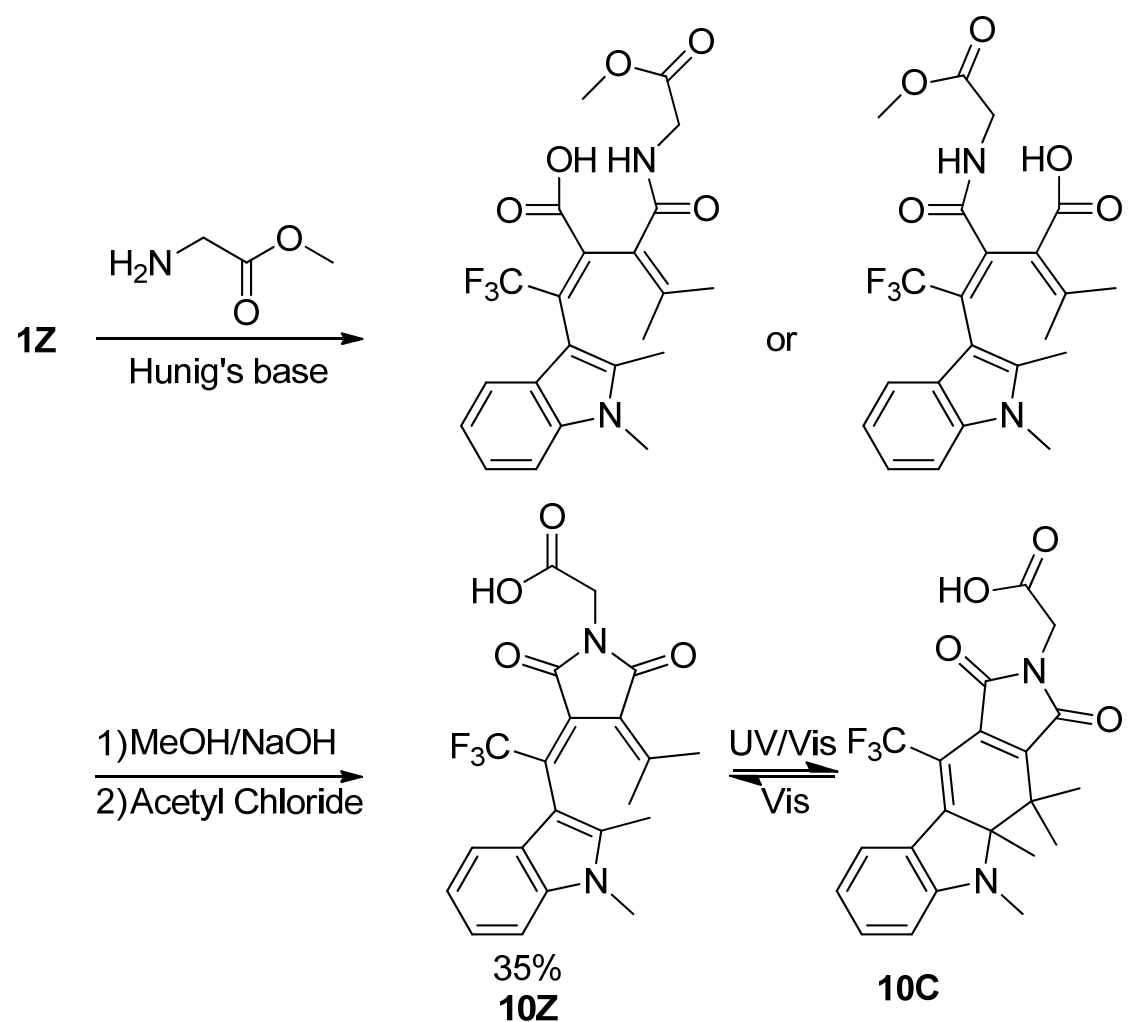

The $N, N$-Diisopropylethylamine $(2.7 \mathrm{~g}, 20.8 \mathrm{mmol})$ was added slowly with stirring to a mixture of the $\mathrm{HCl}$ salt of glycine methyl ester $(1.28 \mathrm{~g}, 10 \mathrm{mmol})$ and trifluoromethyl indolylfulgide $\mathbf{1 Z}(1.84 \mathrm{~g}, 5.2 \mathrm{mmol})$ in $100 \mathrm{~mL}$ of acetonitrile at $0{ }^{\circ} \mathrm{C}$. After stirring overnight, the solvent was removed in vacuo. The residue was added to $100 \mathrm{~mL}$ of $\mathrm{HCl}$ $(0.5 \mathrm{M})$ and extracted with EtOAc $(3 \times 100 \mathrm{~mL})$. The combined organic layers were dried over $\mathrm{MgSO}_{4}$, filtered, and concentrated in vacuo. Purification of the residue by silica gel chromatography (60:40:2 hexanes/EtOAc/AcOH) provided $1.94 \mathrm{~g}$ of the crude amide acid ester (orange solid). Sodium hydroxide $(1.1 \mathrm{~g}, 26.5 \mathrm{mmol})$ was added to the crude amide acid ester in $250 \mathrm{~mL}$ of methanol, and the reaction mixture was stirred for $2 \mathrm{~h}$ at 
room temperature. The solvent was then removed in vacuo. The residue was added to 100 $\mathrm{mL}$ of $\mathrm{Na}_{2} \mathrm{CO}_{3}(0.19 \mathrm{M})$ and extracted with EtOAc $(2 \times 75 \mathrm{~mL})$. The aqueous solution was acidified with $8.0 \mathrm{~mL}$ of concd $\mathrm{HCl}$ and extracted with EtOAc $(3 \times 75 \mathrm{~mL})$. The combined organic layers were dried over $\mathrm{MgSO}_{4}$ and filtered. The solvent was concentrated in vacuo to provide $1.75 \mathrm{~g}$ of the crude amide acid. Acetyl chloride $(6.1 \mathrm{~g}$, $78 \mathrm{mmol}$ ) was added to the crude amide acid in $100 \mathrm{~mL}$ of $\mathrm{CH}_{2} \mathrm{Cl}_{2}$ at reflux, and the reaction mixture was refluxed under Ar for $48 \mathrm{~h}$. The solution was cooled down to room temperature and stirred for 7 days under Ar. The solvent was then removed in vacuo. The residue was added to $100 \mathrm{~mL}$ of $\mathrm{H}_{2} \mathrm{O}$ and extracted with EtOAc $(3 \times 75 \mathrm{~mL})$. The combined organic layers were dried over $\mathrm{MgSO}_{4}$, filtered, and concentrated in vacuo. The residue was purified by silica gel chromatography (70:30:2 hexanes/EtOAc/AcOH) and recrystallized from methanol to provide $0.73 \mathrm{~g} \mathrm{(35 \%} \mathrm{from} \mathbf{1 Z})$ of the carboxylic acid indolylfulgimide 10. $Z$-form: ${ }^{1} \mathrm{H}$ NMR $\left(\mathrm{CD}_{3} \mathrm{OD}, 400 \mathrm{MHz}\right) \delta 7.39(\mathrm{~d}, J=8.1 \mathrm{~Hz}, 1 \mathrm{H})$, $7.24(\mathrm{~d}, J=8.0 \mathrm{~Hz}, 1 \mathrm{H}), 7.19(\mathrm{td}, J=7.4,1.1 \mathrm{~Hz}, 1 \mathrm{H}), 7.09(\mathrm{td}, J=7.5,0.9 \mathrm{~Hz}, 1 \mathrm{H}), 4.36$ (s, 2H), 3.73 (s, 3H), $2.26(\mathrm{~s}, 3 \mathrm{H}), 2.11(\mathrm{~s}, 3 \mathrm{H}), 0.96(\mathrm{~s}, 3 \mathrm{H}) .{ }^{13} \mathrm{C}$ NMR $\left(\mathrm{CD}_{3} \mathrm{OD}, 100\right.$ MHz) $\delta 169.4,167.9,165.7,156.1,139.1,138.5,133.8,130.5$ (q, $J=36 \mathrm{~Hz}), 126.8$, $124.0(\mathrm{q}, J=272 \mathrm{~Hz}), 123.8,122.9,121.7,120.2,110.5,108.3,39.7,30.2,26.8,22.3$, 12.0. Anal. Calcd for $\mathrm{C}_{21} \mathrm{H}_{19} \mathrm{~F}_{3} \mathrm{~N}_{2} \mathrm{O}_{4}$ : C, 60.00; H, 4.56; N, 6.66. Found: C, 60.28; H, 4.89; N, 6.39. $C$-form: ${ }^{1} \mathrm{H}$ NMR $\left(\mathrm{CD}_{3} \mathrm{OD}, 400 \mathrm{MHz}\right) \delta 7.67(\mathrm{~d}, J=8.3 \mathrm{~Hz}, 1 \mathrm{H}), 7.38(\mathrm{td}, J=$ 7.8, 1.1 Hz, 1H), 6.77 (t, $J=7.9 \mathrm{~Hz}, 2 \mathrm{H}), 4.24(\mathrm{~d}, J=17.7 \mathrm{~Hz}, 1 \mathrm{H}), 4.20(\mathrm{~d}, J=17.7 \mathrm{~Hz}$, 1H), $2.96(\mathrm{~s}, 3 \mathrm{H}), 1.81$ (s, 3H), 1.37 (s, 3H), 1.23 (s, 3H). ${ }^{13} \mathrm{C} \mathrm{NMR}\left(\mathrm{CD}_{3} \mathrm{OD}, 100 \mathrm{MHz}\right)$ $\delta 171.2,170.0,167.1,161.7,161.6,141.4,137.1,136.3,129.1(\mathrm{q}, J=7 \mathrm{~Hz}), 124.2(\mathrm{q}, J=$ 
$272 \mathrm{~Hz}), 120.5,119.9,110.9,106.8(\mathrm{q}, J=37 \mathrm{~Hz}), 77.3,40.2,39.6,33.0,19.9,19.6$,

14.8. HRMS $\left(\right.$ ESI $\left.^{+}\right)$calcd for $\mathrm{C}_{21} \mathrm{H}_{19} \mathrm{~F}_{3} \mathrm{~N}_{2} \mathrm{O}_{4}(\mathrm{M}+\mathrm{Na})^{+} 443.1195$, obsd 443.1195 .

\subsubsection{Synthesis of dicarboxylic acid indolylfulgimide 19}

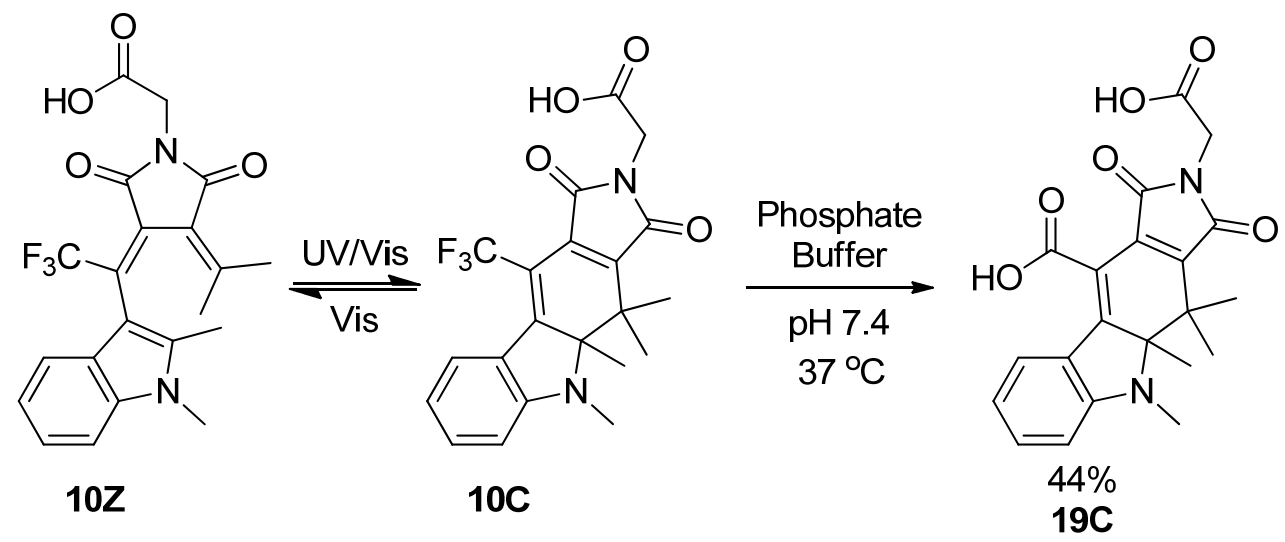

Carboxylic acid indolylfulgimide $10 \mathrm{Z}(0.19 \mathrm{~g}, 0.45 \mathrm{mmol})$ in $250 \mathrm{~mL}$ of toluene was irradiated with $405 \mathrm{~nm}$ light to obtain the photostationary state. Purification of the resulting 10C was performed via silica gel chromatography (70:30:2 hexanes/EtOAc/AcOH) followed by recrystallization from $\mathrm{CH}_{2} \mathrm{Cl}_{2} /$ hexanes to provide $0.14 \mathrm{~g}(74 \%)$ of $10 \mathrm{C}$. Fulgimide $10 \mathrm{C}(0.10 \mathrm{~g}, 0.24 \mathrm{mmol})$ in $50 \mathrm{~mL}$ of $50 \mathrm{mM}$ sodium phosphate buffer $\left(\mathrm{pH}\right.$ 7.4) was incubated at $37{ }^{\circ} \mathrm{C}$ for $12 \mathrm{~h}$. The solution was then acidified with dilute $\mathrm{HCl}(1 \mathrm{M})$ to $\mathrm{pH} 5$ and extracted with EtOAc $(3 \times 25 \mathrm{~mL})$. The combined organic layers were dried over $\mathrm{MgSO}_{4}$, filtered, and concentrated in vacuo. Purification was performed via recrystallization from $\mathrm{CH}_{2} \mathrm{Cl}_{2} /$ toluene to provide $40 \mathrm{mg}$ (42\%) of the dicarboxylic acid indolylfulgimide 19. $C$-form: ${ }^{1} \mathrm{H}$ NMR $\left(\mathrm{CD}_{3} \mathrm{OD}, 400\right.$ MHz) $\delta 7.72(\mathrm{~d}, J=8.3 \mathrm{~Hz}, 1 \mathrm{H}), 7.30(\mathrm{td}, J=8.1,1.2 \mathrm{~Hz}, 1 \mathrm{H}), 6.67-6.71(\mathrm{~m}, 2 \mathrm{H}), 4.22$ (d, $J=17.3 \mathrm{~Hz}, 1 \mathrm{H}), 4.17(\mathrm{~d}, J=17.8 \mathrm{~Hz}, 1 \mathrm{H}), 2.98(\mathrm{~s}, 3 \mathrm{H}), 1.81(\mathrm{~s}, 3 \mathrm{H}), 1.40(\mathrm{~s}, 3 \mathrm{H})$, $1.20(\mathrm{~s}, 3 \mathrm{H}) ;{ }^{13} \mathrm{C}$ NMR $\left(\mathrm{CD}_{3} \mathrm{OD}, 100 \mathrm{MHz}\right) \delta 171.3,170.5,169.9,168.2,159.7,156.6$, $137.8,137.6,135.4,126.8,122.1,119.5,110.9,110.2,74.3,41.4,39.3,32.1,20.4,19.2$, 
15.8. Anal. Calcd for $\mathrm{C}_{21} \mathrm{H}_{20} \mathrm{~N}_{2} \mathrm{O}_{6}: \mathrm{C}, 63.63 ; \mathrm{H}, 5.09 ; \mathrm{N}$, 7.07. Found: $\mathrm{C}, 63.63 ; \mathrm{H}, 5.34$; N, 6.89. Z-form: ${ }^{1} \mathrm{H}$ NMR $\left(\mathrm{CD}_{3} \mathrm{OD}, 400 \mathrm{MHz}\right) \delta 7.46(\mathrm{~d}, J=8.0 \mathrm{~Hz}, 1 \mathrm{H}), 7.41(\mathrm{~d}, J=8.3$ Hz, 1H), 7.20 (t, $J=7.5,1 \mathrm{H}), 7.07$ (t, $J=7.7,1 \mathrm{H}), 4.34(\mathrm{~s}, 2 \mathrm{H}), 3.74(\mathrm{~s}, 3 \mathrm{H}), 2.29(\mathrm{~s}, 3 \mathrm{H})$, $2.26(\mathrm{~s}, 3 \mathrm{H}), 1.07$ (s, 3H); ${ }^{13} \mathrm{C}$ NMR $\left(\mathrm{CD}_{3} \mathrm{OD}, 100 \mathrm{MHz}\right) \delta$ 172.6, 170.7, 169.0, 168.1, $154.1,140.2,138.5,136.8,126.8,123.6,123.4,123.2,121.6,120.3,110.6,110.1,39.7$, 30.2, 26.6, 22.6, 12.0. HRMS $(\mathrm{ESI}+)$ calcd for $\mathrm{C} 20 \mathrm{H} 20 \mathrm{~N} 2 \mathrm{O} 6(\mathrm{M}+\mathrm{Na})+419.1246$, obsd419.1233.

\subsubsection{Synthesis of H-carboxylic acid indolylfulgimide 20}
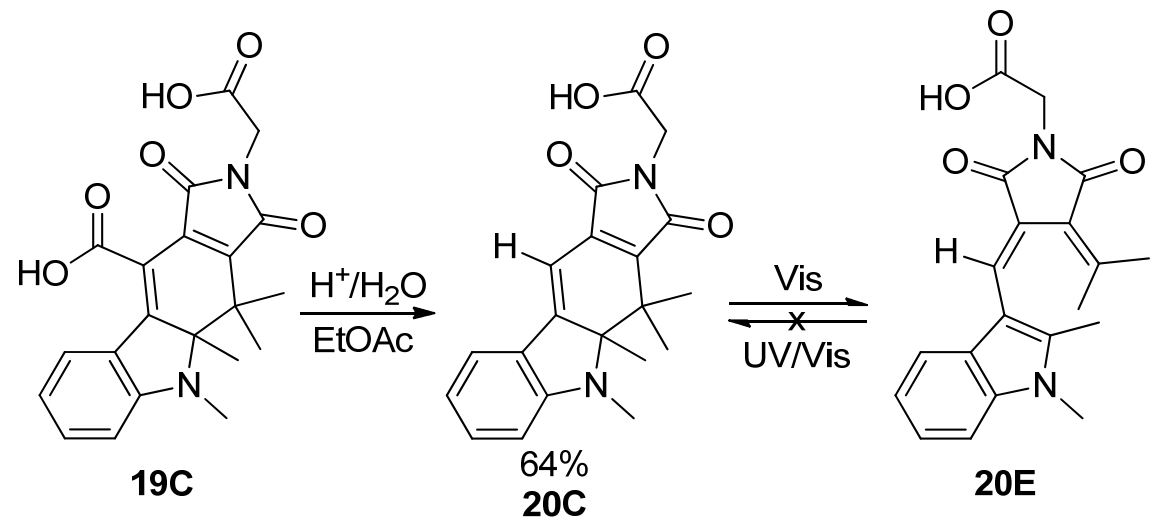

Fulgimide 10C $(0.142 \mathrm{~g}, 0.32 \mathrm{mmol})$ in $250 \mathrm{~mL}$ of $50 \mathrm{mM}$ sodium phosphate buffer (pH 7.4) was incubated at $37{ }^{\circ} \mathrm{C}$ for $12 \mathrm{~h}$. The solution was then acidified with concd $\mathrm{HCl}$ to $\mathrm{pH} 1$ and extracted with EtOAc $(3 \times 75 \mathrm{~mL})$. The combined organic layers were left overnight, dried over $\mathrm{MgSO}_{4}$, filtered, and concentrated in vacuo. Purification was performed via recrystallization from $\mathrm{CH}_{2} \mathrm{Cl}_{2} /$ hexanes to provide $76 \mathrm{mg}(64 \%)$ of the carboxylic acid indolylfulgimide 20. $C$-form: ${ }^{1} \mathrm{H}$ NMR $\left(\mathrm{D}_{2} \mathrm{O}, 400 \mathrm{MHz}\right) \delta 7.58(\mathrm{~d}, J=7.6$ $\mathrm{Hz}, 1 \mathrm{H}), 7.34$ (td, $J=7.7,1.2 \mathrm{~Hz}, 1 \mathrm{H}), 6.79(\mathrm{td}, J=7.5,0.8 \mathrm{~Hz}, 1 \mathrm{H}), 6.74(\mathrm{~d}, J=8.3$, 1H), $6.52(\mathrm{~s}, 1 \mathrm{H}), 4.00(\mathrm{~s}, 2 \mathrm{H}), 3.93(\mathrm{~s}, 3 \mathrm{H}), 1.74(\mathrm{~s}, 3 \mathrm{H}), 1.33(\mathrm{~s}, 3 \mathrm{H}), 1.14(\mathrm{~s}, 3 \mathrm{H}) ;{ }^{13} \mathrm{C}$ $\operatorname{NMR}\left(\mathrm{CDCl}_{3}, 100 \mathrm{MHz}\right) \delta 173.0,170.0,168.5,157.8,157.4,138.9,135.2,133.4,123.5$, 
123.4, 118.8, 109.1, 100.3, 72.8, 41.3, 38.6, 31.9, 20.2, 19.3, 16.1. HRMS $\left(\mathrm{ESI}^{+}\right)$calcd for $\mathrm{C}_{20} \mathrm{H}_{20} \mathrm{~N}_{2} \mathrm{O}_{4}(\mathrm{M}+\mathrm{Na})^{+}$375.1321, obsd 375.1323. E-form: ${ }^{1} \mathrm{H} \mathrm{NMR}\left(\mathrm{D}_{2} \mathrm{O}, 400 \mathrm{MHz}\right)$ $\delta 7.87(\mathrm{~s}, 1 \mathrm{H}), 7.51(\mathrm{~d}, J=8.3 \mathrm{~Hz}, 1 \mathrm{H}), 7.45(\mathrm{~d}, J=7.9 \mathrm{~Hz}, 1 \mathrm{H}), 7.30(\mathrm{td}, J=7.4,1.0 \mathrm{~Hz}$, 1H), $7.17(\mathrm{td}, J=7.6,1.0 \mathrm{~Hz}, 1 \mathrm{H}), 4.17(\mathrm{~s}, 2 \mathrm{H}), 3.75(\mathrm{~s}, 3 \mathrm{H}), 2.45(\mathrm{~s}, 3 \mathrm{H}), 2.31(\mathrm{~s}, 3 \mathrm{H})$, 1.19 (s, 3H); ${ }^{13} \mathrm{C}$ NMR $\left(\mathrm{CDCl}_{3}, 100 \mathrm{MHz}\right) \delta 172.2,169.6,168.2,152.1,141.2,136.9$, 127.5, 126.4, 123.4, 122.1, 121.3, 121.0, 120.1, 110.4, 109.4, 38.9, 30.2, 26.7, 22.2, 11.6. HRMS (ESI ${ }^{+}$) calcd for $\mathrm{C}_{20} \mathrm{H}_{20} \mathrm{~N}_{2} \mathrm{O}_{4}(\mathrm{M}+\mathrm{Na})^{+}$375.1321, obsd 375.1305.

\subsubsection{Spectral determination}

Concentrated, air-saturated stock solutions of $10 \mathrm{Z}$ in toluene and $50 \mathrm{mM}$ sodium phosphate buffer $(\mathrm{pH}$ 7.4) were prepared in duplicate or triplicate. From each stock solution, five samples ranging in concentration from 0.25 to $0.05 \mathrm{mM}$ were then prepared by dilution with toluene or buffer. A UV-vis spectrum was then acquired for each sample. Extinction coefficients and $\lambda_{\max }$ were determined. According to ${ }^{1} \mathrm{H}$ NMR data, $Z / E$ isomerization in $\mathrm{D}_{2} \mathrm{O}$ with sodium phosphate buffer at room temperature in $1 \mathrm{~h}$ was insignificant (1 - 2\%). No isomerization was observed in toluene.

A concentrated, air-saturated stock solution of $\mathbf{1 0 C}$ (see synthesis) in toluene was diluted to four or five different concentrations, and their UV-vis spectra obtained. Each 10C solution was then quantitatively converted to $10 \mathrm{Z}$ solution by illumination with 515 $\mathrm{nm}$ light, and the concentration of fulgimide present was ascertained using the predetermined extinction coefficient of $10 \mathrm{Z}$. Since the original concentration of $10 \mathrm{C}$ will be equivalent to the final concentration of $10 \mathrm{Z}$, the original concentration of $10 \mathrm{C}$ was determined. The extinction coefficient and $\lambda_{\max }$ for $\mathbf{1 0 C}$ were then determined from the initial spectra. 
The extinction coefficient and $\lambda_{\max }$ for $19 \mathrm{C}$ in $50 \mathrm{mM}$ sodium phosphate buffer $(\mathrm{pH}$ 7.4) were determined in the same manner as for $\mathbf{1 0 Z}$. To obtain these values for $\mathbf{1 9 Z}$, four or five diluted 19C solutions in buffer were then quantitatively converted to $19 \mathrm{Z}$ solutions by irradiation with $515 \mathrm{~nm}$ light. The UV-vis spectra of freshly prepared $\mathbf{1 9 Z}$ solutions were measured, and the extinction coefficient was obtained using the previously determined extinction coefficient of 19C. Typical error was 3\%.

\subsubsection{Photostationary state (PSS) measurements}

A solution of $10 Z$ in toluene- $\mathrm{d}_{8}$ was illuminated with $405 \mathrm{~nm}$ light, and the $Z / E / C$ ratio was monitored via ${ }^{1} \mathrm{H}$ NMR spectroscopy until $\mathrm{PSS}_{405 \mathrm{~nm}}$ was achieved. To measure the $\mathrm{PSS}_{405 \mathrm{~nm}}$ of 19 in $\mathrm{D}_{2} \mathrm{O}$ with $50 \mathrm{mM}$ sodium phosphate buffer (pD 7.4), a solution of 19C, which was initially obtained from $10 \mathrm{C}$, was converted to $\mathbf{1 9 Z}$ using $515 \mathrm{~nm}$ light. PSS was then achieved by irradiation of $\mathbf{1 9 Z}$ with $405 \mathrm{~nm}$ light. $Z / E / C$ - ratio was monitored by ${ }^{1} \mathrm{H}$ NMR spectroscopy.

\subsubsection{Thermal/Hydrolytic stability}

The thermal/hydrolytic stability of the $Z$ - and $C$-forms of fulgimides $\mathbf{1 0}$ and $\mathbf{1 9}$ was measured using UV-vis and ${ }^{1} \mathrm{H}$ NMR spectroscopy. Solutions of $\mathbf{1 0 Z}$ were prepared in toluene or $50 \mathrm{mM}$ sodium phosphate buffer $(\mathrm{pH}$ 7.4) and transferred into several ampoules. The NMR samples of $\mathbf{1 0 Z}$ were prepared in toluene- $\mathrm{d}_{8}$ or $\mathrm{D}_{2} \mathrm{O}$ with $50 \mathrm{mM}$ sodium phosphate buffer (pD 7.4). The UV-vis and ${ }^{1} \mathrm{H}$ NMR spectra of these initial samples were then acquired. Ampoules and NMR tubes were sealed and incubated in water baths which were maintained at $80{ }^{\circ} \mathrm{C}$ (toluene) or at $37{ }^{\circ} \mathrm{C}$ (buffer). At predetermined times, ampoules and NMR tubes were removed, and their contents were analyzed by UV-vis and ${ }^{1} \mathrm{H}$ NMR spectroscopy, respectively. The UV-vis and ${ }^{1} \mathrm{H}$ NMR 
spectra were then compared to the initial spectra. The thermal stability of $10 \mathrm{C}$ in toluene was measured using a $\mathrm{PSS}_{405 \mathrm{~nm}}$ solution, and evaluated as described for 10Z. In the case of $10 \mathrm{C}$ in buffer, the UV-vis spectra of $10 \mathrm{C}$ and its decomposition product were almost identical, thus UV-vis spectroscopy was not used to follow the decomposition of 10C; only the 1H NMR experiment was performed. Several pure 10C solutions were prepared in $\mathrm{D}_{2} \mathrm{O}$ with buffer ( $\mathrm{pD}$ 7.4) and transferred into several ampoules which were then placed in a water bath maintained at $37{ }^{\circ} \mathrm{C}$. At prescribed times, solutions were transferred into NMR tubes, and their spectra were taken immediately.

To determine the stability of $19 \mathrm{C}$ and $19 \mathrm{Z}$ in buffer, pure $19 \mathrm{C}$ solutions were used while $19 \mathrm{Z}$ solutions were prepared by irradiation of a 19C solution with $515 \mathrm{~nm}$ light. These $19 \mathrm{C}$ and $19 \mathrm{Z}$ solutions were then analyzed in the same manner as $10 \mathrm{Z}$. In addition, decomposition of 19C in $\mathrm{D}_{2} \mathrm{O}$ with buffer (pD 7.4) was also followed by UV-vis spectroscopy. Typical error was $5 \times 10^{-5} \mathrm{~h}^{-1}$ with the exception of $\mathbf{1 0 Z}$ in toluene which was $0.003 \mathrm{~h}^{-1}$.

For ${ }^{1} \mathrm{H}$ NMR spectroscopy, the residual toluene resonance (toluene) or added DMSO resonance (buffer) were utilized as internal standards, and signals corresponding to the individual species were integrated relative to the internal standards. To confirm the solvent isotope effect of $19 \mathrm{C}$ in buffer, two experiments in $\mathrm{D}_{2} \mathrm{O}$ and $\mathrm{H}_{2} \mathrm{O}$ buffer solutions were performed simultaneously and followed by UV-vis spectroscopy.

\subsubsection{Photochemical stability}

Air-saturated solutions of $\mathbf{1 0 Z}$ in toluene and in toluene in the presence of an excess of tributylamine $(27 \mathrm{mM})$ or acetic acid $(27 \mathrm{mM})$ were prepared with initial absorbencies of $0.6-0.8$ at the absorption maxima. Samples were irradiated to $\mathrm{PSS}_{405 \mathrm{~nm}}$ with $405 \mathrm{~nm}$ 
light, and the absorbencies at $\lambda_{\max }$ were measured. Then, in three cases (toluene, toluene/tributylamine, toluene/acetic acid), fresh $\mathbf{1 0 Z}$ solutions were irradiated to $90 \%$ of PSS $_{405 \mathrm{~nm}}$. The time taken to achieve $90 \%$ of the absorbance at $\mathrm{PSS}_{405 \mathrm{~nm}}$ was then recorded (coloration reaction $Z$ to $C$ ). The $90 \%$ PSS mixture was then irradiated with 515 nm light using a separate filter. The time taken for the absorbance at $\lambda_{\max }$ of the $C$-form to reach $<1 \%$ was recorded (decoloration reaction $C$ to $Z$ ). Once the duration of irradiation was established for both the $90 \% \mathrm{PSS}_{405 \mathrm{~nm}}$ coloration and $<1 \% C$-form decoloration reactions, the system was automated through the use of a filter switch. All solutions were capped and stirred. After a designated number of irradiation cycles (coloration followed by decoloration), the samples were fully converted to $\mathrm{PSS}_{405 \mathrm{~nm}}$, and their UV-vis spectra scanned. The photochemical stability was then determined by comparison with the initial $\mathrm{PSS}_{405 \mathrm{~nm}}$ (PSS at zero irradiation cycles) absorption spectra.

To measure the photochemical stability of $\mathbf{1 9}$ in $50 \mathrm{mM}$ sodium phosphate buffer $(\mathrm{pH}$ 7.4) the freshly obtained $19 \mathrm{C}$ solutions were quantitatively converted to $\mathbf{1 9 Z}$ solutions by irradiating with $515 \mathrm{~nm}$ light. The same procedure as described for $\mathbf{1 0}$ was then applied. A control experiment to investigate the thermal decomposition of $\mathbf{1 9 Z}$ at room temperature after $120 \mathrm{~h}$ was also performed. After $120 \mathrm{~h}$, besides $Z$ to $E$ isomerization, the thermal decomposition was determined by ${ }^{1} \mathrm{H}$ NMR to be $1 \% . Z$ to $E$ isomerization will not affect the photochemical decomposition results as these two forms are interconverted photochemically under aqueous conditions. Typical error was $20 \%$. All the photochemical and thermal measurements were performed by Dr. Islamova in Dr. Lees' group. 


\subsection{Results and Discussion}

\subsubsection{Synthesis}

\section{Scheme 24. Synthesis of indolylfulgimide 10}
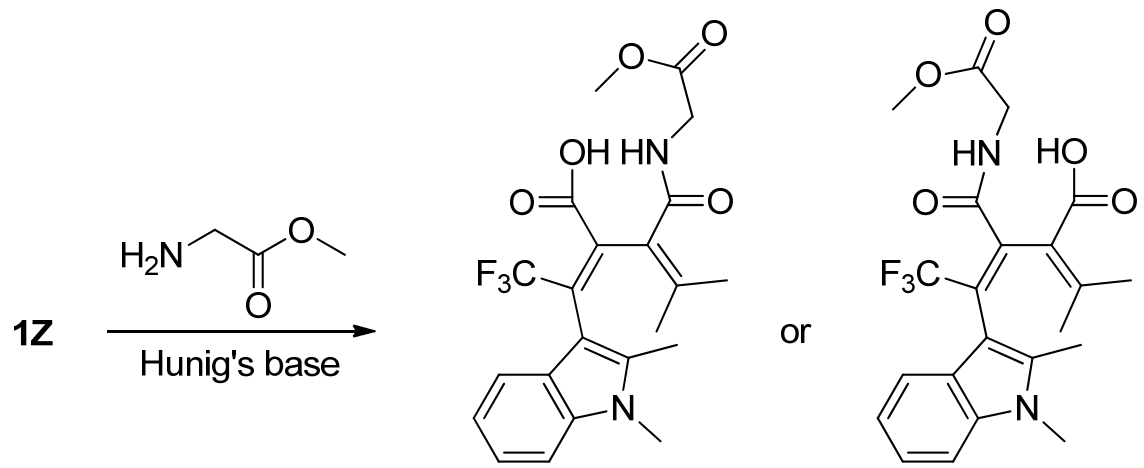

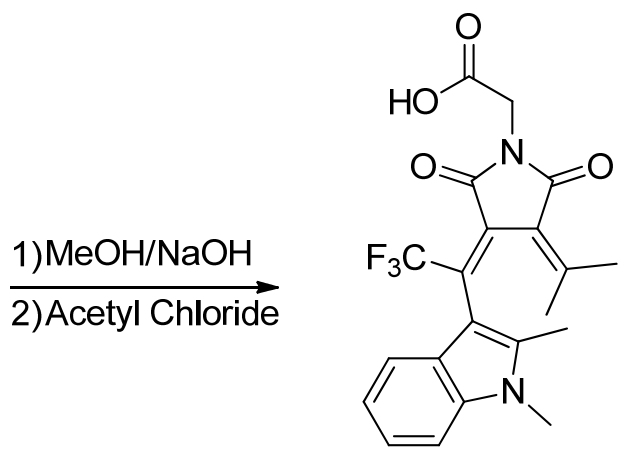

$10 Z$

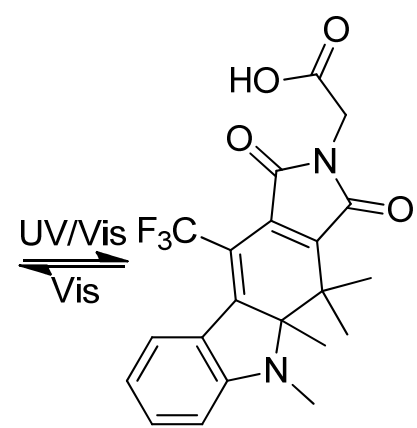

$10 \mathrm{C}$

Trifluoromethyl indolylfulgide $\mathbf{1}^{60}$ was used as the starting material for the synthesis of carboxylic acid indolylfulgimide 10 (Scheme 24). The anhydride ring of 1 was opened via addition of glycine methyl ester. The resulting methyl ester succinamic acid, one of the two possible regioisomers, ${ }^{93}$ was saponified to generate the corresponding carboxylic acid succinamic acid. Subsequent dehydration of the succinamic acid intermediate with acetyl chloride yielded carboxylic acid indolylfulgimide 10Z. Fulgimide 10C was obtained by irradiating $\mathbf{1 0 Z}$ with $405 \mathrm{~nm}$ light (Scheme 24). 

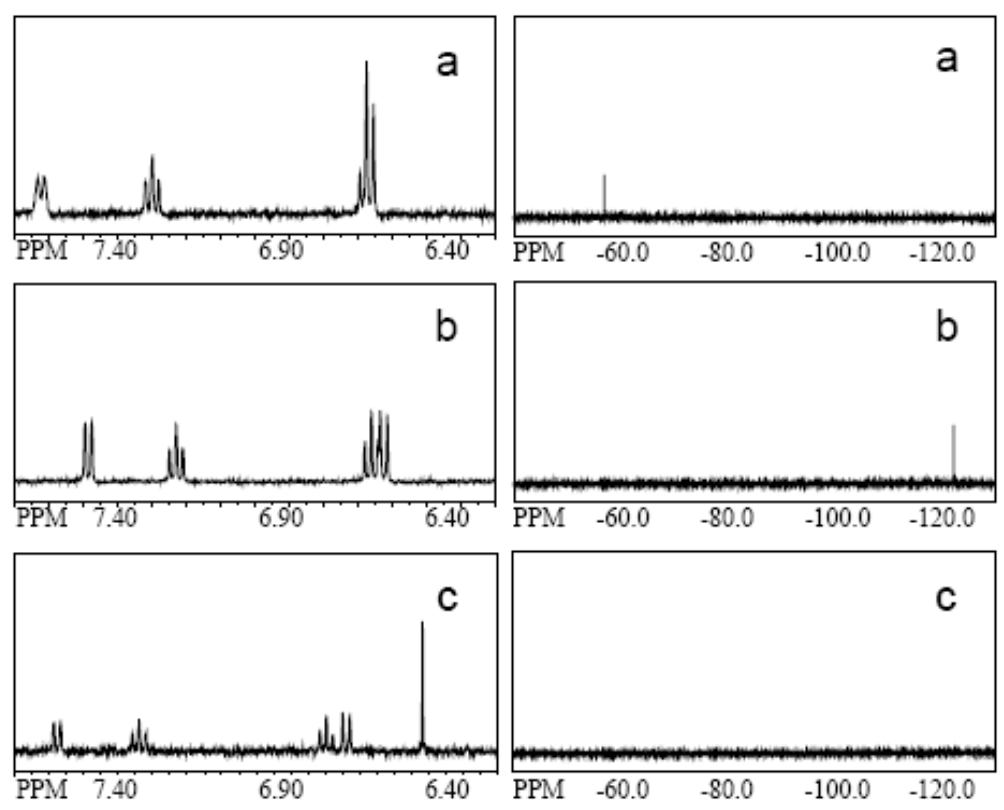

Figure 15. ${ }^{1} \mathrm{H}$ and ${ }^{19} \mathrm{~F}$ NMR spectra of $\mathbf{1 0 C}$ in $50 \mathrm{mM} \mathrm{D}_{2} \mathrm{O}$ sodium phosphate buffer, $\mathrm{pD}$ 7.4, at $37^{\circ} \mathrm{C}$ after (a) $0 \mathrm{~h}$, (b) $6 \mathrm{~h}$, (c) following extraction and purification

During thermal stability measurements of $\mathbf{1 0 C}$ in $50 \mathrm{mM}$ sodium phosphate buffer (pH 7.4) at $37^{\circ} \mathrm{C}$, an unexpected reaction was observed. The reaction was followed by ${ }^{1} \mathrm{H}$ and ${ }^{19} \mathrm{~F}$ NMR spectroscopy. The NMR data indicated an unusually high reactivity for 10C. Previously reported $C$-forms of fluorinated indolylfulgimides have proven to be very stable under various conditions. ${ }^{40,41}$ In the case of $\mathbf{1 0 C}$, before incubation at $37{ }^{\circ} \mathrm{C}$, only one resonance at $-58 \mathrm{ppm}$ in the ${ }^{19} \mathrm{~F}$ NMR spectrum corresponding to the fluorines of the trifluoromethyl group was observed (Figure 15a). After $6 \mathrm{~h}$ at $37^{\circ} \mathrm{C}$, the resonance at $-58 \mathrm{ppm}$ disappeared, and a new fluorine signal appeared at $-122 \mathrm{ppm}$, which is consistent with the chemical shift of the fluoride anion. The ${ }^{1} \mathrm{H}$ NMR spectrum showed a downfield shift of all hydrogen and methyl resonances (Figure 15b). In order to provide further support for the structure of the resulting product, ${ }^{13} \mathrm{C}$ NMR spectroscopy was performed. The quartet for the carbon of the trifluoromethyl group of $\mathbf{1 0 C}$ at $122 \mathrm{ppm}$ 
disappeared, and a new singlet at $170 \mathrm{ppm}$ appeared suggesting a carboxylic acid group. Furthermore, the resulting product still maintained photochromic properties and was stable in buffer at $37{ }^{\circ} \mathrm{C}$ for several days. Therefore, the most plausible mechanism was the hydrolysis of the trifluoromethyl group to form a carboxylic acid group. ${ }^{94-96}$ The reaction yielded the photochromic dicarboxylic acid indolylfulgimide 19C (Scheme 25).

\section{Scheme 25. Mechanism for the hydrolysis of $10 \mathrm{C}$}
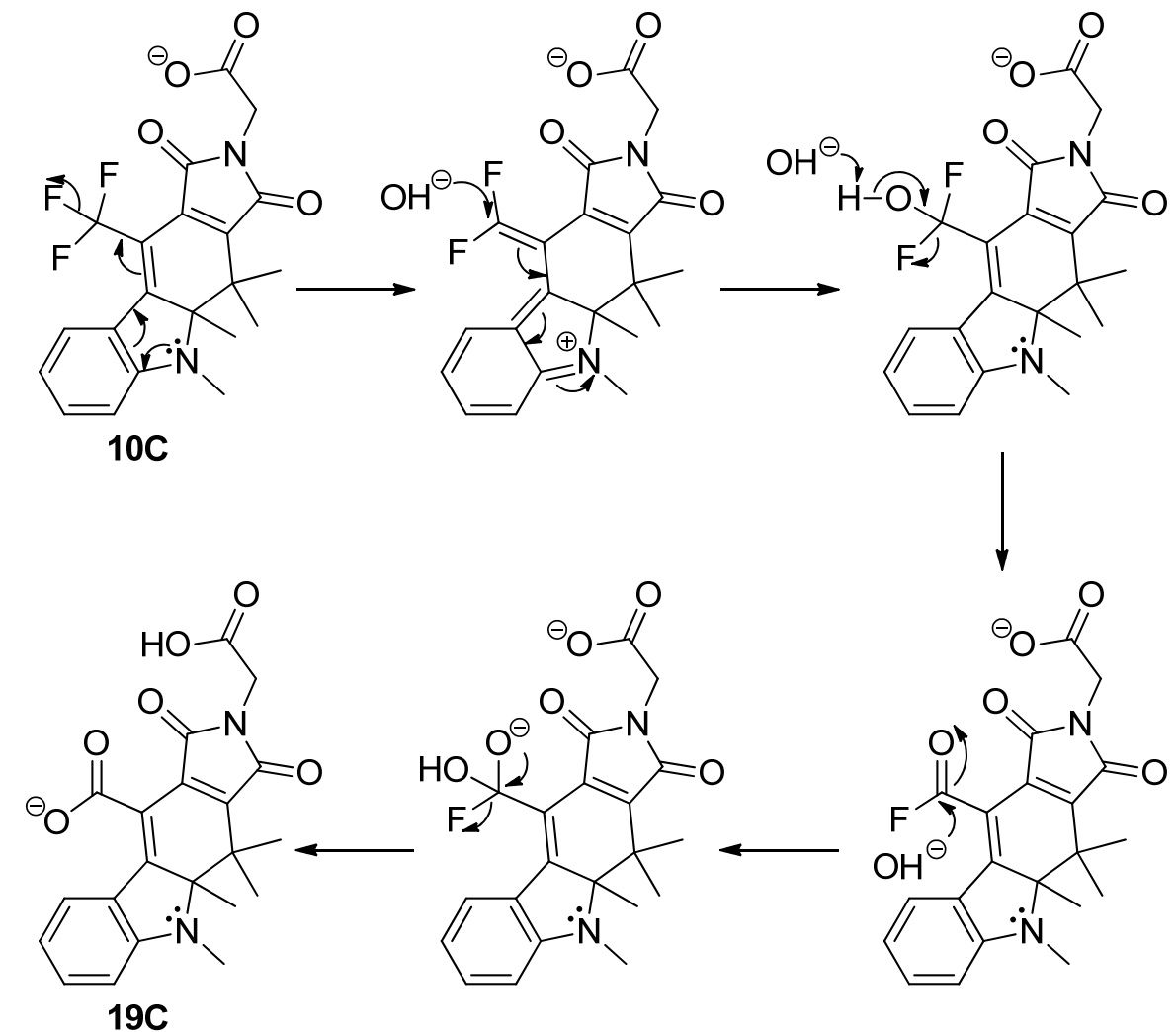

$19 \mathrm{C}$

Interestingly, when I initially attempted to isolate $19 \mathrm{C}$ by EtOAc extraction from an acidified aqueous solution, the organic layer did not contain 19C (Figure 15c). Instead, an extra hydrogen resonance appeared at $6.41 \mathrm{ppm}$ in the ${ }^{1} \mathrm{H}$ NMR spectrum, and the ${ }^{13} \mathrm{C}$ NMR spectrum showed only 20 carbon resonances in comparison with the 21 carbon resonances for $10 \mathrm{C}$ and $19 \mathrm{C}$, indicating another compound had been formed during the 
acidic extraction. The missing carbon resonance occurred in the carboxylic acid region. The lack of any ${ }^{19} \mathrm{~F}$ NMR resonance suggested that the fluoride anion was removed in the aqueous layer during extraction. Therefore, I propose that the carboxylic acid group generated from the hydrolysis of the trifluoromethyl group can be decarboxylated to form compound 20C (Scheme 26). ${ }^{97,98}$

Photochromic studies demonstrated that $20 \mathrm{C}$ can be converted to $20 \mathrm{E}$ ( $E$-form because of IUPAC priority rules), but the reverse reaction was not observed (Scheme 26). Previously reported indolylfulgides substituted at the 3-position on the indole and having hydrogen at the bridging position were initially obtained in their $E$-form and also could not be converted to the $C$-form. ${ }^{42,43,99}$ For the first time, I obtained the $C$-form of such a fulgimide with a hydrogen at the bridging position. No further investigation of the optical properties of $\mathbf{2 0}$ was conducted as it was not photochromic.

\section{Scheme 26. Decarboxylation of $19 \mathrm{C}$ and photochemical reaction of 20}

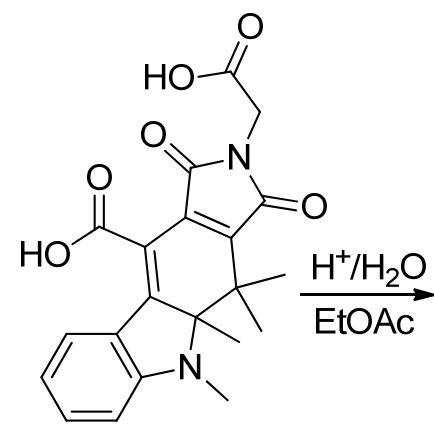

$19 \mathrm{C}$

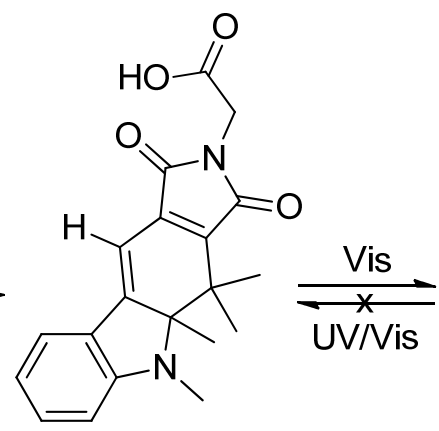

20C

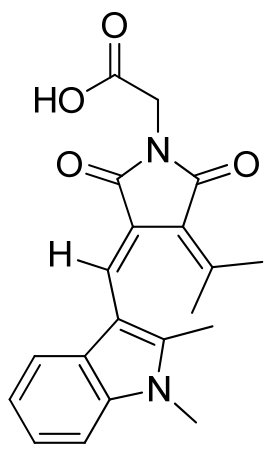

20E

Syntheses of the dicarboxylic acid indolylfulgimide 19 and the carboxylic acid indolylfulgimide 20 were then carried out as described above. The reaction of $10 \mathrm{C}$ to 19C occurred quantitatively and rapidly in buffer $(\mathrm{pH} 7.4)$ at $37^{\circ} \mathrm{C}$. Fulgimide $19 \mathrm{C}$ was relatively stable in acidic aqueous solution, but $\mathrm{CO}_{2}$ was lost during prolonged extraction with EtOAc. 


\subsubsection{UV-vis absorption spectra}

The UV-vis absorption spectra of $\mathbf{1 0 Z}$ and $\mathbf{1 0 C}$ were measured in toluene. The spectra of 10Z, 19Z, and 19C were obtained in $50 \mathrm{mM}$ sodium phosphate buffer $(\mathrm{pH} 7.4)$ (Figure 16). No UV-vis measurements for $\mathbf{1 0 C}$ in buffer and $\mathbf{1 9}$ in toluene were performed because of the instability of $\mathbf{1 0 C}$ in buffer (see above) and the poor solubility of 19 in toluene. The wavelengths of maximum absorbance and the extinction coefficients are shown in Table 1. Fulgimide $\mathbf{1 0 Z}$ showed a small bathochromic shift (4 $\mathrm{nm})$ as the solvent was switched from toluene to buffer. In comparison with $\mathbf{1 0 Z}, \mathbf{1 9 Z}$ in buffer demonstrated a $16 \mathrm{~nm}$ hypsochromic shift at its absorbance maxima.
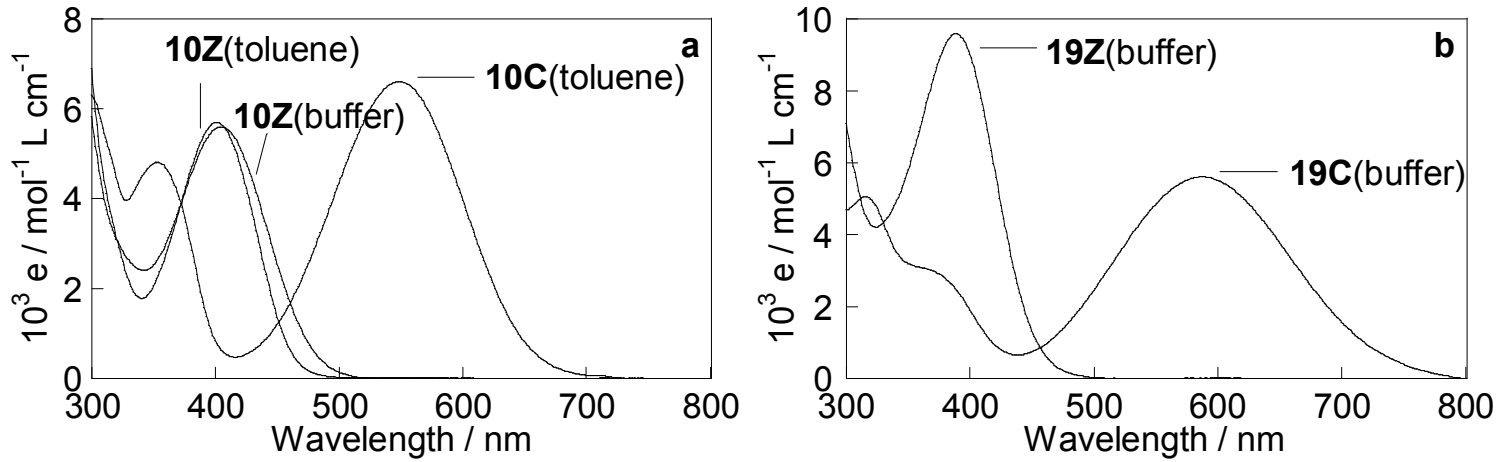

Figure 16. UV-vis absorption spectra of (a) $10 \mathrm{Z}$ and $10 \mathrm{C}$ in toluene and $10 \mathrm{Z}$ in $50 \mathrm{mM}$ sodium phosphate buffer ( $\mathrm{pH} 7.4$ ); (b) $\mathbf{1 9 Z}$ and 19C in $50 \mathrm{mM}$ sodium phosphate buffer $(\mathrm{pH} 7.4)$ 
Table 6. Extinction coefficients at $\lambda_{\max }$ for 10 in toluene and $50 \mathrm{mM}$ sodium phosphate buffer (pH 7.4) and for 19 in $50 \mathrm{mM}$ sodium phosphate buffer (pH 7.4)

\begin{tabular}{ccccc}
\hline \multicolumn{4}{c}{$\lambda_{\max }(\mathrm{nm})\left(\varepsilon_{\max }\left(\mathrm{mol}^{-1} \mathrm{~L} \mathrm{~cm}^{-1}\right)\right)$} \\
\hline Compd & Medium & Z-form & $C$-form & PSS $_{405 \mathrm{~nm}}{ }^{a}(C: Z: E)$ \\
$\mathbf{1 0}$ & Toluene & $401\left(5.7 \times 10^{3}\right)$ & $549\left(6.6 \times 10^{3}\right)$ & $90: 7: 3$ \\
$\mathbf{1 0}$ & Buffer & $405\left(5.6 \times 10^{3}\right)$ & Unstable $^{b}$ & Unstable $^{b}$ \\
$\mathbf{1 9}$ & Buffer & $389\left(9.6 \times 10^{3}\right)$ & $588\left(5.6 \times 10^{3}\right)$ & $87: 6: 6$
\end{tabular}

${ }^{\text {aphotostationary state (PSS): } C / Z / E \text {-ratio reached by prolonged exposure to } 405}$ nm light; evaluated by ${ }^{1} \mathrm{H}$ NMR spectroscopy.

${ }^{b}$ Hydrolysis of $10 C$ to $19 C$ was completed in $3 \mathrm{~h}$.

\subsubsection{Thermal stability}

Thermal stability is one of the most important characteristics of fulgides and fulgimides for their applications in optical memory devices or optical switches. ${ }^{49,52,71}$ Previously, the thermal stability of fulgides and fulgimides was examined in toluene at $80{ }^{\circ} \mathrm{C} .{ }^{40,41,64}$ Therefore, the thermal stability of $\mathbf{1 0 Z}$ and $\mathbf{1 0 C}$ was determined under these conditions. The stability of $\mathbf{1 0}$ and $\mathbf{1 9}$ at $37^{\circ} \mathrm{C}$ in sodium phosphate buffer (pH 7.4) was also examined as this mimics physiological conditions of humans to some extent. The thermal decomposition of $\mathbf{1 0}$ and $\mathbf{1 9}$ was followed by both ${ }^{1} \mathrm{H}$ NMR and UV-vis spectroscopy. The results are presented in Table 7.

In pure toluene at $80{ }^{\circ} \mathrm{C}$, the decomposition of $10 \mathrm{Z}$ was fit to a single exponential decay (Figure 17a). The decomposition rate constants were 0.023 and $0.010 \mathrm{~h}^{-1}$ by UVvis and ${ }^{1} \mathrm{H}$ NMR spectroscopy, respectively (Table 7). These values are similar to those observed for the parent fulgide $\mathbf{1 Z}\left(0.023 \mathrm{~h}^{-1}\right)$ and ethyl ester fulgimide $\mathbf{9 Z}\left(0.009 \mathrm{~h}^{-}\right.$ $\left.{ }^{1}\right) .{ }^{40,64}$ The UV-vis spectra also showed a similar pattern, an initial drop in absorbance 
followed by a red shift and subsequent increase in absorbance. ${ }^{40,50,64}$ Previous studies demonstrated that the thermal decomposition pathway for the $Z$-form of fluorinated indolylfulgides in toluene involves either a reversible $Z$-to- $E$-isomerization or the conversion of the $Z$-form to an intermediate via a 1,5-hydrogen shift from the isopropylidene group $^{50,52}$ The intermediate then subsequently rearranges to form a mixture of two isomers. On the basis of similar spectral kinetics, I postulate that fulgimide $10 \mathrm{Z}$ undergoes the same degradation pathway as fulgide $\mathbf{1 Z}$. Therefore, the offset observed in the UV-vis data in Figure 17a is because of the absorbance of the decomposition products at the $\lambda_{\max }$ of $\mathbf{1 0 Z} .^{50,52}$ In the case of fulgimide $10 \mathrm{C}$ in toluene at $80{ }^{\circ} \mathrm{C}$, a double exponential fit was applied since a relatively rapid decomposition of $3 \%$ was observed followed by a slow decomposition (Figure 17a). Fulgimide 10C showed much higher stability than $\mathbf{1 0 Z}$ in toluene, consistent with previously reported fulgides and fulgimides. ${ }^{40,41,51}$

Table 7. Thermal decomposition rate constants $\left(h^{-1}\right)$ for 10 in toluene, and 10 and 19 in $50 \mathrm{mM}$ sodium phosphate buffer (pH 7.4)

\begin{tabular}{|c|c|c|c|c|c|}
\hline \multirow[b]{3}{*}{ Compd } & \multirow[b]{3}{*}{ Medium } & \multicolumn{4}{|c|}{ Rate constants $\left(\mathrm{h}^{-1}\right)$} \\
\hline & & \multicolumn{2}{|c|}{ UV-vis ${ }^{\mathrm{a}}$} & \multicolumn{2}{|c|}{${ }^{1} \mathrm{H}$ NMR } \\
\hline & & $Z$-form & $C$-form & $Z$-form & $C$-form \\
\hline 10 & Toluene & 0.023 & $0.3 \times 10^{-4}$ & 0.010 & $0.5 \times 10^{-4}$ \\
\hline 10 & Buffer & $12 \times 10^{-4}$ & $\mathrm{~b}$ & $7 \times 10^{-4}$ & 0.7 \\
\hline 19 & Buffer & $0.9 \times 10^{-4}$ & $2.8 \times 10^{-4}$ & $2.4 \times 10^{-4}$ & $0.6 \times 10^{-4}$ \\
\hline
\end{tabular}



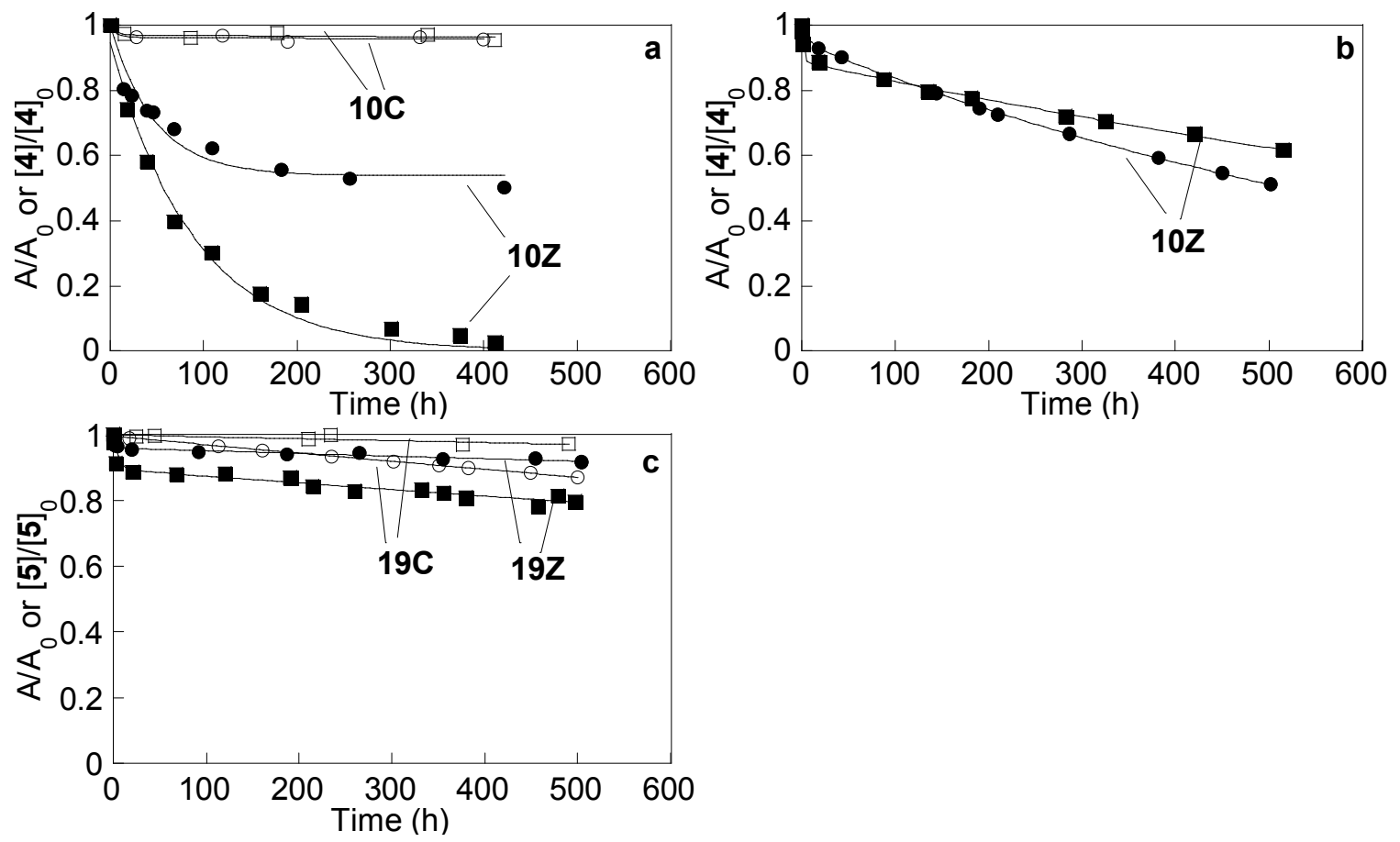

Figure 17. Thermal decomposition of $Z$-(closed symbols) and $C$-forms (open symbols) of 10 and 19 as a function of time as measured by UV-vis (circles) and ${ }^{1} \mathrm{H}$ NMR spectroscopy (squares): (a) $\mathbf{1 0}$ in toluene at $80{ }^{\circ} \mathrm{C}$, (b) $\mathbf{1 0}$ in $50 \mathrm{mM}$ sodium phosphate buffer (pH 7.4) at $37^{\circ} \mathrm{C}$ and (c) 19 in $50 \mathrm{mM}$ sodium phosphate buffer $(\mathrm{pH} 7.4)$ at $37^{\circ} \mathrm{C}$

In $50 \mathrm{mM}$ sodium phosphate buffer $(\mathrm{pH} 7.4)$ at $37^{\circ} \mathrm{C}$, single and double exponential fits were applied to the $C$ - and $Z$-forms, respectively. Compound $10 Z$ and $19 Z$ showed a relatively rapid decline in concentration, which corresponded to $Z$-to- $E$-isomerization, followed by a slower decline which corresponds to decomposition (Figures 17b, 17c). According to ${ }^{1} \mathrm{H}$ NMR data, $\mathbf{1 9 Z}$ decomposed three times slower than $\mathbf{1 0 Z}$ in buffer. Fulgimide $10 \mathrm{C}$ is unstable and completely converted to $19 \mathrm{C}$ in buffer after $3-6 \mathrm{~h}$ at $37{ }^{\circ} \mathrm{C}$. Compound 19C showed great thermal durability and very little decomposition was observed after prolonged time in buffer at $37^{\circ} \mathrm{C}$. To account for the difference between the UV-vis and NMR data for 19C in buffer, the decomposition of 19C by UV-vis 
spectroscopy in both $\mathrm{D}_{2} \mathrm{O}$ and $\mathrm{H}_{2} \mathrm{O}$ buffers were measured and determined a solvent isotope effect of 3-4.

\subsubsection{Photochemical stability}

The repeatability of the photochemical opening and closing of fulgimides $\mathbf{1 0}$ and $\mathbf{1 9}$ was measured in toluene and $50 \mathrm{mM}$ sodium phosphate buffer ( $\mathrm{pH} 7.4$ ), respectively. Photochemical stability is required for many applications. ${ }^{49}$ In toluene, the most stable fulgide reported to date can be switched back and forth over 10,000 times before degrading by $13 \%^{52}$ although for most fulgides the number is less. ${ }^{51,64}$ In the case of fluorinated indolylfulgimides, a previous study indicated that they can be cycled back and forth between 700 and 3,000 times in toluene before degrading by $20 \%{ }^{40,41}$
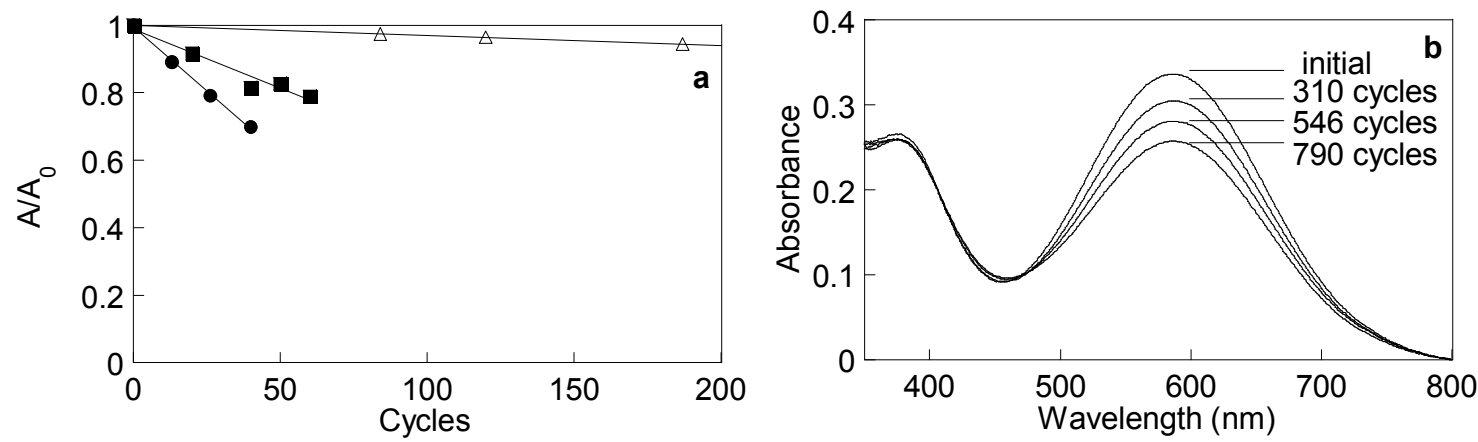

Figure 18. (a) Photochemical decomposition of $\mathbf{1 0}$ (closed symbols) in pure toluene (circles) and in toluene in the presence of tributylamine (squares) and 19 (open symbols; triangles) in $50 \mathrm{mM}$ sodium phosphate buffer (pH 7.4). (b) PSS spectra of 19 in $50 \mathrm{mM}$ sodium phosphate buffer ( $\mathrm{pH} 7.4)$ after the indicated number of cycles

In protic solvent systems, such as methanol, ethanol/water, or water, fulgides are too unstable and/or insoluble to measure their photochemical stability. ${ }^{7}$ On the other hand, fulgimides previously examined in protic solvents only cycled back and forth a limited number of times. ${ }^{6,41,71}$ A recent study in our group reported that the ethyl ester 
indolylfulgimide 9 can be cycled back and forth 360 times before degrading by $20 \%$ in $70 / 30$ ethanol/water. ${ }^{40}$ Several reports about applications of fulgimides in aqueous biological systems have demonstrated that fulgimides can be cycled back and forth several times. ${ }^{6,70}$

The photochemical stability of fulgimide $\mathbf{1 0}$ was initially measured in pure toluene where it degraded by $20 \%$ after being cycle back and forth 21 times (Figure 18a), much

less stable than its ethyl ester analog $9 .^{40}$ I speculate that the rapid photochemical decomposition was affected by the carboxylic acid group and that the addition of base would increase the stability. In the presence of tributylamine $(27 \mathrm{mM})$ in toluene, 10 cycled back and forth 55 times before degrading by $20 \%$ (Figure 18a). The cycling times were approximately $35 \mathrm{~s}$ ( $Z$ - to $C$-form) and $20 \mathrm{~s}$ ( $C$ - to $Z$-form) in both cases, suggesting that the addition of tributylamine slowed down the photochemical decomposition but not the photochemical reaction. Addition of acetic acid $(27 \mathrm{mM})$ did not affect photochemical stability. The photochemical stability of $\mathbf{1 0}$ was not measured in buffer because of the instability of 10C. Fulgimide 19 cycled back and forth 670 times before degrading by $20 \%$ in buffer (Figure 18) with cycling times of $80 \mathrm{~s}$ (Z- to $C$-form) and 600 s (C- to $Z$-form). The increased photochemical stability of $\mathbf{1 9}$ makes it promising for applications in aqueous solution.

\subsection{Conclusion}

In summary, I have synthesized three novel aqueous soluble indolylfulgimides, 10, 19, and 20. Hydrolysis of the trifluoromethyl group of $10 \mathrm{C}$ was observed in a fluorinated indolylfulgimide for the first time. Hydrolysis of $10 \mathrm{C}$ resulted in $19 \mathrm{C}$ which was further decarboxylated to $20 \mathrm{C}$ upon extraction. 20C lacked any photochromic properties. The 
absorbance maxima of $\mathbf{1 0 Z}$ varied only slightly between toluene and buffer. A notable blue shift in the absorbance maxima of $19 \mathrm{Z}$ compared to $10 \mathrm{Z}$ was observed in buffer because of the additional carboxylic acid group on the bridging carbon. Fulgimide 19 displayed great thermal and photochemical stabilities in sodium phosphate buffer $(\mathrm{pH}$ 7.4). $19 \mathrm{Z}$ and $19 \mathrm{C}$ degraded less than $20 \%$ after $500 \mathrm{~h}$ at $37^{\circ} \mathrm{C}$, and 19 underwent 670 photochemical cycles before degrading by $20 \%$. Fulgimide 19 is the most robust fulgimide yet reported in aqueous solution. 


\section{CHAPTER 6}

\section{SYNTHESIS OF METHYL CARBOXYLIC ACID INDOLYLFULGIMIDE}

\subsection{Abstract}

A novel aqueous soluble methyl carboxylic acid indolylfulgimide 11 was synthesized from methyl indolylfulgide 2 . The indolylfulgide $\mathbf{2}$ was prepared in five steps with an overall yield of $21 \%$. The indolylfulgimide 11 was synthesized by treating fulgide 2 with glycine methyl ester, and dehydration of the resulting amide acid. The methyl carboxylic acid indolylfulgimide 11 was expected to have improved thermal and photochemical stabilities in aqueous solutions relative to the trifluoromethyl analog 10. Previous study indicated that the trifluoromethyl analog $\mathbf{1 0}$ underwent a rapid hydrolysis in sodium phosphate buffer $(\mathrm{pH} 7.4)$ at $37^{\circ} \mathrm{C}$. Therefore, replacing the trifluoromethyl group with methyl group should prohibit the hydrolysis and subsequently improve the stability in aqueous solutions.

\subsection{Introduction}

The fulgide and fulgimide family is an important class of organic photochromic compounds. The ability of fulgides and fulgimides to interconvert between two key forms by irradiation with different wavelength has made them promising material for use in optical memory devices, optical switches, and sensors (Scheme 1). ${ }^{15}$ Among fulgide derivatives, fulgimides are the most important and practical because another substituent can be attached onto the succinimide ring without a significant change of photochromic properties. ${ }^{15}$ Although fulgides display promising photochromic properties, the succinic anhydride ring causes rapid solvolytic degradation in protic solvents or aqueous media. $^{59,71}$ Fulgimides improve the hydrolytic stability of fulgides by replacing the 
succinic anhydride ring with a succinimide ring and retain the promising photochromic properties. Hydrolytic stability is crucial for applications in biological systems and humid environments.

\section{Scheme 27. Hydrolysis and subsequent decarboxylation of fulgimide 10}

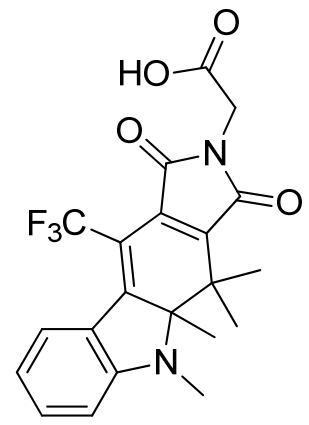

10C

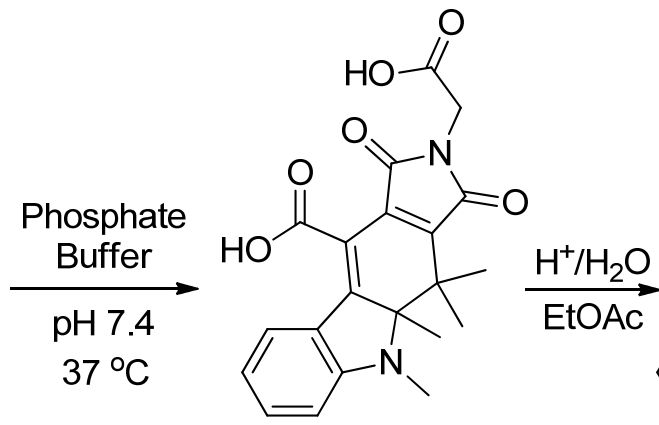

19C

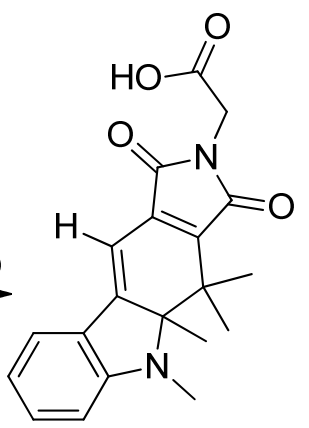

20C

In my previous study, the stability of fulgimides in aqueous solutions was reported. ${ }^{44}$ The stability of a trifluoromethyl carboxylic acid indolylfulgimide $\mathbf{1 0}$ was characterized in sodium phosphate buffer ( $\mathrm{pH}$ 7.4). The $C$-form displayed rapid decomposition in phosphate buffer at $37{ }^{\circ} \mathrm{C}$ (Scheme 27). The thermal decomposition product was isolated and indicated that the trifluoromethyl group of the $C$-form was hydrolyzed to a carboxylic acid group. The resulting dicarboxylic acid indolylfulgimide $\mathbf{1 9}$ showed great thermal and photochemical stabilities in sodium phosphate buffer $(\mathrm{pH} 7.4)$ and is the most robust fulgimide yet reported in aqueous solution. ${ }^{44}$ However, the carboxylic acid group on the bridging position of fulgimide 19 can further decarboxylate. The resulting H-carboxylic acid indolylfulgimide $\mathbf{2 0}$ did not display photochromic properties (Scheme 27).

Herein, the hydrolytic unstable trifluoromethyl group was replaced with a methyl group at the bridging position. The methyl analog $\mathbf{1 1}$ should not undergo hydrolysis in 
phosphate buffer at $\mathrm{pH} 7.4$ (Scheme 28). The methyl fulgimide 11 is expected to have improved thermal and photochemical stabilities relative to the trifluoromethyl fulgimide 10 in aqueous solutions. Currently, the photochromic properties of the methyl fulgimide are under investigation by Dr. Islamova.

Scheme 28. Proposed stability of fulgimide 11 in phosphate buffer at pH 7.4<smiles>CC(C)=C1C(=O)C(C)=C2C(=O)N(CC(=O)O)C(=O)/C2=C(/C)C2c3ccccc3N(C)C(C)C12</smiles>

\subsection{Experimental Section}

\subsubsection{General procedures and materials}

All commercially available materials were used without further purification. The NMR spectra were recorded on a Brüker $400 \mathrm{MHz}$ NMR spectrometer. The ${ }^{1} \mathrm{H}$ and ${ }^{13} \mathrm{C}$ NMR samples were internally referenced to TMS $(0.00 \mathrm{ppm})$ or solvent $(7.26$ and 77.00 ppm, respectively for chloroform). Flash chromatography was performed with 230-400 mesh silica gel.

\subsubsection{Synthesis of 3-acetyl-1,2-dimethylindole 21}

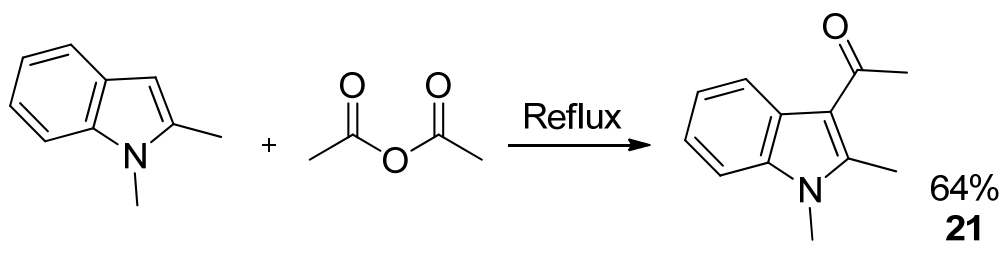


The 1,2-dimethylindole ( $5 \mathrm{~g}, 34.5 \mathrm{mmol}$ ) was dissolved in $98 \mathrm{~mL}$ of acetic anhydride $(106 \mathrm{~g}, 1.04 \mathrm{~mol})$ at room temperature and reflux for $12 \mathrm{~h}$ under argon gas. The reaction mixture was concentrated in vacuo to yield a brown oil. The brown residue was further purified via silica gel chromatography (3:1 hexanes/EtOAc). Recrystallization from isopropanol provided $4.1 \mathrm{~g}(64 \%)$ of 3-acetyl-1,2-dimethylindole 21.

\subsubsection{Synthesis of cis/trans indole lactones 22}

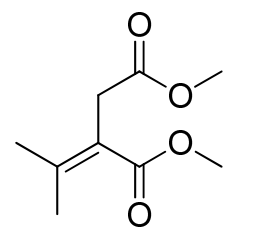

15

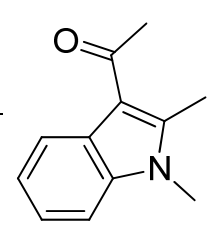

21

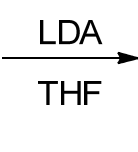

Cis

22

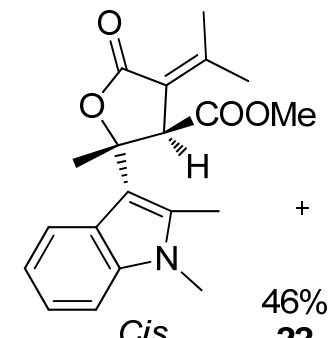

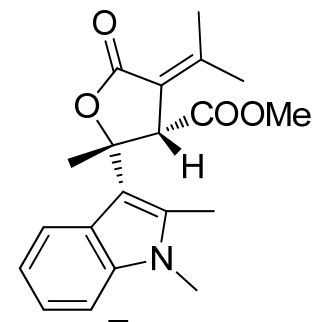

Trans

Dimethyl isopropylidenesuccinate 15 (previously synthesized, $41.0 \mathrm{~g}, 0.19 \mathrm{~mol}$ ) was dissolved in $200 \mathrm{~mL}$ of dry $\mathrm{THF}$ and cooled to $-78{ }^{\circ} \mathrm{C}$ under argon gas. Lithium diisopropylamide (LDA) was added dropwise via an addition funnel to the solution and allowed to react for $30 \mathrm{~min}$ at $-78{ }^{\circ} \mathrm{C}$ under argon gas. To a solution of 3-acetyl-1,2dimethylindole $21(7.0 \mathrm{~g}, 38 \mathrm{mmol})$ in $200 \mathrm{~mL}$ of $\mathrm{THF}$ at $0{ }^{\circ} \mathrm{C}$, the lithium diisopropylamide/dimethyl isopropylidenesuccinate/THF solution was added dropwise via cannula under argon gas. The mixture was warmed to room temperature and stirred for $2 \mathrm{~d}$. The solvent was then concentrated in vacuo. The residue was quenched with 500 $\mathrm{mL}$ of water, acidified with $5 \% \mathrm{H}_{2} \mathrm{SO}_{4}$ solution to $\mathrm{pH} 1$, and extracted with diethyl ether $(3 \times 200 \mathrm{~mL})$. The combined organic layers were washed with brine $(2 \times 100 \mathrm{~mL})$, dried over $\mathrm{MgSO}_{4}$, filtered, and concentrated in vacuo. Purification was performed via silica gel chromatography (1:2 hexanes/ether) and provided $4.63 \mathrm{~g} \mathrm{(42 \% )}$ of a cis/trans mixture of indolelactones $\mathbf{2 2}$ in a 1:2 ratio. The cis/trans mixture was further separated via silica 
gel chromatography (4:1 hexanes/EtOAc) and recrystallized from ethanol. transIndolelactone: ${ }^{1} \mathrm{H} \mathrm{NMR}\left(\mathrm{CDCl}_{3}, 400 \mathrm{MHz}\right) \delta 7.81(\mathrm{~s}, 1 \mathrm{H}), 7.27-7.29(\mathrm{~m}, 1 \mathrm{H}), 7.20(\mathrm{td}, J$ $=7.0,1.1 \mathrm{~Hz}, 1 \mathrm{H}), 7.15(\mathrm{td}, J=7.4,1.5 \mathrm{~Hz}, 1 \mathrm{H}), 4.47(\mathrm{~s}, 1 \mathrm{H}), 3.85(\mathrm{~s}, 3 \mathrm{H}), 3.63(\mathrm{~s}, 3 \mathrm{H})$, $2.56(\mathrm{~s}, 3 \mathrm{H}), 2.25$ (s, 3H), $1.80(\mathrm{~s}, 3 \mathrm{H}), 1.70(\mathrm{~s}, 3 \mathrm{H}) ;{ }^{13} \mathrm{C} \mathrm{NMR}\left(\mathrm{CDCl}_{3}, 100 \mathrm{MHz}\right) \delta$ $171.3,168.8,154.0,136.8,132.9,124.8,121.1,120.7,119.7,118.9,114.7,109.0,82.8$, $56.7,52.2,29.2,25.3,24.3,20.3,11.5$. cis-Indolelactone as a mixture of atropisomers, approximately 2:1 ratio: ${ }^{1} \mathrm{H} \mathrm{NMR}\left(\mathrm{CDCl}_{3}, 400 \mathrm{MHz}\right) \delta 8.14(\mathrm{~d}, J=7.8 \mathrm{~Hz}, 0.3 \mathrm{H}), 7.52(\mathrm{~d}$, $J=7.8 \mathrm{~Hz}, 0.7 \mathrm{H}), 7.17-7.23(\mathrm{~m}, 1 \mathrm{H}), 7.13(\mathrm{t}, J=7.8 \mathrm{~Hz}, 1 \mathrm{H}), 7.06(\mathrm{t}, J=7.1 \mathrm{~Hz}, 1 \mathrm{H})$, $4.27(\mathrm{~s}, 0.7 \mathrm{H}), 4.11(\mathrm{~s}, 0.3 \mathrm{H}), 3.63(\mathrm{~s}, 3 \mathrm{H}), 3.01$ (s, 2H), 2.87 (s, 1H), $2.58(\mathrm{~s}, 2 \mathrm{H}), 2.43$ (s, 1H), 2.37 (s, 3H), 1.96 (s, 3H), 1.88 (s, 2H), 1.78 (s, 1H); ${ }^{13} \mathrm{C}$ NMR $\left(\mathrm{CDCl}_{3}, 100 \mathrm{MHz}\right) \delta$ $170.5,170.4,168.3,168.0,154.0,153.2,136.8,136.2,134.0,131.2,125.9,124.5,122.3$, $120.9,120.7,120.6,120.5,119.7,119.4,118.9,111.5,109.8,108.8,108.1,84.2,83.4$, $58.6,57.7,51.4,51.2,30.1,30.0,29.4,29.3,24.3,20.4,20.3,12.7,11.8$.

\subsubsection{Synthesis of methyl indolylfulgide 2}
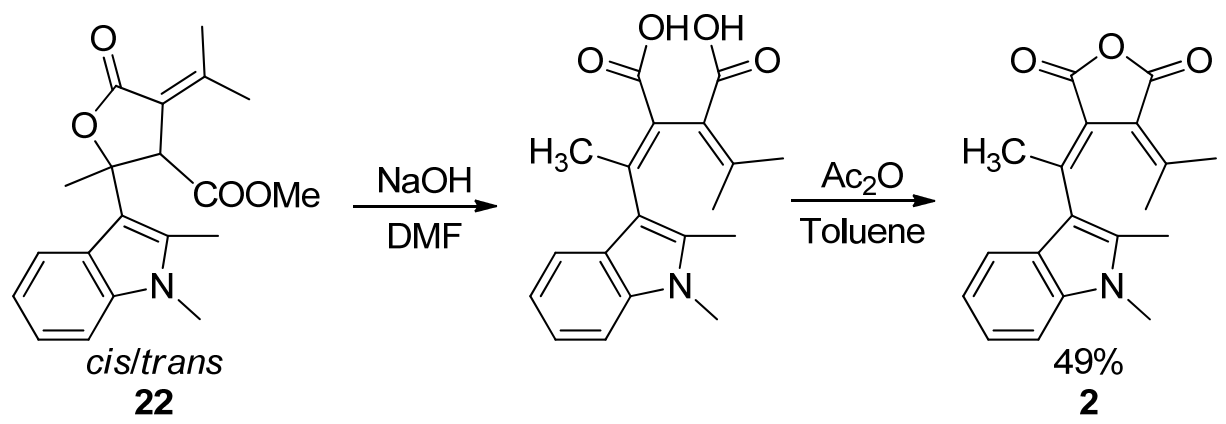

Sodium hydride ( $60 \%$ dispersion in oil, $0.17 \mathrm{~g}, 0.70 \mathrm{mmol}$ ) was added to cis/trans indolelactones $22(1.0 \mathrm{~g}, 2.90 \mathrm{mmol})$ in $100 \mathrm{~mL}$ of $N, N$-dimethylformamide at $0{ }^{\circ} \mathrm{C}$. The mixture was warmed to room temperature and stirred for $1 \mathrm{~h}$. The reaction mixture was recooled to $0{ }^{\circ} \mathrm{C}$, and $1.05 \mathrm{~mL}$ of $\mathrm{H}_{2} \mathrm{O}$ was added. Hydrogen gas evolved, and the 
reaction was stirred overnight. The mixture was concentrated in vacuo and the resulting white solid was then dissolved in $100 \mathrm{~mL}$ of water and extracted with diethyl ether $(3 \times$ $100 \mathrm{~mL}$ ). The aqueous layer was acidified with concentrated $\mathrm{HCl}$ to $\mathrm{pH} 2$ and extracted with diethyl ether $(3 \times 100 \mathrm{~mL})$. The combined organic layers were dried over $\mathrm{MgSO}_{4}$, filtered, and concentrated in vacuo. The resulting crude diacid was suspended in $15 \mathrm{~mL}$ of Tol. Acetic anhydride $(15 \mathrm{~mL}, 0.16 \mathrm{~mol})$ was added, and the reaction mixture was refluxed for $2 \mathrm{~h}$ under argon gas. The solution was then concentrated in vacuo. The residue was quenched in $100 \mathrm{~mL}$ of water and extracted with $\mathrm{CH}_{2} \mathrm{Cl}_{2}(3 \times 30 \mathrm{~mL})$. The combined organic layers were dried over $\mathrm{MgSO}_{4}$, filtered, and concentrated in vacuo. Purification was performed via silica gel chromatography with $\mathrm{CH}_{2} \mathrm{Cl}_{2}$. Recrystallization from $\mathrm{CH}_{2} \mathrm{Cl}_{2} /$ isopropanol provided $0.23 \mathrm{~g}(49 \%)$ of methyl indolylfulgide 2. $E$-form: ${ }^{1} \mathrm{H}$ $\operatorname{NMR}\left(\mathrm{CDCl}_{3}, 400 \mathrm{MHz}\right) \delta 7.40(\mathrm{~d}, J=7.9 \mathrm{~Hz}, 1 \mathrm{H}), 7.30(\mathrm{~d}, J=8.7 \mathrm{~Hz}, 1 \mathrm{H}), 7.24-7.26$ (m, 1H), $7.15(\mathrm{td}, J=7.3,1.1 \mathrm{~Hz}, 1 \mathrm{H}), 3.69(\mathrm{~s}, 3 \mathrm{H}), 2.81(\mathrm{~s}, 3 \mathrm{H}), 2.20(\mathrm{~s}, 3 \mathrm{H}), 1.55(\mathrm{~s}$, 3H), $0.94(\mathrm{~s}, 3 \mathrm{H}) ;{ }^{13} \mathrm{C} \mathrm{NMR}\left(\mathrm{CDCl}_{3}, 100 \mathrm{MHz}\right) \delta 164.1,163.8,153.1,149.5,137.1$, 135.2, 125.0, 122.1, 121.6, 120.8, 119.6, 119.1, 116.7, 109.2, 29.9, 26.2, 24.7, 23.7, 12.2.

\subsubsection{Synthesis of amide acid ester 23}
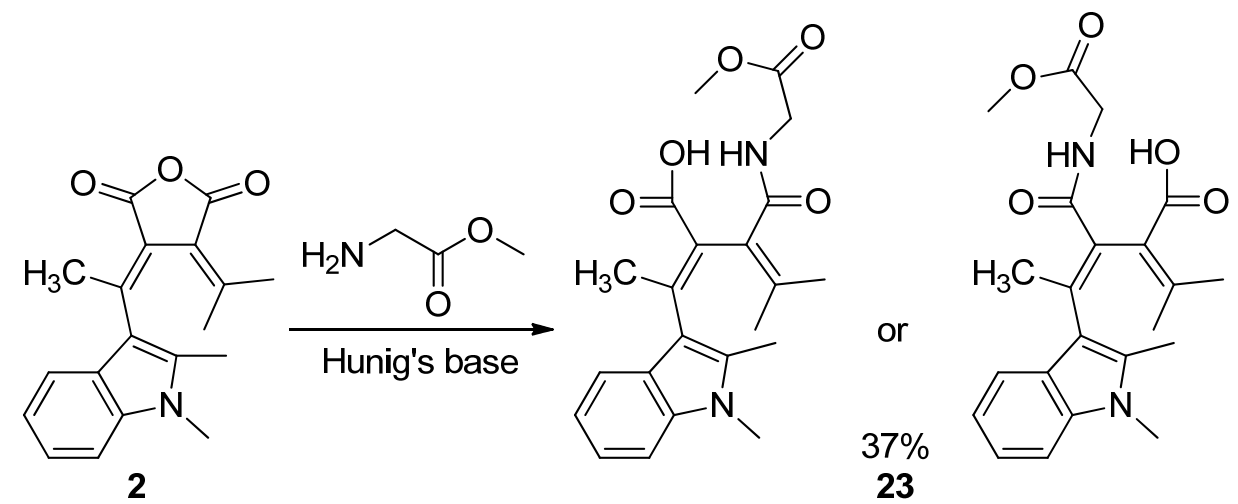

23

$N, N$-Diisopropylethylamine $(0.64 \mathrm{~g}, 4.97 \mathrm{mmol})$ was added dropwise to a mixture of 
the $\mathrm{HCl}$ salt of glycine methyl ester $(0.23 \mathrm{~g}, 25.8 \mathrm{mmol})$ and methyl indolylfulgide 2 $(0.22 \mathrm{~g}, 0.71 \mathrm{mmol})$ in $50 \mathrm{~mL}$ of acetonitrile at room temperature. The reaction mixture was allowed to stir overnight and then concentrated in vacuo. The residue was quenched with $50 \mathrm{~mL}$ of water and extracted with EtOAc $(3 \times 35 \mathrm{~mL})$. The aqueous layer was acidified with $0.5 \mathrm{M} \mathrm{HCl}$ to $\mathrm{pH} 1$ and extracted with EtOAc $(3 \times 35 \mathrm{~mL})$. The combined organic layers were dried over $\mathrm{MgSO}_{4}$, filtered, and concentrated in vacuo. Trituration with $\mathrm{CHCl}_{3}$ provided $0.11 \mathrm{~g}(39 \%)$ of the amide acid ester $23 .{ }^{1} \mathrm{H}$ NMR $\left(\mathrm{CD}_{3} \mathrm{OD}, 400\right.$ MHz) $\delta 7.34(\mathrm{~d}, J=7.9 \mathrm{~Hz}, 1 \mathrm{H}), 7.24(\mathrm{~d}, J=8.1 \mathrm{~Hz}, 1 \mathrm{H}), 7.06(\mathrm{td}, J=7.5,1.0 \mathrm{~Hz}, 1 \mathrm{H})$, $6.95(\mathrm{td}, J=7.5,0.7 \mathrm{~Hz}, 1 \mathrm{H}), 4.09(\mathrm{~d}, J=17.5 \mathrm{~Hz}, 1 \mathrm{H}), 4.01(\mathrm{~d}, J=17.6 \mathrm{~Hz}, 1 \mathrm{H}), 3.75$ (s, 3H), $3.63(\mathrm{~s}, 3 \mathrm{H}), 2.33(\mathrm{~s}, 3 \mathrm{H}), 2.16(\mathrm{~s}, 3 \mathrm{H}), 1.87(\mathrm{~s}, 3 \mathrm{H}), 1.85(\mathrm{~s}, 3 \mathrm{H}) ;{ }^{13} \mathrm{C}$ NMR $\left(\mathrm{CD}_{3} \mathrm{OD}, 100 \mathrm{MHz}\right) \delta 172.9,171.9,171.1,149.1,143.1,138.5,135.4,133.8,128.4$, $127.5,121.7,120.1,120.1,114.9,109.8,52.6,42.2,29.7,24.3,22.5,22.3,11.4$.

\subsubsection{Synthesis of amide diacid 24}

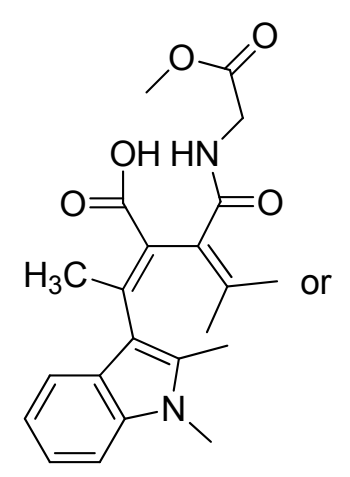

23

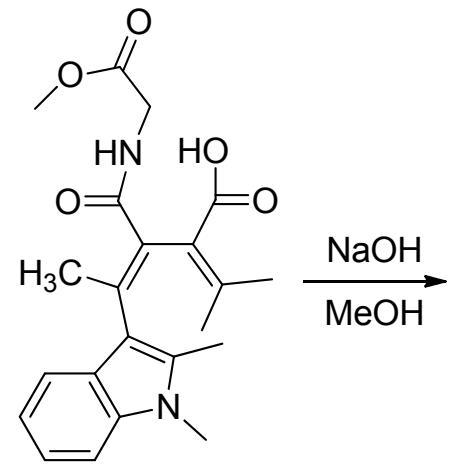

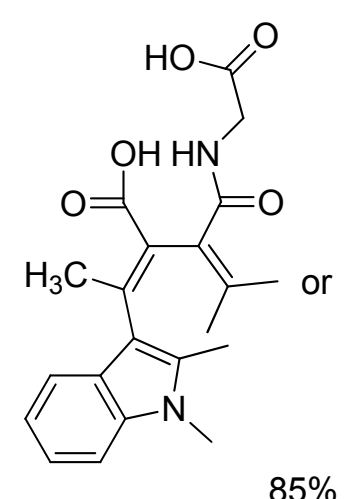

24

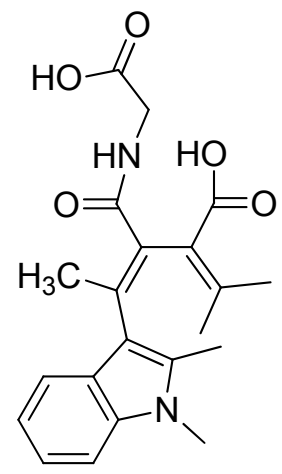

Sodium hydroxide $(0.1 \mathrm{~g}, 2.64 \mathrm{mmol})$ was added to the amide acid ester $23(0.11 \mathrm{~g}$, $0.28 \mathrm{mmol}$ ) in $100 \mathrm{~mL}$ of methanol and stirred at room temperature overnight. The solution was concentrated in vacuo. The resulting white precipitate was quenched with 25 $\mathrm{mL}$ of $\mathrm{Na}_{2} \mathrm{CO}_{3}(0.19 \mathrm{M})$ and extracted with EtOAc $(2 \times 25 \mathrm{~mL})$. The aqueous layer was 
acidified with concentrated $\mathrm{HCl}$ to $\mathrm{pH} 1$ and extracted with EtOAc $(3 \times 25 \mathrm{~mL})$. The combined organic layers were dried over $\mathrm{MgSO}_{4}$, filtered, and concentrated in vacuo. A trituration was performed using chloroform to yield $0.09 \mathrm{~g}(85 \%)$ of amide diacid $\mathbf{2 4} .{ }^{1} \mathrm{H}$ NMR $\left(\mathrm{CD}_{3} \mathrm{OD}, 400 \mathrm{MHz}\right) \delta 7.34(\mathrm{~d}, J=7.8 \mathrm{~Hz}, 1 \mathrm{H}), 7.24(\mathrm{~d}, J=8.0 \mathrm{~Hz}, 1 \mathrm{H}), 7.06$ (td, $J$ $=7.6,1.0 \mathrm{~Hz}, 1 \mathrm{H}), 6.95(\mathrm{td}, J=7.4,1.0 \mathrm{~Hz}, 1 \mathrm{H}), 4.06(\mathrm{~d}, J=17.6 \mathrm{~Hz}, 1 \mathrm{H}), 4.00(\mathrm{~d}, J=$ $17.8 \mathrm{~Hz}, 1 \mathrm{H}), 3.62$ (s, 3H), 2.33 (s, 3H), 2.15 (s, 3H), $1.86(\mathrm{~s}, 3 \mathrm{H}), 1.84(\mathrm{~s}, 3 \mathrm{H}) ;{ }^{13} \mathrm{C} \mathrm{NMR}$ $\left(\mathrm{CD}_{3} \mathrm{OD}, 100 \mathrm{MHz}\right) \delta 173.0,172.8,171.1,149.0,142.9,138.5,135.3,133.9,128.4$ $127.5,121.7,120.1,120.0,114.8,109.8,42.2,29.7,24.2,22.5,22.3,11.4$.

\subsubsection{Synthesis of methyl carboxylic acid indolylfulgimide 11}

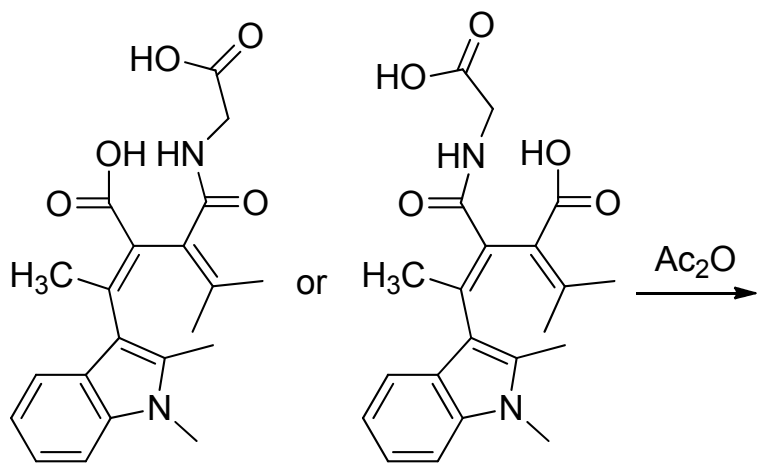

24

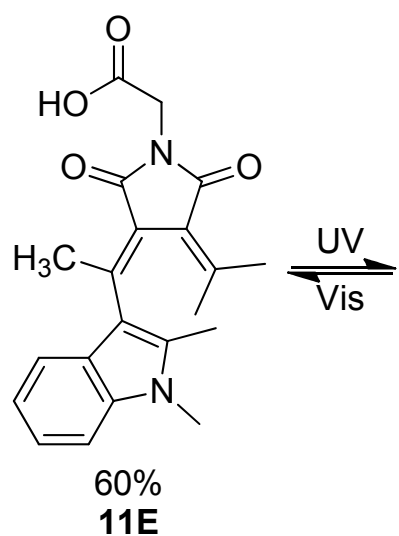

$11 \mathrm{E}$

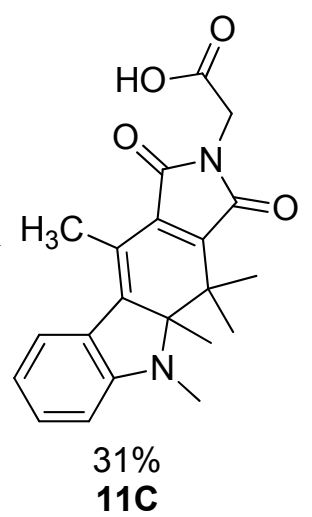

Acetic anhydride $(15 \mathrm{~mL})$ was added to the amide diacid $24(0.07 \mathrm{~g}, 0.18 \mathrm{mmol})$ in $15 \mathrm{~mL}$ of toluene at $0{ }^{\circ} \mathrm{C}$. The reaction mixture was allowed to stir at $0{ }^{\circ} \mathrm{C}$ for $2 \mathrm{~h}$ and then warmed to room temperature. The reaction mixture was dissolved in $25 \mathrm{~mL}$ of EtOAc and extracted with saturated $\mathrm{NaHCO}_{3}(3 \times 20 \mathrm{~mL})$ and $\mathrm{H}_{2} \mathrm{O}(2 \times 20 \mathrm{~mL})$. The organic layer was dried over $\mathrm{MgSO}_{4}$, filtered, and concentrated in vacuo. The residue was purified by silica gel chromatography (70:30:1 EtOAclhexanes $\backslash A c O H)$ and provided 40 mg $(60 \%)$ of $E$-form methyl carboxylic acid indolylfulgimide. Compound 11E was 
illuminated with $365 \mathrm{~nm}$ light in toluene and purified by silica gel chromatography (70:30:0.5 EtOAclhexanes $\backslash \mathrm{AcOH}$ ). Recrystallization from $\mathrm{CH}_{2} \mathrm{Cl}_{2}$ /hexanes provided 21 mg (31\%) of $C$-form methyl carboxylic acid indolylfulgimide 11. $C$-form: ${ }^{1} \mathrm{H}$ NMR $\left(\mathrm{CDCl}_{3}, 400 \mathrm{MHz}\right) \delta 7.57(\mathrm{~d}, J=7.6 \mathrm{~Hz}, 1 \mathrm{H}), 7.22(\mathrm{td}, J=7.6,1.0 \mathrm{~Hz}, 1 \mathrm{H}), 6.73(\mathrm{td}, J=$ 7.4, $1.1 \mathrm{~Hz}, 1 \mathrm{H}), 6.54$ (d, J=8.1 Hz, 1H), 4.28 (s, 2H), 2.89 (s, 3H), 2.41 (s, 3H), 1.76 (s, 3H), 1.28 (s, 3H), $1.18(\mathrm{~s}, 3 \mathrm{H}) ;{ }^{13} \mathrm{C} \mathrm{NMR}\left(\mathrm{CDCl}_{3}, 100 \mathrm{MHz}\right) \delta 171.5,169.3,168.7,157.3$, $150.7,138.6,136.3,131.7,126.0,124.5,118.0,115.0,108.1,72.5,40.0,38.1,31.8,19.9$, 19.0, 15.5, 13.7. E-form: ${ }^{1} \mathrm{H} \mathrm{NMR}\left(\mathrm{CDCl}_{3}, 400 \mathrm{MHz}\right) \delta 7.44(\mathrm{~d}, J=7.7 \mathrm{~Hz}, 1 \mathrm{H}), 7.28(\mathrm{~d}$, $J=5.1 \mathrm{~Hz}, 1 \mathrm{H}), 7.21(\mathrm{td}, J=7.0,1.0 \mathrm{~Hz}, 1 \mathrm{H}), 7.13(\mathrm{td}, J=7.4,1.0 \mathrm{~Hz}, 1 \mathrm{H}), 4.48(\mathrm{~d}, J=$ 17.2 Hz, 1H), 4.43 (d, $J=17.3 \mathrm{~Hz}, 1 \mathrm{H}), 3.67$ (s, 3H), 2.80 (s, 3H), 2.18 (s, 3H), 2.15 (s, 3H), 0.93 (s, 3H); ${ }^{13} \mathrm{C} \mathrm{NMR}\left(\mathrm{CDCl}_{3}, 100 \mathrm{MHz}\right) \delta 168.2,167.9,149.0,145.2,137.1$, $134.4,125.5,123.6,122.5,121.6,120.4,119.7,117.1,109.0,38.3,29.8,26.3,22.9,22.2$, 12.0.

\subsection{Results and Discussion}

\subsubsection{Synthesis of methyl indolylfulgide 2}

Methyl carboxylic acid indolylfulgimide $\mathbf{1 1}$ was synthesized from the precursor indolylfulgide 2. A previous study demonstrated an improved synthetic route to trifluoromethyl indolylfulgide 1 which involved five steps. ${ }^{60}$. Herein, the five step sequence with several modifications was followed to synthesize methyl indolylfulgide $\mathbf{2}$ (Scheme 29). The 1,2-Dimethyl-3-acetylindole 21 was prepared by refluxing 1,2dimethylindole in acetic anhydride. A Stobbe condensation combined the dimethyl isopropylidenesuccinate $\mathbf{1 5}$ and 1,2-dimethyl-3-acetylindole $\mathbf{2 1}$. The resulting cis/trans indolelactone 22 was treated with sodium hydroxide in DMF and yielded the dicarboxylic 
acid. The methyl indolylfulgide 2 was afforded in $21 \%$ overall yield from 1,2-Dimethyl3-acetylindole 21 by treating the dicarboxylic acid with acetic anhydride in toluene.

Scheme 29. Synthesis of methyl indolylfulgide 2

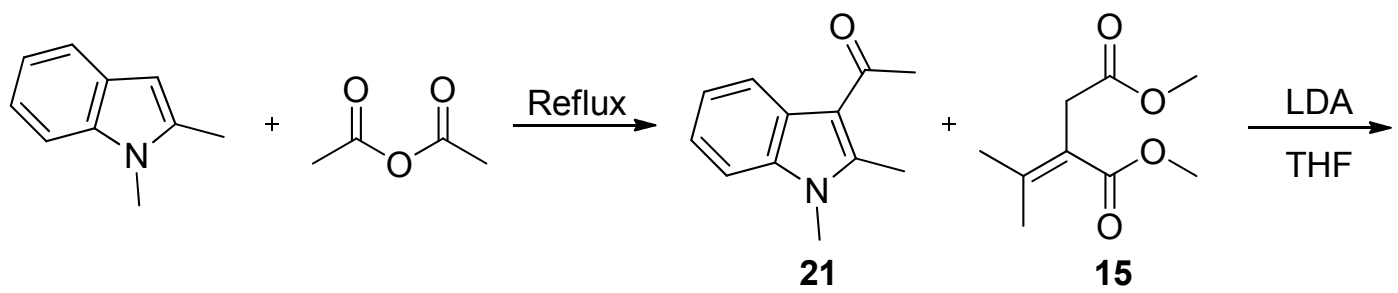

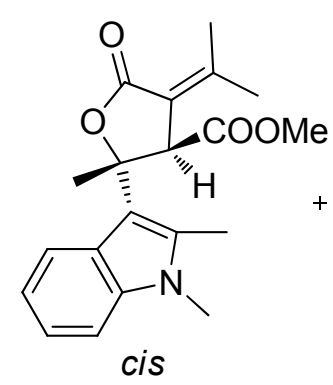

22

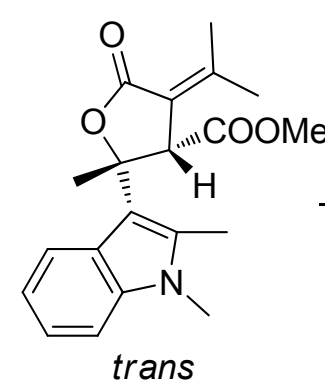

trans

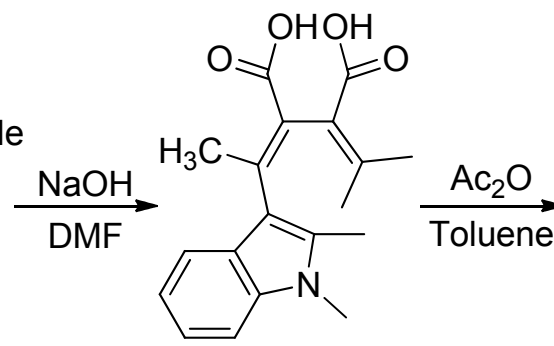

$\underset{\mathrm{DMF}}{\stackrel{\mathrm{NaOH}}{\longrightarrow}}$<smiles>CC(C)=C1C(=O)OC(=O)C1=C(C)c1c(C)n(C)c2ccccc12</smiles>

$21 \%$ from 21

2

\subsubsection{Synthesis of methyl carboxylic acid indolylfulgimide 11}

Methyl indolylfulgide 2 was used as the starting material for the synthesis of carboxylic acid indolylfulgimide 11 (Scheme 30). The anhydride ring of 2 was opened via addition of glycine methyl ester. The resulting methyl ester succinamic acid, one of two possible regioisomers,${ }^{93}$ was saponified to generate the corresponding carboxylic acid succinamic acid. Subsequent dehydration of the succinamic acid intermediate with acetyl chloride yielded carboxylic acid indolylfulgimide 11E. Fulgimide 11C was obtained by irradiating 11E with $365 \mathrm{~nm}$ light and 31\% yield from fulgide 2 (Scheme 30).

\section{Scheme 30. Synthesis of methyl carboxylic indolylfulgimide 11}




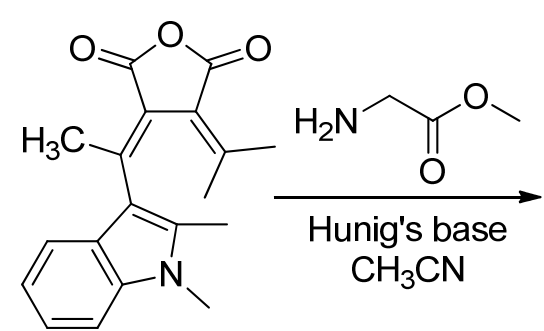

2<smiles>CC(C)=C(C(=O)NCC(=O)O)C(C(=O)O)=C(C)c1c(C)n(C)c2ccccc12</smiles>

24

or<smiles>CC(C)=C(C(=O)O)C(C(=O)NCC(=O)O)=C(C)c1c(C)n(C)c2ccccc12</smiles>

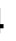<smiles>COC(=O)CNC(=O)C(C(=O)O)=C(c1c(C)n(C)c2ccccc12)C(C)C</smiles>

or<smiles>COC(=O)CNC(=O)C(C(=O)O)=C(C)c1c(C)n(C)c2ccccc12</smiles>

23

\subsection{Conclusion}<smiles>CC(C)=C1C(=O)N(CC(=O)O)C(=O)/C1=C(/C)c1c(C)n(C)c2ccccc12</smiles>

11E<smiles>CC1=C2c3ccccc3N(C)C2(C)C(C)(C)C2=C1C(=O)N(CC(=O)O)C2=O</smiles>

Methyl carboxylic acid indolylfulgimide 11 was successfully synthesized from methyl indolylfulgide 2. Methyl indolylfulgide $\mathbf{2}$ was prepared in a similar manner as trifluoromethyl indolylfulgide 1. Optimization of the synthesis provided indolylfulgide 2 with an overall yield of $21 \%$. Preliminary results obtained by Dr. Islamova suggest that the both $E$ - and $C$-forms of fulgimide 11 were thermally stable. The NMR measurement indicated that minor decomposition of both $11 \mathrm{E}$ and $11 \mathrm{C}$ was observed after 14 days in sodium phosphate buffer ( $\mathrm{pH} 7.4)$ at $37^{\circ} \mathrm{C}$.

\section{CHAPTER 7}




\section{CONCLUSIONS AND FUTURE RESEARCH}

The overall goal of the project was to develop thermally and photochemically stable photochromic compounds suitable for application in aqueous environments. I have successfully synthesized several indolylfulgides and indolylfulgimides with enhanced thermal and photochemical stabilities. Compounds were prepared with novel synthetic pathways with optimized conditions and procedures. Characterization of the compounds was performed by NMR spectroscopy and elemental analysis or high resolution mass spectrometry.

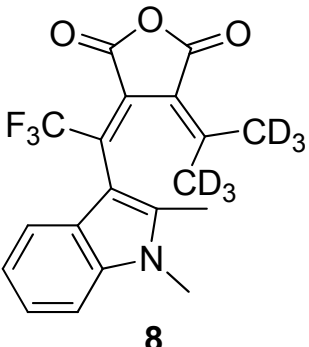

8

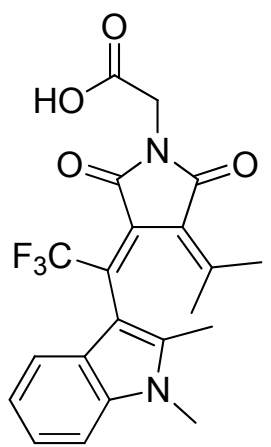

10

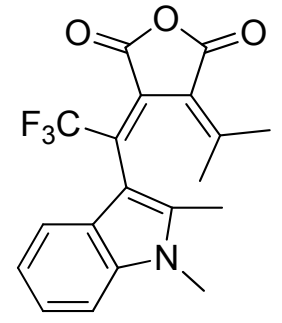

1

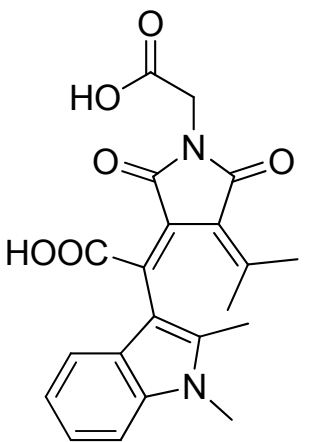

19

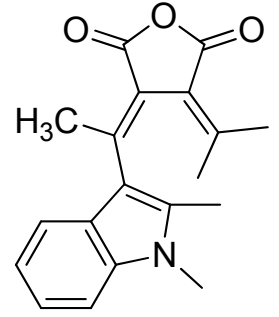

2

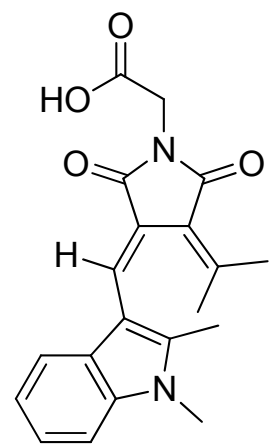

20<smiles></smiles>

9

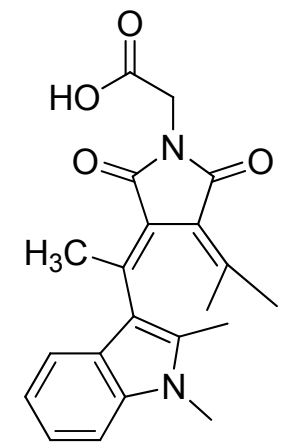

11

A novel photochromic deuterated trifluoromethyl indolylfulgide $\mathbf{8}$ was synthesized and displayed enhanced thermal stability. The isopropylidene group of the new fulgide was perdeuterated. The deuterated fulgide $\mathbf{8}$ was successfully prepared in a similar manner as proteo fulgide 1, except deuterated reagents and solvents were used. The $Z$ - 
form of deuterated indolylfulgide $\mathbf{8}$ displayed enhanced thermal stability in toluene, 7 fold, as expected on the basis of kinetic isotope effects. Deuteration should be considered as a general strategy to enhance the thermal stability of all fulgides that degrade via a similar mechanism.

Indolylfulgide $\mathbf{1}$ and $\mathbf{2}$ were prepared as synthetic precursors for indolylfulgimides. A reliable and productive pathway for the synthesis of trifluoromethyl indolylfulgide $\mathbf{1}$ on a large scale was successfully developed for the first time. The synthetic route was an optimized five step sequence, including a Stobbe condensation followed by hydrolysis, second Stobbe condensation, elimination, and dehydration. The synthesis provided 20 grams of the trifluoromethyl indolylfulgide 1 with an overall yield of $18 \%$. The synthesis of methyl indolylfulgide 2 was performed in a similar manner as the trifluoromethyl indolylfulgide 1. Optimization of the second Stobbe condensation and elimination provided 5 grams of the methyl indolylfulgide 2 in an overall yield of $21 \%$.

A new trifluoromethyl $N$-ethoxycarbonylmethyl indolylfulgimide 9 was synthesized from trifluoromethyl indolylfulgide 1 by aminolysis. The UV-vis and ${ }^{1} \mathrm{H}$ NMR data indicated that fulgimide $\mathbf{9 Z}$ degraded $22 \%$ and $26 \%$ and $9 \mathrm{C}$ degraded $10 \%$ and $26 \%$ respectively in $70 / 30$ ethanol/water at $50{ }^{\circ} \mathrm{C}$ after 21 days. In $70 / 30$ ethanol/water, fulgimide 9 underwent 360 photochemical cycles before degrading by $20 \%$. In conclusion, fulgimide 9 which I prepared was thermally and photochemically stable in protic solvents.

Three novel aqueous soluble indolylfulgimides 10, 19, and 20 were synthesized from trifluoromethyl indolylfulgide 1. Fulgmides 10, 19, 20 were synthesized and chemically characterized for the first time. The purification of aqueous soluble fulgimides was 
always considered challenging because of the carboxylic acid group. The appropriate recrystallization solvent systems allow obtaining the target fulgimides in high purity. Hydrolysis of the trifluoromethyl group of $\mathbf{1 0 C}$ was observed in a fluorinated indolylfulgimide for the first time. Hydrolysis of $10 \mathrm{C}$ resulted in $19 \mathrm{C}$ which contained another carboxylic acid group at the bridging position. Fulgimide 19C was found to undergo further decarboxylation upon prolong acidic extraction to form 20C. Compound 20C has a single hydrogen at the bridging position and lacks any photochromic properties. A notable blue shift in the absorbance maxima of $19 \mathrm{Z}$ compared to $10 \mathrm{Z}$ was observed in buffer because of the additional carboxylic acid group at the bridging carbon. Fulgimide 19 displayed great thermal and photochemical stabilities in sodium phosphate buffer $(\mathrm{pH}$ 7.4). Compound $19 \mathrm{Z}$ and $19 \mathrm{C}$ degraded less than $20 \%$ after $500 \mathrm{~h}$ at $37{ }^{\circ} \mathrm{C}$, and $\mathbf{1 9}$ underwent 670 photochemical cycles before degrading by $20 \%$. Fulgimide 19 is the most robust fulgimide yet reported in aqueous solution.

A methyl carboxylic acid indolylfulgimide $\mathbf{1 1}$ was successfully synthesized from methyl indolylfulgide 2. The synthetic pathway of aqueous soluble fulgimides from methyl indolylfulgide was reported for the first time. The difficulty of ring closure was resolved by treating the diacid intermediate 24 with neat acetic anhydride at $0{ }^{\circ} \mathrm{C}$ without any solvent presented. The crystal form of $\mathbf{1 1 C}$ was obtained by recrystallization from $\mathrm{CH}_{2} \mathrm{Cl}_{2} /$ Hexanes. Replacement of the trifluoromethyl group with the methyl group at the bridging position was expected to improve the thermal stability of fulgimide in aqueous solutions. Preliminary results obtained by Dr. Islamova suggest that the both $E$ - and $C$ forms of fulgimide $\mathbf{1 1}$ were thermally stable. The NMR measurements indicated that minor decomposition of both 11E and 11C was observed after 14 days in sodium 
phosphate buffer $\left(\mathrm{pH} \mathrm{7.4)}\right.$ at $37^{\circ} \mathrm{C}$.

Future research will involve the applications of the aqueous soluble indolylfulgimides in biological systems. The carboxylic acid group allows for fulgimides to be covalently attached to proteins. The two photochromic states of fulgimides are expected to have a significant effect on the binding constant of substrate to proteins. Therefore, photoswitchable protein-substrate binding is induced by the photochromic reactions of fulgimides. The photoregulated protein-substrate binding provides new therapeutic systems controlled by external light.

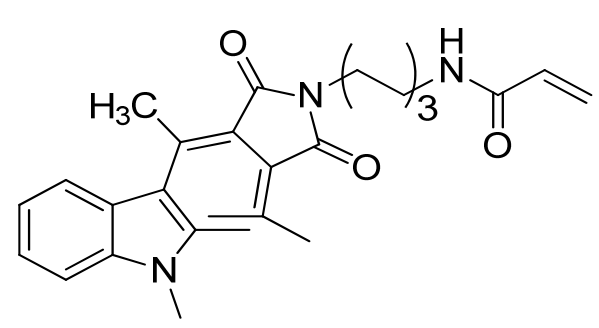

Singly substituted indolylfulgimide

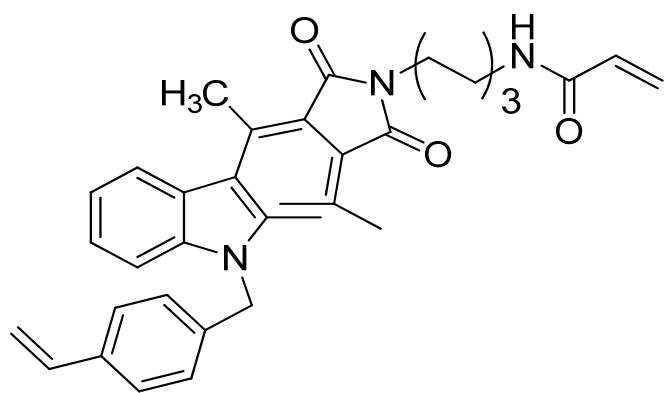

Doubly substituted indolylfulgimide

Additionally, fulgimides have the potential to be incorporated into polymers. Singlyand doubly-substituted indolylfulgimides and their copolymers will be synthesized. The fulgimide-copolymers will be used for enzyme immobilization. The polymers will switch between the flexible form and the rigid form as the fulgimide is switched between the open and closed form, respectively. The enzyme will be immobilized in a rigid form polymer. Immobilization in the rigid form polymer will affect the conformation of the enzyme or substrate accessibility to the active site. Thus, the enzyme is not functional and in the "off" state. In the "on" state, enzyme is released from the flexible form polymer. Therefore, the fulgimide-copolymer is able to turn enzyme "off" and "on" with light. 

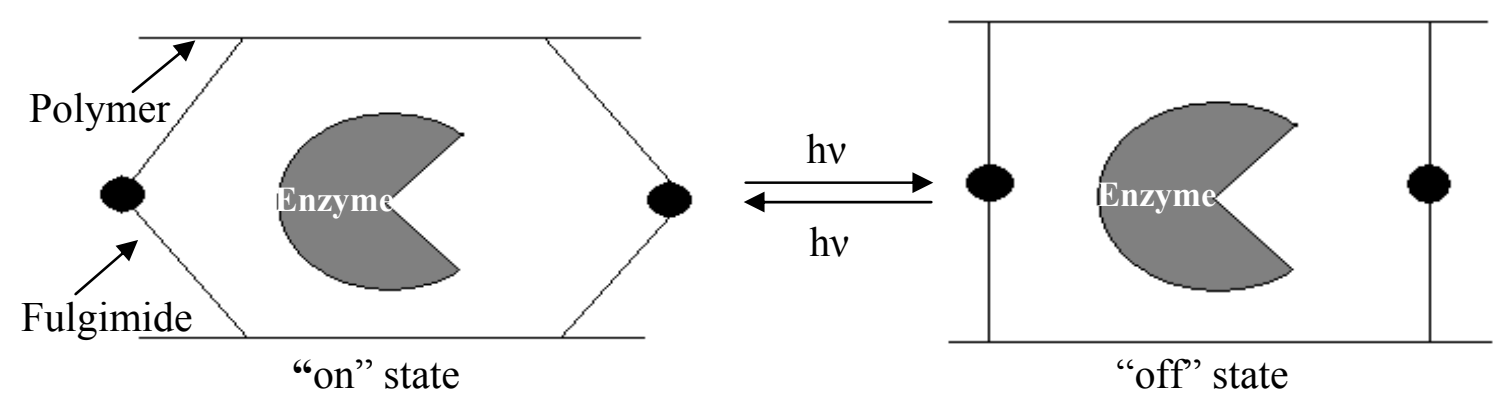


\section{REFERENCE}

(1)Crano, J. C.; Flood, T.; Knowles, D.; Kumar, A.; Van Gemert, B. "Photochromic compounds: chemistry and application in ophthalmic lenses" Pure Appl. Chem. 1996, 68, 1395.

(2)Crano, J. C.; Guglielmetti, R. J.; Editors Organic Photochromic and Thermochromic Compounds, Volume 1: Main Photochromic Families; Plenum Press: New York, 1999. 2001

(3) Garrity, N. E. "Organic photochromic contact lens" Application: US, 6174464 ,

(4)Barachevsky, V. A. "Photonics of organic photochromic systems: Modern trends" J. Photochem. Photobiol., A 2008, 196, 180.

(5)Barachevsky, V. A.; Strokach, Y. P.; Puankov, Y. A.; Krayushkin, M. M. "Thermally irreversible organic photochromic compounds for optical memory" J. Phys. Org. Chem. 2007, 20, 1007.

(6)Berns, M. W.; Krasieva, T.; Sun, C.-H.; Dvornikov, A.; Rentzepis, P. M. "A polarity dependent fluorescence "switch" in live cells" J. Photochem. Photobiol., B 2004, 75,51 .

(7)Bouas-Laurent, H.; Durr, H. "Organic photochromism" Pure Appl. Chem. 2001, $73,639$.

(8)Glenn H, B.; Editor Photochromism; Wiley-Interscience: New York, 1971.

(9)Fritzsche, M. "Nole sur les carbures d'hyfogene solides, tires du goudron de houille" Compt. Rend. Acad. Sci. 1867, 64, 1035.

(10)ter Meer, E. "Ueber Dinitroverbindungen der Fettreihe" Justus Liebigs Annalen der Chemie 1876, 181, 1. 140.

(11)Marckwald, W. "Over phototropy. [machine translation]" Z. physik. Ch. 1899, 30,

(12)Fischer, E.; Hirshberg, Y. "Formation of colored forms of spirans by lowtemperature irradiation" J. Chem. Soc. 1952, 4522.

(13)Hirshberg, Y. "Photochromie dans la serie de la bianthrone" Compt. Rend. Acad. Sci. 1950, 231, 903. 
(14)Bertelson, R. C. "Reminiscences about organic photochromics" Mol. Cryst. Liq. Cryst. Sci. Technol., Sect. A 1994, 246, 1.

(15)Yokoyama, Y. "Fulgides for memories and switches" Chem. Rev. 2000, 100, 1717.

(16)Lukyanov, B. S.; Lukyanova, M. B. "Spiropyrans: Synthesis, properties, and application" Chem. Heterocycl. Compd. (N. Y., NY, U. S.) 2005, 41, 281.

(17)Jiang, G.; Song, Y.; Guo, X.; Zhang, D.; Zhu, D. "Organic functional molecules towards information processing and high-density information storage" Adv. Mater. (Weinheim, Ger.) 2008, 20, 2888.

(18)Ono, H.; Osada, C. "Photochromic spiro compounds" Application: GB, 1186987, 1970

(19)Arnold, G.; Vollmer, H. P.; Wilhelm, A.; Paal, G. "Spiro[benzothiazole(or indoline)-2,3'-[3H]naphth[2,1-b][1,4]oxazines]" Application: DE, 1927849, 1970

(20)Hovey, R. J.; Chu, N. Y. C.; Piusz, P. G.; Fuchsman, C. H. "Photochromic compounds" Application: US, 4342668, 1982

(21)Heller, H. G. "Photochromic compounds" Application: US, 4220708, 1980

(22)Lokshin, V.; Samat, A.; Metelitsa, A. V. "Spirooxazines: synthesis, structure, spectral and photochromic properties" Russ. Chem. Rev. 2002, 71, 893.

(23)Hobley, J.; Wilkinson, F. "Photochromism of naphthoxazine-spiro-indolines by direct excitation and following sensitization by triplet-energy donors" J. Chem. Soc., Faraday Trans. 1996, 92, 1323.

(24)Irie, M.; Mohri, M. "Thermally irreversible photochromic systems. Reversible photocyclization of diarylethene derivatives" J. Org. Chem. 1988, 53, 803.

(25)Nakamura, S.; Irie, M. "Thermally irreversible photochromic systems. A theoretical study" J. Org. Chem. 1988, 53, 6136.

(26)Nakayama, Y.; Hayashi, K.; Irie, M. "Thermally irreversible photochromic systems. Reversible photocyclization of non-symmetric diarylethene derivatives" Bull. Chem. Soc. Jpn. 1991, 64, 789.

(27)Hanazawa, M.; Sumiya, R.; Horikawa, Y.; Irie, M. "Thermally irreversible photochromic systems. Reversible photocyclization of 1,2-bis(2methylbenzo[b]thiophen-3-yl)perfluorocycloalkene derivatives" J. Chem. Soc., Chem. Commun. 1992, 206. 
(28)Gritsan, N. P.; Klimenko, L. S.; Fokin, E. P. "Photochromism of quinoid compounds" Sib. Khim. Zh. 1992, 58.

(29)Gritsan, N. P.; Klimenko, L. S. "Photochromism of quinoid compounds: properties of photoinduced ana-quinones" J. Photochem. Photobiol., A 1993, 70, 103.

(30)Gritsan, N. P.; Klimenko, L. S. "Photochromism of quinoid compounds" Mol. Cryst. Liq. Cryst. Sci. Technol., Sect. A 1994, 246, 103.

(31)Barachevsky, V. A. "Photochromism of aryloxyquinones" Mol. Cryst. Liq. Cryst. Sci. Technol., Sect. A 1994, 246, 95.

(32)Yager, K. G.; Barrett, C. J. "Novel photo-switching using azobenzene functional materials" J. Photochem. Photobiol., A 2006, 182, 250.

(33)Zhao, Y.; Ikeda, T.; Editors Smart light-responsive materials: Azobenzenecontaining polymers and liquid crystals, 2009.

(34)Wyman, G. M. "The cis-trans isomerization of conjugated compounds" Chem. Rev. (Washington, DC, U. S.) 1955, 55, 625.

(35)Dugave, C.; Demange, L. "Cis-Trans Isomerization of Organic Molecules and Biomolecules: Implications and Applications" Chem. Rev. (Washington, DC, U. S.) 2003, $103,2475$.

(36)Oliveira, O. N.; dos Santos, D. S.; Balogh, D. T.; Zucolotto, V.; Mendonca, C. R. "Optical storage and surface-relief gratings in azobenzene-containing nanostructured films" Adv. Colloid Interface Sci. 2005, 116, 179.

(37)Irie, M. "Photochromism and molecular mechanical devices" Bull. Chem. Soc. Jpn. 2008, 81, 917.

(38)Natansohn, A.; Rochon, P. "Photoinduced Motions in Azo-Containing Polymers" Chem. Rev. (Washington, DC, U. S.) 2002, 102, 4139.

(39)Stobbe, H. "The color of the "Fulgenic acid" and "Fulgides"." Ber. Dtsch. chem. Ges. 1905, 38, 3673.

(40)Islamova, N. I.; Chen, X.; DiGirolamo, J. A.; Silva, Y.; Lees, W. J. "Thermal stability and photochromic properties of a fluorinated indolylfulgimide in a protic and aprotic solvent" J. Photochem. Photobiol., A 2008, 199, 85.

(41)Wolak, M. A.; Thomas, C. J.; Gillespie, N. B.; Birge, R. R.; Lees, W. J. "Tuning the optical properties of fluorinated indolylfulgimides" J. Org. Chem. 2003, 68, 319. 
(42)Li, Y.; Wang, H.; Zhu, H.; Wang, F. "Synthesis and photochromism of 3indylfulgides" Chin. J. Chem. 1991, 9, 258.

(43)Fan, G.; Wang, H.; Cui, X.; Li, Y.; Zhu, H. "Crystal structures of 1,2-dimethyl-3indolylmethylidenesuccinic fulgide anhydride and 1,2-dimethyl-3indolylethylidenesuccinic fulgide anhydride" Acta. Phys. -Chim. Sin. 1992, 8, 545.

(44)Chen, X.; Islamova, N. I.; Garcia, S. P.; DiGirolamo, J. A.; Lees, W. J. "Synthesis and optical properties of aqueous soluble indolylfulgimides" J. Org. Chem. 2009, 74, 6777.

(45)Draxler, S.; Brust, T.; Malkmus, S.; Koller, F. O.; Heinz, B.; Laimgruber, S.; Schulz, C.; Dietrich, S.; Rueck-Braun, K.; Zinth, W.; Braun, M. "Ultrafast reaction dynamics of the complete photo cycle of an indolylfulgimide studied by absorption, fluorescence and vibrational spectroscopy" J. Mol. Liq. 2008, 141, 130.

(46)Koller, F. O.; Schreier, W. J.; Schrader, T. E.; Sieg, A.; Malkmus, S.; Schulz, C.; Dietrich, S.; Rueck-Braun, K.; Zinth, W.; Braun, M. "Ultrafast Structural Dynamics of Photochromic Indolylfulgimides Studied by Vibrational Spectroscopy and DFT Calculations" J. Phys. Chem. 2006, 110, 12769.

(47)Heinz, B.; Malkmus, S.; Laimgruber, S.; Dietrich, S.; Schulz, C.; Rueck-Braun, K.; Braun, M.; Zinth, W.; Gilch, P. "Comparing a photoinduced pericyclic ring opening and closure: differences in the excited state pathways" J. Am. Chem. Soc. 2007, 129, 8577.

(48)Koller, F. O.; Schreier, W. J.; Schrader, T. E.; Malkmus, S.; Schulz, C.; Dietrich, S.; Rueck-Braun, K.; Braun, M. "Ultrafast Ring-Closure Reaction of Photochromic Indolylfulgimides Studied with UV-Pump-IR-Probe Spectroscopy" J. Phys. Chem. 2008, $112,210$.

(49)Yokoyama, Y.; Takahashi, K. "Trifluoromethyl-substituted photochromic indolylfulgide. A remarkably durable fulgide towards photochemical and thermal treatments" Chem. Lett. 1996, 1037.

(50)Wolak, M. A.; Sullivan, J. M.; Thomas, C. J.; Finn, R. C.; Birge, R. R.; Lees, W. J. "Thermolysis of a fluorinated indolylfulgide features a novel 1,5-indolyl shift" J. Org. Chem. 2001, 66, 4739.

(51)Liang, Y.; Dvornikov, A. S.; Rentzepis, P. M. "Photochemistry of photochromic 2-indolylfulgides with substituents at the 1'-position of the indolylmethylene moiety" $J$. Photochem. Photobiol., A 2001, 146, 83. 
(52)Islamova, N. I.; Chen, X.; Garcia, S. P.; Guez, G.; Silva, Y.; Lees, W. J. "Improving the stability of photochromic fluorinated indolylfulgides" J. Photochem. Photobiol., A 2008, 195, 228.

(53)Santiago, A.; Becker, R. S. "Photochromic fulgides. Spectroscopy and mechanism of photoreactions" J. Amer. Chem. Soc. 1968, 90, 3654.

(54)Heller, H. G.; Oliver, S. "Photochromic heterocyclic fulgides. Part 1. Rearrangement reactions of (E)-N1-3-furylethylidene(isopropylidene)succinic anhydride" J. Chem. Soc., Perkin Trans. 1 1981, 197.

(55)Heller, H. G.; Langan, J. R. "Photochromic heterocyclic fulgides. Part 3. The use of (E)-N1-(2,5-dimethyl-3-furylethylidene)(isopropylidene)succinic anhydride as a simple convenient chemical actinometer" J. Chem. Soc., Perkin Trans. 2 1981, 341.

(56)Heller, H. G.; Koh, K.; Elliot, C.; Whittall, J. "Fulgides and fulgimides for practical applications" Mol. Cryst. Liq. Cryst. Sci. Technol., Sect. A 1994, 246, 79.

(57)Heller, H. G.; Elliot, C. C.; Koh, K.; Al-Shihry, S.; Whittall, J. "The design and development of photochromic systems for commercial applications" Spec. Publ. - R. Soc. Chem. 1993, 125, 156.

(58)Yokoyama, Y.; Kurita, Y. "Photochromism of fulgides and related compounds" Mol. Cryst. Liq. Cryst. Sci. Technol., Sect. A 1994, 246, 87.

(59)Kaneko, A.; Tomoda, A.; Ishizuka, M.; Suzuki, H.; Matsushima, R. "Photochemical fatigue resistances and thermal stabilities of heterocyclic fulgides in PMMA film" Bull. Chem. Soc. Jpn. 1988, 61, 3569.

(60)Thomas, C. J.; Wolak, M. A.; Birge, R. R.; Lees, W. J. "Improved Synthesis of Indolyl Fulgides" J. Org. Chem. 2001, 66, 1914.

(61)Yokoyama, Y.; Tanaka, T.; Yamane, T.; Kurita, Y. "Synthesis and photochromic behavior of 5-substituted indolylfulgides" Chem. Lett. 1991, 1125.

(62)Uchida, S.; Yokoyama, Y.; Kiji, J.; Okano, T.; Kitamura, H. "Electronic effects of substituents on indole nitrogen on the photochromic properties of indolylfulgides" Bull. Chem. Soc. Jpn. 1995, 68, 2961.

(63)Yokoyama, Y.; Sagisaka, T.; Mizuno, Y.; Yokoyama, Y. "Role Of the Methoxy Substituents On the Photochromic Indolylfulgides - Absorption Maximum Vs Molar Absorption Coefficient Of the Colored Form" Chem. Lett. 1996, 587.

(64)Wolak, M. A.; Gillespie, N. B.; Thomas, C. J.; Birge, R. R.; Lees, W. J. "Optical properties of photochromic fluorinated indolylfulgides" J. Photochem. Photobiol., A 2001, 
$144,83$.

(65)Wolak, M. A.; Gillespie, N. B.; Thomas, C. J.; Birge, R. R.; Lees, W. J. "Optical and thermal properties of photochromic fluorinated adamantylidene indolylfulgides" $J$. Photochem. Photobiol., A 2002, 147, 39.

(66)Goldschmidt, S.; Riedle, R.; Reichardt, A. "Bisbiphenylenefulgides and the cleavage of bisbiphenylenefulgenic acid to optically active components" Justus Liebigs Ann. Chem. 1957, 604, 121.

(67)Hart, R. J.; Heller, H. G.; Salisbury, K. "Photochemical rearrangements of some photochromic fulgimides" Chem. Commun. 1968, 1627.

(68)Straight, S. D.; Terazono, Y.; Kodis, G.; Moore, T. A.; Moore, A. L.; Gust, D. "Photoswitchable Sensitization of Porphyrin Excited States" Aust. J. Chem. 2006, 59, 170.

(69)Liang, Y.; Dvornikov, A. S.; Rentzepis, P. M. "Photochromic cross-linked copolymer containing thermally stable fluorescing 2-indolylfulgimide" Chem. Commun. 2000, 1641.

(70)Willner, I.; Rubin, S.; Wonner, J.; Effenberger, F.; Baeuerle, P. "Photoswitchable binding of substrates to proteins: photoregulated binding of alpha -D-mannopyranose to concanavalin A modified by a thiophenefulgide dye" J. Am. Chem. Soc. 1992, 114, 3150.

(71)Matsushima, R.; Sakaguchi, H. "Comparison of the photochromic properties of fulgides and fulgimides" J. Photochem. Photobiol., A 1997, 108, 239.

(72)Kohno, Y.; Tamura, Y.; Matsushima, R. "Photochromic properties of cationic oxazolylfulgimides in hydroxylic media" J. Photochem. Photobiol., A 2009, 203, 161.

(73)Wolak, M. A.; Finn, R. C.; Rarig, R. S., Jr.; Thomas, C. J.; Hammond, R. P.; Birge, R. R.; Zubieta, J.; Lees, W. J. "Structural properties of a series of photochromic fluorinated indolylfulgides" Acta Crystallogr., Sect. C Cryst. Struct. Commun. 2002, C58, o389.

(74)Kiji, J.; Konishi, H.; Okano, T.; Kometani, S.; Iwasa, A. "One-step synthesis of fulgides by palladium-catalyzed carbonylation of substituted 2-butyne-1,4-diols" Chem. Lett. 1987, 313.

(75)Kiji, J.; Konishi, H.; Okano, T. "Development of one-step synthesis of fulgides by palladium-catalyzed carbonylation and synthesis of photochromic organic materials" Kenkyu Hokoku - Asahi Garasu Zaidan 1990, 56, 203.

(76)Kiji, J.; Okano, T.; Takemoto, A.; Mio, S.-Y.; Konishi, T.; Kondou, Y.; Sagisaka, T.; Yokoyama, Y. "A convenient and general synthetic method for photochromic fulgides 
by palladium-catalyzed carbonylation of 2-butyne-1,4-diols" Mol. Cryst. Liq. Cryst. Sci. Technol., Sect. A 2000, 344, 235.

(77)Kiji, J.; Kondou, Y.; Asahara, M.; Yokoyama, Y.; Sagisaka, T. "Palladiumcatalyzed carbonylation of 2-butyne-1,4-diol derivatives: formation of fulgide or lactone" J. Mol. Catal. A Chem. 2003, 197, 127.

(78)Liang, Y.; Dvornikov, A. S.; Rentzepis, P. M. "Synthesis of novel photochromic fluorescing 2-indolylfulgimides" Tetrahedron Lett. 1999, 40, 8067.

(79)Reddy, P. Y.; Kondo, S.; Toru, T.; Ueno, Y. "Lewis Acid-HexamethyldisilazanePromoted Efficient Synthesis of N-Alkyl- and N-Arylimide Derivatives" J. Org. Chem. 1997, 62, 2652.

(80)Li, X.; Li, C.; Pang, S.; Chen, H.; Zhang, P. "Convenient, Microwave-Assisted, One-Pot Synthesis of Photochromic Fulgimides Bearing Reactive Groups" Synth. Commun. 2010, 40, 157.

(81)Lee, W.-W. W.; Gan, L.-M.; Loh, T.-P. "Microwave-assisted synthesis of photochromic fulgimides" J. Photochem. Photobiol., A 2007, 185, 106.

(82)Yoshioka, Y.; Usami, M.; Yamaguchi, K. "Ab initio molecular orbital study on thermal and photochemical reactions of 3-furyl, 3-pyrryl, and 3-thienyl fulgides" Mol. Cryst. Liq. Cryst. Sci. Technol., Sect. A 2000, 345, 81.

(83)Liang, Y.; Dvornikov, A. S.; Rentzepis, P. M. "Solvent and ring substitution effect on the photochromic behavior of fluorescent 2-indolylfulgide derivatives" $J$. Photochem. Photobiol., A 1999, 125, 79.

(84)Sullivan, J. M.; Armstrong, W. L.; Wells, M. C.; Lees, W. J.; Wolak, M. A. "Blue/yellow/red: Thermal degradation of a fulgide yields 3-D memory candidate" Abstracts of Papers, 221st ACS National Meeting, San Diego, CA, United States, April 15, 2001 2001, CHED.

(85)Wolak, M. A.; Gillespie, N. B.; Birge, R. R.; Lees, W. J. "Thermolysis of fluorinated cycloalkylidene fulgides yields a new class of photochromic compounds" Chem. Commun. 2003, 992.

(86)Liang, Y.; Dvornikov, A. S.; Rentzepis, P. M. "Synthesis and photochemistry of photochromic fluorescing 2-indolylfulgimides" J. Mater. Chem. 2000, 10, 2477.

(87)Yokoyama, Y.; Uchida, S.; Yokoyama, Y.; Sugawara, Y.; Kurita, Y. "Diastereoselective Photochromism of an (R)-Binaphthol-Condensed Indolylfulgide" $J$. Am. Chem. Soc. 1996, 118, 3100. 
(88)Liang, Y.; Dvornikov, A. S.; Rentzepis, P. M. "New near infrared-sensitive photochromic fluorescing molecules" J. Mater. Chem. 2003, 13, 286.

(89)Janicki, S. Z.; Schuster, G. B. "A liquid crystal opto-optical switch: Nondestructive information retrieval based on a photochromic fulgide as trigger" $\mathrm{J}$. Am. Chem. Soc. 1995, 117, 8524.

(90)Heller, H. G.; Megit, R. M. "Overcrowded molecules. IX. Fatigue-free photochromic systems involving (E)-2-isopropylidene-3-(mesitylmethylene)succinic anhydride and N-phenylimide" J. Chem. Soc., Perkin Trans. 1 1974, 923.

(91)Hart, R. J.; Heller, H. G.; Salisbury, K. "Photochemical rearrangements of some photochromic fulgimides" Chem. Commun. 1968, 1627.

(92)Willner, I.; Rubin, S. "Control of the structure and functions of biomaterials by light" Angew. Chem., Int. Ed. Engl. 1996, 35, 367.

(93)Asiri, A. M. "Reactions of fulgides: regioselectivity in the ring opening reactions of unsymmetrical bis-substituted dimethylene-succinic anhydrides with nucleophiles" $J$. Chem. Soc. Pak. 2000, 22, 124.

(94)Guerniou, V.; Gasparutto, D.; Sauvaigo, S.; Favier, A.; Cadet, J. "New Synthesis of 5-Carboxy-2'-deoxyuridine and its Incorporation into Synthetic Oligonucleotides" Nucleosides Nucleotides Nucleic Acids. 2003, 22, 1073.

(95)Bornstein, J.; Leone, S. A.; Sullivan, W. F.; Bennett, O. F. "Facile hydrolysis of the trifluoromethyl group in the presence of base. Some trifluoromethylated indoles" $J$. Am. Chem. Soc. 1957, 79, 1745.

(96)Choi, K.; Hamilton, A. D. "Rigid Macrocyclic Triamides as Anion Receptors: Anion-Dependent Binding Stoichiometries and 1H Chemical Shift Changes" J. Am. Chem. Soc. 2003, 125, 10241.

(97)Wahlstroem, N.; Romero, I.; Bergman, J. "Synthesis of metabolites of the Ah receptor ligand 6-formylindolo[3,2-b]carbazole" Eur. J. Org. Chem. 2004, 2593.

(98)Sadovoy, A. V.; Golubeva, G. A.; Nasakin, O. E. "Interaction of 2-aminoindoles with tetracyanoethylene. 1. 2-Amino-3,4-dicyano-alpha -carbolines and related compounds" Chem. Heterocycl. Compd. (N. Y., NY, U. S.) 2001, 37, 1145.

(99)Suzuki, H.; Kaneko, A.; Ishizuka, M.; Tomota, A. "Photochromic fulgides containing heterocycles" Application: JP, 02160779, 1990 


\section{APPENDICES}

\section{Profile of Indolylfulgides and Indolylfulgimides}

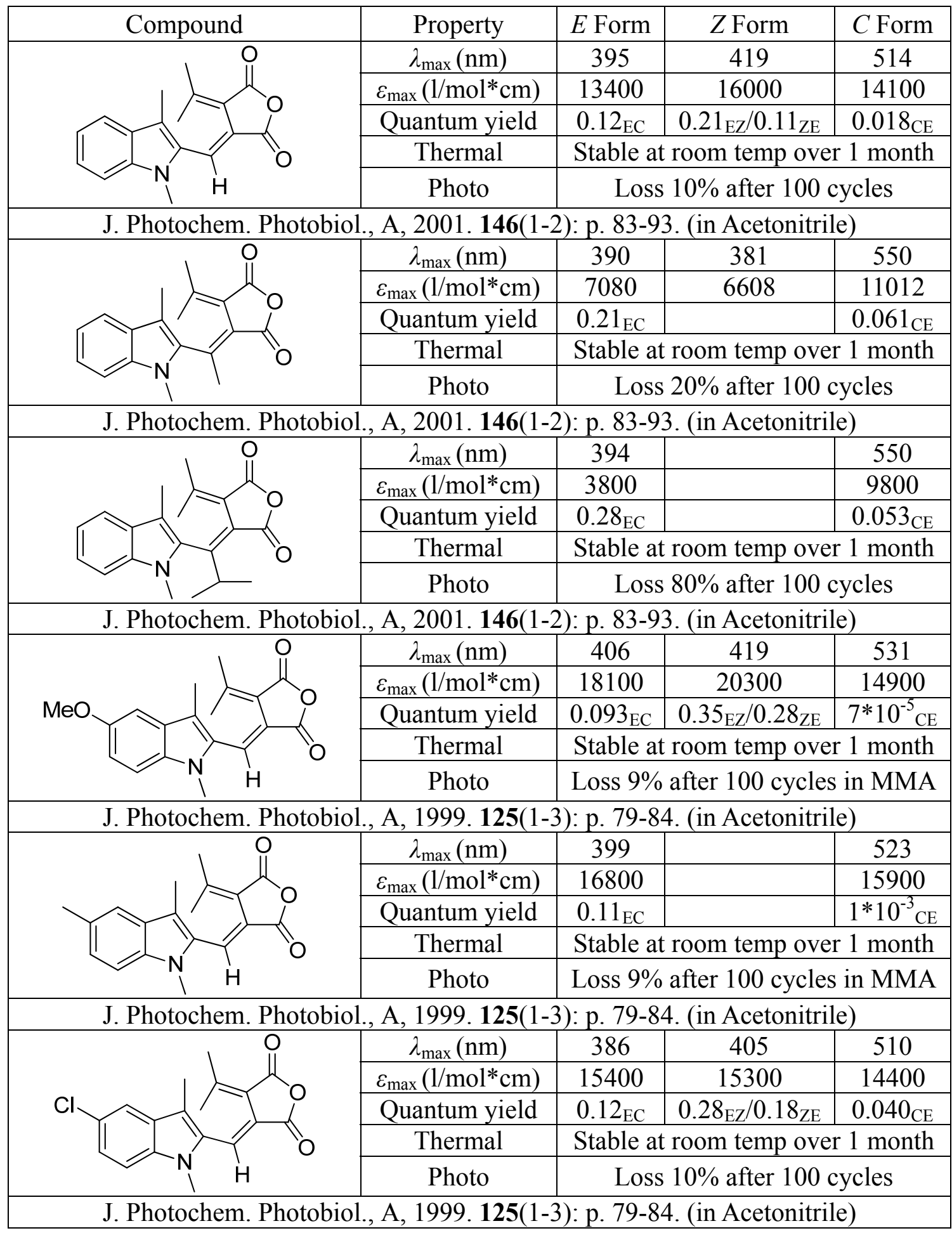




\begin{tabular}{|c|c|c|c|c|}
\hline & Property & $E$ Form & $Z$ Z Form & $C$ Form \\
\hline$\lambda_{\max }(\mathrm{nm})$ & 386 & 513 \\
\hline$\varepsilon_{\max }\left(1 / \mathrm{mol}^{*} \mathrm{~cm}\right)$ & 14700 & 14100 \\
\hline Quantum yield & $0.13_{\mathrm{EC}}$ & $0.022_{\mathrm{CE}}$ \\
\hline Thermal & \multicolumn{2}{|c|}{ Stable at room temp over 1 month } \\
\hline & Photo & \multicolumn{2}{|c|}{ Loss 5\% after 100 cycles } \\
\hline
\end{tabular}




\begin{tabular}{|c|c|c|c|c|}
\hline \multirow[t]{6}{*}{ Compound } & \multirow{2}{*}{$\begin{array}{l}\text { Property } \\
\lambda_{\max }(\mathrm{nm}) \\
\end{array}$} & \multirow[t]{2}{*}{$E$ Form } & \multirow[t]{2}{*}{$Z$ Form } & \multirow[t]{2}{*}{$C$ Form } \\
\hline & & & & \\
\hline & $\varepsilon_{\max }\left(1 / \mathrm{mol}^{*} \mathrm{~cm}\right)$ & & & \\
\hline & Quantum yield & & & \\
\hline & Thermal & & & \\
\hline & Photo & & & \\
\hline \multicolumn{5}{|c|}{ Macromolecules, 2002. 35(25): p. 9377-9382. (in EtOAC) } \\
\hline & $\lambda_{\max }(\mathrm{nm})$ & 382 & & 513 \\
\hline & $\varepsilon_{\max }\left(1 / \mathrm{mol}^{*} \mathrm{~cm}\right)$ & 16300 & & 10900 \\
\hline & Quantum yield & $0.12_{\mathrm{EC}}$ & & $0.10_{\mathrm{CE}}$ \\
\hline & Thermal & & & \\
\hline & Photo & & & \\
\hline \multicolumn{5}{|c|}{ Macromolecules, 2002. 35(25): p. 9377-9382. (in EtOAC) } \\
\hline & $\lambda_{\max }(\mathrm{nm})$ & 383 & & 520 \\
\hline & $\varepsilon_{\max }\left(1 / \mathrm{mol}^{*} \mathrm{~cm}\right)$ & 14100 & & 10600 \\
\hline & Quantum yield & $0.13_{\mathrm{EC}}$ & Acetonitrile & $0.076_{\mathrm{CE}}$ \\
\hline & Thermal & & & \\
\hline & Photo & & & \\
\hline \multicolumn{5}{|c|}{ J. Mater. Chem., 2000. 10(11): p. 2477-2482. (in Tol) } \\
\hline & $\lambda_{\max }(\mathrm{nm})$ & 378 & & 517 \\
\hline & $\varepsilon_{\max }\left(1 / \mathrm{mol}^{*} \mathrm{~cm}\right)$ & 13800 & & 10200 \\
\hline & Quantum yield & $0.14_{\mathrm{EC}}$ & Acetonitrile & $0.11_{\mathrm{CE}}$ \\
\hline & Thermal & & & \\
\hline & Photo & & & \\
\hline \multicolumn{5}{|c|}{ J. Mater. Chem., 2000. 10(11): p. 2477-2482. (in Tol) } \\
\hline & $\lambda_{\max }(\mathrm{nm})$ & 380 & & 519 \\
\hline & $\varepsilon_{\max }\left(1 / \mathrm{mol}^{*} \mathrm{~cm}\right)$ & 14000 & & 10500 \\
\hline & Quantum yield & $0.14_{\mathrm{EC}}$ & Acetonitrile & $0.11_{\mathrm{CE}}$ \\
\hline & Thermal & & & \\
\hline & Photo & & & \\
\hline \multicolumn{5}{|c|}{ J. Mater. Chem., 2000. 10(11): p. 2477-2482. (in Tol) } \\
\hline & $\lambda_{\max }(\mathrm{nm})$ & 390 & & 526 \\
\hline & $\varepsilon_{\max }\left(1 / \mathrm{mol}^{*} \mathrm{~cm}\right)$ & 15500 & & 10800 \\
\hline & Quantum yield & $0.14_{\mathrm{EC}}$ & Acetonitrile & $0.068_{\mathrm{CE}}$ \\
\hline & Thermal & & & \\
\hline & Photo & & & \\
\hline
\end{tabular}




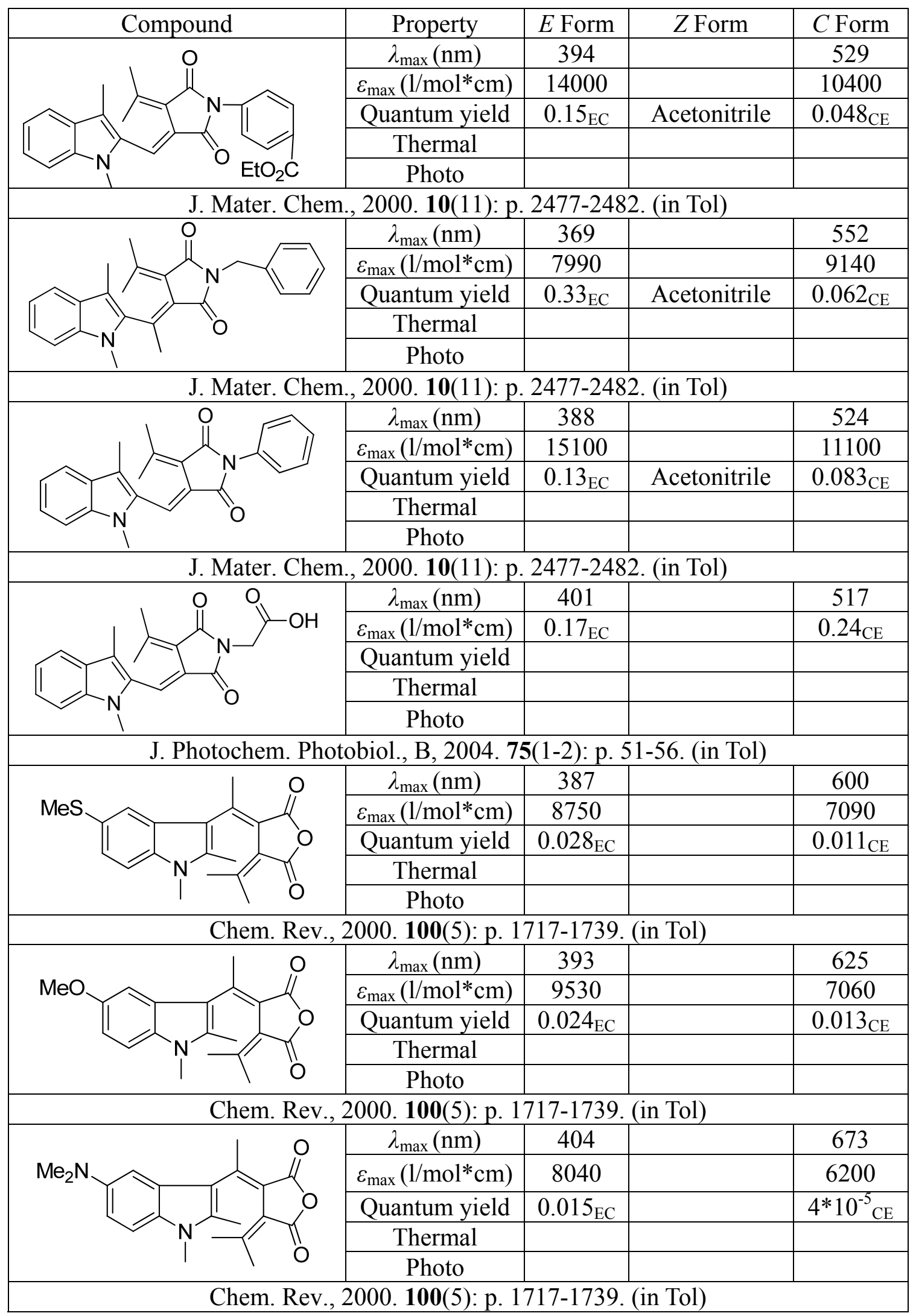




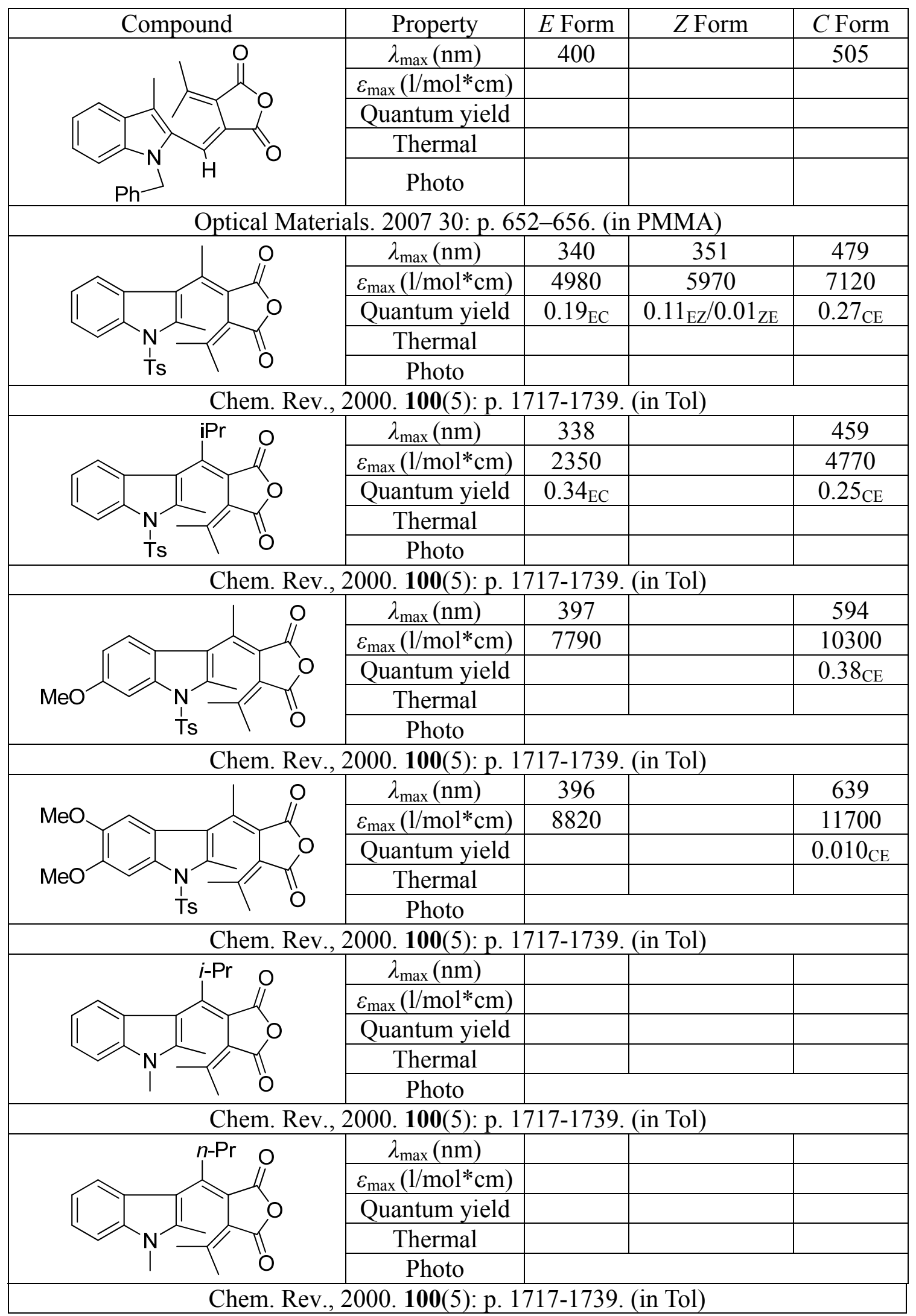




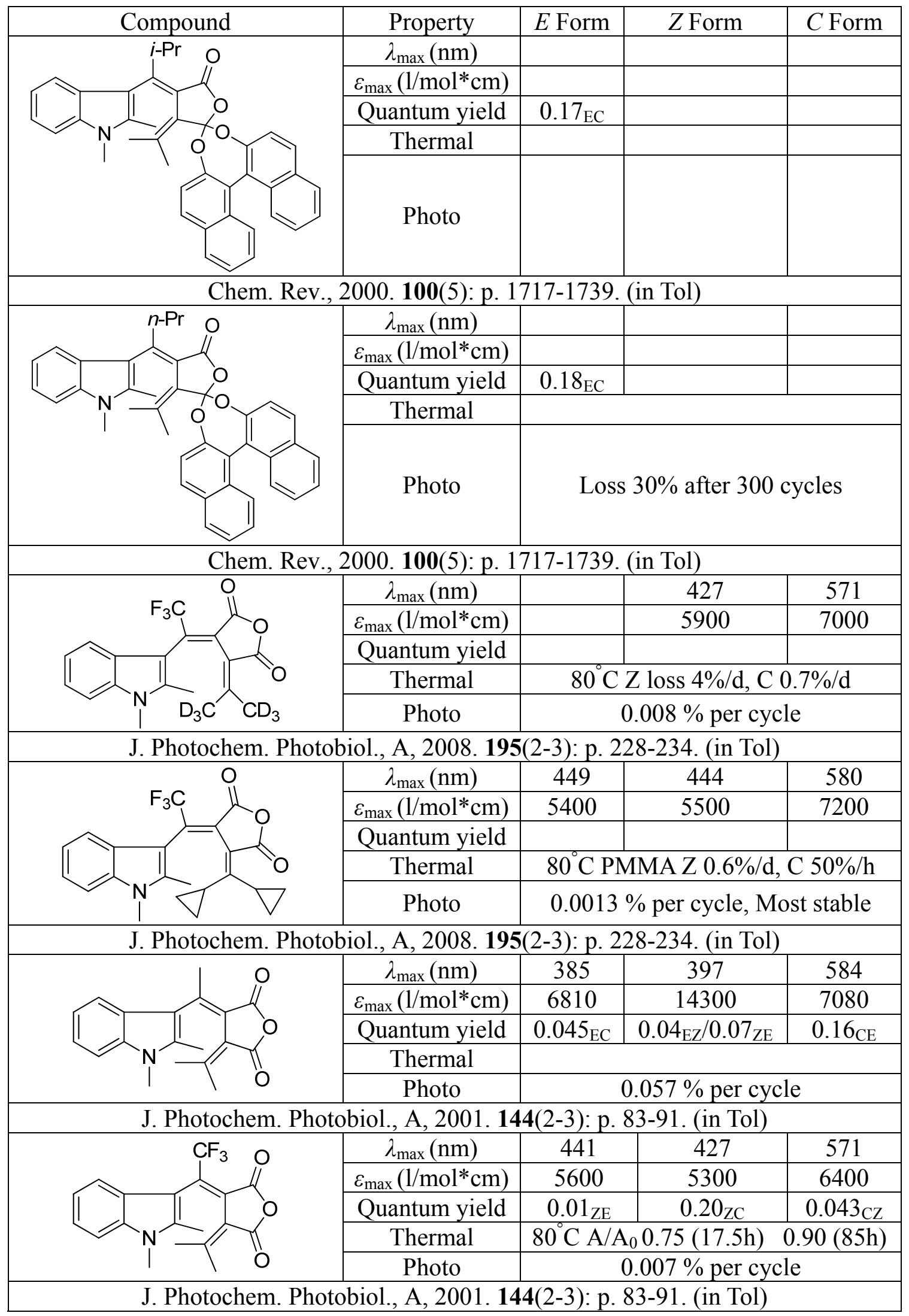




\begin{tabular}{|c|c|c|c|c|}
\hline Compound & Property & $E$ Form & Z Form & $C$ Form \\
\hline & $\lambda_{\max }(\mathrm{nm})$ & 441 & 432 & 580 \\
\hline & $\varepsilon_{\max }\left(1 / \mathrm{mol}^{*} \mathrm{~cm}\right)$ & 4400 & 4400 & 7100 \\
\hline & Quantum yield & $0.003_{\mathrm{ZE}}$ & $0.15_{\mathrm{ZC}}$ & $0.034_{\mathrm{CZ}}$ \\
\hline & Thermal & \multicolumn{3}{|c|}{$80^{\circ} \mathrm{C} \mathrm{A} / \mathrm{A}_{0} 0.56(85 \mathrm{~h}) \quad 0.94(85 \mathrm{~h})$} \\
\hline & Photo & \multicolumn{3}{|c|}{$0.030 \%$ per cycle } \\
\hline \multicolumn{5}{|c|}{ J. Photochem. Photobiol., A, 2001. 144(2-3): p. 83-91. (in Tol) } \\
\hline \multirow[t]{5}{*}{$n-\mathrm{C}_{3} \mathrm{~F}_{7}$} & $\lambda_{\max }(\mathrm{nm})$ & 444 & 434 & 582 \\
\hline & $\varepsilon_{\max }\left(1 / \mathrm{mol}^{*} \mathrm{~cm}\right)$ & 4300 & 3800 & 6300 \\
\hline & Quantum yield & $0.002_{\mathrm{ZE}}$ & $0.18_{\mathrm{ZC}}$ & $0.042_{\mathrm{CZ}}$ \\
\hline & Thermal & $80^{\circ} \mathrm{C} \mathrm{A} / \mathrm{A}$ & $0.55(85 \mathrm{~h})$ & $0.98(85 h)$ \\
\hline & Photo & \multicolumn{3}{|c|}{$0.011 \%$ per cycle } \\
\hline \multicolumn{5}{|c|}{ J. Photochem. Photobiol., A, 2001. 144(2-3): p. 83-91. (in Tol) } \\
\hline \multirow{5}{*}{$\mathrm{MeO}$} & $\lambda_{\max }(\mathrm{nm})$ & 433 & 449 & 616 \\
\hline & $\varepsilon_{\max }\left(1 / \mathrm{mol}^{*} \mathrm{~cm}\right)$ & 7200 & 6100 & 7200 \\
\hline & Quantum yield & & $0.169_{\mathrm{ZC}}$ & $0.012_{\mathrm{CZ}}$ \\
\hline & Thermal & & & \\
\hline & Photo & & & \\
\hline \multicolumn{5}{|c|}{ J. Photochem. Photobiol., A, 2002. 147(1): p. 39-44. (in Tol) } \\
\hline \multirow{5}{*}{$\mathrm{MeO}$} & $\lambda_{\max }(\mathrm{nm})$ & 450 & 435 & 615 \\
\hline & $\varepsilon_{\max }\left(1 / \mathrm{mol}^{*} \mathrm{~cm}\right)$ & 7900 & 5200 & 6000 \\
\hline & Quantum yield & & $0.030_{\mathrm{ZC}}$ & $0.166_{\mathrm{CZ}}$ \\
\hline & Thermal & \multicolumn{3}{|c|}{$80^{\circ} \mathrm{C} \mathrm{Z} \mathrm{A} / \mathrm{A}_{0} 0.72(72 \mathrm{~h})$ in PMMA } \\
\hline & $\begin{array}{l}\text { Photo (not } \\
\text { reported) }\end{array}$ & \multicolumn{3}{|c|}{$\begin{array}{c}\text { Thermal stability } \mathrm{C} \text { of in PMMA } \\
\text { Loss } 73 \% \text { after } 24 \mathrm{~h} \text { at } 80^{\circ} \mathrm{C}\end{array}$} \\
\hline \multicolumn{5}{|c|}{ J. Photochem. Photobiol., A, 2002. 147(1): p. 39-44. (in Tol) } \\
\hline & $\lambda_{\max }(\mathrm{nm})$ & 442 & 426 & 571 \\
\hline & $\varepsilon_{\max }\left(1 / \mathrm{mol}^{*} \mathrm{~cm}\right)$ & 7500 & 4800 & 5400 \\
\hline & Quantum yield & & $0.051_{\mathrm{ZC}}$ & $0.325_{\mathrm{CZ}}$ \\
\hline & Thermal & \multicolumn{3}{|c|}{$80^{\circ} \mathrm{C} \mathrm{Z} \mathrm{A} / \mathrm{A}_{0} 0.87(72 \mathrm{~h})$ in PMMA } \\
\hline & $\begin{array}{l}\text { Photo(not } \\
\text { reported) }\end{array}$ & \multicolumn{3}{|c|}{$\begin{array}{l}\text { Thermal stability of C in PMMA } \\
\text { Loss } 100 \% \text { after } 24 \mathrm{~h} \text { at } 80^{\circ} \mathrm{C}\end{array}$} \\
\hline \multicolumn{5}{|c|}{ J. Photochem. Photobiol., A, 2002. 147(1): p. 39-44. (in Tol) } \\
\hline & $\lambda_{\max }(\mathrm{nm})$ & 445 & 431 & 588 \\
\hline & $\varepsilon_{\max }\left(1 / \mathrm{mol}^{*} \mathrm{~cm}\right)$ & 5600 & 4000 & 5500 \\
\hline & Quantum yield & & $0.034_{\mathrm{ZC}}$ & $0.326_{\mathrm{CZ}}$ \\
\hline & Thermal & \multicolumn{3}{|c|}{$80^{\circ} \mathrm{C} \mathrm{Z} \mathrm{A} / \mathrm{A}_{0} 0.92(72 \mathrm{~h})$ in PMMA } \\
\hline & $\begin{array}{l}\text { Photo(not } \\
\text { reported) }\end{array}$ & \multicolumn{3}{|c|}{$\begin{array}{l}\text { Thermal stability of C in PMMA } \\
\text { Loss } 100 \% \text { after } 24 \mathrm{~h} \text { at } 80^{\circ} \mathrm{C}\end{array}$} \\
\hline \multicolumn{5}{|c|}{ m. Photobiol., A, 2002. 147(1): p. 39-44. (in Tol) } \\
\hline
\end{tabular}




\begin{tabular}{|c|c|c|c|c|}
\hline Compound & Property & $E$ Form & \multirow{2}{*}{$\begin{array}{c}\text { Form } \\
433\end{array}$} & $C$ Form \\
\hline \multirow{5}{*}{$\mathrm{C}_{3} \mathrm{~F}_{7}$} & $\lambda_{\max }(\mathrm{nm})$ & 450 & & 589 \\
\hline & $\varepsilon_{\max }\left(1 / \mathrm{mol}^{*} \mathrm{~cm}\right)$ & 5500 & 3900 & 5400 \\
\hline & Quantum yield & & $0.040_{\mathrm{ZC}}$ & $0.319_{\mathrm{CZ}}$ \\
\hline & Thermal & \multicolumn{3}{|c|}{$80^{\circ} \mathrm{C} \mathrm{Z} \mathrm{A} / \mathrm{A}_{0} 0.73(72 \mathrm{~h})$ in PMMA } \\
\hline & $\begin{array}{l}\text { Photo(not } \\
\text { reported) }\end{array}$ & \multicolumn{3}{|c|}{$\begin{array}{l}\text { Thermal stability of } \mathrm{C} \text { in PMMA } \\
\text { Loss } 100 \% \text { after } 24 \mathrm{~h} \text { at } 80^{\circ} \mathrm{C}\end{array}$} \\
\hline \multicolumn{5}{|c|}{ J. Photochem. Photobiol., A, 2002. 147(1): p. 39-44. (in Tol) } \\
\hline \multirow{5}{*}{$=$} & $\lambda_{\max }(\mathrm{nm})$ & 444 & 431 & 570 \\
\hline & $\varepsilon_{\max }\left(1 / \mathrm{mol}^{*} \mathrm{~cm}\right)$ & 5400 & 5600 & 5500 \\
\hline & Quantum yield & & $0.017_{\mathrm{ZC}}$ & $0.032_{\mathrm{CZ}}$ \\
\hline & Thermal & \multicolumn{3}{|c|}{$80^{\circ} \mathrm{C} \mathrm{A} / \mathrm{A}_{0} 0.29(168 \mathrm{~h}) 0.86(168 \mathrm{~h})$} \\
\hline & Photo & \multicolumn{3}{|c|}{$0.018 \%$ per cycle } \\
\hline \multicolumn{5}{|c|}{ Chem. Commun., 2003(8): p. 992-993.(in Tol) } \\
\hline \multirow{6}{*}{$\mathrm{MeO}_{\mathrm{N}}$} & $\lambda_{\max }(\mathrm{nm})$ & 457 & 438 & 615 \\
\hline & $\varepsilon_{\max }\left(1 / \mathrm{mol}^{*} \mathrm{~cm}\right)$ & 6600 & 5100 & 5200 \\
\hline & Quantum yield & & $0.014_{\mathrm{ZC}}$ & $0.012_{\mathrm{CZ}}$ \\
\hline & Thermal & \multicolumn{3}{|c|}{$80^{\circ} \mathrm{C} \mathrm{A} / \mathrm{A}_{0} 0.28(168 \mathrm{~h}) 0.92(168 \mathrm{~h})$} \\
\hline & Photo & \multicolumn{3}{|c|}{$0.030 \%$ per cycle } \\
\hline & \multicolumn{4}{|c|}{ Chem. Commun., 2003(8): p. 992-993.(in Tol) } \\
\hline & $\lambda_{\max }(\mathrm{nm})$ & 443 & 428 & 572 \\
\hline & $\varepsilon_{\max }\left(1 / \mathrm{mol}^{*} \mathrm{~cm}\right)$ & 6600 & 4500 & 5100 \\
\hline & Quantum yield & & $0.08_{\mathrm{ZC}}$ & $0.087_{\mathrm{CZ}}$ \\
\hline & Thermal & \multicolumn{3}{|c|}{$80^{\circ} \mathrm{C} \mathrm{A} / \mathrm{A}_{0} 0.27(168 \mathrm{~h}) 0.49(168 \mathrm{~h})$} \\
\hline & Photo & \multicolumn{3}{|c|}{$0.023 \%$ per cycle } \\
\hline \multicolumn{5}{|c|}{ Chem. Commun., 2003(8): p. 992-993.(in Tol) } \\
\hline \multirow{5}{*}{$\mathrm{MeO}_{\mathrm{N}}$} & $\lambda_{\max }(\mathrm{nm})$ & 451 & 433 & 617 \\
\hline & $\varepsilon_{\max }\left(1 / \mathrm{mol}^{*} \mathrm{~cm}\right)$ & 7200 & 4700 & 5200 \\
\hline & Quantum yield & & $0.06_{\mathrm{ZC}}$ & $0.036_{\mathrm{CZ}}$ \\
\hline & Thermal & \multicolumn{3}{|c|}{$80^{\circ} \mathrm{C} \mathrm{A} / \mathrm{A}_{0} 0.27(168 \mathrm{~h}) 0.13(168 \mathrm{~h})$} \\
\hline & Photo & \multicolumn{3}{|c|}{$0.006 \%$ per cycle } \\
\hline \multicolumn{5}{|c|}{ Chem. Commun., 2003(8): p. 992-993.(in Tol) } \\
\hline \multirow{6}{*}{ 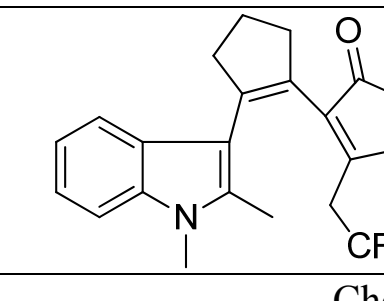 } & $\lambda_{\max }(\mathrm{nm})$ & & 485 & No $\mathrm{C}$ form \\
\hline & $\varepsilon_{\max }\left(1 / \mathrm{mol}^{*} \mathrm{~cm}\right)$ & & 2000 & \\
\hline & Quantum yield & & & \\
\hline & Thermal & $80^{\circ}$ & $/ \mathrm{A}_{0} \mathrm{Z} 1.0$ & $(168 \mathrm{~h})$ \\
\hline & Photo & & & \\
\hline & \multicolumn{4}{|c|}{ Chem. Commun., 2003(8): p. 992-993.(in Tol) } \\
\hline
\end{tabular}




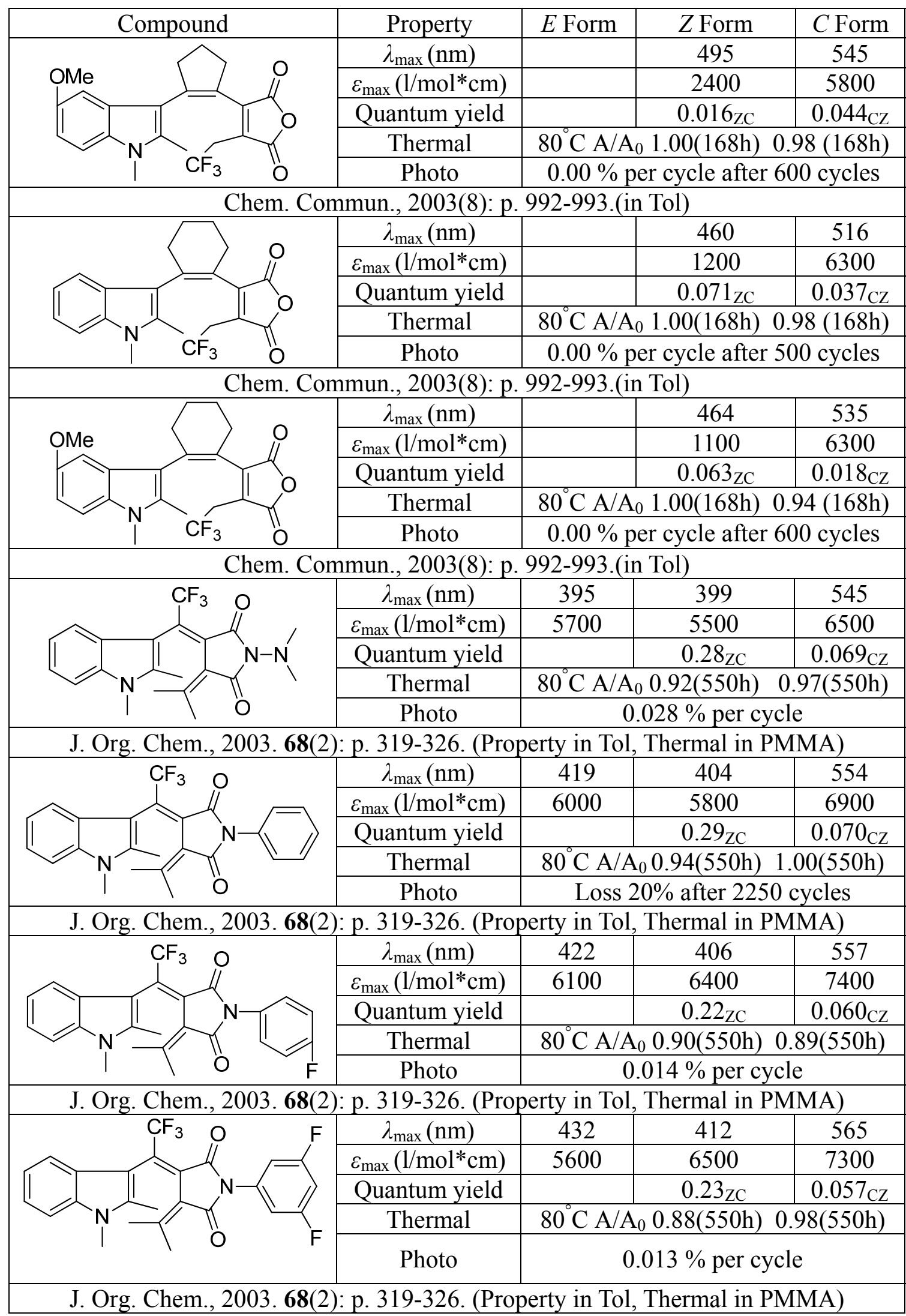




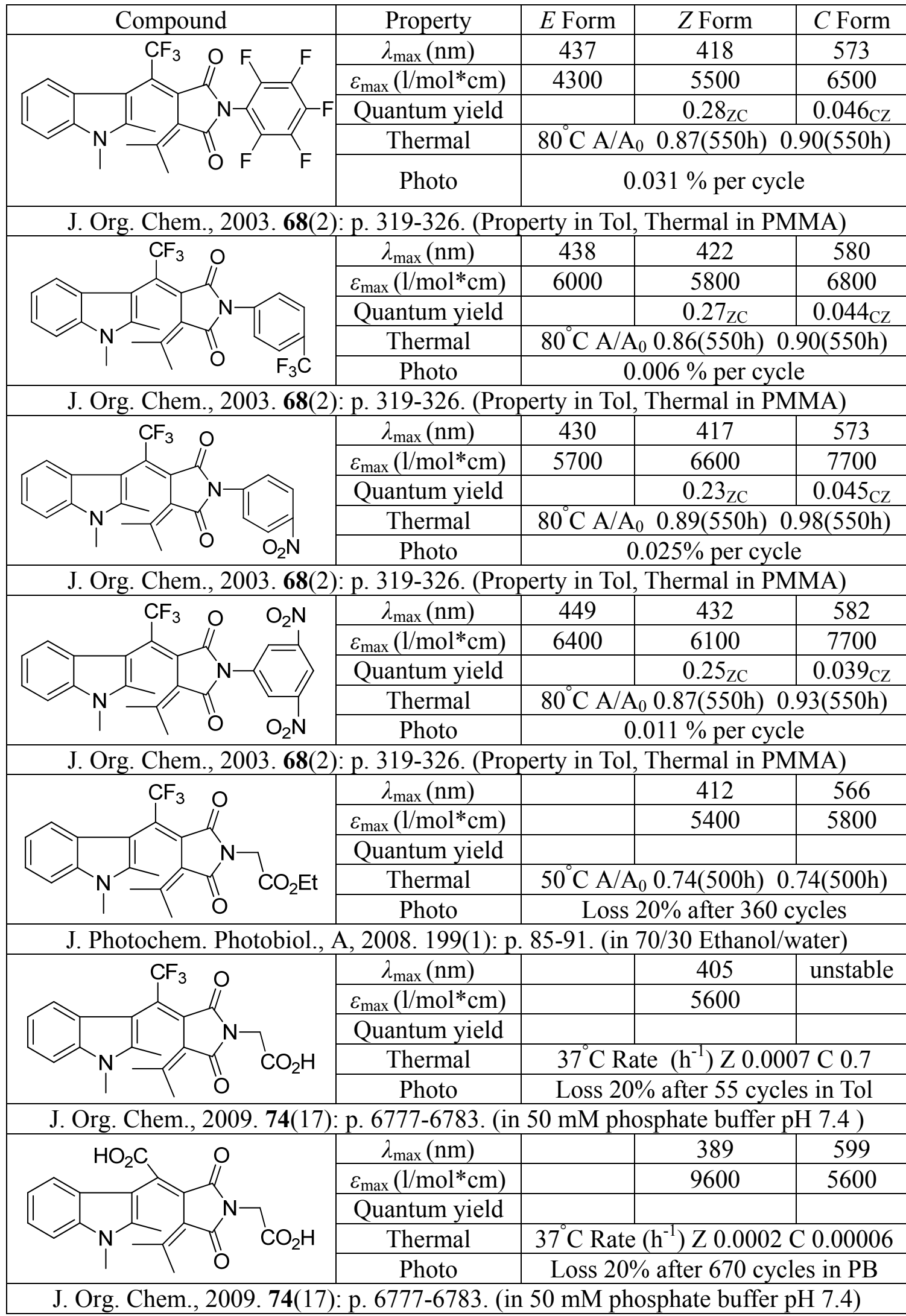


<smiles>Cc1c2c(cc3c4ccccc4n(C)c13)C(=O)N(CC(=O)O)C2=O</smiles>

\begin{tabular}{|c|c|c|c|}
\hline Property & $E$ Form & $Z$ Form & $C$ Form \\
\hline$\lambda_{\max }(\mathrm{nm})$ & & & \\
\hline$\varepsilon_{\max }\left(1 / \mathrm{mol}^{*} \mathrm{~cm}\right)$ & & & \\
\hline Quantum yield & & & \\
\hline Thermal & & & \\
\hline Photo & \multicolumn{3}{|c|}{ Not photochromic } \\
\hline
\end{tabular}

J. Org. Chem., 2009. 74(17): p. 6777-6783. (in $50 \mathrm{mM}$ phosphate buffer $\mathrm{pH} 7.4$ )<smiles>Cc1c2c(c(C)c3c1c1ccccc1n3Cc1ccccc1)C(=O)N(c1ccc(C(=O)O)cc1)C2=O</smiles>

\begin{tabular}{|c|l|l|l|}
\hline$\lambda_{\max }(\mathrm{nm})$ & & & \\
\hline$\varepsilon_{\max }\left(1 / \mathrm{mol}^{*} \mathrm{~cm}\right)$ & & & \\
\hline Quantum yield & & & \\
\hline Thermal & & & \\
\hline Photo & & & \\
\hline
\end{tabular}

Synthetic Communication, 2010. 40: p. 157-166.<smiles>Cc1c2c(c(C)c3c1c1ccccc1n3Cc1ccccc1)C(=O)N(c1ccc(O)cc1)C2=O</smiles>

\begin{tabular}{|c|}
\hline$\lambda_{\max }(\mathrm{nm})$ \\
\hline$\varepsilon_{\max }\left(1 / \mathrm{mol}^{*} \mathrm{~cm}\right)$ \\
\hline Quantum yield \\
\hline Thermal \\
\hline Photo
\end{tabular}

Synthetic Communication, 2010. 40: p. 157-166.<smiles>Cc1c2c(c(C)c3c1c1ccccc1n3Cc1ccccc1)C(=O)N(c1ccc(N)cc1)C2=O</smiles>

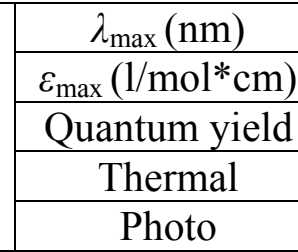

Synthetic Communication, 2010. 40: p. 157-166.<smiles>Cc1c2c(c(C)c3c1c1ccccc1n3Cc1ccccc1)C(=O)N(CCO)C2=O</smiles>

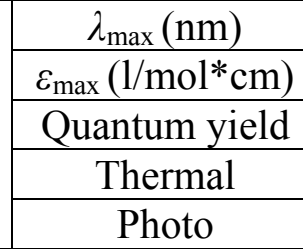

Synthetic Communication, 2010. 40: p. 157-166.<smiles>Cc1c2c(c(C)c3c1c1ccccc1n3Cc1ccccc1)C(=O)N(CC(=O)O)C2=O</smiles>

\begin{tabular}{|c|l|l|l|}
\hline$\lambda_{\max }(\mathrm{nm})$ & & & \\
\hline$\varepsilon_{\max }\left(1 / \mathrm{mol}^{*} \mathrm{~cm}\right)$ & & & \\
\hline Quantum yield & & & \\
\hline Thermal & & & \\
\hline Photo & & & \\
\hline
\end{tabular}

Synthetic Communication, 2010. 40: p. 157-166.<smiles>Cc1c2c(c(C)c3c1[nH]c1ccccc13)C(=O)OC2=O</smiles>

\begin{tabular}{|c|}
\hline$\lambda_{\max }(\mathrm{nm})$ \\
\hline$\varepsilon_{\max }\left(1 / \mathrm{mol}^{*} \mathrm{~cm}\right)$ \\
\hline Quantum yield \\
\hline Thermal \\
\hline Photo \\
\hline
\end{tabular}

Doctoral dissertation, Steffen Dietrich, Technischen Universitat Berlin, 2006 (in $\mathrm{C}_{6} \mathrm{H}_{6}$ ) 


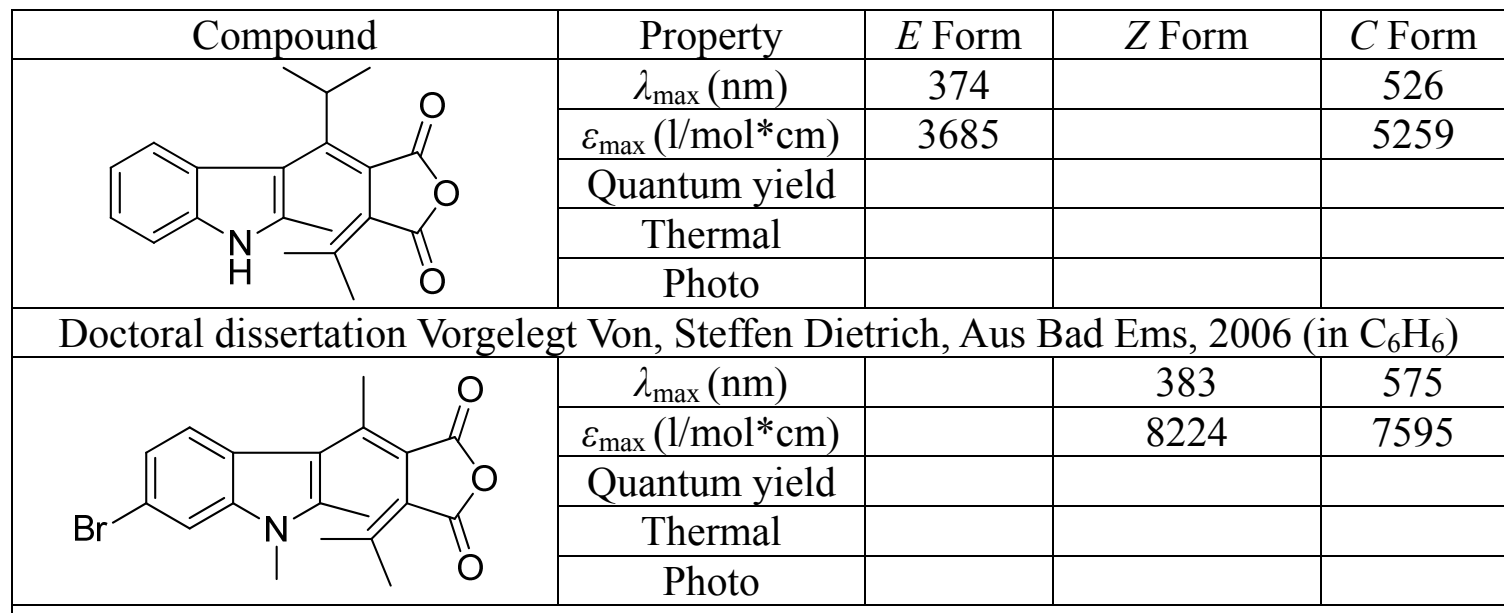

Doctoral dissertation, Steffen Dietrich, Technischen Universitat Berlin, 2006 (in $\mathrm{C}_{6} \mathrm{H}_{6}$ )<smiles>Cc1c2c(c(C)c3c1c1ccccc1n3C)C(=O)OC2=O</smiles>

\begin{tabular}{|c|c|l|c|}
\hline$\lambda_{\max }(\mathrm{nm})$ & 385 & & 584 \\
\hline$\varepsilon_{\max }\left(1 / \mathrm{mol}^{*} \mathrm{~cm}\right)$ & & & 7307 \\
\hline Quantum yield & $0.045_{\mathrm{EC}}$ & $0.04_{\mathrm{EZ}} / 0.07_{\mathrm{ZE}}$ & $0.16_{\mathrm{CE}}$ \\
\hline Thermal & & & \\
\hline Photo & & & \\
\hline
\end{tabular}

Doctoral dissertation, Steffen Dietrich, Technischen Universitat Berlin, 2006 (in $\mathrm{C}_{6} \mathrm{H}_{6}$ )

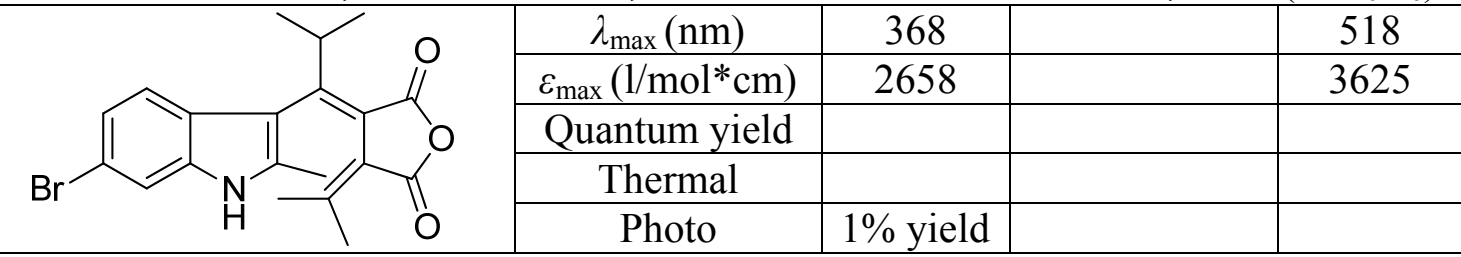

Doctoral dissertation, Steffen Dietrich, Technischen Universitat Berlin, 2006 (in $\mathrm{C}_{6} \mathrm{H}_{6}$ )<smiles>Cc1c2c(c(C(C)C)c3c4ccc(Br)cc4n(C)c13)C(=O)OC2=O</smiles>

\begin{tabular}{|c|l|l}
\hline$\lambda_{\max }(\mathrm{nm})$ & \\
\hline$\varepsilon_{\max }\left(1 / \mathrm{mol}^{*} \mathrm{~cm}\right)$ & \\
\hline Quantum yield & \\
\hline Thermal & \\
\hline Photo & $1 \%$ yield & \\
\hline
\end{tabular}

Doctoral dissertation, Steffen Dietrich, Technischen Universitat Berlin, 2006 (in $\mathrm{C}_{6} \mathrm{H}_{6}$ )

\begin{tabular}{|c|c|c|c|c|}
\hline & $\lambda_{\max }(\mathrm{nm})$ & 451 & & 551 \\
\hline$\varepsilon_{\max }\left(1 / \mathrm{mol}^{*} \mathrm{~cm}\right)$ & & & 7211 \\
\hline Quantum yield & & & \\
\hline Thermal & & & \\
\cline { 2 - 4 } & Photo & & & \\
\hline
\end{tabular}

Doctoral dissertation, Steffen Dietrich, Technischen Universitat Berlin, 2006 (in $\mathrm{C}_{6} \mathrm{H}_{6}$ )

\begin{tabular}{|c|c|c|c|}
\hline \\
\hline
\end{tabular}

Doctoral dissertation, Steffen Dietrich, Technischen Universitat Berlin, 2006 (in $\mathrm{C}_{6} \mathrm{H}_{6}$ ) 


\begin{tabular}{|c|c|c|c|c|}
\hline \multirow[t]{5}{*}{ Compound } & Property & $E$ Form & $Z$ Form & $C$ Form \\
\hline & $\lambda_{\max }(\mathrm{nm})$ & & & 562 \\
\hline & $\varepsilon_{\max }\left(1 / \mathrm{mol}^{*} \mathrm{~cm}\right)$ & & & 3265 \\
\hline & Quantum yield & & & \\
\hline & Thermal & & & \\
\hline & Photo & & & \\
\hline
\end{tabular}

Doctoral dissertation, Steffen Dietrich, Technischen Universitat Berlin, 2006 (in $\mathrm{C}_{6} \mathrm{H}_{6}$ )<smiles></smiles>

\begin{tabular}{|c|l|l|c|}
\hline$\lambda_{\max }(\mathrm{nm})$ & & & 563 \\
\hline$\varepsilon_{\max }\left(1 / \mathrm{mol}^{*} \mathrm{~cm}\right)$ & & & 4323 \\
\hline Quantum yield & & & \\
\hline Thermal & & & \\
\hline Photo & & & \\
\hline
\end{tabular}

Doctoral dissertation, Steffen Dietrich, Technischen Universitat Berlin, 2006 (in $\mathrm{C}_{6} \mathrm{H}_{6}$ )

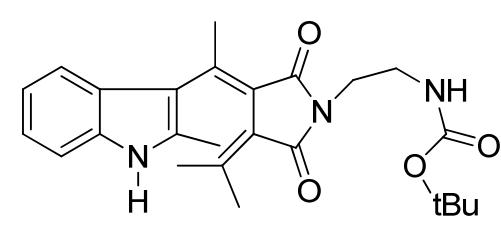

\begin{tabular}{|c|l|l|l|}
\hline$\lambda_{\max }(\mathrm{nm})$ & & & \\
\hline$\varepsilon_{\max }\left(1 / \mathrm{mol}^{*} \mathrm{~cm}\right)$ & & & \\
\hline Quantum yield & & & \\
\hline Thermal & & & \\
\hline Photo & & & \\
\hline
\end{tabular}

Doctoral dissertation, Steffen Dietrich, Technischen Universitat Berlin, 2006 (in $\mathrm{C}_{6} \mathrm{H}_{6}$ )<smiles>Cc1c2c(c(C)c3c1c1ccccc1n3C)C(=O)N(CCNC(=O)O[Ga])C2=O</smiles>

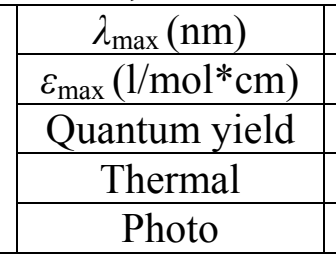

Doctoral dissertation, Steffen Dietrich, Technischen Universitat Berlin, 2006 (in $\mathrm{C}_{6} \mathrm{H}_{6}$ )

\begin{tabular}{|l|l|l|l|l|}
\hline & $\lambda_{\max }(\mathrm{nm})$ & & & \\
\hline$\varepsilon_{\max }\left(\mathrm{l} / \mathrm{mol}^{*} \mathrm{~cm}\right)$ & & & \\
Quantum yield & & & \\
\hline Thermal & & & \\
\hline Photo & & & \\
\hline
\end{tabular}

Doctoral dissertation, Steffen Dietrich, Technischen Universitat Berlin, 2006 (in $\mathrm{C}_{6} \mathrm{H}_{6}$ )<smiles></smiles>

\begin{tabular}{|c|l|l|l|}
\hline$\lambda_{\max }(\mathrm{nm})$ & & & \\
\hline$\varepsilon_{\max }\left(1 / \mathrm{mol}^{*} \mathrm{~cm}\right)$ & & & \\
\hline Quantum yield & & & \\
\hline Thermal & & & \\
\hline Photo & & & \\
\hline
\end{tabular}

Doctoral dissertation, Steffen Dietrich, Technischen Universitat Berlin, 2006 (in $\mathrm{C}_{6} \mathrm{H}_{6}$ )

\begin{tabular}{|l|l|l|l|}
\hline & & & 565 \\
\hline
\end{tabular}

Doctoral dissertation, Steffen Dietrich, Technischen Universitat Berlin, 2006 (in $\mathrm{C}_{6} \mathrm{H}_{6}$ ) 


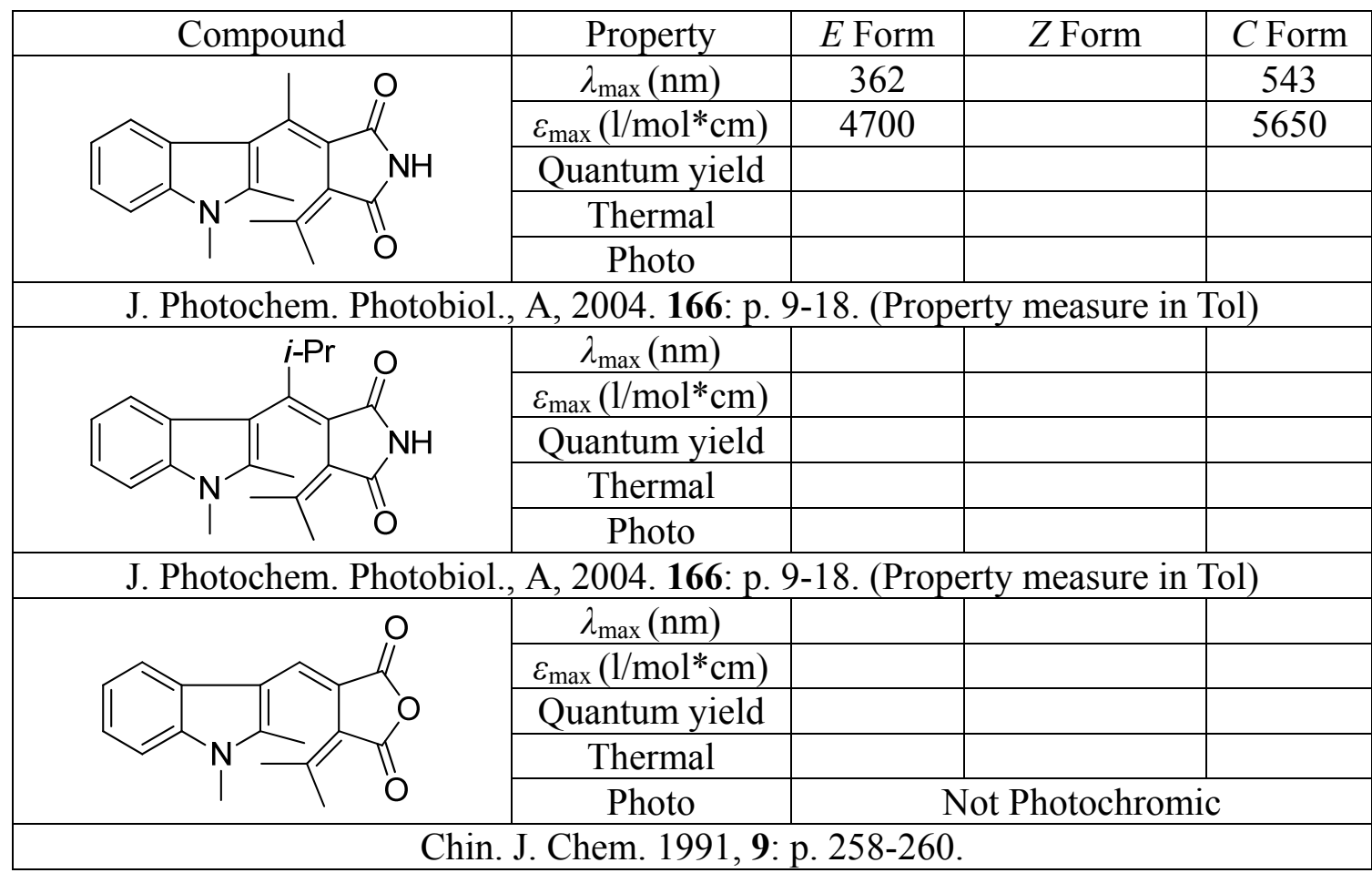


VITA

Xi Chen

January 06, 1983

2001-2005

2005-2008
Born, Shijiazhuang, Hebei, China

B.S., Polymer Material and Science

Beijing University of Chemical Technology

Beijing, China

Teaching Assistant

Florida International University

Miami, Florida

\section{PUBLICATIONS AND PRESENTATIONS}

T. Brust, S. Draxler, A. Popp, X. Chen, W. J. Lees, W. Zinth, M. Braun. Stability and Reaction Dynamics of Trifluorinated Indolylfulgides. Chem. Phy. Lett. 2009, 477, 298303.

X. Chen, N. I. Islamova, S. P. Garcia, J. A. DiGirolamo, W. J. Lees. Synthesis and Optical Properties of Aqueous Soluble Indolylfulgimides. J. Org. Chem. 2009, 74, 6777-6783.

X. Chen, N. I. Islamova, S. P. Garcia, J. A. DiGirolamo, W. J. Lees. Synthesis of novel indolylfulgimides. 239th ACS National Meeting, San Francisco, CA, U.S., 2010

X. Chen, N. I. Islamova, W. J. Lees. Synthesis of Novel Carboxylic Acid Indolylfulgimides with Improved Aqueous Solubility. FAME, Orlando, FL, U.S., 2008

X. Chen, G. Guez, Y. Silva, W. J. Lees. Synthesis of a Novel Deuterated Isopropylidene Trifluoromethyl Indolyfulgide with Improved Thermal Stability. FAME, Orlando, FL, U.S., 2007

N. I. Islamova, X. Chen, S. P. Garcia, J. A. DiGirolamo, Y. Silva, W. J. Lees. Thermal Stability and Photochromic Properties of a Fluorinated Indolylfulgimide in a Protic and Aprotic Solvent. J. Photochem. Photobiol., A 2008, 199, 85-91.

N. I. Islamova, X. Chen, S. P. Garcia, G. Guez, Y. Silva, W. J. Lees. Improving the Stability of Photochromic Fluorinated Indolylfulgides. J. Photochem. Photobiol., A 2008, 195, 228-234. 